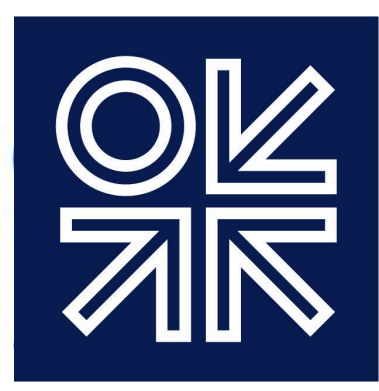

THE OXFORD INSTITUTE FOR ENERGY STUDIES

\title{
Building New Gas Transportation Infrastructure in the EU - what are the rules of the game?
}

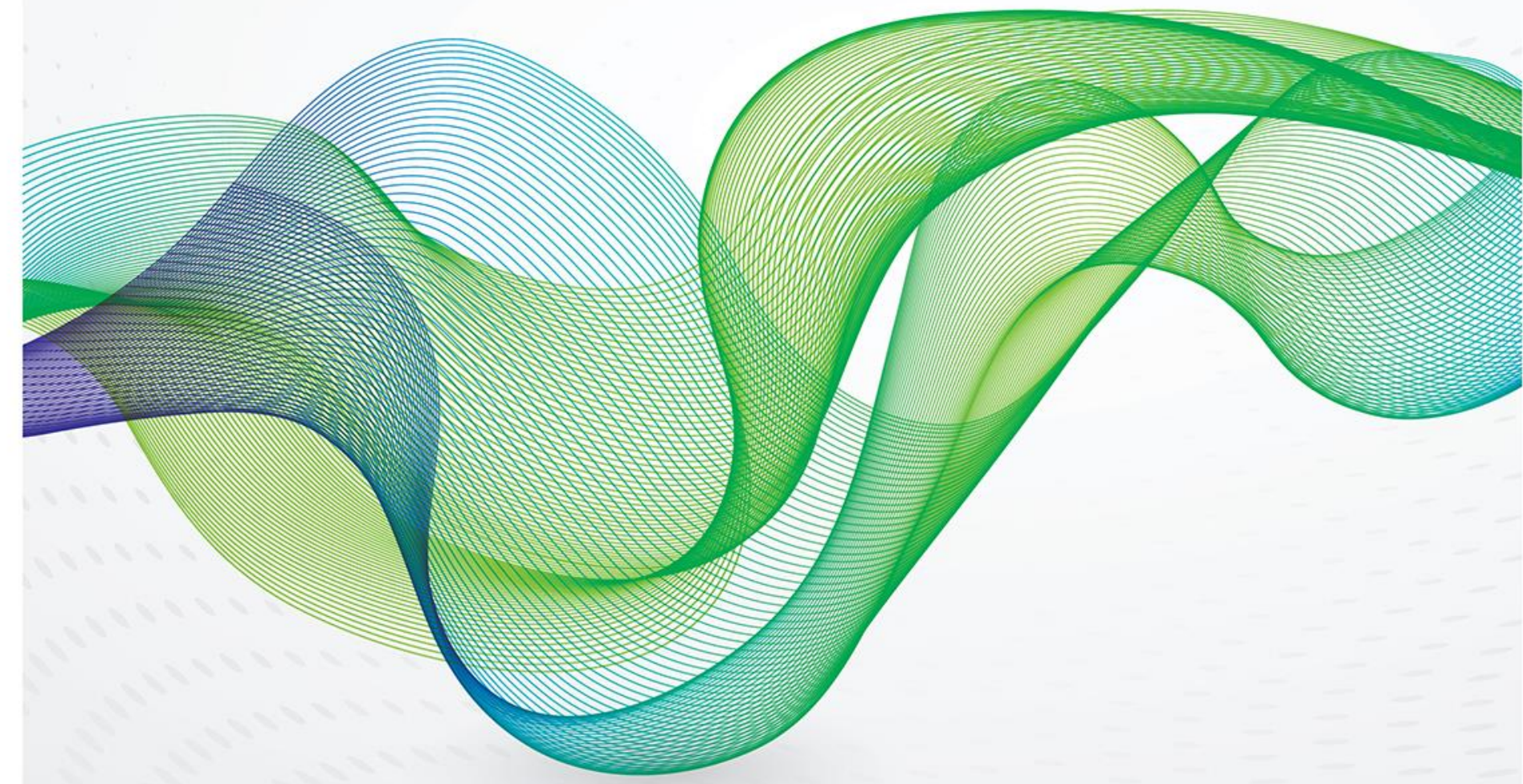


The contents of this paper are the author's sole responsibility. They do not necessarily represent the views of the Oxford Institute for Energy Studies or any of its members.

Copyright $\odot 2018$

Oxford Institute for Energy Studies

(Registered Charity, No. 286084)

This publication may be reproduced in part for educational or non-profit purposes without special permission from the copyright holder, provided acknowledgment of the source is made. No use of this publication may be made for resale or for any other commercial purpose whatsoever without prior permission in writing from the Oxford Institute for Energy Studies.

ISBN 978-1-78467-115-0

DOI: https://doi.org/10.26889/9781784671150 

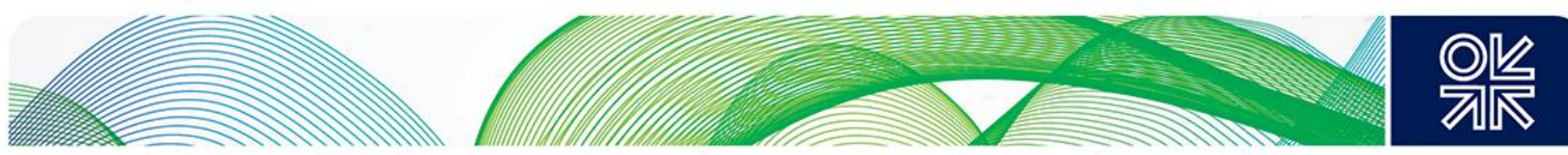

\section{Acknowledgements}

Researching and writing this paper has been a challenge on many fronts - the complexity of the subject of EU regulation, its rapidly evolving nature, and its ongoing politicization, particularly as far as Russian gas pipelines are concerned. I was privileged to count on support and advice from Professor Jonathan Stern, a Distinguished Research Fellow on the OIES Natural Gas Research Programme, to whom I am extremely grateful for the time he spent on reading and commenting on this (very long) paper. I also thank everyone else who has lent their time and expertise in various ways. Special thanks go to Catherine Riches for her excellent editing which made this paper significantly more readable. I also thank Kate Teasdale for her administrative support. Responsibility for all the views expressed and all the conclusions reached is solely mine. 

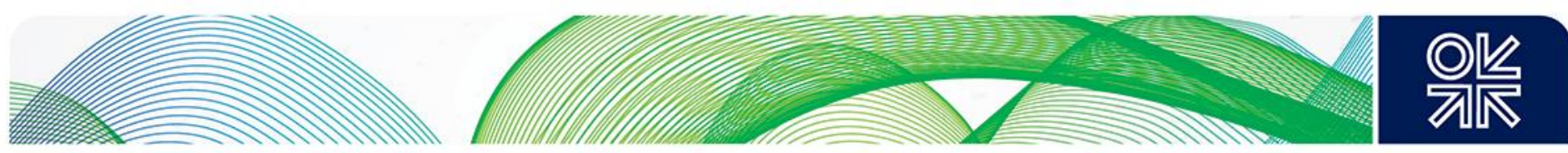

\section{Preface}

In the late 2010s, European gas pipelines have again become a controversial political issue, with various governments and stakeholder groups either supporting, or fiercely opposing, different projects. Much of this debate is not well based on gas supply and demand analysis, or on how post-2014 developments have changed the picture for European gas import requirements in the 2020s. But potentially more importantly, there has been almost no detailed consideration of the evolution and importance of pipeline gas regulation, partly because it has become extremely complex, but also because it is continuing to evolve. Calls over the past decade for gas pipeline promoters to 'respect EU rules' have tended to ignore the fact that these rules had either not been established or were not clear, requiring forensic examination and interpretation of the language of, and potential contradictions between, EU Directives and Regulations.

This paper provides an essential guide to the different regimes for incremental (new) pipeline capacity which have evolved over the past decade. By disaggregating this 'messy' evolution, the paper not only sets out the different regimes and the projects to which they apply, but also shows how this rather unsatisfactory situation became increasingly politicized post-2014 in respect of all Russian pipelines, but especially Nord Stream 2. The paper also discusses the impact of the new security and governance regulations, and the possible amendment of the Third Gas Directive to include offshore pipelines and specifically Nord Stream 2.

Over a period of nearly 30 years, enormous effort has been expended in creating a regulatory regime for EU gas pipelines. The result seems likely to be that complexity and politicization will persuade those wishing to bring additional gas to EU countries to do so as LNG, rather than as pipeline gas. It is not clear whether this is a desirable outcome, and important that all stakeholders understand both the reasons why it has resulted and their potential consequences. Katja Yafimava's paper provides a unique guide for those who need to understand the detail of the different regulatory frameworks, as well as for those who only need to grasp the essentials as a way of charting the likely future of European gas trade.

Professor Jonathan Stern

Oxford, July 2018 

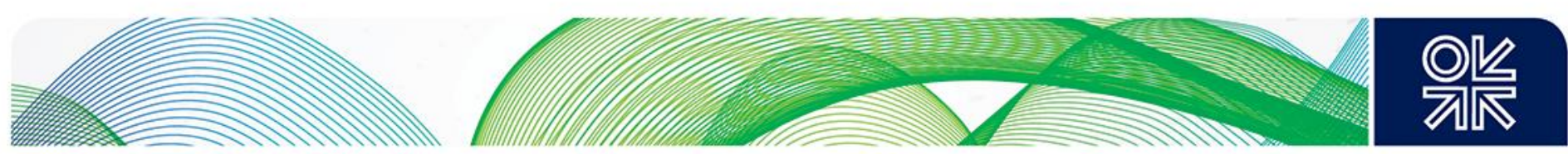

\section{Executive Summary}

The process of developing a legally binding regulatory framework for the creation of incremental pipeline capacity in the EU and hence for the construction of new gas pipelines has been uneven and slow. Eight years after the TEP was adopted in March 2009, and more than five years after it entered into force in September 2011, the CAM NC was finally established in March 2017. However, it did not fully resolve all the problematic issues in respect of the regulatory treatment of incremental capacity. The passage of time meant that many new pipelines, which were initiated around the time of the TEP's adoption and entry into force, developed under a patchwork of TEP exemptions, OS procedures, and IGAs. This meant that incremental capacity was allocated and contracted under different regulatory regimes which - while not dissimilar - were not identical to the regulatory framework established by the CAM NC.

In addition, although the CAM NC established a legally binding regulatory framework for conducting an incremental capacity process, it left important regulatory specificities, particularly in respect of capacity allocation methods, for the TSOs and NRAs to decide. This meant that the latter have been able to develop capacity allocation methods which differ across the EU. As a result, there are differences in the regulatory treatment of incremental capacity both between the CAM NC and the previous frameworks (exemptions, OS procedures, and IGAs) as well as within the CAM NC itself. Thus, the problem of the regulatory treatment of incremental capacity - created under diverse frameworks with varying degrees of consistency - has not been fully resolved at the EU level and uncertainty remains in respect of its future treatment.

These problems have been made more difficult by the ongoing politicization of EU gas regulation, particularly in respect of Russian gas, and this adds further uncertainty in respect of the regulatory treatment of new EU pipelines, connected with Russian export pipelines. Signs of such politicization started to appear even before the sharp deterioration in the EU-Russia political relationship in the aftermath of the 2014 Ukraine crisis. For example, the cap imposed in 2009 by the EC on the utilization by Gazprom of OPAL (and hence Nord Stream) capacity was not justifiable on regulatory grounds. Such signs became even more evident post-2014, when the EU started to develop its new policy initiatives, which aimed de facto at reducing EU dependence on Russian gas and placing artificial constraints on Russia's Europe-bound export pipeline capacity, in order to inter alia preserve significant transit of Russian gas across Ukraine.

As the EC exhausted its ability to control capacity in Nord Stream 2 on the basis of the existing acquis, it launched several legislative initiatives - most importantly, the proposal to amend the Third Gas Directive. If adopted, the amended Directive would enable the EC to control the degree of utilization of capacity in pipelines coming to the EU from third countries and hence the degree of utilization of capacity in the EU's internal connected pipelines (irrespective of whether the latter are regulated). This would increase the (already significant) uncertainty in respect of regulatory treatment of incremental capacity in the EU (including the projects that have been initiated prior to adoption of the amended Directive). At the time of writing, lack of political agreement among member states means that it is uncertain whether such regulatory action will succeed. To the extent that it does succeed, it will politicize - and ultimately undermine - an EU regulatory framework that has been painstakingly constructed over several decades.

This paper concludes that, given the uncertainty and complexity associated with the regulatory treatment of incremental capacity, the projects that have been initiated prior to the CAM NC's entry into force should proceed under the rules which were in place at the time of their initiation. Although the EC and the regulatory authorities might be tempted to request some changes in respect of their regulatory treatment - particularly where this differs from what would have been required under the CAM NC - this temptation should be resisted, as further changes would unnecessarily increase uncertainty and complexity. Overall, the complexity and the lack of clarity associated with the regulatory framework for incremental capacity 

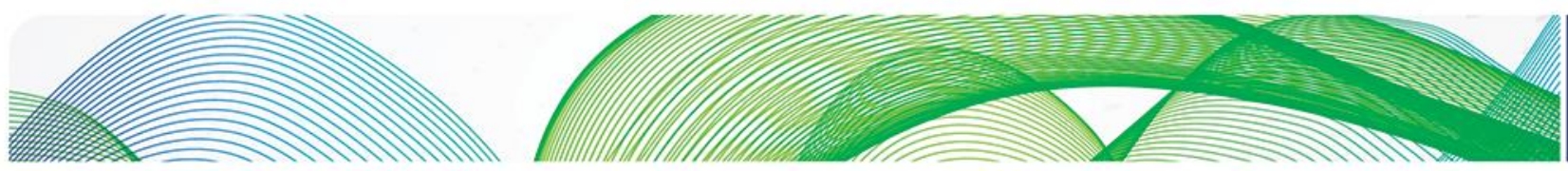

\section{OVI}

in the EU (resulting from the way in which regulation has developed, as well from its subsequent politicization) suggests that very few major new pipelines will be built in the EU in the future, apart from those under construction or foreseen in this paper (including TAP, EUGAL, and the Baltic Pipe) and possibly also those pipelines needed for connecting the second string of Turkish Stream with European markets. This is because it will be much easier for those wishing to bring additional gas to Europe to do so via $\mathrm{LNG}$ import terminals. 

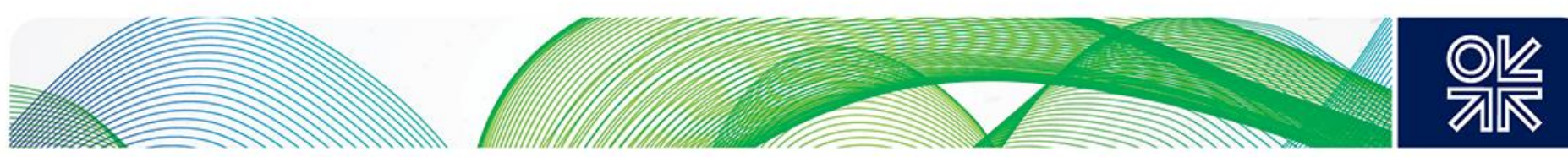

\section{Contents}

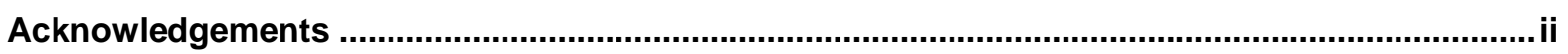

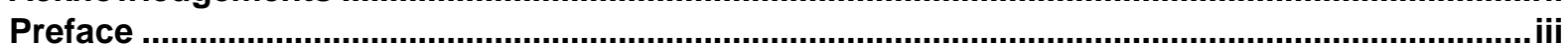

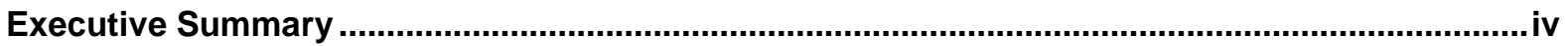

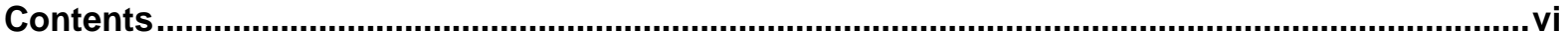

Figures and Tables ..................................................................................................................

1. Introduction: new architecture of the EU gas market and regulatory treatment of new

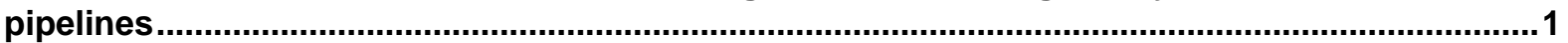

2. The evolving EU regulatory framework for construction and utilization of incremental capacity

2.1 The Capacity Allocation Mechanisms (CAM) Network Code ............................................. 7

2.1.1 Scope and definitions: incremental capacity, incremental capacity project, incremental

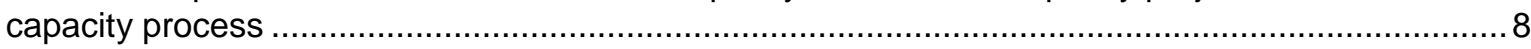

2.1.2 Capacity allocation rules: auctions, alternative allocation mechanism (AAM) and

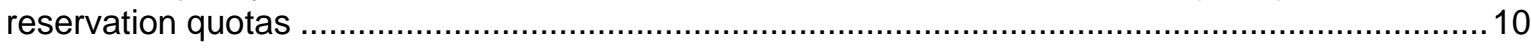

2.1.3 Auctions: booking horizons, capacity calculations, and timings ....................................... 11

2.1.4 The CAM Network Code: incremental capacity process procedure .................................. 13

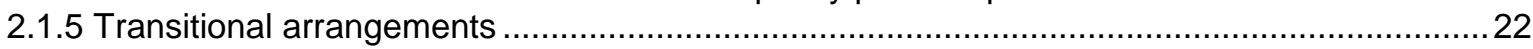

2.2 An Exemption Regime: Second and Third Gas Directives.............................................24

2.3 Projects of Common Interest (PCl): Infrastructure Regulation .......................................28

$2.4 \quad$ Open Seasons: Guidelines for Good Practice in Open Season (GGPOS) ........................31

2.5 Intergovernmental Agreements (IGAs): Decision 994/2012 and Decision 2017/684 ..........35

3. New pipeline capacity in the EU (planned and under construction): case studies .........38

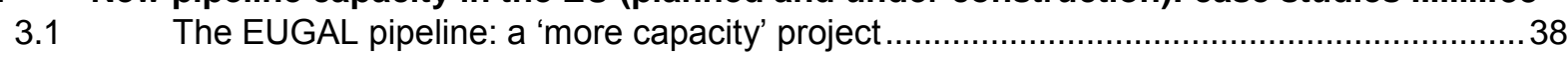

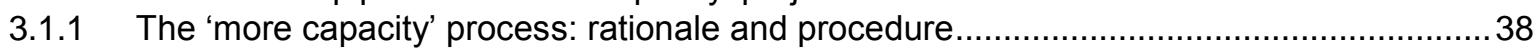

3.1.2 Non-binding phase: market survey, technical studies, demand assessment, consultation 40

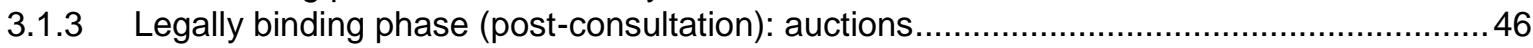

3.1.4 First demand assessment process for incremental capacity under CAM NC ........................49

3.1.5 German and EU-level Network Development Plans: 'more capacity' projects........................ 49

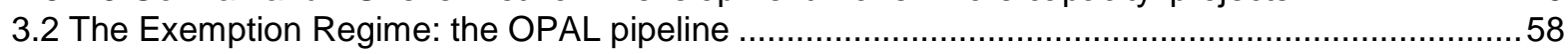

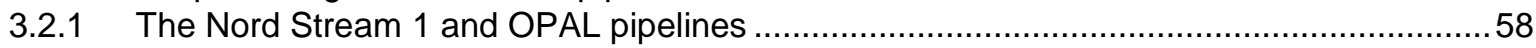

3.2.2 The 2009 Exemption Decision and OPAL underutilization ...........................................6

3.2.3 The October 2013 settlement agreement: failed attempt to find a solution .........................62

3.2.4 The 2016 Exemption Decision: reaching the settlement and increased OPAL utilization ..63

3.2.5 The legal action against the 2016 OPAL Exemption Decision: interim decision of the CJEU

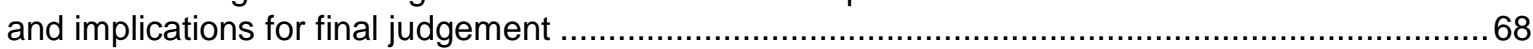

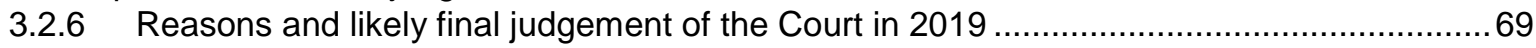

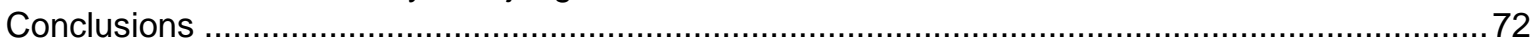

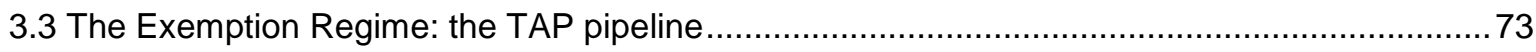

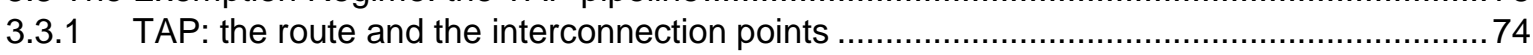

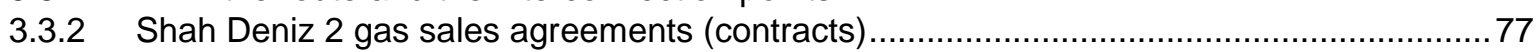

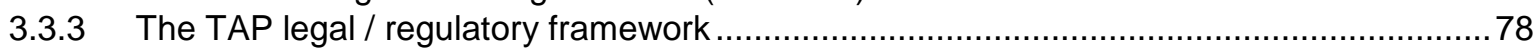

3.3.4 TAP's Exemption Application: capacity allocation and tariff principles ...............................78

3.3.5 The TAP First Market Test procedure: Expression of Interest and Booking Phases ...........80

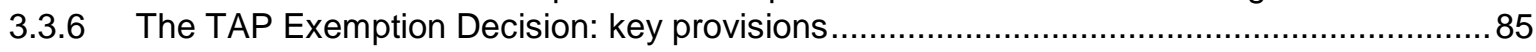

3.3.7 The TAP Exemption Decision additional conditions: TAP Network Code, capacity caps,

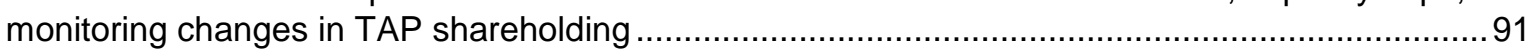

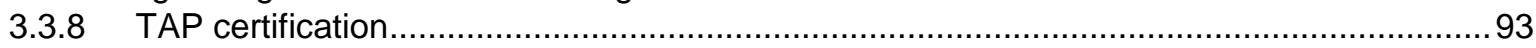

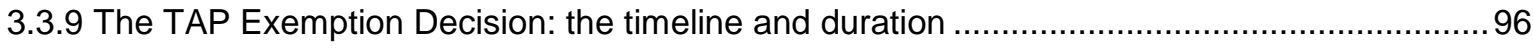

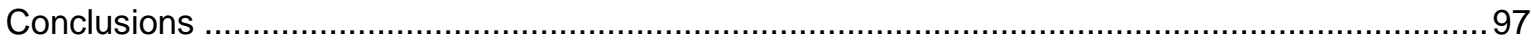

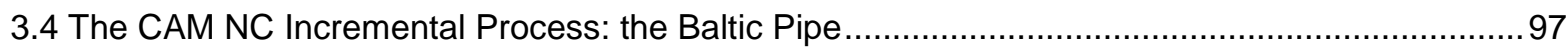



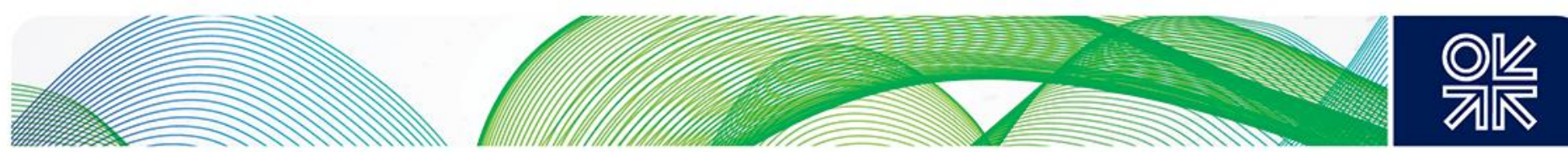

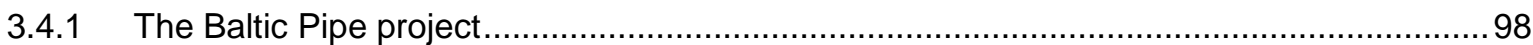

3.4.2 The Baltic Pipe regulatory procedure: 'Open Season 2017 Rules' ..............................103

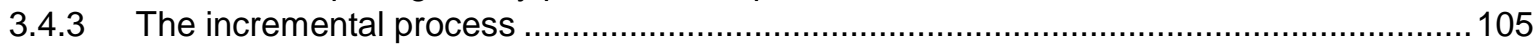

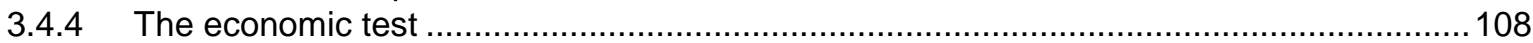

3.5 Intergovernmental Agreements: Yamal-Europe and South Stream ...........................113

3.5.1 The Polish-Russian IGA and the Yamal-Europe pipeline ......................................114

3.5.2 The South Stream IGAs and the South Stream pipeline .....................................117

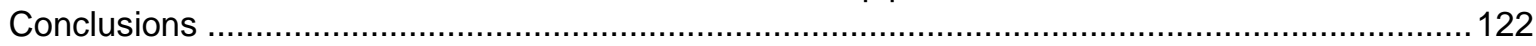

4. Energy Union legal initiatives: potential impact on construction and utilization of incremental capacity.

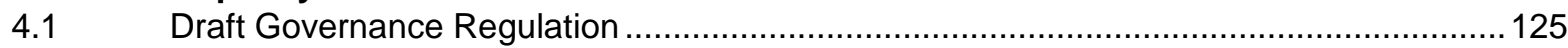

4.1.1 Development of the ECPs: energy security and IEM dimensions ................................126

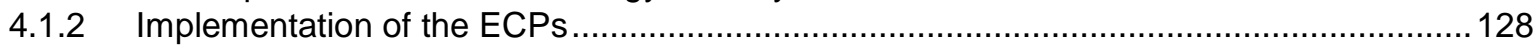

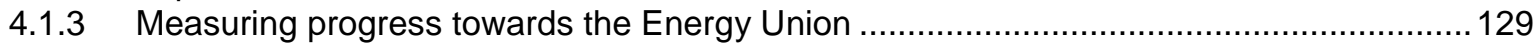

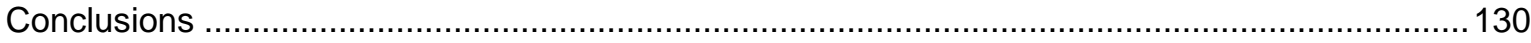

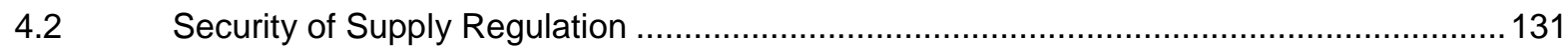

4.2.1 The security of gas supply: shared responsibility and solidarity ............................... 131

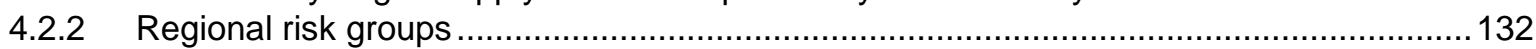

4.2.3 Common and national risk assessments and a cooperation mechanism .......................133

4.2.4 Preventive action and emergency plans and a cooperation mechanism ...................... 134

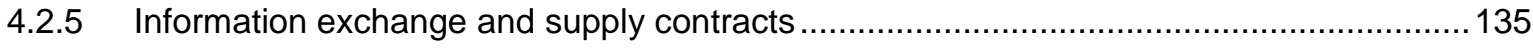

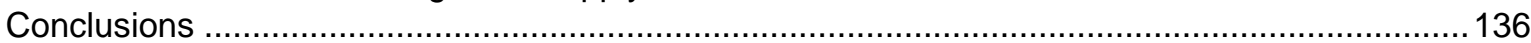

4.3 The EC proposal to amend the Third Gas Directive (draft) ....................................... 137

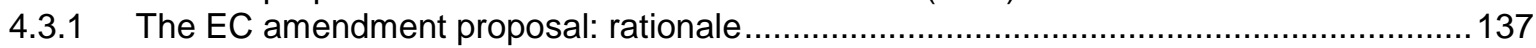

4.3.2 The EC amendment proposal: analysis ............................................................ 138

4.3.3 The EC amendment proposal: existing and new pipelines potentially affected ..............142

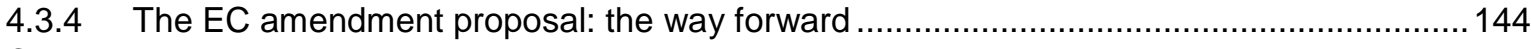

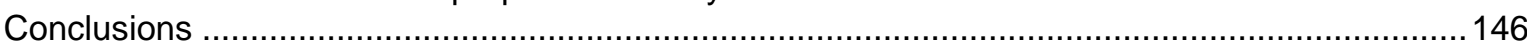

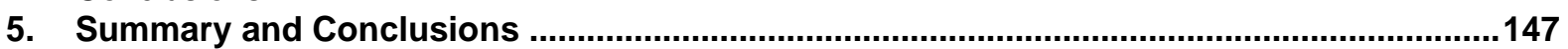

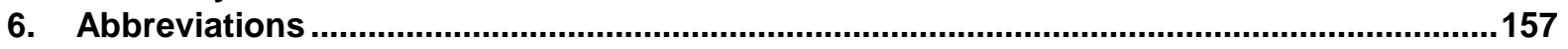

Bibliography ...................................................................................................................................160

Additional documents (Directives, Protocols, Regulations, Intergovernmental Agreements, etc.) .... 170

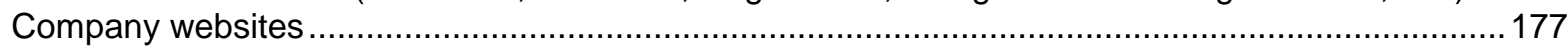

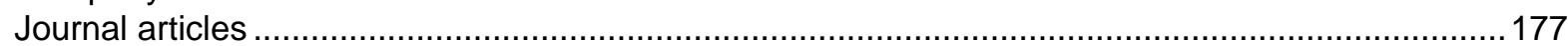

Annex. More Capacity Draft Preliminary Agreement and Supplementary Terms and Conditions

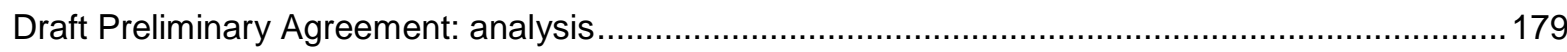

The draft Supplementary Terms and Conditions (STC): analysis ...................................... 181 

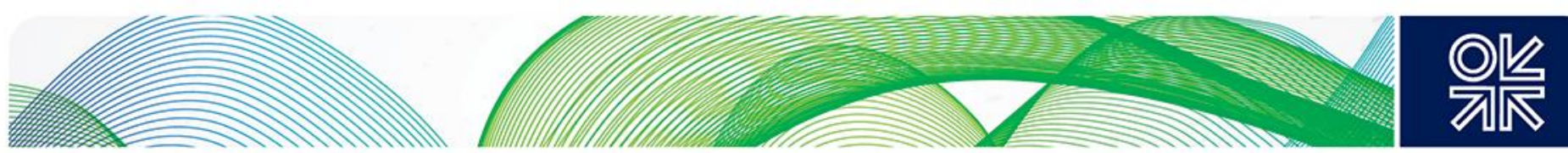

\section{Figures and Tables}

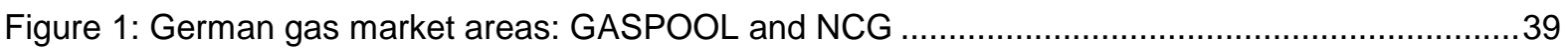

Figure 3: The EUGAL, OPAL, and NEL pipelines: new network points ........................................4 44

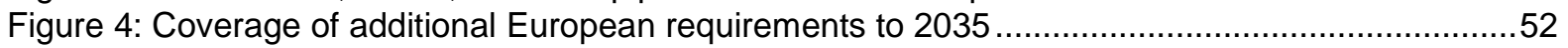

Figure 5: Additional capacity requirements in 2024 and 2029 (compared to 2018): gas-fired power

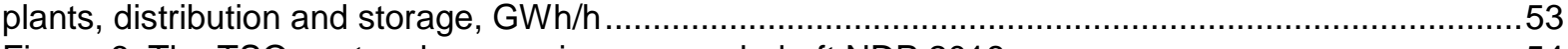

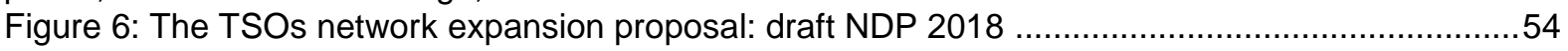

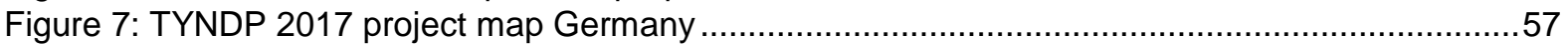

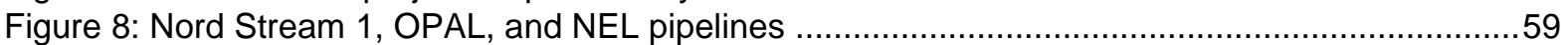

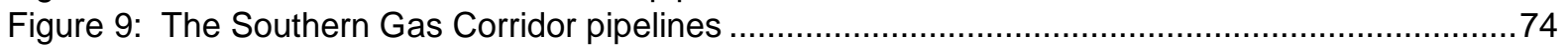

Figure 10: Trans Adriatic Pipeline (TAP) and Trans Anatolian Pipeline (TANAP) ............................75

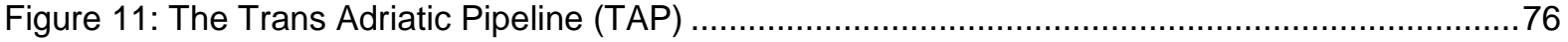

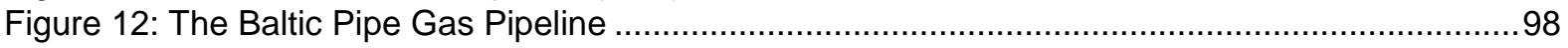

Figure 13: The Norwegian offshore transmission network Gassled ............................................102

Figure 14: The open season time schedule for the Baltic Pipe project ........................................107

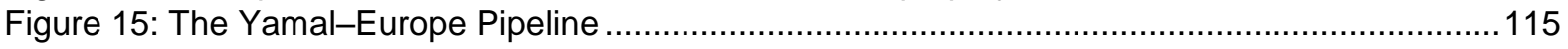

Table 1: Results of the criteria check as to the necessity of technical studies ..................................43

Table 2: 'More capacity' offer levels at GASPOOL borders: existing and new ...................................43

Table 3: Supplies distribution in the NDP 2015 by region and the modelling cases for the NDP 2016:

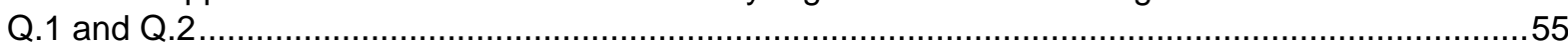

Table 4: Gas supply risk groups: regional cooperation............................................................132

Table 5: Existing and new pipelines from third countries potentially affected by the amendment of the Gas Directive 

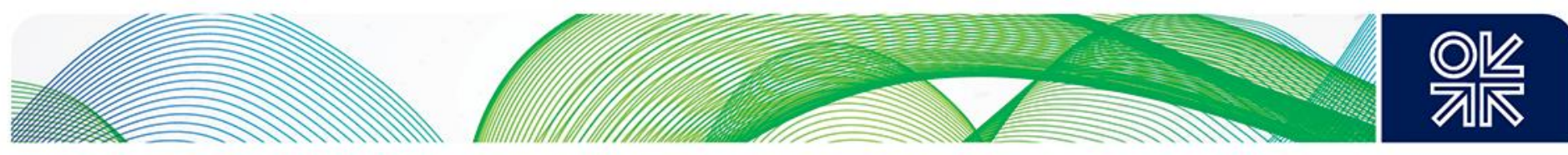

\section{Introduction: new architecture of the EU gas market and regulatory treatment of new pipelines}

The EU has long been trying to establish a single liberalized gas market within its borders. This process, which can be traced back to 1988, has been extremely slow, mostly due to the fact that neither the founding EEC Treaty (1957) nor the Maastricht Treaty (1992) provided the Community with the competence to develop energy policy. Hence any legislative action which could be interpreted as an attempt to develop such a policy ran the risk of being perceived by EU member states as lacking legitimacy. This explains the Community's decades-long quest for a formal treaty-based competence in the energy sector, which materialized only in November 2009 when the Lisbon Treaty was ratified.

However, even before it had acquired this competence in 2009, the Community had been able to expand its energy acquis communautaire (acquis) ${ }^{1}$ by using its - shared with member states - competences in different areas to develop the Single European Market (SEM). This, in turn, justified the application of European competition law and European environmental policy. By linking the issues that arose from the development of the SEM and environmentalism with those relating to energy, the Community was able to legislate on matters affecting the energy sectors of member states. In so doing, it secured a shared authority in the energy sector without having formal competence. This was made possible by the 1987 Single European Act (SEA), which introduced a qualified majority voting (QMV) procedure on matters concerning the development of the SEM, which enabled the Community to adopt legally binding measures affecting the energy sectors of member states without unanimous agreement.

By treating energy as a commodity and applying a QMV procedure, the Community adopted inter alia the Gas Transit Directive, 1991; the First Gas Directive, 1998; the Second Gas Directive, 2003; the Security of Supply Directive, 2004, and Gas Regulation 1775, 2005. ${ }^{2}$ The contribution of these documents towards the creation of the single gas market was slow and limited, although it was strengthened over time. ${ }^{3}$ The Gas Transit Directive was a largely procedural document (due to the failure of member states to agree on third-party access (TPA) to transmission pipelines), with no provisions on transit tariffs, capacity allocation, or congestion management procedures. The First Gas Directive (which operated in parallel with the Gas Transit Directive) left member states to choose between regulated and negotiated TPA to transmission. Both Directives were repealed by the Second Gas Directive, which eliminated the notion of transit and awarded an identical treatment to all gas flows inside the EU, irrespective of whether they were cross-border(s), by mandating regulated TPA to all transmission on the basis of tariffs (or methodologies) approved by national regulatory authorities. Neither the Second Gas Directive nor Gas Regulation 1775 prescribed any concrete tariffication model; however, the Regulation set the requirements which tariffs must meet, which made it uncertain that any model other than entry-exit (EE) could comply with them.

As, despite the avalanche of Directives and Regulations adopted since the early 1990s the EU single liberalized gas market had failed to make serious progress, the European Commission (EC) began to use EU competition law - its most powerful instrument - to implement the SEM more and more actively. In 2005, the DG COMP launched its Energy Sector Inquiry (ESI), which demonstrated that the Second Gas Directive and Regulation 1775 did not provide the necessary framework for achieving the objective of a competitive and transparent internal gas market, mostly because the legacy transportation (capacity) contracts largely remained beyond their reach. This Inquiry also demonstrated that EU competition law did not provide sufficient means for changing those clauses in the legacy contracts that were incompatible with new regulation. In particular, it showed that access to transit pipelines, transit congestion, and

\footnotetext{
A collective term for EU legal/regulatory framework.

2 Gas Transit Directive, First Gas Directive, Second Gas Directive, and Gas Regulation 1775 (see Additional documents).

${ }^{3}$ For a comprehensive overview of these documents see Yafimava (2011).
} 

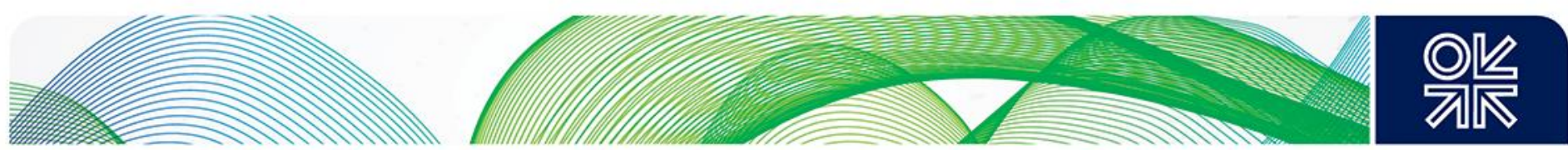

transparency of access to transit networks could not be tackled effectively solely through application of competition law.

Therefore, the EC adopted a fundamentally new approach that aimed at changing the architecture of the EU gas market from one dominated by vertically integrated companies simultaneously engaged in supply, production, and transportation, to one where transportation would be separate from supply and production activities. In doing so, the EC was guided by the Gas Target Model (GTM) - a non-legally binding policy document developed by the European regulatory authorities - which reflected their vision of how the markets should evolve, namely that it was necessary to:

- establish functioning wholesale markets within the EU, structured as entry-exit zones where entry capacity is allocated separately from exit capacity, so that any gas that enters the zone can be delivered (at least commercially) to any exit point in that zone, and each zone should have its own physical or virtual trading point or hub;

- connect these newly established wholesale markets with each another by means of adequate capacity allocation mechanisms (CAM) and congestion management procedures (CMP);

- ensure secure supply to, and economic investment in, these markets by means of building sufficient new capacity in a timely manner.

In July 2009 the EC adopted the Third Gas Directive and Gas Regulation 715 - repealing the Second Gas Directive and Gas Regulation $1775^{4}$ - as well as ACER Regulation $713,{ }^{5}$ which reflected the GTM vision. These three documents formed a set of EU legislation which became known as the Third Energy Package (TEP) for gas, which the EC believed would be capable of rectifying the problems identified by the 2006 Inquiry, and which became law in March 2011. ${ }^{6}$

The TEP introduced several fundamentally new elements, heralding the establishment of new gas market architecture:

\section{- Third Gas Directive:}

- unbundling of transmission assets \& certification of transmission system operators (TSO) under various models including: ownership unbundling (OU), independent transmission operator (ITO), and Independent System Operator (ISO). OU was made the only possible option if, on 3 September 2009, the TSO did not belong to a vertically integrated company) (Art. 9, Art. 10);

- regulated TPA to transmission capacity on the basis of published tariffs, or their methodologies fixed or approved by the national regulatory authority;

\section{- Gas Regulation 715:}

- entry-exit tariff methodology: tariffs are set separately for every entry and exit point; they are not to be calculated on the basis of contract paths and they should be transparent and cost reflective, facilitating trade and competition, avoiding cross subsidization, not restricting liquidity,

- TSO certification (including in relation to third countries); congestion management procedures (CMP): long-term UIOLI mechanisms, surrender of contracted capacity, oversubscription, and buyback (all October 2013), short-term UIOLI mechanisms (July 2016),

\footnotetext{
${ }^{4}$ Third Gas Directive, Gas Regulation 715, ACER Regulation 713 (see Additional documents).

${ }^{5}$ See below.

${ }^{6}$ The Third Gas Directive (see Additional documents) was adopted on 13 July 2009, entered into force on 3 September 2009, with member states being obliged to transpose it into their national legislation, thus making it fully applicable, by 3 March 2011 the date from which the Second Gas Directive (see Additional documents) was repealed. Gas Regulation 715 (see Additional documents) was also adopted on 13 July 2009 and entered into force on 3 September 2009, fully applicable as of 3 March 2011, the date from which Gas Regulation 1775 (see Additional documents) was repealed. For a comprehensive overview of these documents see Yafimava (2011).
} 

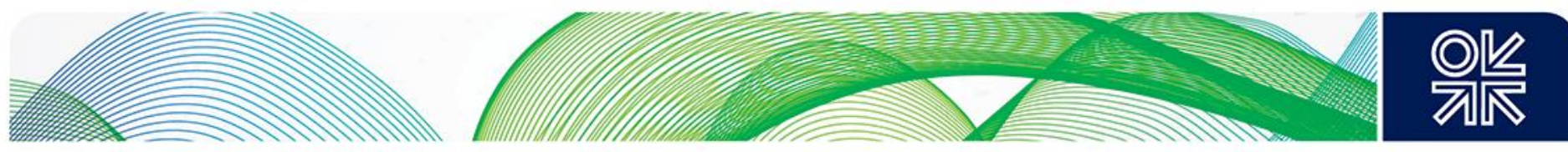

establishment of the European Network of Transmission System Operators for Gas (ENTSOG), charged with the development of legally binding EU Network Codes (NC) on cross-border issues;

\section{- ACER Regulation 713:}

establishment of the Agency for the Cooperation of Energy Regulators (ACER), charged with the development of non-legally binding Framework Guidelines (FG) on the basis of which the aforementioned NCs were to be developed.

While the TEP outlined general regulatory rules - such as TSO unbundling, regulated TPA, and regulated tariffs - it did not provide detailed regulatory procedures as to how these rules should be applied in respect of existing and incremental pipeline capacity. These procedures were to be outlined in the EU NCs, four of which have been developed and adopted to date - Capacity Allocation Mechanisms (CAM), ${ }^{7}$ Balancing, Tariffs, and Interoperability. ${ }^{8}$

Provisions concerning existing capacity were developed as part of the CAM NC which entered into force in November 2013, and applied from November 2015 (CAM NC 2013). ${ }^{9}$ However, at the time, no such procedures were developed as part of the CAM NC in respect of incremental capacity. While the European regulators acknowledged its importance - being one of the three main GTM pillars, namely, ensuring economic investment in new infrastructure - it was deemed too complex to be addressed within the CAM NC 2013..$^{10}$ Thus, none of the provisions of the CAM NC 2013 (with the exception of provisions on bundling and short-term reservation quota) applied to incremental capacity. However, in 2013, shortly after being adopted, the CAM NC 2013 was re-opened, specifically with the aim of including regulatory procedures for incremental capacity as an additional chapter. The Tariffs NC, which had been under development in parallel with the re-opened CAM NC, also envisaged regulatory procedures in respect of payment - tariffs or their methodologies - for both existing and incremental capacity. Both the amended CAM NC (repealing the CAM NC 2013) and the Tariffs NC entered the comitology stage ${ }^{11}$ in mid-2016 and came into force in April 2017. Provisions in both the CAM NC and the Tariffs NC concerning new capacity are analysed in detail in Section 2.1.

One of the main reasons why the development of regulatory procedures for incremental capacity at the EU level had only advanced at a glacial pace was that there has been limited interest on the part of European players in having such procedures, as they had no plans to build major new multi-border pipelines in the post-2000 liberalized EU gas market environment. Those few new pipelines that were still being built were under the Exemption Regime envisaged by the Third (and previously Second) Gas Directive (Section 2.2). Notably, Russia's Gazprom was the only supplier making - and proposing to make - substantial investment in new cross-border pipelines - such as South Stream, Nord Stream 2, and Yamal 2. Unsurprisingly, there had been little appetite on the part of EU authorities to accelerate the development of generic regulatory procedures for incremental pipeline capacity that would be mostly used by Gazprom.

As a result, the legally binding regulatory procedures governing construction, allocation, and payment for incremental capacity were only established at the EU level on 6 April 2017, when the CAM NC (and the Tariffs NC) came into force (Section 2.1). Given the long lead times associated with the development of any significant new cross-border pipeline project - at least five years - it is clear that no significant new capacity can be built in the EU before, or by, 2020 under the framework provided by the CAM NC. Those few pipeline projects that were initiated before the CAM NC's entry into force have proceeded under other frameworks, such as:

\footnotetext{
Congestion Management Procedures were outlined in Gas Regulation 715 (see Additional documents).

${ }^{8}$ CAM NC, Tariffs NC, Interoperability NC, and Balancing NC (see Additional documents).

CAM NC 2013 (see Additional documents)

${ }^{10}$ Pirani and Yafimava (2016), pp. 27-9.

${ }^{11} \mathrm{~A}$ process by which regulation is codified and which takes place in authorized committees where the EC is assisted by representatives of the member states.
} 

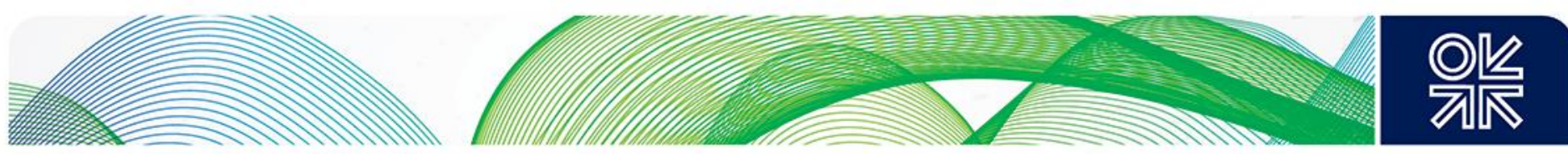

- the Exemption Regime (Section 2.2),

- the negotiated regime based on Intergovernmental Agreements (IGAs) (Section 2.5),

- the open season (OS) regime under the EU Guidelines of Good Practice for Open Seasons (GGPOS) (Section 2.4), and

- member states' national legislation.

Some projects have also proceeded as projects of common interest $(\mathrm{PCI})$ under EU TEN-E Regulation (Section 2.3).12 However, those new pipelines initiated before the CAM NC entry into force for which no applicable approvals have been given by 1 August 2017, together with new pipelines initiated after the CAM NC entry into force, will have to be built under the CAM NC (unless an exemption is granted). This will lead to a situation when by (and after) 2020 there will be new pipelines built in the EU, the capacity in which will have been allocated under different regulatory regimes. This raises a question about their future regulatory treatment, in particular the degree of consistency between the regime provided by the CAM $\mathrm{NC}$ and the regimes provided by other frameworks.

This paper, which is part of the OIES series on regulatory issues, provides an analysis of the legal / regulatory frameworks for construction, allocation, and payment for incremental pipeline capacity in the EU. It examines the regulatory procedures, both under the CAM NC and other frameworks used prior to CAM NC adoption in 2017 such as:

- the GGPOS outlining an Open Season procedure,

- the Third Gas Directive establishing an Exemption Regime,

- the TEN-E Regulation establishing a PCI Framework, and

- a framework provided by Intergovernmental Agreements (IGAs).

This analysis shows the similarities and dissimilarities of these approaches and aims to understand their consistency, with a view of suggesting how the future regulatory treatment of new pipelines that have been initiated prior to CAM NC might be impacted by the latter's provisions. The paper analyses several new pipeline projects which have been - or are planned to be - developed under all of the aforementioned frameworks, these include:

- EUGAL (developed under an OS procedure prior to CAM NC's entry into force),

- OPAL (developed under an Exemption Regime),

- Baltic Pipe (developed under the CAM NC),

- TAP (developed under an Exemption Regime), and

- Yamal-Europe and South Stream ${ }^{13}$ (developed under an IGA framework).

By October 2017, the process of creating a single liberalized gas market in the EU had been largely completed; this had taken several decades and had required multiple legislative initiatives, of which the TEP has been the most significant and effective. The EC then initiated a proposal to revise the Third Gas Directive to extend the application of the energy acquis to pipelines to and from third countries (Amendment Proposal) (Section 4.3). ${ }^{14}$ (The energy acquis had hitherto remained restricted to the internal gas market within EU borders.) If adopted, this proposal could potentially have an impact not only on the regulatory treatment of new (and existing) pipelines to and from third countries, but also on the regulatory treatment of new (and existing) domestic EU pipelines. The EC has also initiated the

\footnotetext{
12 Infrastructure Regulation (see Additional documents).

13 The Yamal-Europe pipeline has been built whereas the South Stream pipeline has been cancelled.

${ }^{14}$ The Amendment Proposal (see Additional documents). Also see EC (2017a)
} 

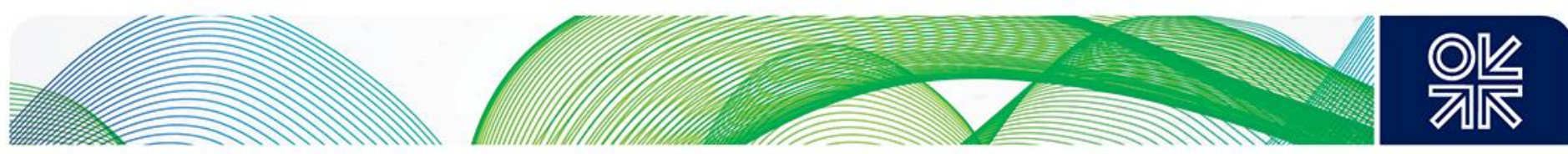

development of the new Governance Regulation (Draft Governance Regulation, ${ }^{15}$ see Section 4.1) and the amendment of the existing Security of Supply Regulation 2010 (Security of Supply Regulation 2017, ${ }^{16}$ see Section 4.2). The paper analyses the EU's ongoing legislative activity in respect of the three aforementioned initiatives, as all of them could have the potential to impact the regulatory treatment of incremental (and existing) pipeline capacity in the EU developed under the CAM NC and other frameworks.

The paper is structured in four sections following this introduction. Section 2 overviews and analyses the evolving EU regulatory framework for construction and utilization of incremental capacity: the CAM NC, an Exemption Regime, the PCI status, the GGPOS, and the IGAs are all covered. Section 3 analyses several incremental capacity projects - the EUGAL, the OPAL, the TAP, the Baltic Pipe, the YamalEurope, and the South Stream pipelines - which have been developed under these frameworks. Section 4 overviews the ongoing and recently completed EU legislative initiatives, including the Draft Governance Regulation, the Security of Supply Regulation, and the proposal to amend the Third Gas Directive, and analyses their potential impact on the development of incremental capacity in the EU; Section 5 provides a summary of the issues and a conclusion.

\footnotetext{
${ }^{15}$ See Additional documents.

${ }^{16}$ See Additional documents.
} 

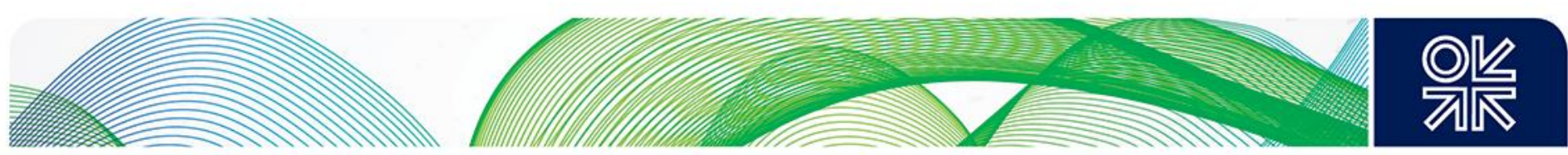

\section{The evolving EU regulatory framework for construction and utilization of incremental capacity}

This chapter provides a comprehensive analysis of various legal / regulatory frameworks for the development, allocation, and payment for incremental pipeline capacity in the EU, specifically the:

- Incremental Capacity Process under the CAM NC,

- Exemption Regime under the Third (and previously the Second) Gas Directives,

- $\mathrm{PCl}$ status under the TEN-E Regulation,

- Open Season procedure under the GGPOS,

- Intergovernmental Agreements.

The chapter begins with an overview and analysis of the CAM NC, ${ }^{17}$ adopted in March 2017, which - in addition to the general rules established by the TEP - has established specific regulatory procedures for the development and allocation of incremental (and existing) capacity in the EU (Section 2.1).

An explanation and analysis of the Exemption Regime then follows. Under this scheme, major new gas pipelines and LNG facilities could be exempted from various provisions of the Third (and previously the Second) Gas Directive, namely on TSO unbundling, regulated TPA, and regulated tariffs (Section 2.2). Prior to the CAM NC adoption in 2017, the Exemption Regime has been the main framework under which the majority of new pipeline (and LNG) infrastructure has been developed in the EU. Although the CAM NC adoption does not prevent the Exemption Regime from continuing to be used, the fact that the CAM NC has established the regulatory procedures for the development of incremental capacity - previously absent in the TEP - has weakened the rationale for using the Exemption Regime.

The chapter proceeds with explaining a $P C /$ status, under which some new pipelines (and LNG facilities) have been developed in the EU (Section 2.3). Although the PCI status does not constitute a regulatory regime per se and - unlike an exemption - does not relieve a project from its obligation to be compliant with the acquis, it provides for favourable regulatory treatment, including accelerated permit granting, rules for cross-border cost allocation, and eligibility for EU funding. The $\mathrm{PCl}$ status can continue to be used after the CAM NC adoption.

Having analysed the new legally binding framework as provided by the CAM NC, as well as the Exemption Regime (allowing for new infrastructure to be exempted from certain TEP provisions), together with the $\mathrm{PCl}$ status (facilitating the development of new infrastructure in line with TEP provisions), the chapter proceeds (Section 2.4) to analyse an Open Season procedure for the development of incremental capacity, as stipulated by the non-legally binding GGPOS, adopted in May 2007. Several new projects have been developed under this regime in the EU. However, once the CAM NC was adopted in March 2017 it has overridden all the previous non-legally binding EU-level documents for allocation of incremental capacity, including the GGPOS.

Finally, the chapter analyses a framework for the development of incremental capacity in the EU based on IGAs concluded between host EU member states and third countries (Section 2.5). The IGA framework had been attractive for as long as no legally binding framework for incremental capacity had been in existence at the EU level, as it allowed its parties a significant degree of freedom in designing regulatory procedures governing incremental capacity. However, with the adoption of the CAM NC, and with the acquisition by the EC of the right to check IGAs' compliance with the acquis, its attractiveness is likely to decline.

${ }^{17}$ See Additional documents. 

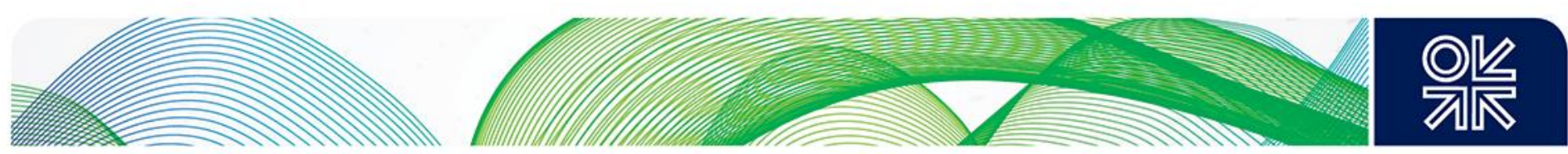

\subsection{The Capacity Allocation Mechanisms (CAM) Network Code}

The first CAM NC, which sought to establish regulatory procedures in respect of allocation of existing as opposed to incremental ${ }^{18}$ - capacity, was adopted on 14 October 2013 (CAM NC 2013). ${ }^{19}$ It had applied from 1 November 2015 and was repealed on 6 April 2017 when its successor - the 2017 CAM NC (CAM NC) - was adopted and entered into force. ${ }^{20}$ The 2017 CAM NC has a wider scope than its 2013 predecessor as it includes detailed regulatory provisions in respect of both existing and incremental capacity. ${ }^{21}$ It was not until its adoption that a set of legally binding regulatory procedures for incremental capacity was established at EU level. Previously, such procedures only existed at the level of individual member states as part of their national laws, while the Guidelines of Good Practice on Open Seasons (GGPOS), adopted in 2007 when the TEP did not exist, was the only document providing (not legally binding) guidance in respect of regulatory treatment of incremental (new) capacity at the EU level. ${ }^{22}$

The CAM NC 2013 went through a lengthy development process lasting more than two years, with the European Network of Transmission System Operators for Gas (ENTSOG) having developed two different drafts - one in March 2012 and another in September 2012. ${ }^{23}$ In June 2012, the Agency for the Cooperation of European Regulators (ACER) issued a reasoned opinion on the March 2012 draft, stating that it 'generally shows a high degree of compliance' with the CAM Framework Guidelines (FG), developed by ACER, while also stressing that 'some specific provisions of the CAM NC are not in line with those of the FG or with the objectives set out therein or are out of scope'. ${ }^{24}$ Taking into account ACER's opinion, ENTSOG prepared the September 2012 draft. In October 2012 ACER recommended this draft to the EC - albeit with significant qualifications - and the draft finally went into comitology in December 2012. ${ }^{25}$

As noted in Section 1, soon after the CAM NC was adopted in October 2013 it was re-opened for revision, with a view of developing previously absent detailed regulatory procedures in respect of incremental capacity. Based on ACER's guidance, issued on 2 December 2013,26 ENTSOG prepared an amended draft CAM NC, which was submitted to ACER on 26 December 2014 (ENTSOG's draft CAM NC). ${ }^{27}$

ACER made significant changes to the draft, particularly in respect of the definition and procedure for offering incremental capacity (Chapter IV(a)). ACER had subsequently run a public consultation process during February-March 2015 (ACER's first draft). ${ }^{28}$ Following the consultation, the draft was changed again, both in terms of content and structure. In particular, Chapter IV(a) was heavily restructured, and the entire procedure governing the incremental process was significantly changed. Whereas ACER's draft preserved (albeit re-worded) some of its sections (for example demand assessment, design phase, auctioning of incremental capacity), others were deleted altogether (for example the principles of Open Seasons (OS) and allocation of incremental capacity via OS). ACER also made technical changes concerned with the default auction calendar, auction algorithms, allocation of interruptible services, and bundling. ACER presented the amended draft to stakeholders for a second public consultation during July-August 2015 (ACER's second draft). ${ }^{29}$

Finally, on 14 October 2015, ACER sent its recommendation on the draft CAM NC to the EC for adoption. However, the draft caused significant disagreements between stakeholders on issues such as:

\footnotetext{
18 'Incremental' means 'new'.

${ }^{19}$ CAM NC 2013 (see Additional documents)

${ }^{20}$ CAM NC (see Additional documents)

${ }^{21}$ It has also clarified provisions related to the definition and offer of firm and interruptible capacity and capacity bundling.

22 GGPOS (ERGEG (2007)).

${ }^{23}$ ENTSOG (2012a); ENTSOG (2012b).

${ }^{24}$ ACER (2012).

25 The major provisions of two CAM NC drafts were analysed in Yafimava (2013).

${ }^{26}$ ACER (2013).

27 ENTSOG (2014).

${ }^{28}$ See ACER (2015a).

${ }^{29}$ ACER (2015b).
} 

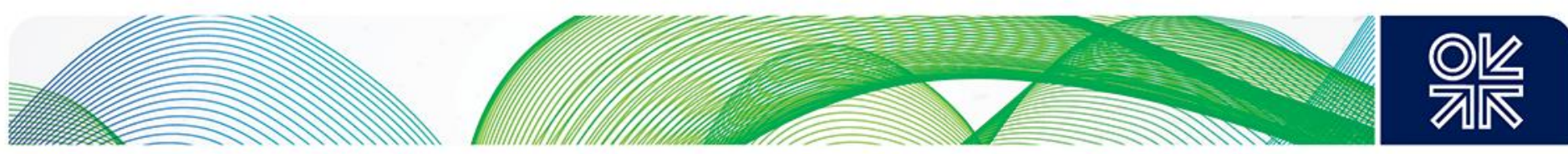

- obligation vs discretion on the part of national regulatory authorities to consider extension of the capacity booking horizon beyond 15 years,

- obligation on the part of ACER to decide on the alternative allocation rule (AAM) in the absence of a national regulatory authority decision,

- discretion on the part of the national regulatory authority over deciding on a 20 per cent capacity reservation quota.

Unable to reach agreement, the EC decided to prepare a 'compromise' CAM NC that would be acceptable to all stakeholders. This was done in parallel with the preparation of the 'compromise' Tariff NC - the preliminary drafts of which also met with significant criticism - allowing the synchronization of tariffs in respect of existing and incremental (new) capacity. Overall, the amendment process continued for more than three years until the code was finally adopted in March 2017 (CAM NC), being put into force and applied as of 6 April 2017.30

\subsubsection{Scope and definitions: incremental capacity, incremental capacity project, incremental capacity process}

The CAM NC applies to interconnection points (IP), with an IP being defined as 'a physical or virtual point connecting adjacent entry-exit systems or connecting an entry-exit system with an interconnector, in so far as these points are subject to booking procedures by network users'. This definition makes it clear that the CAM NC applies to interconnections between adjacent entry-exit zones irrespective of whether or not these zones are located in the same EU member state. It also makes clear that the CAM NC does not apply to cross-border points if they happen to be situated (physically or virtually) in the same entryexit zone.

The CAM NC does not apply to:

- entry points from liquefied natural gas (LNG) terminals and production (in other words connections between upstream and transmission networks) facilities;

- exit points to end consumers and distribution networks;

- entry points from, or exit points to, storage facilities.

The CAM NC does not apply to entry points from, and exit points to, third countries (in other words nonEU countries sharing a border or a maritime zone with EU member states) but 'may apply' to such points, 'subject to the decision of the relevant national regulatory authority'.

Likewise, the Congestion Management Procedures (CMP) Guidelines ${ }^{31}$ stipulate that CMPs 'may apply' to 'entry points from and exit points to third countries' subject to the decision of the relevant national regulatory authority. ${ }^{32}$ (Notably, this suggests that if the EC proposal to amend the Third Gas Directive is adopted (Section 4.3), thus making it applicable to pipelines to and from third countries, the CAM NC and CMP would not apply to entry points from, and exit points to, third countries, unless the relevant national regulatory authority so decides).

The CAM NC applies to all capacity at IPs as follows:

\footnotetext{
${ }^{30}$ CAM NC (see Additional documents).

${ }^{31}$ Gas Regulation 715 (see Additional documents), Annex I.

${ }^{32}$ Thus, as far as its scope is concerned, the CAM NC (see Additional documents) is consistent with the GTM as it does not create artificial barriers for gas trade within the same entry-exit zone. Notably, the EC proposal to amend the Third Gas Directive (see Additional documents) may impact the regulatory treatment of connections with third countries, see Section 5 .
} 

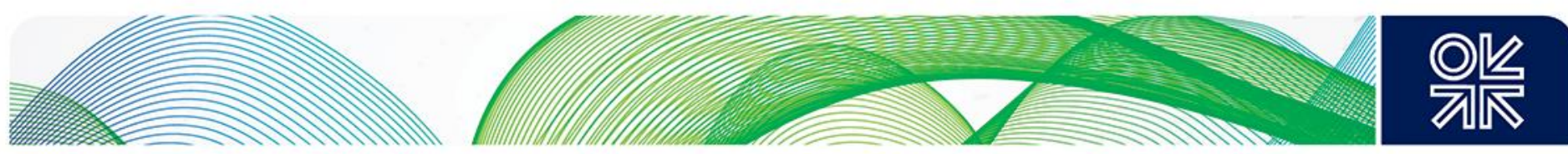

- technical capacity, defined as:

'the maximum firm capacity that the transmission system operator can offer to the network users, taking account of system integrity and the operational requirements of the transmission network';

- interruptible capacity, defined as:

'gas transmission capacity that may be interrupted by the transmission system operator in accordance with the conditions stipulated in the transport contract' (Art. 2, Gas Regulation 715);

- additional capacity (in the meaning of point 2.2.1 of Annex I of Gas Regulation 715), defined as:

'the firm capacity offered in addition to the technical capacity of an interconnection point calculated on the basis of Art. $16.1^{33}$ of this Regulation' whereas 'any additional capacity made available through the application of one of the congestion management procedures as provided for in points 2.2.2, 2.2.3, 2.2.4 and 2.2.5 shall be offered by the respective TSO(s) in the regular allocation process' (CMP (Annex I to Gas Regulation 715));

- incremental capacity.

The CAM NC defined 'incremental capacity' (Art. 3.1) as:

'a possible future increase via market-based procedures in technical capacity or possible new capacity created where none currently exists that may be offered based on investment in physical infrastructure or long-term capacity optimization and subsequently allocated subject to positive outcome of an economic test, in the following cases:

0 at existing interconnection points;

- by establishing a new interconnection point or points;

- as physical reserve flow capacity at an interconnection point or points, which has not been offered before.

The definition of incremental capacity has changed several times during the CAM NC development process. In 2012, the Council of European Energy Regulators (CEER), which had developed proposals on 'how to identify and integrate new capacity, based on market demand and coordinated market procedures', suggested to make a distinction between incremental and new capacity, with 'incremental capacity' defined as capacity provided on top of technical capacity available at an existing interconnection point (in other words new capacity in existing systems) and 'new capacity' defined as capacity provided at a new interconnection point (in other words new capacity in new systems). ${ }^{34}$ On its part, ENTSOG suggested to define incremental capacity as 'a possible future increase via market-based procedures in technical capacity that may be offered based on investment or long-term capacity optimization and subsequently allocated subject to the positive outcome of an economic test', whereas ACER had subsequently requested to modify the ENTSOG definition by making a distinction between an increase in (existing) technical capacity and the creation of new capacity where none currently existed. In the end, the CAM NC appears to have merged the CEER categories of incremental and new capacities into one category (and definition) of incremental capacity.

The CAM NC defined an 'incremental capacity project' as:

'a project to increase the amount of technical capacity at an existing interconnection point or to establish a new interconnection point based on capacity allocation in the preceding incremental capacity process'.

In turn, an 'incremental capacity process' is defined as

\footnotetext{
${ }^{33}$ Art.16.1 reads: 'The maximum capacity at all relevant points referred to in Art.18.3 shall be made available to market participants, taking into account system integrity and efficient network operation'.

${ }^{34}$ CEER (2012).
} 

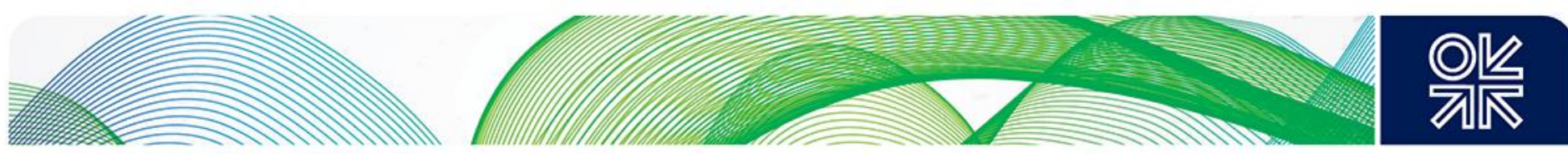

'a process to assess the market demand for incremental capacity that includes a non-binding phase, in which network users express and quantify their demand for incremental capacity, and a binding phase, in which binding commitments for contracting capacity are requested from network users by one or more transmission system operators'.

This suggests that the CAM NC's incremental capacity process is just a 'classic' open season process in all but name. Interestingly, ENTSOG's draft CAM NC used the same wording for defining an open season. ${ }^{35}$ However, the CAM NC never mentions - let alone defines - an open season. According to ACER, the 'open season' term became 'obsolete, as all incremental processes are run as "open seasons", with a non-binding and a binding phase.'

Instead, the CAM NC defines an 'alternative allocation mechanism' (AAM) as

'an allocation mechanism for offer level${ }^{36}$ or incremental capacity designed on a case-by-case basis by the transmission system operators, and approved by the national regulatory authorities, to accommodate conditional demand requests'.

\subsubsection{Capacity allocation rules: auctions, alternative allocation mechanism (AAM) and reservation quotas}

The CAM NC stated that 'auctions shall be used for the allocation of capacity at an interconnection point, unless provided otherwise' (Art. 8) thus making auctions a default capacity allocation mechanism while also providing for other alternative (to auctions) allocation mechanisms (AAM) (Art. 30). ${ }^{37}$

The CAM NC defines the following standard capacity products for auctions: yearly, quarterly, monthly, daily, and within-day. The longest duration Standard Capacity Products - namely, yearly - are to be offered first, followed by the next shortest capacity duration for the respective period. The auction processes 'start simultaneously for all concerned interconnection points' whereas 'each auction process, relating to a single [Standard Capacity Product], shall allocate capacity independently of every other auction process except where incremental capacity is offered or where, subject to the agreement of the directly involved transmission system operators and the approval of relevant national regulatory authorities, competing capacity is allocated.' The CAM NC specifies that when incremental capacity is offered, 'the independent allocation shall not apply to the simultaneous auction processes for the respective offer levels, since these are dependent on each other, as only one offer level can be allocated' (Art. 8.2).

In respect of existing capacity, the CAM NC stipulates 'an amount at least equal to 20 per cent of the existing technical capacity at each interconnection point shall be set aside' (Art. 6) to be offered as follows (Art. 7):

(a) an amount at least equal to 10 per cent of the existing technical capacity at each interconnection point shall be offered no earlier than in the annual yearly capacity auction ... held in accordance with the auction calendar during the fifth gas year preceding the start of the relevant gas year; and

(b) a further amount at least equal to 10 per cent of the existing technical capacity at each interconnection point shall first be offered no earlier than the annual quarterly capacity auction

\footnotetext{
${ }^{35}$ ENTSOG (2014)

36 'Offer level' means the sum of the available capacity and the respective level of incremental capacity offered for each of the yearly standard capacity products at an interconnection point, see CAM NC, Art. 3.

ENTSOG's draft CAM NC (see ENTSOG (2014)) stated 'auctions shall be used for the allocation of capacity at interconnection points' while also providing for the usage of OS procedures for allocation of incremental capacity (Art. 20.f). However, the ACER's second draft CAM NC (see ACER (2015b)) no longer contained articles on principles of open season procedures or on allocation of incremental capacity in open season procedures.
} 

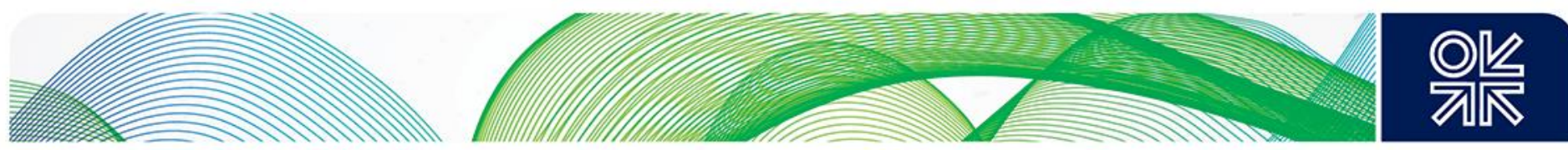

... held in accordance with the auction calendar during the gas year preceding the start of the relevant gas year.'

In respect of incremental capacity, the CAM NC stipulates 'an amount at least equal to 10 per cent of the incremental technical capacity at the concerned interconnection point shall be set aside and offered no earlier than the annual quarterly capacity auction ... held in accordance with the auction calendar during the gas year preceding the start of the relevant gas year.' (Art. 8). ${ }^{38}$ The CAM NC further specifies that 'the exact proportion of capacity to be set aside' - both existing and incremental - 'shall be subject to a stakeholder consultation, alignment between transmission system operators and approval by national regulatory authorities at each interconnection point'. Furthermore, national regulatory authorities 'shall in particular consider setting aside higher shares of capacity with a shorter duration to avoid foreclosure of downstream supply markets' (Art. 9). The rationale for making these quotas part of the CAM NC is to avoid capacity hoarding and market foreclosure.

The CAM NC has thus established the minimum levels of reservation quotas -20 per cent for the existing technical capacity and 10 per cent for the incremental technical capacity - but it prescribed no upper limits for reservation quotas in respect of either existing or incremental capacity, thus leaving the national regulatory authorities to decide on the upper limits. As a result, reservation quotas could differ widely across the EU, depending on the decisions of the national regulatory authorities. However, there is one exception: when the alternative allocation mechanism (AAM) is applied in respect of incremental capacity, if booking is prioritized by either duration or volume, the CAM NC has limited the upper level of reservation quota at 20 per cent, thus suggesting that the national regulatory authority would not be able to impose a reservation quota higher than 20 per cent.

The CAM NC stipulates that 'capacity created via non-market-based procedures and for which the final investment decision has been taken without prior commitments from network users shall be offered and allocated as available standard capacity products' thus suggesting that such capacity is not to be considered incremental (Art. 8.10). This reflects a suggestion made by ACER during the consultation stage that 'capacity created via non-market based or partially market based procedures' - namely via non-market based PCl, an EU ten-year network development plan (TYNDP), or central planning - 'was to be treated as available capacity'. This means that such capacity could only be allocated via auctions (rather than via the AAM), and that that the 20 per cent (as for existing) rather that the 10 per cent quota (as for incremental) would be applied.

\subsubsection{Auctions: booking horizons, capacity calculations, and timings}

The CAM NC stipulated that yearly capacity auctions are to be held once a year, with the auction process to 'offer capacity at least for the upcoming 5 gas years and for no longer than the upcoming 15 gas years for existing capacity' (Art. 11.3). Thus, contrary to the ENTSOG's draft, the CAM NC has stipulated not only the maximum but also the minimum horizon for which capacity must be offered at an auction. In respect of incremental capacity, the CAM NC stipulated that 'the offer levels may be offered in yearly capacity auctions for a maximum of 15 years after the start of operational use'.

As from 2018, yearly capacity auctions shall start on the first Monday of July each year (Art. 11.4). ${ }^{39}$ At least one month before the auction starts, TSOs must notify network users about the amount of firm capacity to be offered in each year for the upcoming yearly capacity auction (Art. 11.8). The capacity to be offered during the yearly auction shall be equal to:

\footnotetext{
${ }^{38}$ It is worth noting that the preliminary versions of the CAM NC referred to 'incremental capacity' -rather than 'incremental technical capacity' - a clarification that the $10 \%$ quota refers to 'incremental technical capacity' is important as it makes clear the quota does not apply to additional capacity [is this so?]

${ }^{39}$ According to the CAM NC 2013 (see Additional documents), annual yearly auctions start on the first Monday of March. As the CAM NC (see Additional documents) mandated the auctions to be held on the first Monday of July from 2018 , in 2017 the auctions were still held in March.
} 

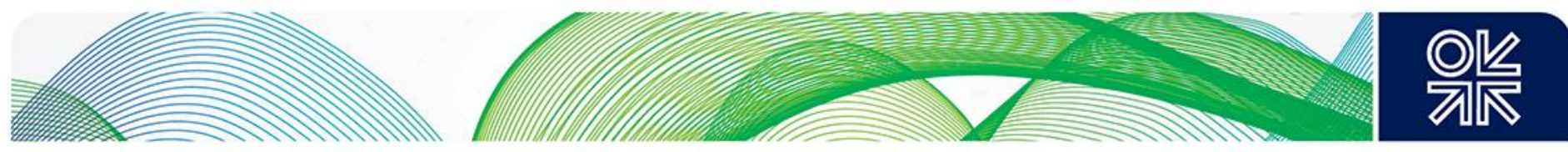

$A-B-C+D+E-F$

where:

A is the TSO's technical capacity;

B is the amount of technical capacity (A) set aside in accordance with Art. 8.7 (reservation quota) for annual yearly auctions offering capacity for the next five years, or the amount of technical capacity (A) set aside in accordance with Art. 8.7 for annual yearly auctions for capacity beyond the first five years;

C is the previously sold technical capacity, adjusted by the capacity which is re-offered in accordance with applicable CMP;

D is additional capacity for such a year, if any;

E is the incremental capacity for such a year included in a respective offer level, if any;

$\mathrm{F} \quad$ is the amount of incremental capacity $(\mathrm{E})$, if any, set aside in accordance with Art. 8.8 and Art. 8.9 (reservation quota).

The CAM NC obliged the TSOs to notify network users about 'the amount of firm capacity to be offered for each year for the upcoming annual yearly capacity auction' at least one month before the auction starts (Art. 11.8). An obligation, present in both ENTSOG and ACER drafts, to notify network users about 'any additional capacity' that 'may be made available' has not been included in the CAM NC.

The CAM NC has also stated that as far as incremental capacity is concerned, 'the binding commitments of network users for contracting capacity, including whether the conditions for a repeated auction ... are met, shall be made available no later than the next business day after the closing of the bidding round' whereas the results of the economic tests (see Section 2.1.4 below) shall be made available no later than two business days after the closing of the bidding round (Art. 11.10). Both the ENTSOG and the ACER drafts envisaged that both the binding commitments and the results of the economic test were to be made available simultaneously no later than the next business day.

Four quarterly capacity auctions shall be held during each gas year. The four quarterly auctions shall start on the first Monday of August, the first Monday of November, the first Monday of February, and the first Monday of May, respectively (Art. 12.4). The capacity to be offered in all quarterly auctions shall be equal to the TSO's technical capacity minus the previously sold technical capacity (adjusted by the capacity which is re-offered in accordance with CMPs) plus additional capacity for such quarter (if any) (Art. 12.5). Two weeks before the auctions start, TSOs shall notify network users about the amount of capacity to be offered for each quarter for the upcoming quarterly auction. The monthly capacity auction is to be held once a month. Monthly capacity auctions shall start on the third Monday of each month. The capacity to be offered in the monthly auction shall be equal to the transmission system operator's technical capacity minus the previously sold technical capacity (adjusted by the capacity which is re-offered in accordance with CMPs) plus additional capacity for such month (if any) (Art. 13. 5). One week before the auction starts, TSOs shall notify network users about the amount of capacity to be offered for the upcoming monthly auction. The day-ahead capacity auction shall be held once a day. Every day, a Standard Capacity Product for the following gas day shall be auctioned through the day-ahead auction. At the time the bidding round opens, TSOs shall notify network users about the amount of capacity to be offered for the upcoming auction. Subject to capacity being made available, a within-day capacity auction shall be held every hour during a gas day. TSOs shall publish the available amount of within-day firm capacity on offer, after closure of the last day-ahead auction.

As far as the price payable for the capacity is concerned, the CAM NC states that 'all network users who have placed valid volume bids at the clearing price shall be allocated the capacity according to their volume bids at the clearing price'. It notes further that 'where incremental capacity is offered, the allocation of incremental capacity shall be subject to the outcome of the economic test ... Successful network users shall pay the clearing price of the specific auction, which may be a fixed or a floating payable price 

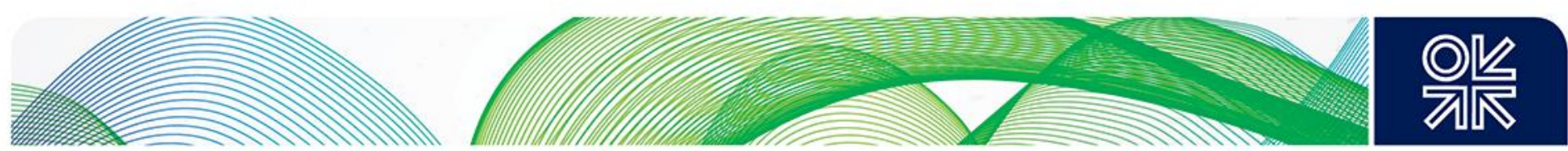

approach' and 'any other possible charges applicable at the time when the capacity allocated to them can be used' (Art. 17.20). ${ }^{40}$

According to the Tariffs NC (Art. 24), the payable price for a given Standard Capacity Product at an IP shall be calculated in accordance with one or other of the following formulas:

(a) where the floating payable price approach is applied:

$P_{\text {flo }}=P_{R, f l o}+A P$

Where:

$P_{\text {flo }} \quad$ is the floating payable price;

$\mathrm{P}_{\mathrm{R}, \mathrm{flo}} \quad$ is the reserve price for a Standard Capacity Product applicable at the time when this product may be used;

AP is the auction premium, if any.

(b) Where the fixed payable price approach is applied:

$P_{\mathrm{fix}}=\left(P_{\mathrm{R}, \mathrm{y}}{ }^{*} I N D\right)+R P+A P$

Where:

$P_{\text {fix }}$ - is the fixed payable price;

$\mathrm{P}_{\mathrm{R}, \mathrm{y}}$ - is the applicable reserve price for a yearly Standard Capacity Product which is published at the time when this product is auctioned;

IND - is the ratio between the chosen index at the time of use and the same index at the time the product was auctioned;

$\mathrm{RP}$ - is the risk premium reflecting the benefits of certainty regarding the level of transmission tariff, where such premium shall be no less than 0 ;

$\mathrm{AP}-$ is the auction premium, if any.

While both the ENTSOG's and the ACER's August-September 2015 consultation drafts stated that the allocation of incremental capacity would be subject not only to the outcome of the economic test but also to 'any necessary subsequent approval processes' (the nature of which was not specified), the CAM NC has not included this provision, thus reducing uncertainty for network users in respect of approval process.

\subsubsection{The CAM Network Code: incremental capacity process procedure}

As noted previously, the CAM NC differs significantly from the ENTSOG's draft in respect of the procedure governing the incremental capacity process. This is a result of changes made by the ACER and the EC which were subsequently incorporated in the final CAM NC. As such, the CAM NC is a result of a compromise that was reached between all the stakeholders. This compromise, however, is not necessarily optimal for the achieving of a single liberalized EU gas market as far as the GTM's third pillar (ensuring secure supply to, and economic investment in, the markets by means of building sufficient new capacity in a timely manner) is concerned.

The economic test

The CAM NC stipulates that the TSO(s) or the national regulatory authority (as decided by the latter) shall carry out an economic test; this test is applied in order to assess the economic viability of incremental capacity projects. It is performed for each offer level of an incremental capacity project after the binding commitments of network users for contracting capacity have been obtained by the TSOs (Art. 22.1).

\footnotetext{
40 The CAM NC (see Additional documents) wording is odd, as it does not say that the clearing price may be a fixed or a floating price or that it may be based on a fixed or a floating price approach, instead conflating the two. This might be a result of a compromise as both the ENSTOG and the ACER drafts referred to 'the clearing price of the specific auction, which may be a fixed or a variable price'.
} 

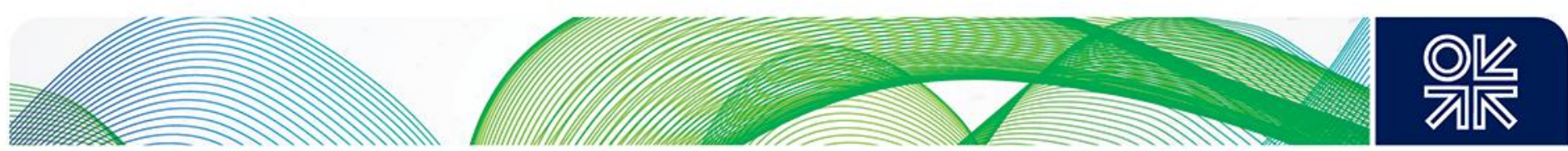

The CAM NC states that the test must consist of the following parameters:

(a) the present value of binding commitments, which is calculated as the discounted sum of:

(i) the sum of the respective estimated reference prices and a potential auction premium and a potential mandatory minimum premium, multiplied by the amount of contracted incremental capacity;

the sum of a potential auction premium and a potential mandatory minimum premium, ${ }^{41}$ multiplied by the amount of available capacity that was contracted in combination with the incremental capacity;

(b) the present value of the estimated increase in the allowed or target revenue of the TSO associated with the incremental capacity, as approved by the national regulatory authority;

(c) the f-factor, defined as the share of the present value of the estimated increase in the allowed or target revenue of the TSO associated with the incremental capacity included in the respective offer level to be covered by the present value of binding commitments.

The reference prices used for calculation of the parameter set out in (a), as well as the parameters set out in (b) and (c), must be submitted by the TSO(s) to the relevant national regulatory authority(ies) for approval (Art. 25.1).

The outcome of the economic test is considered:

positive, if the value of (a) is at least equal to (b) as defined by the f-factor (c), negative, if not.

If the economic test is positive on both sides of an IP for at least one offer level that includes incremental capacity, an incremental capacity project shall be initiated. In other words, a positive outcome of the economic test is both a necessary and a sufficient condition for initiation of an incremental capacity project.

Given that the level of the f-factor is one of the key parameters determining the outcome of the economic test, it is important to understand how it is set. The CAM NC states that the level of the f-factor for a given offer level is set by the national regulatory authority, taking into account the following factors (Art. 23.1):

(a) the amount of technical capacity set aside (the CAM NC prescribes at least 10 per cent but places no upper limit, leaving it to the national regulatory authority to determine (Art. 8.8), except when the AAM rule is applied in which case there is an upper limit of 20 per cent, see Section 2.1.2);

(b) positive externalities of the incremental capacity project on the market or the transmission network, or both (the CAM NC does not specify what these externalities might be or how they might be measured);

(c) the duration of the binding commitments of network users for contracting capacity, compared to the economic life of the asset (the CAM NC stipulates that 15 years is a maximum booking period);

(d) the extent to which demand for the capacity established in the incremental capacity project can be expected to continue after the end of the time horizon used in the economic test.

The national regulatory authority thus has a significant degree of discretion over the level of the f-factor. Notably, the CAM NC neither stipulates any range for the f-factor, nor requires the national regulatory authority to provide justification for its decision on the f-factor. It is worth noting that the level of f-factor

\footnotetext{
${ }^{41}$ According to the Tariffs NC (Art. 33.3), in case the allocation of all incremental capacity at the reference price would not generate sufficient revenues for a positive economic test outcome, a mandatory minimum premium may be applied in the first auction or AAM in which the incremental capacity is offered. Such premium may also be applied in subsequent auctions when the capacity is offered that initially remained unsold or when capacity is offered that was initially set aside (short term reservation quota).
} 

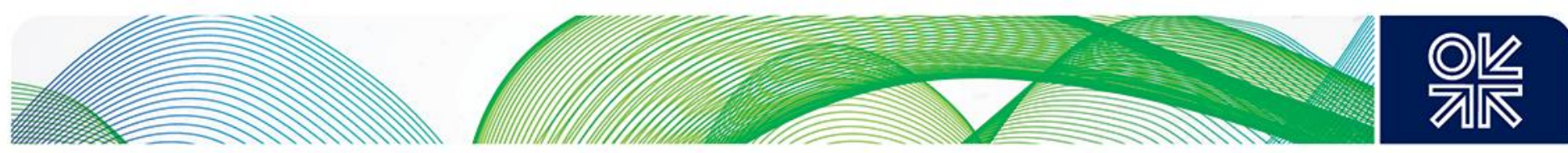

was a controversial issue during the CAM NC development process, with some stakeholders arguing that it should not be allowed to be less than 1 and that instead there should be a stipulation that 100 per cent of the present value of the estimated increase in the allowed or target revenue associated with incremental capacity would be covered by the present value of binding commitments. However, this position has not been reflected in the CAM NC.

The CAM NC says that individual economic test parameters shall be combined into a single economic test (Art. 24.1). Should a redistribution of revenues potentially lead to a decrease in the level of binding commitments required for a positive single economic test, the TSOs may submit the mechanisms for a redistribution of revenues from incremental capacity to the relevant national regulatory authorities for coordinated approvals (Art. 24.4). However, unlike ACER's second draft, which obliged the national regulatory authorities to 'issue coordinated decisions on the parameters of a single economic test', the CAM NC has no such requirement.

\section{Market demand assessment}

The CAM NC stipulated that 'immediately after the start of the annual yearly capacity auction at least in each odd-numbered year TSOs shall cooperate in the processes of assessing market demand for incremental capacity' and of conducting corresponding technical studies. ACER's second draft did not envisage the possibility of assessing market demand each year, as it stated that a market demand assessment is to be 'repeated every two years' (Art. 20.a.1). The CAM NC stipulates that as from 2018, yearly capacity auctions start on the first Monday of July each year (Art. 11.4).42 It also (Art. 26.1) states that 'the first demand assessment shall be conducted in 2017 as from the entry into force of this Regulation' thus implying that it would be conducted as of 6 April 2017 (the date of CAM NC's entry into force).

No later than eight weeks after the start of the yearly auction, the TSOs on each side of an entry-exit system shall produce common market demand assessment reports. TSOs shall consider non-binding demand indications submitted no later than eight weeks after the start of the annual yearly auction in the ongoing market demand assessment (Art. 26.6) and may consider non-binding demand indications submitted after that, in the ongoing market demand assessment, or introduce them into the next market demand assessment (Art. 26.7). If demand for incremental capacity is expressed by network users no later than eight weeks after the start of the yearly auction in even-numbered years, the TSOs may agree - but are not obliged - to also conduct a market demand assessment in an even-numbered year, subject to certain conditions.

The non-binding demand indications shall contain at least the following information:

- the two or more adjacent entry-exit systems between which demand for incremental capacity (on one or both sides of an interconnection point) is expressed and the requested duration;

- the gas year(s) for which a demand for incremental capacity is expressed;

- the amount of capacity demanded between the respective entry-exit systems;

- information on non-binding demand indications which were, or will be, submitted to other TSOs, in case such indications are linked to each other - such as demand for capacities at several related interconnection points (Art. 26.8). ${ }^{43}$

The CAM NC obliges network users to indicate whether their demand is subject to any conditions in relation to the above information.

\footnotetext{
42 Notably, under the CAM NC 2013 (see Additional documents), yearly capacity auctions were held on the first Monday of March each year (Art. 11.4).

${ }^{43}$ It is not clear what is meant by 'related' IPs. Whereas ENTSOG's draft (see ENTSOG (2014)) contained a reference to demand for capacities which are 'forming a transport route, or are at least partly mutually exclusive' (Art. 20.b.2), the CAM NC (see Additional documents) does not contain any such references.
} 

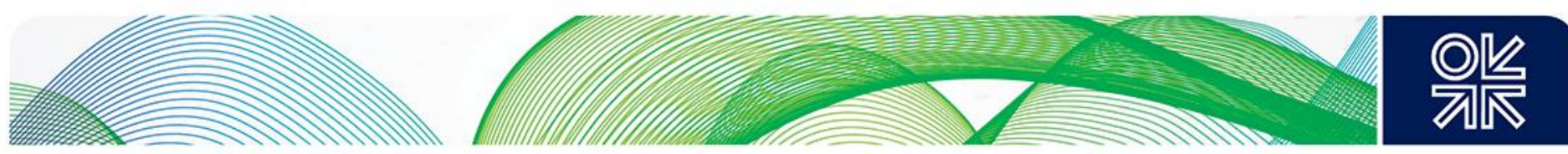

A TSO is allowed to charge fees for activities resulting from the submission of non-binding demand indications, reflecting the administrative costs, which shall be subject to approval by the relevant national regulatory authority. These fees are to be reimbursed should the economic test be positive (Art. 26.11).

The TSOs are obliged to respond to non-binding demand indications within 16 weeks after the start of the yearly auctions, or within eight weeks of receipt of demand indications. Their response shall provide at least the following:

- whether the demand indicated can be considered by the TSO in the ongoing process;

- whether, in the case of demand indications submitted after the deadline, they are sufficient to consider the initiation of an incremental capacity process, when the TSO may agree to conduct an assessment in an even-numbered year;

- the market demand assessment report in which the indicated demand will be assessed, provided that the demand indicated cannot be considered under the two above sections, (this is to be justified).

The TSO thus appears to have significant - but not absolute - discretion over if and when the incremental capacity project will be initiated. Notably, although the receipt and evaluation by the TSO of non-binding demand indications submitted by network users constitutes an ongoing incremental capacity process, it does not automatically mean that an incremental capacity project will be initiated. Initiation of the incremental capacity project by the TSO is subject to market demand assessment, conducted by the TSO, and it is the market demand assessment report, prepared by the TSO, that must state whether or not the incremental capacity project is initiated.

According to the CAM NC, the market demand assessment report must take into account all the following criteria:

- whether the Union-wide 10-year network development plan (TYNDP) identifies a physical capacity gap whereby a specific region is undersupplied in a reasonable peak scenario and where offering incremental capacity at the interconnection point in question could close the gap; or a national network development plan identifies a concrete and sustained physical transport requirement;

- whether no yearly Standard Capacity Product linking two adjacent entry-exit systems is available in the annual yearly capacity auction for the year in which incremental capacity could be offered for the first time and in the three subsequent years, because all the capacity has been contracted;

- whether network users have submitted non-binding demand indications requesting incremental capacity for a sustained number of years and all other economically efficient means for maximizing the availability of existing capacity are exhausted.

By stating that the report must take into account all of the above criteria, the CAM NC makes it possible for the TSOs to prepare the report stating that an incremental capacity project would not be initiated if the answer to any of the above questions is negative. For example, the TSOs would be able to conclude that no incremental capacity project would be initiated should neither the TYNDP nor a national network development plan (NDP) identify a capacity gap and a physical transport requirement, even although users of networks might have submitted their demand indications for a sustained number of years and all other economically efficient measures are exhausted. ${ }^{44}$ At the same time, should all of the CAM NC criteria be met (namely either the TYNDP or the NDP identify a gap and no Standard Capacity Product is offered and network users submitted their demand indications) it would be extremely difficult - most likely impossible - for the TSOs not to initiate the incremental capacity project.

\footnotetext{
${ }^{44}$ It is worth noting that the ENTSOG's draft was worded differently as it had not stated that 'all' criteria are to be taken into account. Nonetheless, under the ENTSOG's draft, the TSO would have also been able to refuse the initiation of the incremental capacity project.
} 

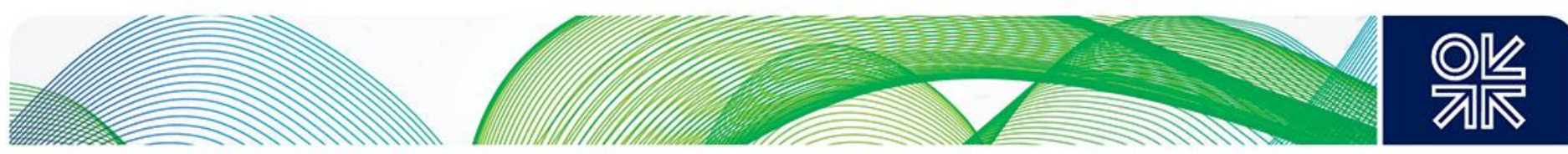

The CAM NC stipulates that the market demand assessment must be published no later than 16 weeks after the start of the yearly capacity auction and include inter alia the following:

- a conclusion on whether to initiate an incremental capacity project,

- the aggregated non-binding demand indications, together with an assessment of the expected amount, direction, and duration of demand for incremental capacity at the interconnection points with each adjacent entry-exit system or interconnector (Art. 26.13).

Notably, the market demand assessment report must evaluate the prospective demand for incremental capacity of all network users, thus excluding the possibility of discrimination based on the user's origin (Art. 26.2).

The CAM NC grants TSOs a centre-stage and exclusive role in the incremental capacity process, particularly in conducting the demand assessment and deciding on the initiation of a project. The CAM NC made the assessment a central part of the process, on the basis of which the decision is made on whether to initiate the project. Furthermore, once the assessment report concludes that the incremental capacity project will be initiated and that the technical studies for it will be conducted, such studies can only be based on 'technical feasibility and market demand assessment reports' ${ }^{45}$

At the same time, the CAM NC did not clearly spell out the role of the network users in the incremental capacity process. Although the CAM NC implies the possibility of network users making non-binding demand indications - as these indications serve as one of the criteria on the basis of which the market demand assessment is conducted - it does not outline any specific procedure for doing so. By comparison, the ENTSOG's CAM NC draft outlined such a procedure in specific terms, by explicitly obliging the TSOs to 'enable network users to indicate their demand for incremental capacity by submitting non-binding demand indications' (Art. 20.b(1)). ${ }^{46}$ The CAM NC does not contain an explicit obligation - however, it could be arguably construed to do so as the TSO is obliged to consider nonbinding demand indications, thus suggesting that the network users would be able to indicate their demand.

In addition to the CAM NC, the TEP also contains provisions obliging the TSOs to 'regularly assess market demand for new investment' ('Gas Regulation 715', Art. 16.5) while also stating that 'each TSO shall build sufficient cross-border capacity to integrate European transmission infrastructure accommodating all economically reasonable and technically feasible demands for capacity and taking into account security of gas supply' ('Third Gas Directive', Art. 13.2).

Overall, although the CAM NC provides less clarity than ENTSOG's draft as to when and under which conditions the incremental capacity project is initiated, its provisions - taken together with the aforementioned TSO obligations as stipulated by the TEP - appear to be sufficient to ensure that the TSO will initiate the incremental capacity project for which there is market demand as / if demonstrated in the market demand assessment.

\section{Design phase}

If the demand assessment report identifies demand for incremental capacity projects, the design phase must start the day after the publication of the report (Art. 27.1). ${ }^{47}$ The CAM NC states that TSOs are obliged to conduct technical studies in order to design the incremental capacity project and coordinated

\footnotetext{
45 This is different from ENTSOG's draft CAM NC, see (ENTSOG (2014), which envisaged that such studies would be based on the demand assessment reports or on non-binding demand indications (Art. 20.c.1). This change in wording is significant as it suggests that under the CAM NC, non-binding demand indications would only be considered as constituent parts of demand assessment reports rather than in their own right, thus strengthening the TSO's discretion in respect of the incremental capacity project.

${ }^{46}$ The ACER's second draft (ACER (2015b)) does not contain such an explicit obligation but it could be inferred from its statement that 'network users should submit demand indications'.

${ }^{47}$ Notably, whereas the ACER's second draft (ACER (2015b)) had stated that it was the TSO's obligation to start the design phase, the CAM NC (see Additional documents) does not directly state that it is the TSO's obligation to do so.
} 

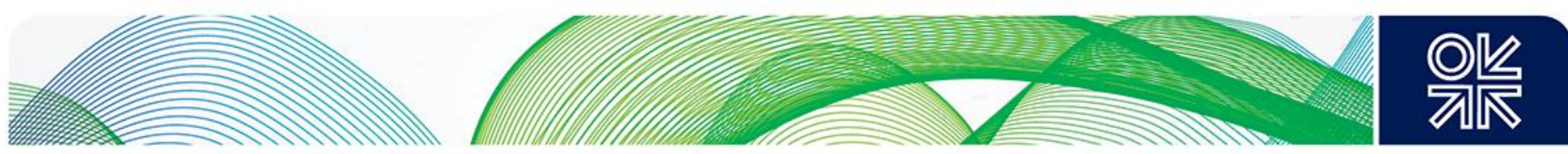

offer levels, based on reports and technical feasibility. Within 12 weeks after the start of the design phase the TSOs must conduct a joint public consultation (at least for one month and at most for two months) on the draft project proposal. The CAM NC stipulated that inter alia the following information must be included in the consultation (Art. 27.3):

- a description of the project, including a cost estimate (notably ACER's second draft did not require a cost estimate to be included);

- where relevant, based on conditional demand indications received, the TSOs' proposed alternative allocation mechanism (AAM) and its justification;

- general rules and conditions that a network user must accept to participate and access capacity in the binding phase, including how 'possible delays in the provision of capacity or the event of a disruption to the project are dealt with contractually' (the ACER's second draft did not require any contractual remedies in the event of delays);

- where a fixed price approach is followed, the ratio between the chosen index at the time of use and the same index at the time the product was auctioned, together with the risk premium reflecting the benefits of certainty regarding the level of transmission tariff, where such a premium shall be no less than 0 ;

- the level of user commitments, expressed as an estimate of the f-factor which, having consulted with the TSOs, is proposed and approved by the national regulatory authorities (the reference to the f-factor as the measure of commitments was not part of the ACER's second draft);

- whether the incremental capacity is likely to result in 'a sustained, significant decrease in the utilization of other non-depreciated gas infrastructure in the same and adjacent entry-exit systems or along the same gas transport route'.

\section{Approval and publication}

Following the consultation and finalization of the design phase, the TSOs are obliged to submit the incremental capacity project proposal to the relevant national regulatory authorities for coordinated approvals. The CAM NC stipulated which information must be included in the project proposal, including the following:

- all offer levels reflecting the range of expected demand for incremental capacity as a result of market demand assessment and a public consultation;

- timelines of the incremental capacity project;

- the economic test parameters;

- whether an exceptionally extended time horizon for contracting capacity - for an additional period of up to five years beyond the allocation of up to 15 years after the start of the operational use - may be required; 48

- where applicable, the proposed alternative allocation mechanism (AAM) including its justification, as well as the conditions approved by the TSO for the binding phase;49

- where a fixed price approach is followed, all the elements necessary for calculating the fixed price.

\footnotetext{
${ }^{48}$ Notably, the CAM NC allows an extension of booking horizon for a further five years only if the economic test could be passed on the basis of the 15 years' bookings (Art. 30). ENTSOG's draft allowed an extension by five years without making it conditional on the result of the economic test (Art. 20.e). Whereas the CAM NC allows for upfront allocation beyond 15 years. The ACER's draft appears to have suggested that no upfront allocation beyond 15 years would be allowed, whereas allocation beyond 15 years would take place in subsequent years (namely one additional gas year can be allocated each following year.

${ }^{49}$ Notably, ACER's second draft stated that the proposal must say 'whether criteria are met to warrant an alternative allocation rule according to Art. 20.d.2, including a justification and to what extent and which terms will be allowed for conditional bids in the binding phase.' The CAM NC does not require the proposal to state whether the criteria are met, presumably because it does not stipulate a clear set of criteria (Art. 30.2), unlike ACER's second draft (Art. 20.d.2). ACER's draft also requested 'a detailed description of the alternative allocation rule', but the CAM NC does not have that requirement.)
} 

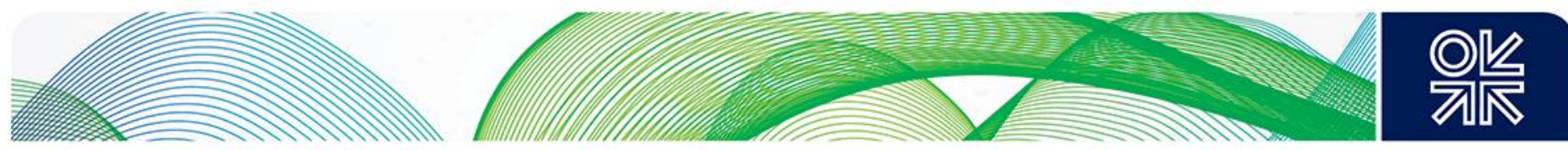

Within six months of receipt of the complete project proposal by the last of the relevant national authorities, the national regulatory authorities must publish coordinated decisions on the project proposal, including justifications. While preparing a decision, each national regulatory authority is obliged to consider the views of the other national regulatory authorities involved and is obliged to take into account any detrimental effects on competition or the effective functioning of the internal gas market associated with the incremental capacity projects concerned. The CAM NC thus stipulates that irrespective of which capacity allocation mechanism is employed - auction or the AAM - the national regulatory authorities are obliged to take into account any detrimental impact on competition or IEM functioning. ${ }^{50}$

If a relevant national authority objects to the project proposal, it is obliged to inform the other involved national regulatory authorities as soon as possible, whereas all the national regulatory authorities involved are obliged to take 'all reasonable steps to work together and reach a common agreement'. The CAM NC stipulates that where the relevant national regulatory authorities cannot reach an agreement on the proposed $A A M$ within six months of receipt of the proposal by the last of the relevant national regulatory authorities, ACER 'shall decide on the alternative allocation mechanism' as stipulated by ACER Regulation (Art. 8.1). ${ }^{51}$ In so doing, ACER must consult 'the national regulatory authorities and the transmission system operators concerned and shall be informed of the proposals and observations of all the transmission system operators concerned'. ACER is obliged to issue a decision within a period of six months from the day of referral (Art. 8.3), thus suggesting that 12 months is the maximum time limit for a decision on the AAM. Notably, the ACER's second draft stipulated that if the national regulatory authorities cannot agree on the AAM, they 'shall coordinate to direct the TSOs to allocate incremental capacity using the auction mechanism' (Art. 20.b.6). The fact that the CAM NC does not allow to allocate incremental capacity via auction should at least one of the involved regulatory authorities disagree with the AAM, suggests that if at least one regulatory authority wants to deploy the AAM whereas others disagree, ACER would be obliged 'to decide on the AAM to be implemented'. This wording suggests that ACER would only be able to decide on what the AAM should be and provide its detailed description, but that ACER would not be able to rule whether the auction - rather than the AAM - would have to be applied. In other words, as long as at least one national regulatory authority is in favour of the application of the AAM, it would not be possible to apply an auction in respect of the incremental capacity project in question.

No later than two months before the offer of incremental capacity in the yearly capacity auction, the TSOs shall jointly publish a notice including the compulsory information relating to the project proposal and a template of the contract(s) related to the capacity offered.

\section{Allocation of incremental capacity: auctioning and an AAM}

Subject to completion of the market design phase, the TSOs are obliged to offer the incremental capacity, together with the respective available capacity, in the annual yearly auction as standard bundled products as a default rule (thus also respecting provisions on capacity reservation quotas for incremental capacity as stipulated in Art. 8.8 and Art. 8.9).

Although the CAM NC made auctions a default capacity allocation mechanism, it has also stipulated that 'an alternative allocation mechanism can be used, subject to national regulatory authorities' approval, where it is reasonable to conclude from the market demand assessment ... or the consultation ... that the ascending clock auction is not suitable and that the incremental capacity project fulfils both of the following conditions (Art. 30.2):

- it involves more than two entry-exit systems and bids are requested along several interconnection points during the allocation procedure;

\footnotetext{
${ }^{50}$ Interestingly, it was only if the AAM were to be used for allocating incremental capacity with bids spanning a number of different yearly capacity products at an IP, that ACER's draft obliged TSOs to substantiate that these bids would not be detrimental for competition and IEM (to be also supported by public consultation), whereas it had no such requirements in respect of bids made across more than two entry-exit systems (Art. 20.d.2.b).

${ }^{51}$ As of November 2016, ACER Regulation 713 has been undergoing a revision process. The revised draft regulation, as agreed by the Council on 11 June 2018, contains similar provisions in respect of ACER's tasks for cross-border issues (Art. 6.8, 6.9 and 6.10), see Draft ACER Regulation.
} 

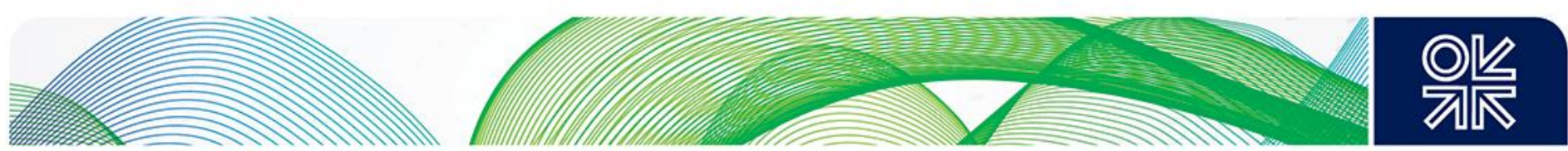

- bids with a duration of more than one year are requested.'

Notably, the CAM NC does not specify the nature of the alternative allocation mechanism and only defines it as:

'an allocation mechanism for offer level or incremental capacity designed on a case-by-case basis by the transmission system operators, and approved by the national regulatory authorities, to accommodate conditional demand requests' (Art. 3.3),

while adding that the AAM must be 'transparent and non-discriminatory' and that it 'may allow for the prioritization of booking duration or bids for higher amounts of capacity for a yearly [Standard Capacity Product]', in which case the NRAs must decide on setting aside an amount of at least 10 per cent and up to 20 per cent of the technical capacity at each interconnection point (see Art. 8.8). The CAM NC thus placed an upper limit on the amount of the incremental capacity that can be set aside for short-term bookings.

This is in contrast with ENTSOG's draft which, while also making an auction a default mechanism, stipulated that Open Seasons would have to be conducted for incremental capacity, should at least one of the following conditions be met:

- when an incremental capacity project involves more than two entry-exit systems or is connected to, or impacted by, exempted infrastructure;

- when conditional binding commitments are envisaged (in other words allocation is subject to the fulfilment of a specified condition);

- when the required levels cannot be efficiently derived from the demand assessment report;

- when the time horizon of 15 years for binding commitments provided in an auction is assumed not to be sufficient for a positive economic test at the reserve price.

In other words, ENTSOG's draft would have guaranteed the usage of OS for any incremental capacity project if any of the above conditions were met, with neither the TSOs nor the national regulatory authorities being able to refuse it. However, ACER's first draft had suggested that the application of OS procedures should be optional rather than obligatory, even if at least one of the aforementioned criteria was met. The ACER's second draft failed to mention the usage of OS altogether. Due to ACER's position, the CAM NC does not define or stipulate the usage of OS procedures.

Notably, the CAM NC also does not stipulate a set of conditions under which the AAM would have to be applied. It merely states that the AAM can be used where it is reasonable to conclude that auction is not suitable and that the project involves more than two entry-exit systems and bids with a duration of more than one year (namely long-term) are requested. The CAM NC does not specify which conditions need be met for the AAM application to be considered 'reasonable'. The CAM NC thus leaves it for the TSO to decide whether or not it is reasonable to conclude that an auction is not suitable, without providing any guidance as to how to assess its decision. However, the CAM NC makes it clear that in respect of any project that does not involve more than two entry-exit systems and bids with long-term duration, the AAM cannot be applied. Should the TSO conclude that an auction is not suitable, the CAM NC leaves it for the national regulatory authority to decide

(a) whether to allow the usage of an AAM, and

(b) whether to approve the mechanism itself.

It would thus appear that both the TSO and the national regulatory authority will have some discretion over whether or not to apply the AAM, even if the project involves more than two entry-exit systems and long-term bids are requested. 

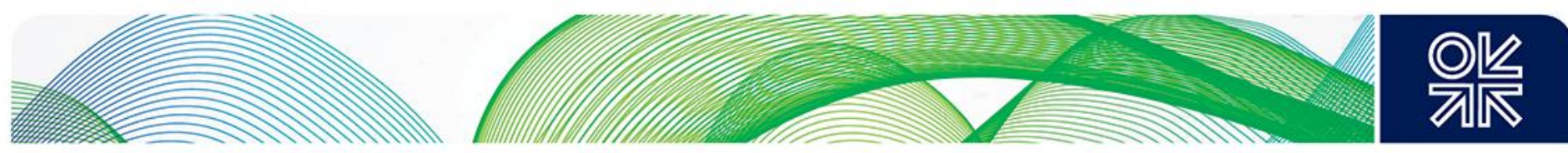

When the AAM is employed, network users 'may submit binding conditional bids for contracting capacity subject to one or more of the following conditions specified by the transmission system operators' in the approved (by the national regulatory authorities or ACER) project proposal:

- commitments linking or excluding commitments at other interconnection points;

- commitments across a number of different yearly standard capacity products at an interconnection point;

- commitments conditional on the allocation of a specific or minimum amount of capacity.

The AAM is subject to approvals by the concerned national regulatory authorities. As noted above, the mechanism must be 'transparent and non-discriminatory but may allow for the prioritization of booking duration or bids for higher amounts of capacity for a yearly standard capacity product' (Art. 30.4).52 Furthermore, 'if either booking duration or bids for higher amounts of capacity are prioritized, national regulatory authorities shall decide on setting aside an amount of at least 10 per cent and up to 20 per cent of the technical capacity at each interconnection point' (Art. 30.5). Thus, the CAM NC stipulates that in case of prioritization of bids by duration or by amount of capacity, at least 10 per cent of capacity will have to be set aside.

Unless the AAM is applied, the CAM NC places no upper limit on the share of incremental capacity to be set aside for short-term bookings and leaves it to the national regulatory authority to decide on the size of the quota (Art. 8.8 and Art. 8.9). However, if the AAM is applied, the CAM places an upper limit of 20 per cent on the size of the quota, and the national regulatory authority cannot decide on a higher quota (Art. 30.5). There is a compulsory minimum (10 per cent) reservation quota to be applied to incremental capacity, irrespective of whether auction or the AAM is applied (Art. 8.8).

ACER's second draft differs significantly in respect of principles for alternative allocation mechanism (Art. 20.d). Notably it stated:

'the AAM can be used, subject to NRA approvals, where market feedback during the demand assessment phase expressed a clear need for conditional bids to be allowed during the allocation procedure as follows:

- $\quad$ the incremental capacity project involves more than two entry-exit systems and bids are requested along several interconnection points during the allocation procedure, $\underline{\mathrm{OR}}$

- $\quad$ bids spanning a number of different yearly products at an interconnection point are requested in one of the following two cases:

- the incremental capacity project involves more than two entry-exit systems and bids are requested along several interconnection points during the allocation procedure;

o or

- $\quad$ it is substantiated by TSOs and supported by public consultation that these bids, if fulfilled, are not detrimental to competition or the effective functioning of the internal gas market'.

This suggests that ACER's second draft allowed the usage of the AAM in respect of capacity allocation not only across more than two entry-exit systems, but also between just two entry-exit systems (provided

\footnotetext{
52 Notably, ACER's second draft did not allow prioritization of bids for higher amounts of capacity for a standard capacity product (Art. 20.d.4). It allowed prioritization of bids of longer duration while noting that in the latter case NRAs 'shall consider higher levels of capacity to be set aside according to Art. 8.8. and 8.9' (which stipulate setting aside at least 10 per cent of capacity and no upper limit); however, this wording suggests that NRAs, although obliged to consider the 10 per cent quota, would be under no obligation to impose it.
} 

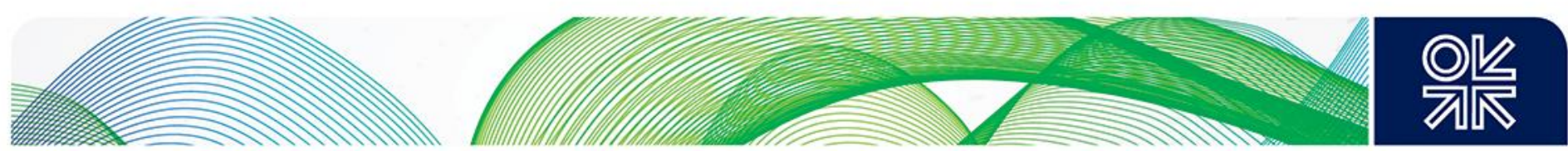

that there was no detrimental impact on competition or the IEM). This suggestion has not been accepted and the CAM NC only allows for AAM usage if capacity is allocated across more than two entry-exit systems.

\subsubsection{Transitional arrangements}

The CAM NC entered into force on 6 April 2017 (the twentieth day following the date of its publication in the Official Journal of the EU on 17 March 2017) and the CAM NC $2013^{53}$ was also repealed in the process. As noted previously, prior to the CAM NC entering into force, no legally binding framework governing construction and utilization of new pipeline capacity had existed at the EU level. Nonetheless, prior to the CAM NC being adopted, several new pipeline projects had been initiated under other legal / regulatory regimes (such as OS procedures, TEP exemptions, or IGAs) that had been applied at the member state level. Some of these projects are currently under development - major examples being the TAP pipeline (under an Exemption Regime) (Section 3.3) and the EUGAL pipeline (under a national level OS procedure, consistent with the GGPOS and mirroring the draft CAM NC) (Section 3.1) - and are to be completed by the end of 2019.

There is a legitimate question about what role - if any - the CAM NC might play in respect of the incremental capacity projects that have been initiated prior to the CAM NC's entry into force, and its Art. 31 (Transitional Arrangements) attempts to provide an answer:

'In the case of incremental capacity projects initiated before the entry into force of this Regulation, Articles 26 to 30 shall apply unless such projects have been granted the applicable approvals for capacity allocation by the respective national regulatory authorities before 1 August 2017.

This means that the CAM NC provisions stipulated in Art. 26-30 (namely key provisions on the incremental capacity process including: market demand assessment, design phase, approval and publication, auctioning of incremental capacity, alternative allocation mechanisms) shall apply to incremental capacity projects that were 'initiated' before 6 April 2017, unless the national regulatory authorities had granted the applicable approvals for capacity allocation before 1 August 2017.

The CAM NC provides for a transitional period of 7 April-31 July 2017, during which any such incremental capacity project would be able to apply to the relevant national regulatory authorities to receive the applicable approvals for capacity allocation (if it had not done so prior to the CAM NC's entry into force). Should such approvals not be applied for, or should they not be granted, all of the CAM NC provisions would apply from 1 August 2017. Notably, the decision to make the transitional arrangements part of the CAM NC - and the choice of this particular wording - was made at the very last stages of finalizing the CAM NC - possibly during comitology - as neither ENTSOG's nor ACER's drafts contained any transitional arrangements. This suggests that many member states must have been uncomfortable with the lack of transitional arrangements in the CAM NC and were able to insist on their late-stage inclusion.

There are two further questions to consider:

- whether a project is to be considered 'initiated before' the CAM NC's entry into force, and

- which regulatory approvals are to be considered 'applicable'.

In respect of the former, the CAM NC provides no guidance as to how to define a project that has been 'initiated', but it is argued here that at the very least any project that has completed a legally binding capacity allocation process prior to the CAM NC's entry into force should certainly be considered as having been 'initiated'. The fact of conducting a feasibility study or taking a final investment decision (FID) could also be considered as a sufficient criterion for considering the project as having been initiated. This suggests that both the TAP and the EUGAL pipelines - which completed their legally binding capacity

\footnotetext{
${ }^{53}$ See Additional documents.
} 

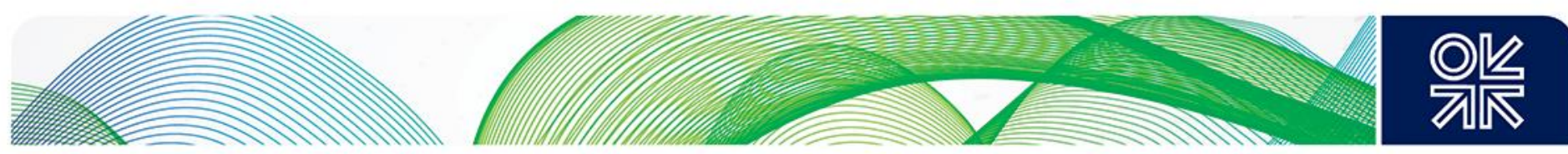

allocation processes in March-December 2014 and March 2017 respectively - should be considered as incremental capacity projects initiated prior to the CAM NC's entry into force.

\section{The EUGAL pipeline}

In respect of EUGAL, however, it must be noted that in some member states (for example Germany) the national regulatory authorities are not required to provide the approvals for capacity allocation, which means that there could be no 'applicable' approvals by the national regulatory authorities, in the meaning of Art. 31. Therefore, it is argued here that an incremental capacity project (such as the EUGAL pipeline) that had been initiated by German TSOs prior to the CAM NC's entry into force and which had not been granted approval in respect of capacity allocation before 1 August 2017 (given that no such approvals were required under the national legislation) would not be subject to the CAM NC provisions in Articles 26-30 (Section 3.1). However, given that the 'more capacity' process (including the demand assessment, in respect of EUGAL pipeline capacity) was launched in 2015 (in other words when the CAM NC had already been under development with a view to including legally-binding regulatory procedures in respect of incremental capacity ${ }^{54}$ ) and given that the legally-binding capacity auctions were held on 6 March 2017 (in other words, just a few weeks before the CAM NC entered into force), it is possible that the EC and / or the German national authority might require some amendments to the regulatory treatment of EUGAL capacity if the regulatory treatment awarded under the 'more capacity' procedure were to differ significantly from what would have resulted from the application of the CAM NC (had it been in force and applicable at the time). This paper argues that although there are differences between the regulatory treatment awarded to EUGAL under the 'more capacity' process and the regulatory treatment that would have been awarded under the CAM NC, these differences do not appear sufficiently significant to warrant major changes.

\section{The TAP pipeline}

As far as TAP is concerned, this pipeline was granted the applicable regulatory approvals in respect of capacity allocation (in the form of national Exemption Decisions amended in line with the EC Exemption Decision) by the Greek, Italian, and Albanian regulatory authorities in 2013 (Section 3.3). Its Initial Capacity and some Expansion Capacity was allocated during the first market test (17 March-1 December 2014). The test was governed by the First Market Test Guidelines and the Booking Phase Guidelines (stipulating details of the booking phase), developed by the NRAs. This suggests that allocation of these capacities in TAP would not be subject to the CAM NC provisions set in Articles 26-30. However, the TAP Exemption Decision (see Section 3.3.6) obliged the TAP consortium to develop and submit to the authorities (no later than 12 months prior to the TAP's commercial operation date, estimated to be within the 1 January-31 December 2020 range) the TAP Network Code (TAP NC). The TAP NC would provide a harmonized regime for capacity allocation for the entire route, and would be used for the allocation of Expansion Capacity during subsequent market tests. The TAP NC is to be developed in line with the principles expressed in the First Market Test Guidelines, in other words an open season consisting of two phases with capacity to be allocated through auction during the second phase, cost-reflective and nondiscriminatory tariffs, and congestion management principles (CMP). ${ }^{55}$ The TAP NC would have to be compliant with Gas Regulation 715 and with all the EU NCs that will be in force at the time - including the CAM NC - as long as they were not in conflict with the exemption. In addition, under the terms of the exemption the Subsequent Market Test Guidelines were to be developed to govern TAP's subsequent market tests. As the CAM NC's provisions governing the incremental capacity process as set in Articles 26-30 (including the usage of an AAM) are not in conflict with the TAP exemption, it could be argued that the TAP NC would have to mirror closely the CAM NC. As the TAP NC must be approved by the NRAs to become binding, should it differ significantly from the CAM NC the NRAs would be able to request changes, thus bringing the TAP NC closer in line with the CAM NC; this suggests that the latter's provisions governing the incremental capacity process, as set in Articles $26-30$, would apply to TAP.

\footnotetext{
${ }^{54}$ With several drafts - both by ENTSOG and ACER - being circulated as of late 2014.

${ }^{55}$ First Market Test Guidelines (see Additional Documents).
} 

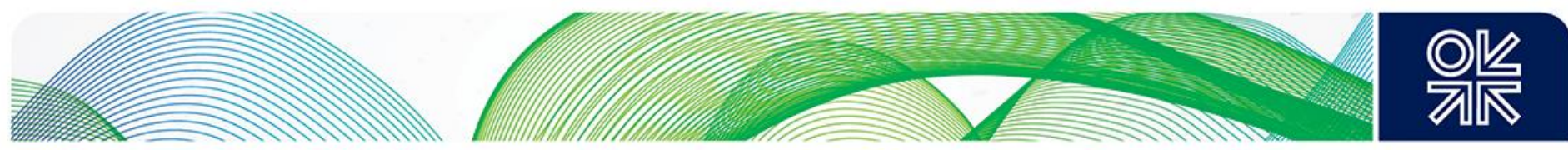

\subsection{An Exemption Regime: Second and Third Gas Directives}

As noted in Section 1, in the absence of a legally binding framework governing incremental capacity, an Exemption Regime under Art. 36 of the Third Gas Directive (and prior to that, an exemption regime under Art. 22 of the Second Gas Directive, ${ }^{56}$ which was repealed by the Third Gas Directive from 3 March 2011) was one of the frameworks in accordance with which new cross-border pipelines could be, and have been, built in the EU. The exemption procedure under Art. 36 is reviewed below, while references are also made to Art. 22 of the Second Gas Directive to demonstrate the continuity of the exemption regime, first established under the latter. ${ }^{57}$ (In October 2017, the EC made a proposal to amend the Third Gas Directive which, if adopted, could have a significant impact on the existing Exemption Regime, see Section 4.3).

The Third Gas Directive (Art. 36.1) states that 'major new gas infrastructure, ${ }^{58}$ i.e. interconnectors, LNG and storage facilities, ${ }^{59}$ may, upon request, be exempted, for defined period of time' from the Directive's provisions of Art. 9 (unbundling), Art. 32 (TPA), Art. 33 (access to storage), Art. 34 (access to upstream pipeline networks), Art. 41.6, 41.8, 41.10 (tariffs/methodologies). In order to be exempted, this infrastructure must meet the exemption criteria:

(a) the investment must enhance competition in gas supply and enhance security of supply;

(b) the level of risk attached to the investment must be such that the investment would not take place unless an exemption was granted;

(c) the infrastructure must be owned by a natural or legal person which is separate at least in terms of its legal form from the system operators in whose systems that infrastructure will be built;

(d) charges must be levied on users of that infrastructure; and

(e) the exemption must not be detrimental to competition or the effective functioning of the internal market in natural gas, or the efficient functioning of the regulated system to which the infrastructure is connected.

An exemption may be granted not only to 'major new infrastructure' but also to 'significant increases of capacity in existing infrastructure and to modifications of such infrastructure which enable the development of new sources of gas supply' (Art. 36.2). ${ }^{60}$

It is worth stressing that the grant of an exemption was not intended to be automatic; in other words, the exemption can be refused (although in reality the vast majority of projects which have applied for an exemption have been granted one), thus suggesting the possibility of discretion being applied by national authorities and the EC. Also, even if granted, an exemption can only be of limited defined duration - it cannot last forever. The decision on whether to grant an exemption, which conditions make part of an exemption, as well as the length of time for which an exemption might be granted, all rest with the NRAs and/or member states, as well as with the EC, with the latter's decision being final and binding. The procedure is explained below.

The Third Gas Directive stipulated the right of the national regulatory authorities (NRAs) to decide on the exemption:

'the regulatory authority ... may, on a case-by-case basis, decide on the exemption' (Art. 36.3),

\footnotetext{
${ }^{56}$ See Additional documents.

57 In 2009, the EC adopted guidance explaining the general framework and the assessment criteria under Art. 22 of the Second Gas Directive, see EC (2009). Notably, the EC has not developed any further guidance in respect of Art. 36 of the Third Gas Directive (see Additional documents) and has continued to refer to the 2009 guidance in its subsequent exemption decisions, for example see the EC TAP decision.

58 'New infrastructure' means 'an infrastructure not completed by 4 August 2003' (Art. 2.33).

${ }^{59}$ Given that Art. 36 uses the abbreviation 'i.e.' - 'that is' - before listing the liable categories, it can be argued that the list of liable categories is exhaustive.

${ }^{60}$ The Directive also left in place the exemptions from TPA granted under Art. 22 of the Second Gas Directive (see Additional documents) until their expiry.
} 

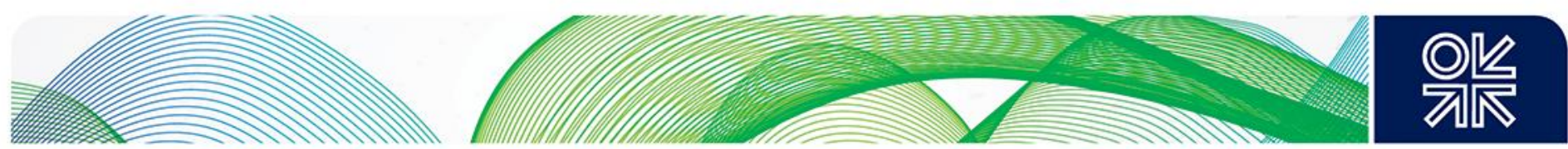

while also providing for member states to make such decisions themselves based on the opinion submitted by their NRA or the Agency for the Cooperation of Energy Regulators (ACER) (Art. 36.3, 36.7):

'member states may provide that their regulatory authority or the Agency ... shall submit, for the purposes of the formal decision, to the relevant body in the member state its opinion on the request for an exemption'.

The Third Gas Directive also states that while deciding on the exemption, consideration must be given 'on a case-by-case basis' to 'the need to impose conditions regarding the duration of the exemption and non-discriminatory access' with account to be taken, in particular, of 'the additional capacity to be built or the modification of existing capacity, the time horizon of the project and national circumstances' (Art. 36.6). Importantly, before granting an exemption, the regulatory authorities are obliged to 'decide upon 'the rules and mechanisms for management and allocation of capacity' that would apply to the exempted new capacity. In this respect, the Third Gas Directive is different from the Second Gas Directive as the latter did not oblige the regulatory authorities to decide on the rules and mechanisms for management and allocation of capacity, leaving it at their discretion whether or not to stipulate such rules (Art. 22.2(c)).

Under the Third Gas Directive, the regulatory authorities are thus obliged to develop a set of legally binding regulatory procedures governing allocation and management of new capacity as part of an exemption, thus effectively filling the gap left in the TEP, which had outlined general rules, but not specific procedures, for either existing or new capacity. As noted above, these gaps had been filled by the CAM NC 2013 in respect of existing capacity, and by the CAM NC in 2017 in respect of incremental capacity (Section 2.1).

The Third Gas Directive stated that these rules must require that 'all potential users of the infrastructure are invited to indicate their interest in contracting capacity before capacity allocation in the new infrastructure, including for own use, takes place'. Furthermore, the regulatory authority is obliged to require 'congestion management rules to include the obligation to offer unused capacity on the market' as well as to require users of the infrastructure to be 'entitled to trade their contracted capacities on the secondary market'. Importantly, the regulatory authority is obliged to take into account the results of this capacity allocation procedure while making its assessment of whether the infrastructure in respect of which an exemption is sought meets the exemption criteria specified in Art. 36.1(a), 36.1(b), and 36.1(e). (In other words, whether the new infrastructure enhances competition and security of supply, whether its level of risk is such that that the investment would not take place without an exemption, and whether it is detrimental to competition, to the effective functioning of the internal gas market, or to the efficient functioning of the regulated system to which it is connected.)

The Third Gas Directive has also introduced a cross-border dimension in the exemption-granting process - absent in the Second Gas Directive - having stipulated a procedure to be followed when the new infrastructure in respect of which an exemption is sought is located in the territory of more than one member state. In this case, the Directive has empowered - but not obliged - the newly created Agency for Cooperation of Energy Regulators (ACER) to submit an advisory opinion to the NRAs of the member states concerned, which 'may be used as a basis for their decision' (Art. 36.4). If all the NRAs agree on the request for exemption within six months of the date on which the request was received by the last NRA, ${ }^{61}$ they are obliged to inform ACER. If the NRAs concerned 'have not been able to reach an agreement' within this period or in the event of a joint request from the NRAs, ACER is obliged to exercise the tasks conferred on the NRAs, including in respect of deciding on an exemption. ${ }^{62}$

The decision on whether to grant an exemption (taken by the national regulatory authority or by the member state, to whom either the national regulatory authority or ACER submitted its opinion) must be

\footnotetext{
${ }^{61}$ All NRAs may, jointly, request that this period is extended by up to three months (Art. 36.4).

62 It is not clear whether in that case ACER would have powers overriding those of member states, where it is member states rather than the NRAs that make exemption decisions.
} 

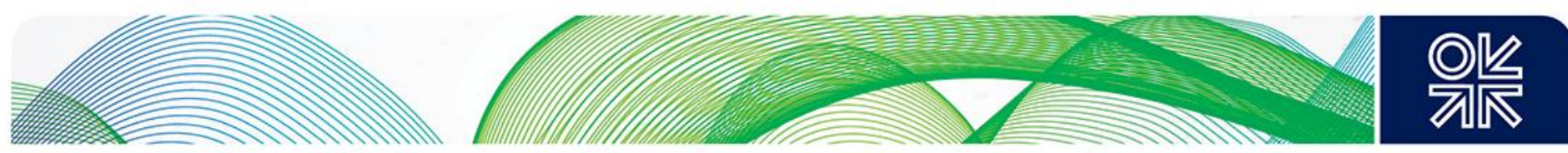

notified to the EC 'without delay' together with 'all the relevant information with respect to the decision', which must contain, in particular:

(a) the detailed reasons on the basis of which the exemption was granted or refused, with a reference to the aforementioned exemption criteria;

(b) the analysis of the effect on competition and the effective functioning of the internal gas market resulting from the grant of the exemption;

(c) the reasons for the time period and for the share of the total capacity for which the exemption is granted;

(d) the result of the consultation with the regulatory authorities if the exemption relates to an interconnector;

(e) the contribution of the infrastructure to the diversification of supply.

Within two months from the day following the receipt of a notification, the EC 'may' take a decision requiring the regulatory authority to amend or withdraw the decision to grant an exemption. This twomonth period may be extended by an additional period of two months if the EC is seeking further information in respect of an exemption; this period is counted from the day following the receipt of the complete information sought by the EC. The Directive thus provides the EC with at least four months for taking a decision. The Directive is much less clear on whether there is an upper limit on the EC decision making period. The Directive states that 'the initial two-month period may also be extended' (for an unspecified duration) with the consent of both the EC and the regulatory authority. It is not clear whether the possibility of an extension refers to the first two-month period (in other words when the EC first received the notification) or to the additional two-month period (in other words when the EC has sought additional information). In any case, given that the Directive does not specify the maximum duration of an extension and does not mention whether an extension could be sought repeatedly, it could be argued that there is no upper limit on the time that could be spent by the EC in deciding on an exemption. By comparison, under the Second Gas Directive, the EC was only allowed to spend two months at most for an exemption assessment (Art. 22.4). Also, unlike the Second Gas Directive, the Third Gas Directive made it mandatory to notify the EC not only about every exemption decision but also about any exemption request (Art. 36.8).

The EC's exemption decision is final and binding (Art. 36.9). Its power - and available discretion - in respect of making the decision is very significant, whereas the process of granting or refusing an exemption lacks transparency. The EC has been able to exercise a significant degree of discretion while making its exemption assessments, mostly due to the fact that the Third Gas Directive (similar to the position for the Second Gas Directive) did not provide any quantitative criteria for granting an exemption, including in respect of its impact on competition. ${ }^{63}$ The Directive is not specific on the financial or volumetric characteristics of projects, and simply refers to 'major' infrastructure and 'significant increases in capacity'. Given that all infrastructure projects in the gas sector are costly - and hence qualify for being called 'major' - one could argue that any infrastructure project could be exempted.

\section{The Bacton-Balgzand pipeline}

The lack of quantitative specifics on costs or technical characteristics in the Second Gas Directive made it possible to award exemptions to projects of a relatively small magnitude, such as the Bacton-Balgzand pipeline (BBL), ${ }^{64}$ the first project that was granted an exemption under Art. 22 of the Second Gas Directive, in 2005. The cost of the BBL was only $€ 0.5$ billion, which is a very small investment by gas industry standards. Granting an exemption to the BBL project thus sent a message that a relatively inexpensive project could get an exemption if it made a good case for meeting the set criteria, while also

\footnotetext{
${ }^{63}$ EC (2008).

${ }^{64}$ The UK-Netherlands Interconnector.
} 

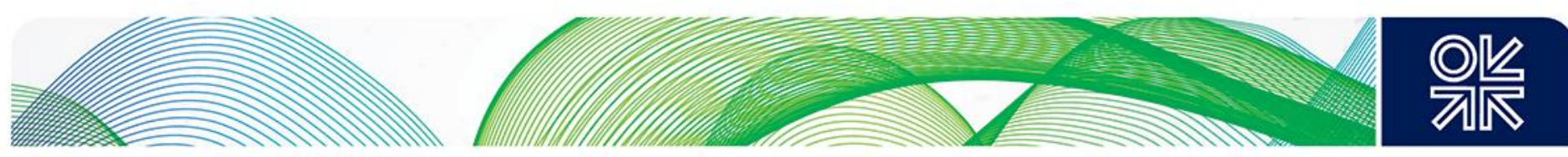

making the refusal of an exemption to any project potentially awkward. Furthermore, 14 European LNG regasification terminals have also received exemptions under the Second and the Third Gas Directives. ${ }^{65}$

\section{The Nabucco pipeline}

The high degree of EC discretion in respect of an exemption has been further illustrated by its decision to grant an exemption to the Nabucco pipeline. Nabucco (originally envisaged to bring gas from the Caspian littoral states to Europe across Turkey) and which does not fit into any category listed under Art. 22 of the Second Gas Directive (it is not an interconnector, as it originates outside the EU borders, nor is it an LNG or storage facility), secured exemptions from all member states involved (Austria, Hungary, Romania, and Bulgaria), and their comfort letters were deposited with the EC, which approved them in 2008-9 (albeit restricting utilisation to 50 per cent of capacity). The exemption decisions on the original Nabucco pipeline were extended to the Nabucco West pipeline under Art. 36 of the Third Gas Directive (as the original exemption could not automatically be applied to the new pipeline) with some modifications. The fact that Nabucco was granted an exemption despite doubts over whether it fitted the list of eligible categories of infrastructure, as well as the questionability of its added value for EU supply (and transit) security (it would cross a number of countries belonging to different regulatory/legal regimes and the project had a history of transit problems) suggests that an exemption regime can be used politically, in other words to support projects that are believed by the EC to be in the best interest of the EU (and correspondingly to complicate those which may not be so considered).

\section{The OPAL pipeline}

Yet another example of EC discretion has been provided by its 2009 decision to require an amendment of the exemption granted by the German NRA to the OPAL pipeline (an onshore pipeline across Germany to connect the Nord Stream 1 pipelines with the Czech Republic transmission system). This EC decision had prevented Gazprom from utilizing more than 50 per cent of capacity in OPAL even though there was no demand on the part of third parties (see Section 3.2). This led to a situation in which the OPAL (and hence Nord Stream 1) pipeline had remained underutilized since 2011. It was not until October 2016, when it had become increasingly difficult to defend its decision on legal / regulatory grounds, that the EC revised its decision, allowing Gazprom to bid for the remaining 50 per cent of OPAL capacity alongside third parties at auctions organized by PRISMA (the European gas capacity trading platform), while guaranteeing access by third parties to up to 20 per cent of capacity. ${ }^{66}$ Overall, the exemption decisionmaking process in respect of OPAL continued during 2008-16. It thus took more than seven years to secure an exemption decision which finally enabled Gazprom to utilize more than 50 per cent in OPAL. ${ }^{67}$

\section{The Gazelle pipeline}

By contrast Gazelle, the pipeline to which OPAL is connected and the function of which is very similar to that of OPAL, was granted its exemptions very quickly over the course of 2011 , and it faced none of the difficulties faced by OPAL.

\section{South Stream pipeline}

It is argued here that the EC treatment of the OPAL exemption caused Gazprom to decide against applying for an exemption in respect of South Stream pipeline sections, despite the fact that the EC had publicly encouraged Gazprom to do so. ${ }^{68} \mathrm{Had}$ Gazprom applied for such an exemption, it would have been very difficult for the EC to justify a refusal, given that it had previously approved an exemption for Nabucco West. A refusal of an exemption to South Stream on the grounds that it is not an interconnector would be awkward, because Nabucco West is not an interconnector either. Refusal on the grounds that it is not a major project would also be awkward, as its costs were about ten times higher than those of the exempted BBL. However, the exemption application issue became less relevant when South Stream took

\footnotetext{
${ }^{65}$ EC (2018a).

${ }^{66}$ Yafimava (2017a)

${ }^{67}$ As OPAL utilization rate has increased, Nord Stream 1 utilization rate has increased as well, reaching 93 per cent in 2017, see Nord Stream (2018).

${ }^{68}$ Gazprom indicated that it might apply for an exemption in 2011 but never did, see Yafimava (2017a).
} 

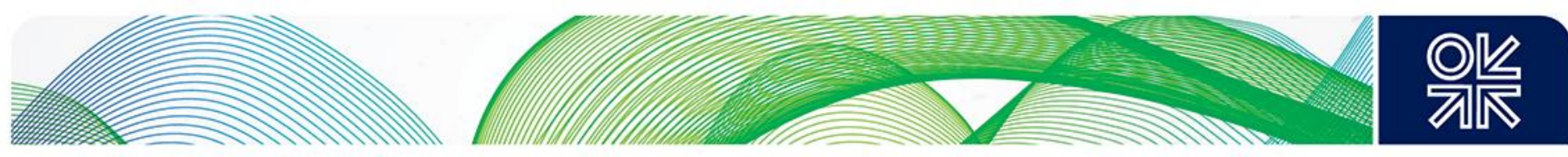

FID in November 2012, ${ }^{69}$ thus weakening its case for an exemption, as this would allow the NRAs and the EC to argue that the project did not comply with one of the major exemption criteria, namely that investment would not take place without an exemption (Art. 36.1(b)).

\subsection{Projects of Common Interest (PCI): Infrastructure Regulation}

The EU energy acquis envisages the possibility that selected new infrastructure projects could have the status of a project of common interest (PCl). Although this status neither constitutes a generic regulatory framework for incremental capacity nor an exemption - as the $\mathrm{PCl}$ project must still abide by the acquis - it nonetheless contains certain regulatory measures aimed at supporting the implementation of new infrastructure.

On 17 April 2013 the EU adopted the Regulation on Guidelines for trans-European energy infrastructure (Infrastructure Regulation), which has established the concept of energy infrastructure priority corridors and areas. The Infrastructure Regulation has outlined a procedure under which the projects considered 'necessary' for the implementation of these priority corridors and areas - the PCls - would be awarded favourable regulatory treatment (Art. 1.2), including:

- 'streamlining, coordinating more closely, and accelerating permit granting process and by enhancing publish participation',

- providing 'rules and guidance for the cross-border allocation of costs',

- determining 'the conditions for eligibility' for EU financial assistance,

while not relieving them from their obligations to comply with the general rules set by the acquis. ${ }^{70}$

As far as permit granting is concerned, the Regulation states that the presence of any project on the EU $\mathrm{PCl}$ list confirms its 'necessity' (from an energy policy perspective) for the purposes of any decisions issued in the permit granting process (Art. 7.1) and obliges project promoters and all authorities concerned to 'ensure that the most rapid treatment legally possible' is given to the $\mathrm{PCl}$ (Art. 7.2). The Regulation envisaged a fast-track permitting procedure for PCls, by giving responsibilities to one competent authority within each member state to 'coordinate and oversee the permit-granting process, setting minimum standards for transparency and public participation', and fixing its maximum allowed duration. The Regulation has thus obliged each member state to designate one national competent authority responsible for facilitating and coordinating the permit granting process (Art. 8.1). The permit granting process consists of two procedures - pre-application and statutory application - of which the former lasts an indicative period of two years, whereas the latter must not exceed one year and six months. In so doing, the Regulation has limited the duration of the entire permit granting process (including the pre-application and the statutory granting procedures) to a period not exceeding three years and six months (Art. 10.2), although allowing for an extension by a maximum of nine months for both procedures combined, thus placing a legally binding limit on the duration of the entire process to four years and three months.

In respect of regulatory treatment, including cost-benefit analysis (CBA) and the enabling of investment with cross-border impact, the Regulation obliged ENTSOG to publish, by 16 November 2013, its methodology for a harmonized system-wide CBA for PCls (Art. 11.1), with ACER to publish its opinion, within three months (Art. 11.2). This was to be followed by the EC delivering its own opinion, within three months, whereas member states were able - but not obliged - to deliver their opinions also (Art. 11.3). The Regulation has obliged ENTSOG to adapt its methodology, within three months, 'taking due account' of the aforementioned opinions and to submit it to the EC for approval (Art. 11.4). Within two weeks of approval by the EC, ENTSOG was obliged to publish the final methodology, which was to be 'updated and improved regularly' (Art. 11.6). The Regulation also stipulated that the 'efficiently incurred investment

\footnotetext{
${ }^{69}$ Gazprom (2012).

${ }^{70}$ As far as gas pipelines are concerned the 'project' is defined as pipelines aiming at building new infrastructure or reinforcing or refurbishing existing infrastructure - so it includes both incremental and new capacity (Art.2).
} 

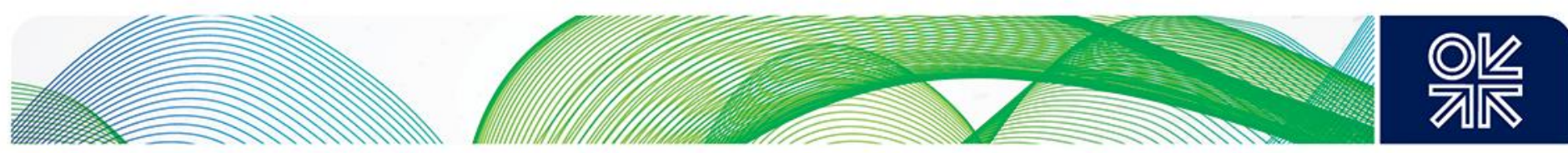

costs' related to a gas infrastructure $\mathrm{PCI}$ must be 'borne by the relevant TSO or the project promoters' of the infrastructure of the member states 'to which the project provides a net positive impact, and, to the extent not covered by congestion rents or other charges, be paid for by network users through tariffs for network access in that or those member states' (Art. 12.1). This provision would apply only if (a) 'at least one project promoter' requests the relevant national authorities to apply the Regulation's provisions on enabling investments with cross-border impacts (namely Art. 12) 'for all or parts of the costs of the project' and (b) an assessment of market demand has been carried out and indicated that these investment costs 'cannot be expected to be covered by the tariffs'. In that case, the NRAs are obliged to 'take coordinated decisions on the allocation of investment costs to be borne by each system operator ... as well as their inclusion in tariffs' (Art. 12.4). Should the NRAs fail to reach an agreement or should they make a joint request to ACER, the latter is obliged to take a decision in respect of cross border cost allocation, as well as the way in which the cost of the investments is reflected in the tariffs, which must also be published (Art. 12.6). Notably, the provisions on cross border impacts do not apply to PCls which have an exemption under Art.36 of the Third Gas Directive (Section 2.2). ${ }^{71}$

As far as eligibility for EU financial assistance is concerned, the PCls are eligible for EU financial assistance in the form of grants for studies and financial instruments (Art. 14.1). They are also eligible for EU financial assistance in the form of grants for works ${ }^{72}$ if they meet all of the following criteria:

- the project's CBA provides evidence concerning 'the existence of significant positive externalities' including security of supply and solidarity,

- the project has received a cross-border cost allocation decision,

- the project is 'commercially not viable' (Art. 14.2).

Notably, the EU has established a regular budget - under its new Connecting Europe Facility (CEF) - for co-financing the construction of infrastructure, with $€ 9.1$ billion earmarked for this purpose over the 201420 period. This is necessary in order to meet common standards for security of gas supply - such as binding infrastructure standard N-1 (by 3 December 2014) and the obligation of reverse flows for TSOs (by 3 December 2013) on all interconnection points between member states - which were introduced by the 2010 Security of Supply Regulation (adopted in the aftermath of the 2009 gas crisis). ${ }^{73}$ Thus the Infrastructure Regulation has allowed for the eligibility of PCIs for CEF funding.

Crucially, only a project that contributes towards the creation of one of four 'priority corridors' (north-south interconnections in western Europe, north-south interconnections in central-eastern and south-eastern Europe, the southern gas corridor, and interconnections in the Baltics) would be considered against a set of specific $\mathrm{PCl}$ criteria and - if awarded a PCl status - thus be eligible for funding under CEF.

The Infrastructure Regulation has established 12 regional groups in respect of electricity, gas, oil, and thematic areas, with the membership of each group being based on a pre-defined priority corridor and area and on their respective geographic coverage (Art. 3.1).

The list of gas priority corridors includes the following groups, all of which have overlapping memberships with one another:

\footnotetext{
${ }^{71}$ It is possible that the same project might apply for - and get - both a $\mathrm{PCl}$ status and an exemption under Art. 36 of the Third Gas Directive (see Additional documents). Given that the criteria for granting a project a PCl status or an exemption are overlapping, it would seem that if a project were to be granted an exemption, it would be difficult to refuse it a $\mathrm{PCl}$ status, and vice versa. Moreover, if a project were to be refused an exemption, it would be difficult to grant it a PCl status.

72 'Works' means the purchase, supply and deployment of components, systems and services including software, the carrying out of development and construction and installation activities relating a project, the acceptance of installations and the launching of a project, see Infrastructure Regulation.

Security of Supply Regulation 2010 (see Additional documents). It has since been repealed and replaced by Security of Supply Regulation 2017 (see Additional documents).
} 

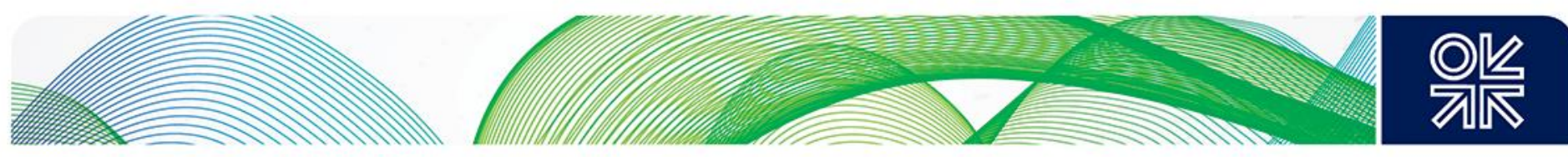

- north-south gas interconnections in western Europe ('NSI West Gas'): gas infrastructure for NorthSouth gas flows in western Europe to further diversify routes of supply and for increasing short-term gas deliverability:

- Belgium, Denmark, France, Germany, Ireland, Italy, Luxembourg, Malta, the Netherlands, Portugal, Spain, and the UK;

- north-south gas interconnections in central eastern and southern eastern Europe ('NSI East Gas'): gas infrastructure for regional connections between and in the Baltic Sea region, the Adriatic and Aegean Seas, the Eastern Mediterranean Sea, and the Black Sea, and for enhancing diversification and security of gas supply:

- $\quad$ Austria, Bulgaria, Croatia, Cyprus, Czech Republic, Germany, Greece, Hungary, Italy,

Poland, Romania, Slovakia, Slovenia;

- the Baltic energy market interconnection plan in gas ('BEMIP Gas'): gas infrastructure aimed at ending the isolation of the three Baltic States and Finland and their dependency on a single supplier, to reinforce internal grid infrastructures accordingly, and to increase diversification and security of supplies in the Baltic Sea region:

- Denmark, Estonia, Finland, Germany, Latvia, Lithuania, Poland, Sweden;

- the Southern Gas Corridor ('SGC'): infrastructure for the transmission of gas from the Caspian Basin, Central Asia, the Middle East, and the Eastern Mediterranean Basin to the EU to enhance diversification of gas supply:

- Austria, Bulgaria, Croatia, Czech Republic, Cyprus, France, Germany, Hungary, Greece, Italy, Poland, Romania, Slovakia, Slovenia.

Each regional group has a right and a responsibility to adopt a regional list of $\mathrm{PCI}$ projects. Although each group includes representatives of the member states, the NRAs, TSOs, the EC, the ACER, and the ENTSOG, only member states and the EC have decision-making powers within each group. Notably, for a project proposal to be included in a regional $\mathrm{PCl}$ list, the approval of those member states to whose territories the proposed project relates is required, whereas any refusal must be substantiated (Art. 3.3(a)).

The EC is empowered to adopt the Union list of $\mathrm{PCls}$ every two years on the basis of the regional $\mathrm{PCl}$ lists (which suggests that a project not included into the regional PCI list cannot be included into the Union $\mathrm{PCl}$ list). The PCls lists are reviewed and updated every two years. Each PCI list is established in form of an annex to the Infrastructure Regulation. According to Art. 3.6 of the Infrastructure Regulation, once the project is a part of the Union PCl list it must be included in the national 10-year network development plans (Art. 22 of the Third Gas Directive) and the regional investment plans (Art. 12 of Gas Regulation 715). After adoption of the first Union list, for all subsequent Union lists adopted, proposed PCls must be included in the latest available EU TYNDP. Three EU PCI lists have been adopted to date - the first one in October 2013, the second - in November 2015, and the third - in April 2018. ${ }^{74}$

Notably, the EC has a right to remove a PCl from the Union list if its inclusion in that list was based on incorrect information which had been a determining factor for inclusion, or if the project does not comply with the EU acquis (Art. 5.8). Although the Regulation does not stipulate a maximum number of PCls on the Union list, it notes that the EC must aim for a 'manageable' (unspecified) number. It states further that should the total number of proposed PCls exceed such a manageable number, the EC is 'obliged to consider' not to include projects with lower Group rankings (Art. 4.4).

The Union PCI list can only include those projects that fulfil a set of general and specific criteria. The Infrastructure Regulation stipulates that a potential PCI must meet all of the following general criteria:

\footnotetext{
${ }^{74}$ First PCI List, Second PCI List, Third PCI List (see Additional documents).
} 

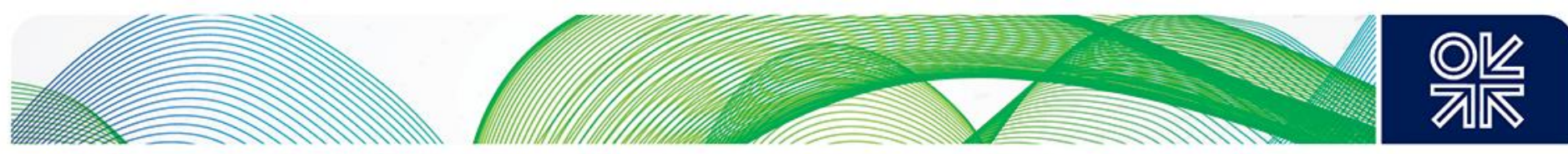

- necessity of the project for the implementation of the priority corridors and areas;

- economic, social, and environmental viability of the project;

- involvement of at least two member states in the project 'either by directly crossing the border of one or more member states or by being located on the territory of one member state and having a significant cross-border impact' (a project which, for example, 'concerns investment in reverse flow capacities or changes the capability to transmit gas across the border(s) of the concerned member state by at least 10 per cent') (Art.4.1).

The Infrastructure Regulation also stipulates that the potential PCls must 'contribute significantly' to at least one of the following specific criteria:

- market integration, interoperability, and system flexibility;

- security of supply (inter alia through diversification of supply sources);

- competition (inter alia through diversification of supply sources, supplying counterparts, and routes);

- sustainability (Art. 4.2(b))

The Regulation also contains instructions as to how each of these criteria is to be measured, including the impact of the potential $\mathrm{PCl}$ on the $\mathrm{HHI}$ and $\mathrm{N}-1,{ }^{75}$ although it does not quantify specific levels (Art. 3.3). ${ }^{76}$

It is worth noting that the $\mathrm{PCl}$ criteria are extremely similar to the exemption criteria (Section 2.2), which suggests that it would be difficult for any project that has been granted an exemption not to be granted $\mathrm{PCl}$ status, and vice versa.

As explained above, being in a possession of PCl status allows a project to shorten its lead time and improve its commercial standing due inter alia to: accelerated permitting, rules for cross-border cost allocation, and eligibility for EU financial assistance. However, $\mathrm{PCl}$ status per se does not constitute a specific regulatory framework for new capacity, as all projects must be in compliance with the energy acquis, including the TEP. Importantly, PCI status is not automatically granted, as any new project must be seen as contributing towards one of the EU's 'priority corridors' and meet a set of general and specific criteria. ${ }^{77}$ It is worth noting that the composition of priority corridors and the criteria are such as to promote and facilitate the development of those new infrastructure projects that are seen by member states - but crucially by the EC, which decides on the Union PCI list - as beneficial for the EU.

\subsection{Open Seasons: Guidelines for Good Practice in Open Season (GGPOS)}

In 2007 the European Regulators' Group for Electricity and Gas (ERGEG) - the forerunner to ACER ${ }^{78}$ developed a set of non-legally binding procedures to be followed in the EU: the Guidelines for Good Practice on Open Season (GGPOS). ${ }^{79}$ The GGPOS were developed in response to the EC request, made at the 11th European Gas Regulatory Forum, for provision of further clarity on the role of OS procedures

\footnotetext{
75 The $\mathrm{HHI}$ index estimates an overall concentration level in a market and is calculated by summing the squares of the individual market shares of all the firms in the market, see EC (2004). The $\mathrm{N}-1$ formula describes 'the ability of the technical capacity of the gas infrastructure to satisfy total gas demand in the calculated area in the event of disruption of the single largest gas infrastructure during a day of exceptionally high gas demand occurring with a statistical probability of once in 20 years' and is defined in Security of Supply Regulation 2010 (see Additional documents)

${ }^{76}$ TEN-E Regulation (see Additional documents), Annex IV (a - d).

77 It is worth noting that both were defined in such a way as to make it unlikely (although arguably not impossible) for onshore extensions/sections of Russian pipelines to qualify. It is understood that the onshore sections of the Gazprom-led South Stream pipeline project applied but were not included into the 2013 PCI list (First PCI List, see Additional documents), whereas some pipelines (for example Tesla and Eastring) that could potentially transport Russian gas delivered via the second string of Gazprom's Turkish Stream, were included in the 2015 PCI list (Second PCI List, see Additional documents).

${ }^{78}$ ERGEG was dissolved in 2011 when ACER became fully operational, https://www.ceer.eu/eer_about.

${ }^{79}$ GGPOS, see (ERGEG (2007).
} 

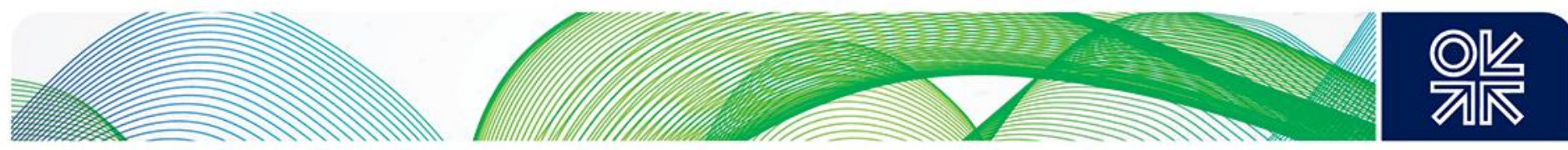

in respect of capacity allocation mechanisms (CAM) and congestion management procedures (CMP). The GGPOS were envisaged to ensure that OS procedures would be conducted in 'a non-discriminatory and transparent manner'. 80

The GGPOS have defined an open season as 'a two-step process which allows a project sponsor to efficiently consult the market about how much infrastructure it needs, and under what terms it would like this infrastructure to be marketed' while also allowing resulting capacity to be allocated on a 'transparent and non-discriminatory basis'. ${ }^{81}$ The GGPOS's scope is defined as follows: 'the whole capacity of new transmission, LNG and storage infrastructure including extensions or upgrades to existing infrastructures unless other mechanisms approved by the NRA or other relevant regulatory authorities, and leading to the same efficient, transparent and non-discriminatory outcomes as OS, are adopted'. Notably the GGPOS only apply to investments resulting in 'a significant amount of new marketable capacity', while a decision on what constitutes such a significant amount is left to the NRAs. ${ }^{82}$ Furthermore, the GGPOS 'should not apply to projects that are at an advanced stage with no prior knowledge of the guidelines' while the advanced stage projects 'may include projects that have already been granted, or have filed for, an authorization or license' while leaving a decision as to whether a project is at an advanced stage to the NRAs. ${ }^{83}$

The GGPOS require the prioritization of the usage of existing infrastructure, saying that 'full use should be made of existing infrastructure via the application of appropriate congestion management mechanisms' before initiating an OS and considering whether new investment is needed'. ${ }^{84}$

The GGPOS identified several categories of players which would be able to initiate an OS process; these include the operator of the existing infrastructure, the NRA, the government, outside investors, as well as shippers. In particular, it specified that the operator of the existing infrastructure 'will see that existing infrastructure is no longer sufficient' whereas in some cases the government or the NRA 'will decide that investment is needed' in which cases 'the existing system operator will be sponsor of the new infrastructure'. At the same time, the GGPOS acknowledge that there 'may be situations where outside investors perceive that there a need for new infrastructure and wish to sponsor it', stressing that 'the legal framework should allow such investments to take place'. ${ }^{85}$

The GGPOS state that in all the aforementioned cases, 'an OS involving the NRA and consultations with users would help decision makers estimate exactly how much and what kind of new capacity is needed, while ensuring that capacity is allocated on a transparent and non-discriminatory basis'. The GGPOS also state that 'if the existing SO [system operator] or outside investors do not decide, or are not ordered, to carry out necessary investments, shippers may wish to notify' the system operator that existing infrastructure is 'no longer sufficient to satisfy their needs'. If the system operator 'does not respond appropriately', shippers could address 'the NRA as well, possibly, as other relevant national regulatory authorities for support and confirmation that congestion is substantial enough to justify additional investment'. According to the GGPOS, this would be 'consistent' with the possibility for member states, introduced by the Second Gas Directive (in force at the time when the GGPOS were issued) to take 'the measures necessary to ensure that the natural gas undertaking refusing access to the system on the basis of lack of capacity, or a lack of connection, makes the necessary enhancements as far as it is economic to do so or when a potential customer is willing to pay for them'.

\footnotetext{
${ }^{30}$ GGPOS, (ERGEG (2007), p. 3).

${ }^{81}$ GGPOS, (ERGEG (2007), p. 5).

82 GGPOS, (ERGEG (2007), p. 6).

${ }^{83}$ GGPOS, (ERGEG (2007), p. 7). The GGPOS guidance on when a project could be considered 'advanced' might be taken into account when deciding whether a project could be considered 'initiated', given that the lack of such guidance in the CAM NC itself (Section 2.1.5).

${ }^{84}$ GGPOS, (ERGEG (2007), p. 8).

${ }^{85}$ GGPOS, (ERGEG (2007), p. 8).
} 

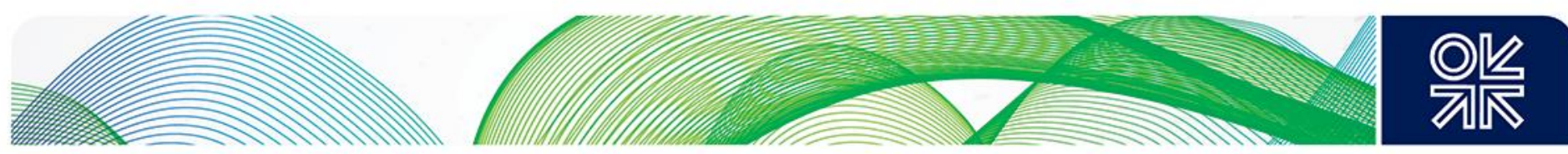

The GGPOS have outlined a 'classic' OS approach, consisting of two phases:

- non-binding bidding by shippers for new capacity in order to establish the level of interest for such capacity and hence decide on the new capacity offer;

- binding subscriptions by shippers allowing for positive FID should these subscriptions cover the preagreed level of cost (in other words passing the economic test). ${ }^{86}$

During the first (non-binding) phase, the project sponsor is required to consult the system users in order to assess how much new capacity, and on what terms, the market needs, while also evaluating the economic and technical constraints associated with a new project. Prior to launching the OS procedure, the sponsor is required to notify the NRA for verification of whether the OS proposal is 'reasonable and non-discriminatory' and 'consistent' with the GGPOS. The sponsor is also required to inform potential users of the new project, allowing them time to study the proposal before making capacity requests, with notice to be issued ahead of the OS to be 'sufficiently publicized' to permit 'meaningful participation' of third parties.

The GGPOS have also outlined the required content of the OS notice:

- the start and the end dates for making non-binding offers (the dates of these to be at least three months apart),

- the mechanism for making non-binding offers,

- the methodology ('economic test') that would be used to decide how much capacity will be built,

- the allocation rules that will be applied if the demand expressed in the OS cannot be met in full,

- the date on which capacity allocations will be communicated to OS participants,

- the date by which the participants will be asked to sign a binding agreement.

The OS notice must also include a certain amount of project information such as: the existing technical capacities, the project's intake and offtake points, the technical and available capacities.

Furthermore, for each possible capacity expansion, the OS notice must provide information on:

- available contract lengths (which need be compatible with the competition acquis) with both longand short-term contracts to be offered,

- the tariffs for each service offered or indicative tariffs or underlying methodologies if the tariffs depend on the level of total subscriptions,

- whether OS participants will only be able to bid once before signing binding agreements.

Tariffs should be given for all possible subscription situations. Furthermore, tariffs or indicative tariffs and underlying methodologies should be set or approved by the regulator before the start of an OS.

The GGPOS have stated that for submission of non-binding bids, the OS procedure must allow parties to indicate the amount and type of capacity (delivery and receipt points, contract duration, firmness) they would want for each design and expansion under consideration, and also allow them to comment on modifications to the proposals. If after bidding, the OS shows that demand for capacity is lower than capacity offered, the sponsor is allowed to conduct another round of bidding using a different tariff, or to conduct an economic test to decide whether an investment should go ahead. In this case, the economic test must be approved by the regulator and should address situations where demand is insufficient either at the non-binding or binding phases.

During the second (binding) phase, the binding agreements are signed for capacity that has been offered in the OS procedure. If the bids made during the first phase have passed the economic test and demonstrated that the investment is viable, the sponsor allocates capacity among the OS participants.

${ }^{86}$ GGPOS, (ERGEG (2007), pp. 10-17). 

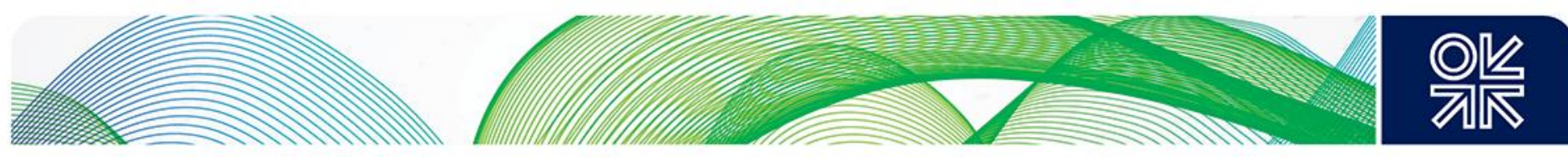

The GGPOS state that different capacity allocation methods can be used, the only requirement being that whatever method is chosen, it must be transparent and non-discriminatory and the NRA must ensure that this is the case. Notably, the GGPOS states that 'short term bookings should be taken into account' as although they 'may raise tariffs ... the benefits from increased competition may outweigh these costs'.

If OS participants are satisfied with the proposed allocation, they conclude a binding agreement with the sponsor in respect of allocated capacity. Such agreement should state the tariff (or indicative tariff and underlying methodology) as well as the amount of capacity that will be built as a result of the OS. Notably, the agreements must be submitted to the regulatory authority for verification that the same terms have been applied to all shippers. Should some OS participants be 'not satisfied with their allocation and decide to relinquish the capacity they have been proposed', this capacity will 'typically be offered to the other OS participants', with the NRA ensuring that its allocation is transparent and non-discriminatory. If capacity cannot be resold to other OS participants, the decision whether the project should still go ahead would be made on the basis of the economic test.

Prior to 6 April 2017, when the new CAM NC entered into force, new capacity projects mostly proceeded on the basis of a classic OS procedure (consisting of binding and non-binding phases for capacity allocation); the GGPOS have provided general non-legally binding guidance for these projects. For example, the EUGAL pipeline, initiated in 2015, has been developed under the 'more capacity' procedure, which is effectively a classic OS procedure, consistent with the GGPOS. Also, the Danish-German interconnector was based on the OS procedure, consistent with the GGPOS. It is argued here that the utilization of a tailor-made classic OS procedure in respect of incremental capacity - provided that the TEP's general rules, applicable to existing and incremental capacity, have been respected - was a fully legitimate and justifiable method for proceeding with the implementation of new projects prior to the CAM $\mathrm{NC}$ entering in force.

At the same time, it should be noted that the GGPOS were developed in 2007, in other words well before the TEP entered into force in 2011, and as such were intended to provide guidance in respect of capacity allocation, access, and tariff issues under the Second Energy Package (SEP), the provisions of which were significantly less far-reaching than those of the TEP, particularly in respect of unbundling. EU regulators have long argued that the classic OS procedure, as outlined in the GGPOS procedures, lacked transparency and coordination, and called for more concrete and detailed procedures to be developed. However, this did not happen even after the TEP had entered into force in 2011, and the GGPOS have remained the only applicable guidance.

As noted earlier, legally binding regulatory procedures for new (incremental) capacity had only started to be developed in late 2013 as part of the amended CAM NC, a few years after the TEP entered into force. These procedures have been finalized and became legally binding as of 6 April 2017, when the amended CAM NC entered into force. Therefore, the GGPOS has remained the only guidance and it continued to be used for any new capacity project that was planned to be built by 2020 (apart from projects under an exemption regime) as it was clear that the CAM NC would not be finalized until 2017 at the earliest, thus leaving insufficient time for project completion. It could be argued that although the usage of the GGPOS as guidance for an OS, in respect of new projects, was legitimate, it was becoming increasingly difficult for the project promoters to design their OS procedures in such a way that their capacity allocation provisions would be vastly different from those being developed as part of the amended CAM NC. This was because any such OS procedure would then run the risk that the EC and/or NRA would attempt to change these provisions after the CAM NC entry into force.

It is argued here that the way to proceed with a new project before the CAM NC's entry into force which would minimize such a risk would have been to conduct an OS procedure that was not only consistent with the GGPOS, but also broadly consistent with the publicly available draft CAM NCs (for example ENTSOG draft CAM NC, ACER draft CAM NCs), in particular in respect of capacity allocation. This is not to suggest that such an OS would have to contain capacity allocation provisions identical to those in the draft CAM NC, which would have been impossible as the drafts differed significantly (see Section 2.1), 

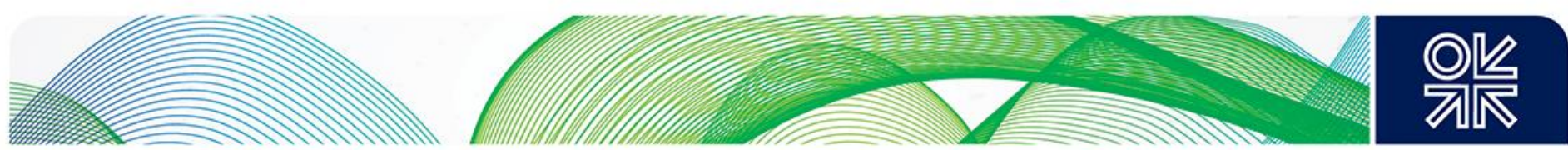

and also because the final CAM NC could still be different from the drafts. Rather, this is to suggest that the OS procedure would have needed to broadly mirror those provisions, whereas any significant deviations (for example booking horizon, reservation quota) would have had to be justified.

\subsection{Intergovernmental Agreements (IGAs): Decision 994/2012 and Decision 2017/684}

An intergovernmental agreement (IGA) constitutes another legal/regulatory framework which was used to build new gas pipeline infrastructure in the EU prior to the establishment of the CAM NC in 2017. Conclusion of an IGA between the government of a project promoter's country and the government of a country on whose territory the new pipeline is planned to be built has allowed parties to develop a bespoke legally binding framework, stipulating regulatory procedures for new pipeline infrastructure including permitting, construction, capacity allocation, access, and tariffs.

One of the major examples of new infrastructure being built under the IGA framework is provided by the Yamal-Europe pipeline, which was built in the 2000s to transport Russian gas to Europe across Poland and Belarus. The Polish section of the Yamal-Europe pipeline is underpinned by the IGA concluded between the Polish and the Russian governments in 1993 and subsequently amended in 2003 and 2010 (Section 3.5). ${ }^{87}$

Another example of new pipeline infrastructure that could have been built under the IGA framework - but was not, due to the project's cancellation in 2014 - is provided by the South Stream pipeline, which was planned to be built in the 2010s to transport Russian gas to southern Europe across the Black Sea. This pipeline was based on several IGAs signed during 2008-10 between the Russian government and the governments of several European (EU and non-EU) host countries, the territories of which the pipeline was planned to cross (Section 3.5). ${ }^{88}$

The IGA framework has allowed its parties significant freedom and flexibility in respect of agreeing on regulatory procedures governing inter alia permitting, capacity allocation, access to pipeline capacity, and tariffs. This was especially important at the time when no legislation which would have stipulated regulatory procedures in respect of new capacity existed at the EU level. The parties were thus able to include in their IGA any provisions they considered suitable as long as these provisions were - in their view - compatible with the EU acquis.

However, this flexibility began to decrease when the EC established an information exchange mechanism with regard to IGAs, whereby it acquired the power to assess the compatibility of all gas-related IGAs with the acquis (in particular on energy and competition). This mechanism was first established in 2012 by Decision 994/2012,89 whereby the EC acquired the powers to assess all gas-related IGAs ex post (in other words after they have been signed and ratified). This was further strengthened in 2017 by Decision 2017/684, which included powers to assess all gas-related IGAs ex ante (in other words before they have been signed and ratified). ${ }^{90}$ Given that at the time the EU acquis did not contain any specific regulatory provisions in respect of new capacity (only the TEP was in force, not the amended CAM NC) this mechanism enabled the EC to exercise a significant degree of discretion while delivering its assessment on compatibility of various IGAs' provisions with the acquis. A brief analysis of both Decisions is provided below.

Decision 994/2012 had defined an IGA as

\footnotetext{
${ }^{87}$ The Russian-Polish IGA, The 2003 Additional Protocol, The 2010 Protocol amending the 2003 Protocol, see Additional Documents.

${ }^{88}$ The northern branch via Bulgaria, Serbia, and Hungary was originally planned to end at Baumgarten in Austria and in Italy; Baumgarten was then dropped as a destination and then reinstated, with Italy seemingly no longer an intended market. The southern branch only appeared to run from Bulgaria to Turkey, abandoning the original plan of a connection to Greece.

${ }^{89}$ Decision 994/2012 (see Additional documents).

${ }^{90}$ Decision 2017/684 (see Additional documents).
} 

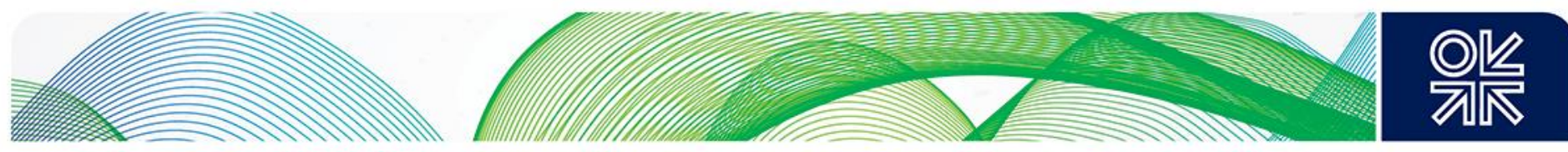

'any legally binding agreement between one or more member states and one or more third countries having an impact on the operation or the functioning of the internal energy market or on the security of energy supply in the Union' (Art. 2.1).

As noted above, Decision 994/2012 gave the EC the powers to access and examine all such gas-related IGAs ex post in order to determine their compatibility with the acquis. This applied to existing (in other words, entered into force or applied provisionally prior to the Decision's entry into force), amended, and newly signed IGAs. In the event of non-compatibility with the acquis, the EC was able to request these IGAs to be amended. However, under Decision 994/2012 the EC could not have access to - let alone assess - any new gas-related IGAs (or amendments to existing IGAs) before they were ratified - unless requested by a member state to do so. Also, the EC was only able to participate in the negotiations of these IGAs as an observer with the written approval of the member state concerned. Therefore, the EC was unable to have any ex ante insight into an IGA without the invitation or approval of a member state.

The EC soon discovered that the value of ex post compatibility verification was limited, due to the extreme practical difficulty of amending finalized (in other words signed and ratified ${ }^{91}$ ) IGAs. For example, when the EC concluded that the South Stream IGAs were not compatible with the acquis and requested them to be renegotiated or cancelled, the Russian government refused to comply. It rejected the EC's request to amend the IGAs, alleging that the EC had failed to prove non-compatibility and declaring that in any event the IGAs had precedence over the acquis. Consequently, the EU member state host countries faced a stark choice of either renouncing the IGAs - thus making themselves liable to penalties imposed by Russia ${ }^{92}$ - or preserving the IGAs - thus making themselves liable to penalties imposed by the EC. Indeed, Gazprom imposed a penalty on Bulgaria - where South Stream was planned to come ashore. ${ }^{93}$ On its part, the EC opened two infringement procedures against Bulgaria - one on the grounds of incompatibility with the TEP and another in respect of the legality of procurement for the pipeline - which led to the suspension of pipeline construction in Bulgaria in August 2014, after which, Gazprom decided to cancel the South Stream project. ${ }^{94}$

The acquis incompatibility argument, which was the main reason for the South Stream cancellation, was somewhat flawed as the acquis, in the form in which it existed in 2014 , did not contain any regulatory procedures for construction and utilization of new pipeline capacity (the CAM NC adopted in 2013 only stipulated procedures for existing capacity). For as long as the acquis did not contain procedures for incremental pipeline capacity, it would fall under procedures for existing capacity. At the time the EC had raised its concerns about the incompatibility of South Stream IGAs with the acquis, the set of regulatory procedures for new capacity was in the early stages of development and was not expected to enter into force until 2017 at the earliest, whereas the first South Stream pipeline was expected to become operational at the end of 2015. Given this regulatory void in respect of new capacity, which would not be filled until the second half of the 2010s, Gazprom and the Russian government should have recognized and acknowledged much earlier in the process that South Stream could not proceed on its original timetable. While it was somewhat disingenuous of the EU to continue to insist that South Stream had to conform to EU legislation and regulation - given that the detail of the latter in relation to large new gas transportation infrastructure was several years away from being clarified - the Russian side appeared to believe either that the EU would be forced to agree a compromise (because of its need for the gas), or that once pipeline construction began it could be presented with a fait accompli. Although these assumptions seemed dubious, a compromise solution between the EC and the Russian government (one that would have allowed Gazprom to ensure access to South Stream capacity sufficient for deliveries under its existing European supply contracts - in the event of transit across Ukraine becoming fully or partly halted) would have been entirely possible from a legal/regulatory point of view. However, following the Ukraine crisis and the Crimean annexation, relations between the EU and Russia on all gas issues

\footnotetext{
Where ratification is required by national laws.

92 It is understood that Gazprom has offered to waiver the penalties due from Bulgaria in respect of cancellation of South Stream as part of DG COMP settlement, see Stern and Yafimava (2017a).

${ }_{93}$ A separate infringement procedure was launched in respect of the legality of procurement for the pipeline.

${ }^{94}$ Interestingly, all South Stream IGAs have remained in force and none of them is understood to have been amended. This suggests that these IGAs could be used again in respect of any potential new southern route for Russian gas to Europe.
} 

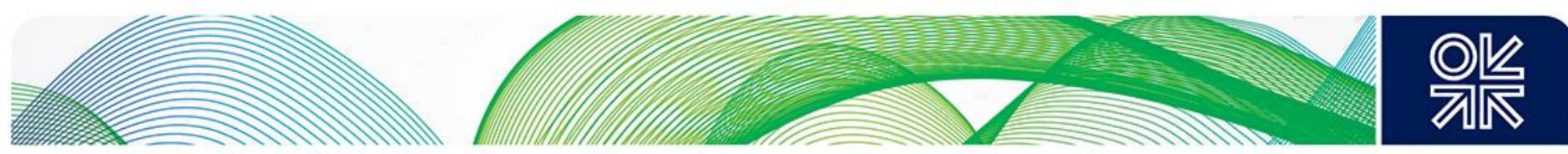

were 'frozen', and the inability of the parties to even hold negotiations, let alone reach a compromise, on regulatory issues ultimately led to the South Stream cancellation.

In 2016, as part of its wider Energy Union legislative initiative, the EC initiated a revision process for Decision 994/2012. The new Decision 2017/684, which has been in force since 2 April 2017, gave the EC a right and an obligation to conduct an ex ante assessment of IGA compatibility with the acquis, without having to seek prior permission from the member state concerned.

Decision 2017/684 has significantly changed the IGA's definition (Art. 2.1), defining it as

'any legally binding agreement, regardless of its formal designation, between one or more member states and one or more third countries, or between one or more member states and an international organization, which concerns:

- the purchase, trade, sale, transit, storage or supply of energy in or to at least one member state; or

- the construction or operation of energy infrastructure with a physical connection to at least one member state'.

Thus Decision 2017/684 specifically singled out IGAs that referred to construction and operation of new infrastructure both inside the EU and arriving from third (non-EU) countries.

Decision 2017/684 requires a member state to inform the EC about its intention to amend an existing IGA, or to conclude a new IGA, before starting negotiations. It also obliges a member state to notify a draft IGA - either amended or new - to the EC before the closure of negotiations, for ex ante assessment. Furthermore, a member state is obliged to notify to the EC all ratified IGAs. The decision states that a member state shall not sign, ratify, or agree to the draft IGA - amended or new - until the EC has informed the member state concerned of any doubts on the IGA's compatibility with the acquis or issued an opinion. A member state is required to take 'utmost account' of the EC opinion. Although the EC opinion is not legally binding, it would appear extremely difficult for a member state to ignore it and proceed with the IGA without risking an infringement procedure. Overall, this Decision has enabled the EC to prevent any IGA which it believes to be non-compatible with the acquis from being signed and ratified, thus effectively empowering it to stop the implementation of any new pipeline project based on such IGAs.

The EC hailed Decision 2017/684 as a major victory that would enable it to prevent signature and ratification by member states of new acquis-incompatible IGAs with third countries, thus avoiding legal and political difficulties, such as those posed by the South Stream IGAs, in the future. However, its importance has been undermined by the fact that signatures of new IGAs in respect of new infrastructures are becoming increasingly obsolete in the EU, with fewer and fewer IGAs being signed. ${ }^{95}$ Whereas IGAs had often served as a valuable additional framework in the past, underpinning long-term gas supply and transport contracts between EU member states and the companies of third countries, they are becoming unnecessary, as corresponding contracts are becoming shorter. Nonetheless, Decision 2017/684 has significantly reduced the scope for project promoters to be able to create a bespoke regulatory framework for the development of new infrastructure.

It is argued here that one of the reasons why the EC was so persistent in its support for Decision 2017/684 was its desire to ensure that should there be any IGA signed in respect of the Nord Stream 2 pipelines between the German and the Russian governments, the EC would have the power to require such an IGA to be compatible with the acquis. However, it has since become clear that neither the German nor the Russian government considered an IGA necessary for the project to proceed.

\footnotetext{
${ }_{95}$ The most recent IGA on gas infrastructure involving EU and third parties was signed in 2012 by Greece, Italy, and Albania in relation to the Trans Adriatic Pipeline (Section 3.3). Prior to that, several IGAs were signed during 2008-10 between several EU countries and Russia in respect of South Stream (Section 3.5). Also, The Russian-Polish IGA (see Additional documents) in respect of the Yamal-Europe pipeline was signed in 1993 but was subsequently amended in 2003 and most recently in 2010 (Section 3.5). There appears to be no suggestion that an IGA is under consideration for the Baltic Pipe project (Section 3.4).
} 

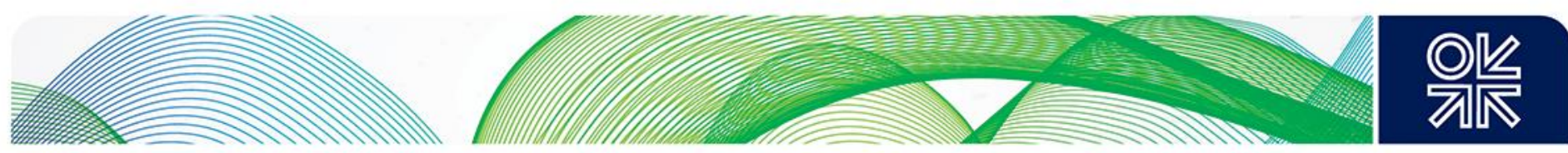

\section{New pipeline capacity in the EU (planned and under construction): case studies}

This chapter complements the previous chapter, in which different legal / regulatory frameworks for incremental capacity were analysed, by examining several new pipeline projects (case studies) which have been developed under these frameworks in the EU. These case studies illustrate the usage of each of these frameworks by providing a concrete example of a specific pipeline project (EUGAL, OPAL, TAP, Baltic Pipe, Yamal Europe, and South Stream) and explaining the regulatory treatment awarded to each pipeline under each framework. The contents of each section are as follows:

3.1 An analysis of the 'more capacity' procedure under which the EUGAL pipeline was developed under an OS procedure, guided by the GGPOS and the draft CAM NC, prior to the adoption of the CAM NC in March 2017. (The EUGAL pipeline is planned to connect with the Nord Stream 2 pipeline, bringing Russian gas from Russia to Germany. ${ }^{96}$ )

3.2 A study of the OPAL exemption, under which the OPAL pipeline has been operated. (The OPAL pipeline connects with the Nord Stream 1 pipeline, which is planned to run geographically in parallel with Nord Stream 2.)

3.3 An analysis of the TAP exemption. (The TAP is planned to be connected to TANAP (the Trans Anatolian Pipeline) at the Greece-Turkey border and bring Azeri gas to Greece, Albania, and Italy.)

(Both the OPAL and the TAP exemptions serve to illustrate the exemption regime.)

3.4 An analysis of the CAM NC incremental capacity process procedure as applied to the Baltic Pipe project. (The Baltic Pipe project is planned to connect the Norwegian production fields with Denmark and Poland.)

3.5 An examination of various IGAs concluded in respect of the Yamal-Europe pipeline (transporting Russian gas to Europe across Belarus and Poland) and the South Stream pipeline (prior to being cancelled in 2014, this was planned to bring Russian gas to Bulgaria and further into Europe, across the Black Sea).

\subsection{The EUGAL pipeline: a 'more capacity' project}

\subsubsection{The "more capacity" process: rationale and procedure}

In 2015 several German TSOs - GASCADE, ONTRAS, and Gasunie Deutschland ${ }^{97}$ - decided to initiate a 'more capacity' process for market-based allocation of new capacities on the borders of GASPOOL (one of the current German H-gas market areas, see Figure 1), in order to determine whether additional capacities at the GASPOOL borders were required by the market and to support the development of relevant new infrastructure. This initiative is consistent with Gas Regulation 715, which stipulates that TSOs 'shall regularly assess market demand for new investment' (Art. 16.5) while taking into account security of supply when planning new investment.

The TSOs jointly developed a procedure, according to which a 'more capacity' process was to be carried out:

- a non-binding phase for determining and analysing market demand for new capacities and translating this information into plans for possible infrastructure development projects,

- a binding phase for allocating and providing the new capacities.

\footnotetext{
${ }^{96}$ Gazprom, Nord Stream 2, News and Events, http://www.gazprom.com/about/production/projects/pipelines/built/nord-stream2/.

${ }^{97}$ In 2016 they were also joined by Fluxys and NEL Gastransport.
} 

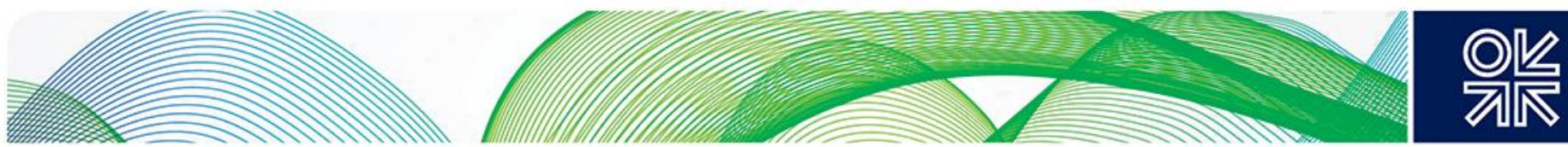

Figure 1: German gas market areas: GASPOOL and NCG

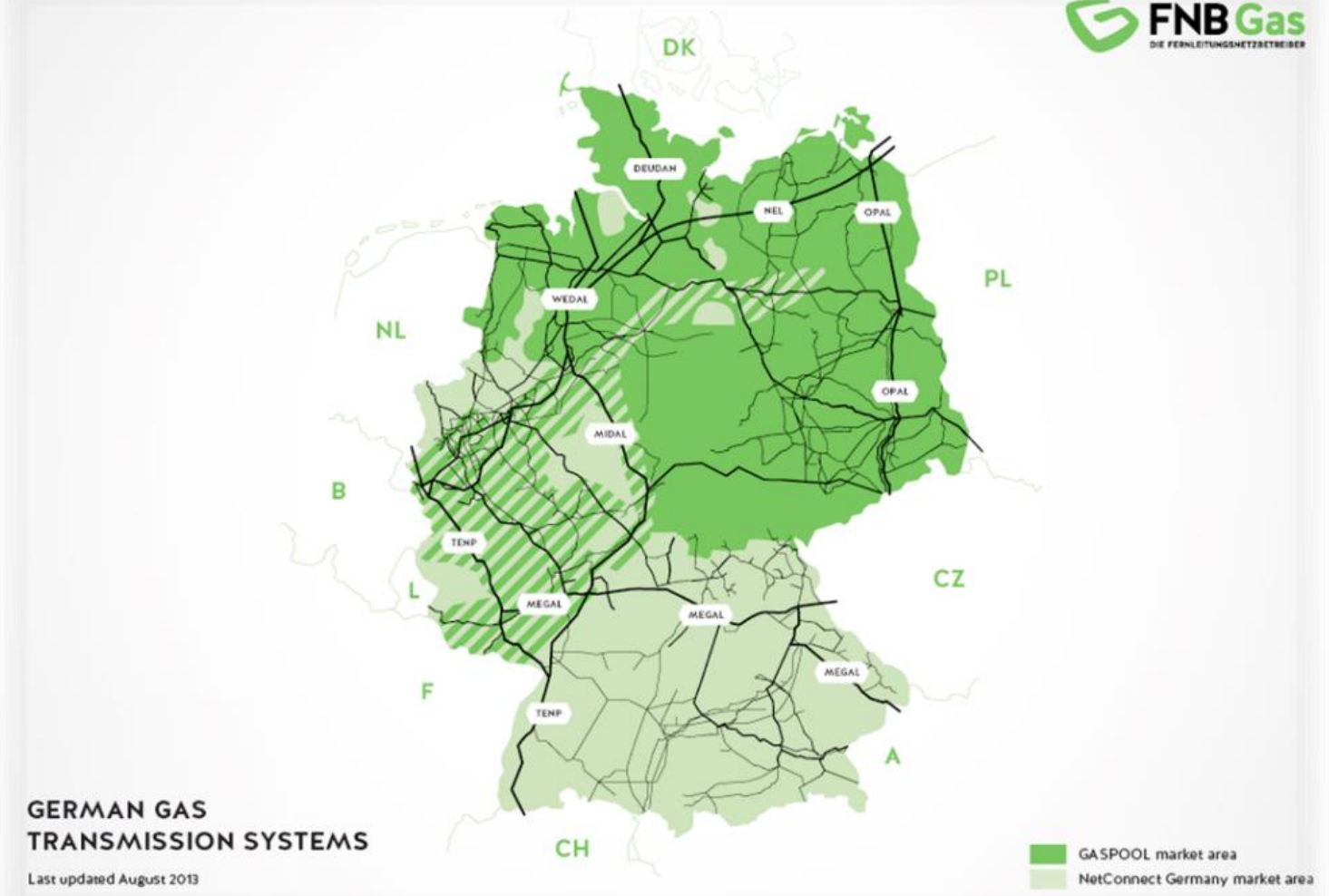

Source: FNB

The 'more capacity' process was to be carried out according to the following schedule (Figure 2).

Figure 2: Schedule of the process for market-based allocation of new capacities

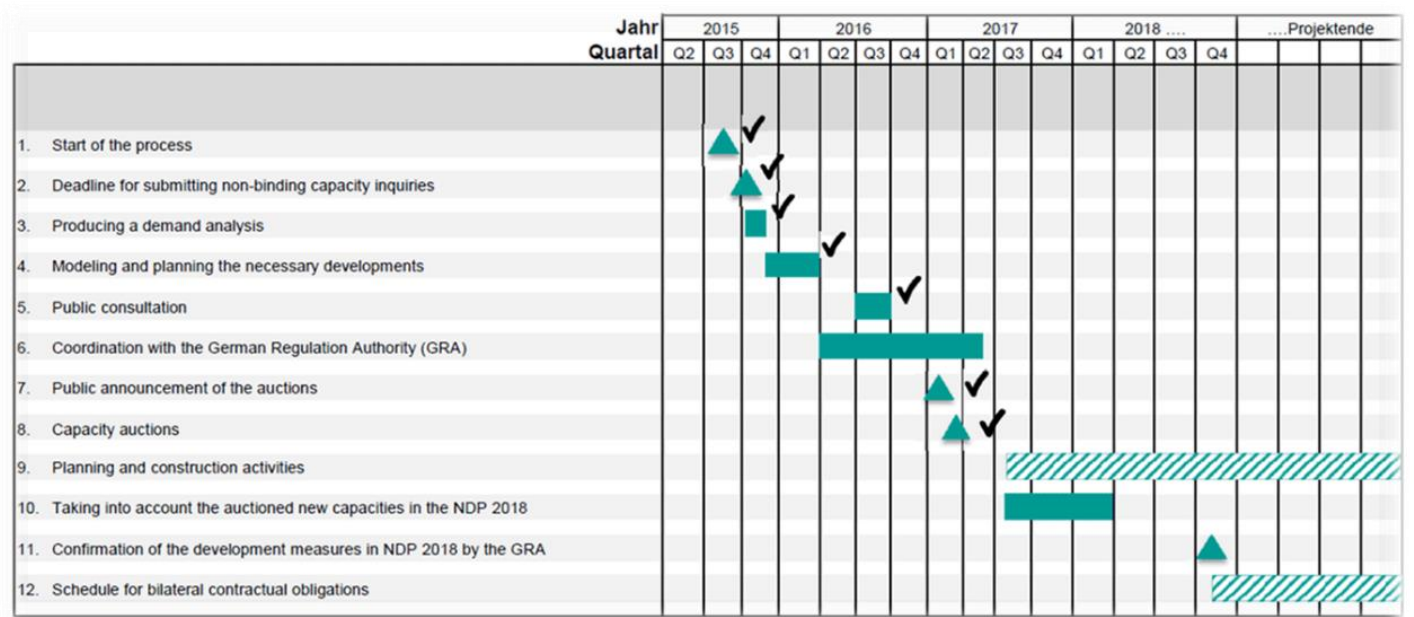

Source: www.more-capacity.eu

As demonstrated in Section 2, at the time when the 'more capacity' process was initiated in 2015, no legally binding regulatory framework for the market-based allocation of incremental capacity existed at the EU level, as the CAM NC 2013 (applicable at the time) had no corresponding provisions for 

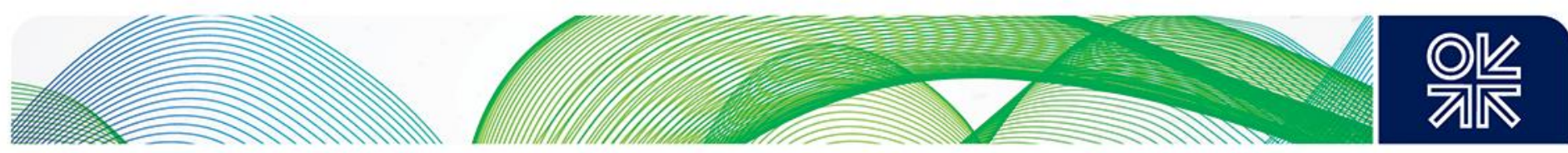

incremental capacity. ${ }^{98}$ The only EU-level regulatory framework for incremental capacity was provided by the non-legally binding EU Guidelines of Good Practice for Open Seasons (GGPOS). Therefore, the 'more capacity' TSOs developed their own 'two-phase' procedure for conducting the market survey, consistent with the classic OS procedure outlined in the GGPOS, on which it appears to have been closely modelled (see Section 2.4); the process also closely mirrored the draft CAM NC which was under development at the time (but which was not finalized until March 2017, see Section 2.1). It was anticipated that the procedure could be changed should the TSOs 'believe that this is necessary or if this is rendered necessary by legal or official requirements'. ${ }^{99}$

\subsubsection{Non-binding phase: market survey, technical studies, demand assessment, consultation}

Market survey

In response to 'a number of individual verbal and written requests', during 21 August-16 October 2015, in line with the aforementioned 'more capacity' procedure and in addition to the German Network Development Plan (NDP) procedure, the three TSOs - GASCADE, Gasunie Deutschland, and ONTRAS ${ }^{100}$ - carried out a coordinated, not legally binding market survey to estimate future demand for new capacities for $\mathrm{H}$-gas ${ }^{101}$ at the GASPOOL market area boundaries.

The market survey enabled the TSOs to 'consult the entire market in a transparent and non-discriminatory manner on a uniform basis' by asking market players to express their interest in new cross-market-area capacities on a non-binding basis. Participants were invited to submit their expressions of interest to the responsible TSOs, providing 'non-binding details regarding their future need for additional transport capacities for $\mathrm{H}$-gas at the boundaries of the GASPOOL market area'. ${ }^{102}$ The survey submissions were used to determine whether there was sufficient demand for capacities at the GASPOOL borders to make it necessary to plan and develop new projects ('demand analysis'). ${ }^{103}$ These expressions of interest were also used as part of technical studies for each market area boundary to define different offering levels.

The following projects were considered as part of the 'more capacity' process, market interest for which was expressed in the survey:

European Gas Pipeline Link (EUGAL) (TRA-N-763, ${ }^{104}$ ID 507-01a ${ }^{105}$ ), developed by GASCADE. A new pipeline which would connect to the Nord Stream 2 pipeline (planned to be built across the Baltic Sea from the Russian to the German coast) at Lubmin II (on the bay of Greifswald), through Germany (Mecklenburg-Western Pomerania, Brandenburg and Saxony regions) to the German-Czech border, where it would connect to the Czech Republic network. Up to the area of Weißack in the Brandenburg region, EUGAL is designed as a double pipeline. EUGAL is planned to be connected to the existing German infrastructure in the Lubmin area with the NEL gas pipeline, in the Kienbaum area with the FGL 306 / NETRA, and in the Radeland area with the JAGAL gas pipeline. According to North West Gas Regional Investment Plan (NWE GRIP), EUGAL would ensure transport of the requested new gas volumes and further improve security of supply for the market areas of Poland, the Czech Republic, GASPOOL, and NCG. 106

\footnotetext{
${ }^{98}$ CAM NC 2013 (see Additional documents).

${ }^{99}$ More Capacity 'Glossary'. https://www.more-capacity.eu/en/our-project/

${ }^{100}$ More Capacity 'Glossary'. https://www.more-capacity.eu/en/our-project/

${ }^{101} \mathrm{H}$-Gas is high calorific gas (87-99\% methane content) usually found in the North Sea and Russia as opposed to L-gas which is

low calorific gas (80-87\% methane content) usually found in northern Germany and the Netherlands.

102 Submission of the inquiry forms constituted an acceptance of terms and conditions, which if breached by a participant could

lead to its exclusion from further participation in the survey, and the new capacities that it requested may not be taken into account in the subsequent procedure.

${ }^{103}$ More Capacity Demand Analysis (see More Capacity (2015b)). The results of the legally binding auctions held in March

2017 confirmed some (albeit not all) results of the survey (see Section 3.1.3)

104 TYNDP 2017 reference number, see ENTSOG (2017a).

${ }^{105}$ Draft NDP 2018 reference number, see FNB Gas (2018b).

${ }^{106}$ NW GRIP 2017 (ENTSOG (2017c)).
} 

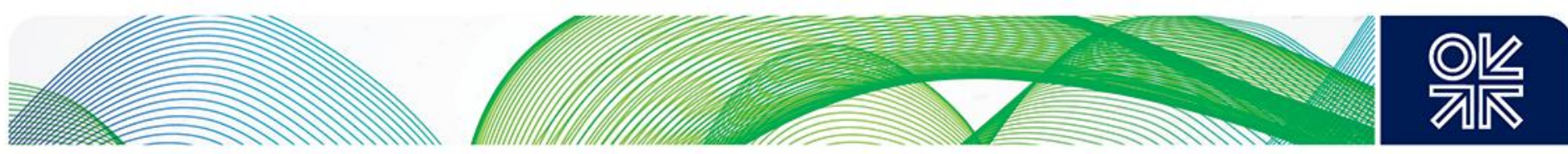

Expansion NEL (TRA-N-807), developed by Gasunie Deutschland, NEL and Fluxys Deutschland. This would be a capacity expansion (adding a new compressor station near Hamburg for imports of Russian gas via Nord Stream 2 to GASPOOL) of the existing NEL pipeline, to cover growing German demand for $\mathrm{H}$-gas caused inter alia by conversion from L-gas;

Transport of gas volumes to the Netherlands (TRA-N-808), developed by Gasunie Deutschland. This project would provide additional capacity (such as imports of Russian gas via Nord Stream 2 via Germany to the Netherlands) to cover demand at the German-Dutch border;

Upgrade Interconnection Points Deutschneudorf and Lasów - This would provide additional cross border capacity at the Deutschneudorf and Lasów interconnection points at the German-Czech and German-Polish borders respectively.

Notably, participation in the survey did not entitle its participants to require the TSOs to proceed with any of the projects. On the contrary, the TSOs were entitled at any time to 'proceed with, change or, where appropriate, end the process' should they believed this was 'appropriate from a business point of view'. The TSOs stated that the survey was 'not connected in any way with an agreement or obligation in respect of any subsequent network development or the acquisition or reservation of new capacities' and did 'not represent a request for network access', addressed to one of the organizing TSOs. Furthermore, the TSOs stated that participation in the survey was not a prerequisite for market players to take part in any subsequent auctions for existing and/or new capacities administered by these TSOs, thus suggesting that those players that did not take part in the survey would still be able to participate in future auctions.

\section{Demand assessment}

Following the completion of the market survey, TSOs had to determine whether the existing capacities, together with the network development measures currently planned at the market area boundaries, would be sufficient to cover the demand for new capacities expressed by market players during the survey. ${ }^{107}$ The decision was based on the assessment of long-term demand for new capacities related to the period beginning with the first year for which a market survey enquiry was made and the following three years.

Thus, after the market survey was completed, the TSOs analysed and summarized the capacity enquiries. The requested capacity was then presented in aggregated form for each market area boundary, ${ }^{108}$ while also showing details of the amount, duration, and product quality. Eight market players submitted 73 individual enquiries relating to both freely allocable capacity (FZK) and dynamically allocable capacity (DZK). ${ }^{109}$ The enquiries extended to the year 2041 and related to the GASPOOL market area transition points with Poland, Russia, the Czech Republic, the Netherlands, and NetConnect Germany (NCG). The requested capacities amounted to $89 \mathrm{GWh} /$ year (entry capacity) and $\sim 107 \mathrm{GWh} /$ year (exit capacity). ${ }^{110}$

In December 2015, the TSOs published a demand analysis (assessment) report, ${ }^{111}$ which incorporated the enquiries made by market players during the market survey. The report concluded that the new capacities requested by the market players during the non-binding market survey related to the following market area crossings:

- Russia $\rightarrow$ GASPOOL,

- GASPOOL $\rightarrow$ Poland,

- Poland $\rightarrow$ GASPOOL,

\footnotetext{
${ }^{107}$ The 'more capacity' process would have been terminated with the demand analysis report if neither individual non-binding enquiries submitted, nor enquiries as a whole, had been sufficient for justifying a project.

${ }^{108}$ Market area boundary - transition point between one market area and a neighbouring market area (market area boundaries with market areas outside the European Union are included) as viewed independently of the existing infrastructure and without focusing on individual transmission system operators or network points.

${ }^{109}$ More Capacity (2015a).

110 Ibid.

${ }^{111}$ More Capacity Demand Analysis (see More Capacity (2015b).
} 

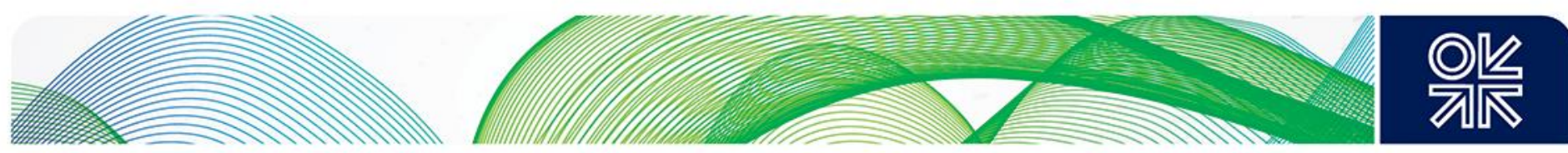

- GASPOOL $\rightarrow$ NCG,

- $\mathrm{GASPOOL} \rightarrow$ Netherlands.

The report also concluded that no capacities were requested for the remaining GASPOOL market area crossings (in other words with Norway, Denmark, and Belgium).

The TSOs had developed a set of criteria which were used to decide whether the expressions of interest made during the market survey would justify carrying out a technical study for new capacity projects in respect of any market area boundary: ${ }^{12}$

- Criterion 1: requested capacity > technically available capacity at the market area crossing.

- If at any point the total requested capacity exceeds the aggregated technically available capacity of the involved TSOs and their partners at a market area transition, a technical study will be necessary.

- Criterion 2: requested capacity > potentially available existing capacity at the market area crossing.

- If the total requested additional capacities in relation to the individual market area transitions exceeds the relevant potentially available existing capacity at any point, the involved TSOs will carry out a technical study.

The amount of potentially available existing capacities was determined on the basis of data from the involved TSOs and their partners that was published in October 2015; this included projects under construction at the time as well as planned projects from the German NDP 2015 ('NDP 2015). Furthermore, it was noted that the (then) current potentially available existing capacities would be on offer during the subsequent annual auction in March 2016 and may be booked by shippers, which would make them unavailable at the given levels for the annual auction in March 2017. The amount of potentially available existing capacity was calculated until the end of 2024 and stayed at that level until the end of the period covered by the market survey. The amount of potentially available capacity was determined as 'the free capacities during the period under consideration' minus 'the necessary reserves of 10 per cent or 20 per cent of the technically available capacity ... for short-notice bookings in accordance with Art. 8 of the NC CAM'. ${ }^{113}$

The demand analysis demonstrated that for some market area crossings (such as GASPOOL $\rightarrow$ Poland, Russia $\rightarrow$ GASPOOL, GASPOOL $\rightarrow$ Czech Republic) both criteria were met. For some market area crossings, only the second criterion was met, whereas the first criterion was not (for example Poland $\rightarrow$ GASPOOL and GASPOOL $\rightarrow$ Netherlands). For one market area crossing - GASPOOL $\rightarrow$ NCG - neither the first nor the second criterion was met (Table 1). Based on these results, the TSOs decided to proceed with carrying out technical studies for each market area boundary except GASPOOL $\rightarrow$ NCG.

\footnotetext{
112 More Capacity Demand Analysis, p. 8. (More Capacity (2015b), p.8)

113 'NC CAM' here refers to CAM NC 2013, which was in force at the time (see Additional documents).
} 

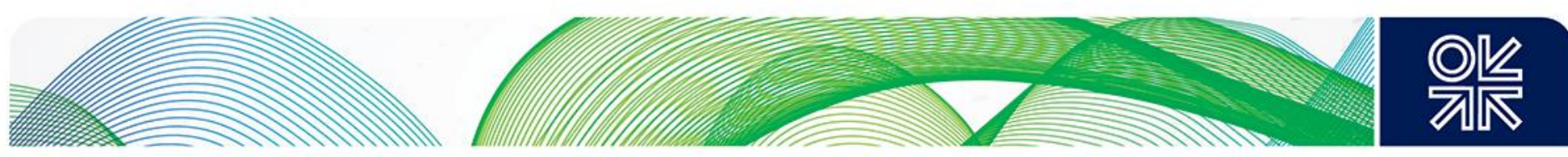

Table 1: Results of the criteria check as to the necessity of technical studies

\begin{tabular}{|l|c|c|c}
\multicolumn{1}{c|}{ Market area transition } & Criterion I & Criterion II & Technical study \\
\hline GASPOOL $\rightarrow$ Poland & Met & Met & Necessary \\
\hline Poland $\rightarrow$ GASPOOL & Not met & Met & Necessary \\
\hline Russia $\rightarrow$ GASPOOL & Met & Met & Necessary \\
\hline GASPOOL $\rightarrow$ Czech Republic & Met & Met & Necessary \\
\hline GASPOOL $\rightarrow$ Netherlands & Not met & Met & Necessary \\
\hline GASPOOL $\rightarrow$ NCG & Not met & Not met & Not necessary \\
\hline
\end{tabular}

Source: Demand analysis, December 2015.

\section{Technical studies}

On the basis of capacity requirements determined during the demand assessment, TSOs produced technical studies for each market area boundary (modelling and planning) for the November 2015-March 2016 period. ${ }^{114}$ These studies have determined the necessary technical development measures such as: new pipelines, feed-in / feed-out stations, and new compressor stations. The modelling process also included upgrades of existing infrastructure on the basis of flow calculations for one or more offering levels at each market area boundary.

In the process of conducting the technical studies, the TSOs defined capacity levels (Table 2) at the interconnection points of specific networks, combining existing (if available) and new capacities; these capacity levels were subsequently used to derive individual development proposals (network expansion measures), which would enable the TSOs to offer new technical capacities at these levels (excluding reservation quotas for short-term capacity bookings). These development proposals also provided an indication of necessary future investment costs.

Table 2: 'More capacity' offer levels at GASPOOL borders: existing and new

\begin{tabular}{|c|c|c|c|c|c|}
\hline & $\begin{array}{l}\text { Interconnection } \\
\text { points }\end{array}$ & $\begin{array}{l}\text { Existing } \\
\text { capacity, } \\
\mathrm{kWh} / \mathrm{h}\end{array}$ & $\begin{array}{c}\text { New capacity } \\
\text { kWh/h }\end{array}$ & $\begin{array}{l}\text { Total capacity, } \\
\mathrm{kWh} / \mathrm{h}\end{array}$ & Project description \\
\hline \multirow[t]{4}{*}{ ENTRY } & Greifswald-NEL & $28,608,944$ & $6,600,600$ & $35,208,944$ & Expansion of the existing capacity \\
\hline & Vierow GASCADE* & - & $79,147,641$ & $79,147,641$ & $\begin{array}{l}\text { New connection at Vierow (near } \\
\text { Greifswald) between the Nord } \\
\text { Stream } 2 \text { system and the } \\
\text { CASCADE pipeline network }\end{array}$ \\
\hline & Vierow Gasunie ${ }^{\star \star}$ & - & $3,145,000$ & $3,145,000$ & $\begin{array}{l}\text { New connection at Vierow between } \\
\text { Nord Stream } 2 \text { and the Gasunie } \\
\text { pipeline network }\end{array}$ \\
\hline & $\begin{array}{l}\text { Gaz-System- } \\
\text { ONTRAS }\end{array}$ & $1,118,626$ & $1,825,000$ & $2,943,626$ & Expansion of the existing capacity \\
\hline \multirow[t]{2}{*}{ EXIT } & \begin{tabular}{|ll} 
Zone & Oude \\
Statenzij| & \\
\end{tabular} & $1,490,567$ & $12,000,000$ & $13,490,567$ & $\begin{array}{l}\text { Expansion of the existing } \\
\text { connection with the Netherlands }\end{array}$ \\
\hline & Mallnow & $7,700,000$ & $\begin{array}{r}4,288,000 \\
(\text { level I) } \\
\\
6,286,000 \\
(\text { level II) } \\
\\
13,986,000 \\
\text { (level III) } \\
\end{array}$ & $\begin{array}{r}11,988,000 \\
(\text { level I)* } \\
13,986,000^{*} \\
(\text { level II) } \\
21,686,000^{*} \\
(\text { level III) }\end{array}$ & $\begin{array}{l}\text { Expansion of the existing } \\
\text { connection with Poland }\end{array}$ \\
\hline
\end{tabular}

\footnotetext{
${ }^{114}$ Technical study: modelling for each market area boundary, at which the necessary technical development or conversion measures for one or more capacity levels are determined. Once modelling is complete, capacity levels for specific network points will be defined.
} 

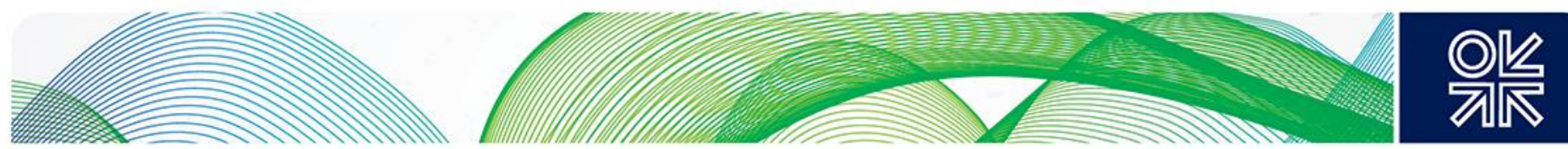

\begin{tabular}{|c|c|c|c|c|}
\hline Deutschneudorf & $4,400,000$ & $2,000,000$ & $6,400,000$ & $\begin{array}{l}\text { Expansion of the existing } \\
\text { connection with the Czech } \\
\text { Republic }\end{array}$ \\
\hline $\begin{array}{l}\text { Deutschneudorf- } \\
\text { EUGAL }\end{array}$ & - & $\begin{array}{r}45,158,999 \\
\text { (level I) } \\
\\
52,413,999 \\
\text { (level II) } \\
\\
56,813,999 \\
\text { (level III) }\end{array}$ & $\begin{array}{r}45,158,999 \\
\text { (level I) } \\
52,413,999 \\
\text { (level II) } \\
\\
56,813,999 \\
\text { (level III) }\end{array}$ & $\begin{array}{l}\text { New connection with the Czech } \\
\text { Republic }\end{array}$ \\
\hline $\begin{array}{l}\text { Gaz-System- } \\
\text { ONTRAS }\end{array}$ & $2,029,300$ & 669,000 & $2,698,300$ & $\begin{array}{l}\text { Expansion of the existing } \\
\text { connection with Poland }\end{array}$ \\
\hline
\end{tabular}

* Offering levels I to III will be offered as freely allocable capacities and are not in competition with the EXIT capacities of other network points in GASCADE's pipeline network.

Note: Vierow has since been renamed as Lubmin II.

Source: www.more-capacity.eu (adapted).

The existing and new interconnection points where either expansion of the existing capacity or creation of new capacity is planned as part of the 'more capacity' process are shown in Figure 3.

Figure 3: The EUGAL, OPAL, and NEL pipelines: new network points

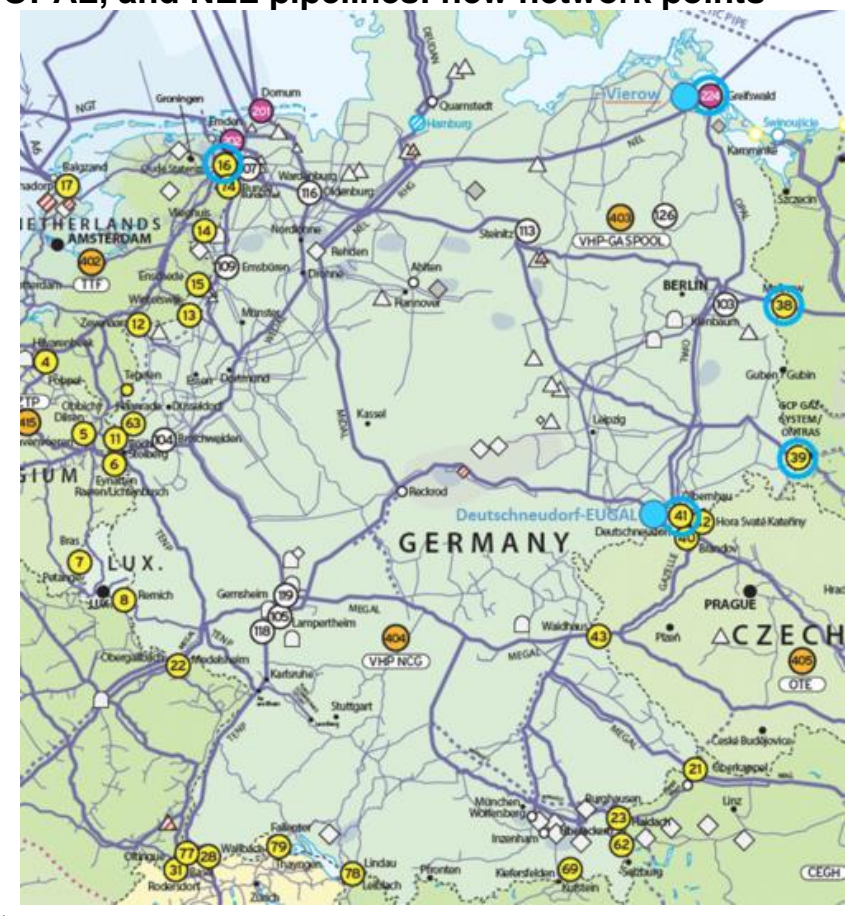

Source: www.more-capacity.eu

The five 'more capacity' TSOs - GASCADE, ONTRAS, Gasunie Deutschland, Fluxys, and NEL Gastransport ${ }^{115}$ - then defined their suggested offering levels with new capacities to be allocated though legally-binding capacity auctions on PRISMA (the European gas capacity trading platform). ${ }^{116}$ (Existing and new capacities were made available in the annual auction of 6 March 2017, see Section 3.1.3). These capacity levels included the reservation quotas for short-term capacity marketing, prescribed under the

\footnotetext{
${ }^{115}$ Fluxys and NEL Gastransport have joined the 'more capacity' process in April 2016 and July 2016 respectively

${ }^{116}$ More Capacity, Marketable capacities.
} 

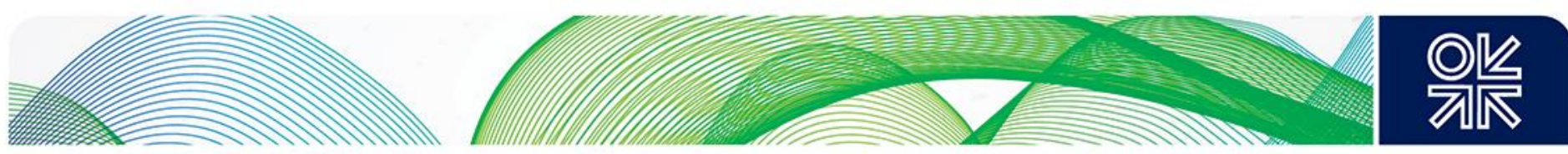

CAM NC 2013 and the decision of the German regulatory authority (BNetzA) BK7-15-001 KARLA Gas 1.1 (KARLA Gas), ${ }^{117}$ whereby 10 per cent of new capacity was set aside for short-term booking in future quarterly and shorter-term auctions, and another 10 per cent was set aside for mid-term bookings in the first five gas years immediately following the auction. New technical capacities earmarked for short-term marketing in accordance with the CAM NC 2013 and KARLA Gas were to be offered accordingly as quarterly products in later auctions.

Importantly, the modelling and planning for 'more capacity' technical studies was done in parallel with modelling for the draft German NDP 2016, in order to identify possible links between the 'more capacity' projects and the projects that were part of the draft NDP 2016. ${ }^{118}$ Technical studies were carried out in consultation with the involved TSOs and with close involvement of BNetzA.

\section{Existing vs new capacity}

Under the CAM NC, the TSO is obliged to make 'the maximum technical capacity' available to network users (Art. 6). ${ }^{119}$ This is consistent with the 'more capacity' TSO statement that in order to 'ensure costeffective and efficient expansion and operation of the network', a TSO must offer existing capacity to shippers before offering new capacity. ${ }^{120}$ As the EU acquis had contained no definition of 'new capacity', when the 'more capacity' project was initiated, the 'more capacity' TSOs developed their own definition of new capacity as a difference between the total capacity demand and the existing capacity. The definition has since been refined as follows: 'a possible increase in technical capacity or future additional capacity which is provided through investments or the long-term optimization of the network and after a positive market test (at existing boundary transition and/or market-area transition points, by constructing one or more new boundary transition and/or market-area transition points, as physical counter-flow capacity which was not previously offered)'. ${ }^{121}$

Accordingly, the 'more capacity' TSOs announced that they will ensure that capacity requirements will be met first by existing capacities being booked at a market area boundary. They have also stipulated the so called 'existing capacity sharing arrangement' whereby if a 'more capacity' TSO cannot ensure that a capacity requirement can be met using its existing capacity, it will report the shortfall to its partners (other 'more capacity' TSOs) operating at the same market area boundary, so that the 'more capacity' TSOs can divide the requirements among themselves until all existing capacities at the same boundary are allocated under preliminary agreements. If multiple shippers have requested capacity from a 'more capacity' TSO, these requests will be transferred on a pro rata basis to one of the 'more capacity' TSOs operating at the same boundary.

A shipper's requirements for new capacities were calculated as: the difference between its total capacity requirements on one hand, and the existing capacities to be booked and the capacity transferred to another 'more capacity' TSO at the same boundary, on the other. Each 'more capacity' TSO allocates new technical capacity to a shipper according to the offering level. If demand for new technical capacities is higher than the respective offering level, the TSO will distribute its offering of new technical capacities on a pro rata basis over the enquiries it has received from all transport customers. Every 'more capacity' TSO reserves the right to adjust its offering levels accordingly if deviations in demand are foreseeable. If a shipper's requirements for new technical capacities cannot be fully met by a 'more capacity' TSO, it can request new technical capacities from another 'more capacity' TSO at the same market area boundary.

\footnotetext{
117 BNetzA (2015).

${ }^{118}$ NDP 2016 (see FNB Gas, 2017h).

${ }^{119}$ CAM NC (see Additional documents). Note that CAM NC 2013 (see Additional documents), which did not stipulate any provisions in respect of new capacity, was in force when the 'more capacity' process was launched. CAM NC 2013 does not define 'new capacity' whereas CAM NC (2017) defines 'incremental capacity'.

${ }^{120}$ More Capacity, The Consultation.

${ }^{121}$ More Capacity, Glossary. The definition of new capacity provided by 'more capacity' TSOs appears to be close to the definition of incremental capacity provided by the CAM NC.
} 

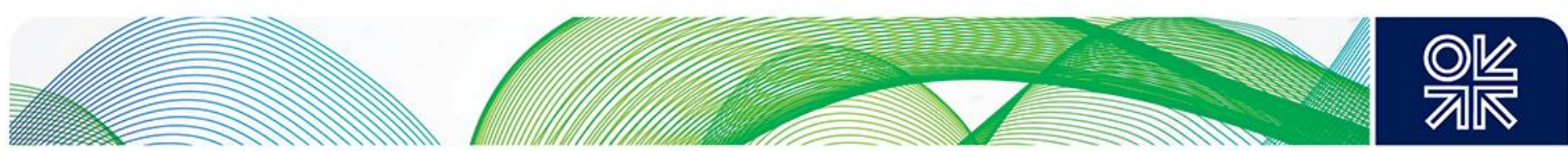

Consultation: preliminary agreements and supplementary terms and conditions

The 'more capacity' market survey demonstrated the need for additional transport capacities and hence for expansion of the network at several GASPOOL boundaries. Timely construction of new capacity, while ensuring that existing capacity was marketed first, necessitated the conclusion of preliminary agreements between transport customers and the 'more capacity' TSOs.

With this in mind, once the demand analysis was complete and the technical studies were developed, the 'more capacity' TSOs (GASCADE, Fluxys, Gasunie, NEL, ONTRAS ${ }^{122}$ ) carried out a four-week public consultation that began on 5 August 2016 and ended on 2 September 2016,123 with regard to the binding marketing of capacities as part of the 'more capacity' process in 2017. During this consultation, market players were asked to give feedback inter alia on the defined offering levels, the project description, and the further process. The relevant information was coordinated in advance with BNetzA and published prior to the start of the consultation.

The consultation process centred around the Preliminary Agreement (on holding capacity auctions and on submission of bids in capacity auctions) and the Supplementary Terms and Conditions (STC) to use in allocating new technical capacities, draft versions of which were published by the TSOs on 4 August 2016. ${ }^{124}$ The Preliminary Agreement is a bilateral agreement concluded between the shipper and each of five aforementioned 'more capacity' TSOs. By signing such an agreement, the shipper commits to bid for a specified amount of capacity, while the respective 'more capacity' TSO commits to offer this capacity in the auctions. The main purpose of the Preliminary Agreement was to provide the required security to both the TSO and the shipper confirming that the new capacities in which the shipper expressed its interest during the market survey, will be offered and requested in the annual auction (taking into account the reservation quotas). The Preliminary Agreement is considered concluded once countersigned by the 'more capacity' TSO. ${ }^{125}$ The STC govern the conclusion of contracts for new capacity. Both the draft Preliminary Agreement and the draft STC are analysed in the Annex. In January 2017, following the consultation process, the final Preliminary Agreements and STCs of all five TSOs were published on the 'more capacity' website, prior to the start of auctions in March 2017. ${ }^{126}$

\subsubsection{Legally binding phase (post-consultation): auctions}

Once the consultation was completed, the 'more capacity' TSOs analysed the results, taking them into account for defining the final offering levels of capacity. Subsequently, the conditions for holding auctions and, where applicable, economic tests for new capacities were discussed by the TSOs with BNetzA on the basis of the preliminary offering levels and the development proposals set out previously. In early February 2017, the market players were informed that the auctions were due to be held on PRISMA, with information provided on the auction date and procedure, the offering levels, and the expected minimum demand for positive economic tests. The final offering levels were published on the websites of PRISMA and of the 'more capacity' TSOs prior to the annual auction scheduled for 6 March 2017.

The auctions for new technical capacities were held in parallel with the auctions for existing capacities as part of the annual auction on 6 March 2017. New capacities were allocated through auctions, with the auction algorithm being identical to the standard algorithm used for annual auctions. The auction results have provided the basis for subsequent economic evaluation (economic tests) and have also been published. New technical capacities were offered for a period of 25 years ${ }^{127}$ and allocated for a period of 20 years $^{128}$ (as of commissioning of the infrastructure). The shipper was obliged to submit the initial bids

\footnotetext{
122 Fluxys Deutschland has been involved in the 'more capacity' market survey since April 2016 and NEL Gastransport has been involved since July 2016

${ }^{123}$ More Capacity (2016)

${ }^{124}$ More Capacity Preliminary Agreement, More Capacity Supplementary Terms and Conditions.

125 The TSOs have published the aggregated results for each network point once all preliminary agreements have been concluded.

${ }^{126}$ More Capacity (2017a).

${ }^{127}$ More Capacity Supplementary Terms and Agreements.

${ }^{128}$ More Capacity (2017b).
} 

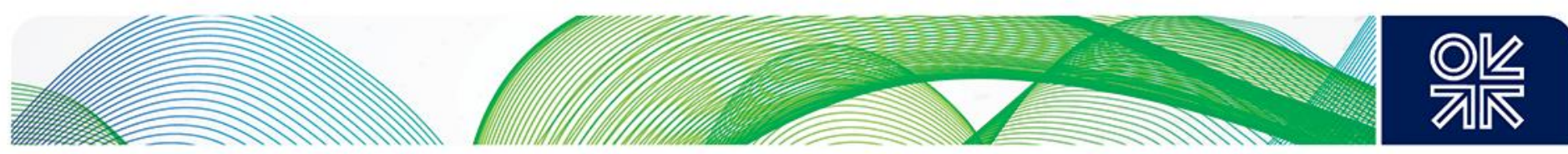

at least in the amount agreed in the respective Preliminary Agreements. In the event of multiple offering levels being offered, the shippers undertook to submit initial bids for all the offering levels offered by the 'more capacity' TSO in question in the first round of the auction. Under the Preliminary Agreements, the shipper is obliged in further annual (and in the subsequent quarterly) auctions to submit initial bids for those capacities that could not be marketed through the specification of reservation quotas in the 2017 annual auction. New technical capacities were offered at variable tariffs for a period of up to 25 years after commissioning. As stated on the 'more capacity' website, due to new European regulations (as the CAM NC and the Tariffs NC were expected to enter into force in 2017), the TSOs were to 'examine' until the end of 2017 whether fixed tariffs could be charged instead of variable tariffs. ${ }^{129}$ It is understood that it was decided that variable - rather than fixed - tariffs will apply. ${ }^{130}$

On 7 March 2017, the 'more capacity' TSOs announced a successful conclusion of the auctions. Shippers had bought new and existing capacities in the amount of $138 \mathrm{GW}$ per year, with the TSOs collectively selling 'up to $78 \mathrm{GW}$ ' of entry capacity to the GASPOOL market at four connection points and 'a total of around $60 \mathrm{GW}$ ' of exit capacity, ${ }^{131}$ which according to the TSOs had 'largely confirmed' the results of the market survey. The auctions results were made available on PRISMA. Notably, the bookings related to the market area interconnection points between (a) GASPOOL and Russia and (b) GASPOOL and the Czech Republic; these include freely allocable capacity (FZK) and dynamically allocable capacity (DZK), extending in part through to 2039. It is understood that no (or insufficient) bookings were made in respect of interconnection points between GASPOOL and NCG, GASPOOL and the Netherlands, ${ }^{132}$ or GASPOOL and Poland.

After the annual auction was concluded, the 'more capacity' TSOs had to decide (as part of an economic analysis) which offering level was to be applied to any expansion. The results of the auctions provided the basis for subsequent economic tests, designed to assess the economic viability of the auctioned offering levels. According to the 'more capacity' TSOs, the principle of such an economic analysis was to compare individual transportation fee revenues with the additional revenue ceilings resulting from the development of new capacities. ${ }^{133}$ Should the former be higher than or equal to the latter, the economic test is considered to be positive. ${ }^{134}$ According to the 'more capacity' TSOs, there were plans 'to take into account 'the regulatory transportation fee which is derived from the revenue ceilings for the planned investment costs' as well as any auction premium, when carrying out the economic tests. Ultimately, the offering level which had provided the greatest additional capacity (if the economic test is positive) was applied and the shippers were to receive a capacity booking in the highest positive offering level. The results of the economic tests have been notified to BNetzA.

Having resulted in legally binding capacity bookings, the auctions confirmed the market interest in new projects related to interconnection points between GASPOOL and Russia (for example EUGAL, construction of the new receiving terminal in Lubmin II, connection to NEL), as well as between GASPOOL and the Czech Republic (upgrade of the interconnection point at Deutschneudorf), with entry capacities to EUGAL and exit capacities the Czech Republic (Deutschneudorf and Olbernhau) having been booked. However, the lack of bookings in respect of interconnections points between inter alia GASPOOL and the Netherlands reflected the lack of market interest in projects relating to NEL expansion

\footnotetext{
${ }^{129}$ More Capacity, Market-based allocation of new cross-market-area capacities.

${ }^{130}$ Notably, the Tariff NC, which entered into force on 6 April 2017, allows a choice between the floating and the fixed price approach when incremental and existing capacity is offered in the same auction or same AAM, but notes that the fixed price approach can only be applied if an AAM is used or if a project has a PCI status, see Art. 25.

${ }_{131}$ More Capacity (2017b); GASCADE (2017a).

${ }^{132}$ Expansion NEL (TRA-N-807) has been postponed due to the results of the auction.

${ }^{133}$ More Capacity, Market-based allocation of new cross-market-area capacities.

${ }^{134}$ As the CAM NC, which obliges the national regulatory authority to set the f-factor (see Section 2.1.4), had not yet been in force when the 'more capacity' process was performed, no specific f-factor was set by BNetzA in respect of 'more capacity' economic tests. However, the above description of the economic tests suggests these tests were considered positive if the f-factor was equal one.
} 

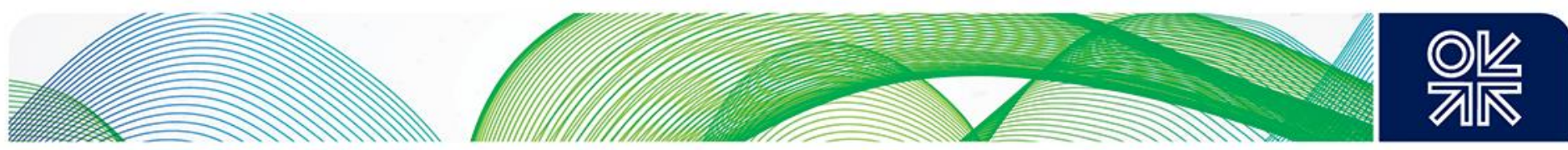

and in the transportation of gas to the Netherlands, while a lack of bookings between GASPOOL and Poland indicated a lack of market interest in respect of upgrading the Lasów interconnection point to offer additional firm capacities from GASPOOL to Poland. Correspondingly, only the projects belonging to the first group (EUGAL, receiving terminal at Lubmin 2, the connection to NEL, the Deutschneudorf interconnection point expansion) were included in the draft 2018 Network Development Plan (NDP) (see Section 3.1)

The TSOs have stated that the results of the auctions served 'as the basis for an economic and sustainable expansion of the pipeline network and should be included as an identified capacity requirement in the scenario framework' for the 2018 NDP, which is expected to be finalized by the end of 2018. ${ }^{135}$ It is understood that the auction result, whereby the capacity in EUGAL has been booked, is being included as an identified capacity requirement in the NDP 2018 process. Thus the draft 2018 NDP includes the EUGAL pipeline (ID 507-01a), the natural gas receiving terminal Lubmin II (ID 412-03), and the NEL connection pipeline (which connects EUGAL and NEL) (ID 507-01b). Confirmation of the NDP 2018 by BNetzA is expected in the fourth quarter of 2018. The relationship between EUGAL and different network developments plans is analysed in Section 3.1.

The EUGAL pipeline has emerged as the major project of the 'more capacity' process as well as one of the biggest projects expected to be included in the German NDP 2018. On 18 October 2017 four TSOs - GASCADE, Fluxys Deutschland, Gasunie Deutschland, and ONTRAS - signed an ownership agreement for the EUGAL pipeline project, ${ }^{136}$ under which GASCADE would have a 50.5 per cent stake and the three other TSOs 16.5 per cent each. It was agreed that GASCADE will continue to manage the EUGAL construction process and will operate the EUGAL pipeline once it is built.

Once the EUGAL ownership agreement was concluded, planning and preparation started in respect of engineering work, obtaining the necessary permissions under public law, procuring materials, and arranging construction services. Several permitting procedures were launched in respect of EUGAL in all the regions whose territories EUGAL is planned to cross - Mecklenburg-Western Pomerania, Brandenburg, and Saxony:

on 24 October 2017 the Stralsund Mining Authority opened a planning approval procedure in respect of the EUGAL pipeline in Mecklenburg-Western Pomerania (the first German region that would be crossed by EUGAL). ${ }^{137}$ The application documents were available for viewing from 24 October 2017 to 23 November 2017 and could be commented on by 27 December 2017. The Mining Authority would decide on the planning approval which would determine the final preferred route of EUGAL in the region;

on 30 October 2017 the Brandenburg State Office for Mining opened a planning approval procedure in respect of the EUGAL pipeline in Brandenburg. ${ }^{138}$ The application documents could be viewed during the period 1-30 November 2017, and subsequently commented on. The State Office would then decide on the planning approval that will determine the final route of the pipeline;

on 1 December 2017 the state authorities in Saxony opened a planning approval procedure in respect of EUGAL in Saxony. ${ }^{139}$ The documents could be viewed from 11 December 2017 to 10 January 2018 and commented on by 10 February 2018 (in respect of the Chemnitz section of the pipeline), and from 13 December 2017 to 19 January 2018 and commented on by 19 February (in respect of the Dresden section of the pipeline).

\footnotetext{
${ }^{135}$ More Capacity (2017b)

${ }^{136}$ GASCADE (2017b)

137 GASCADE $(2017 \mathrm{c})$

${ }^{138}$ GASCADE $(2017 \mathrm{~d})$

${ }^{139}$ GASCADE (2017e)
} 

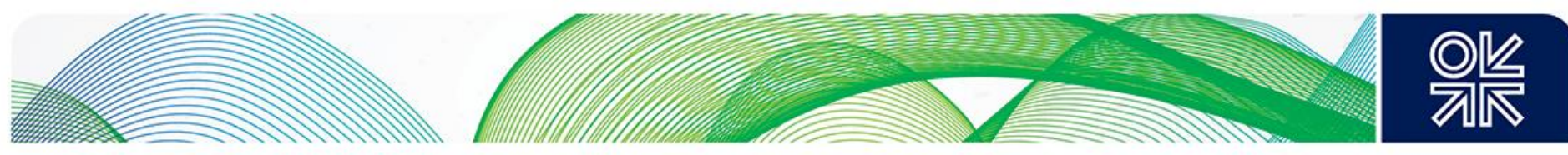

At the time of writing, the aforementioned approval procedures are ongoing. The construction phase can begin once the planning and preparatory work is completed. Meanwhile, on 31 January 2018, the Nord Stream 2 pipeline project, to which EUGAL is planned to connect, received a permit for construction and operation in German territorial waters and for the landfall area near Lubmin ${ }^{140}$ and on 27 March 2018 it also secured the approval of the German maritime authority BSH. ${ }^{141}$ The first string of EUGAL is planned to be completed by the end of 2019 thus tallying up with Nord Stream 2, the first string of which is scheduled to be completed in the same timeframe.

\subsubsection{First demand assessment process for incremental capacity under CAM NC}

One month after the 'more capacity' project was completed, with the auctioning of new capacity at the interconnection points between GASPOOL and neighbouring market areas taking place on 7 March 2017, the new EU CAM NC, which provided a legally binding set of rules for market-based allocation of incremental (new) capacity, entered into force on 6 April 2017 (Section 2.1). ${ }^{142}$ This meant that all incremental capacity projects initiated on or after 6 April 2017 would be subject to the capacity allocation procedures set out in the CAM NC. Incremental projects initiated before 6 April 2017 are also subject to these procedures unless they had been granted the applicable approvals for capacity allocation by the respective NRAs before 1 August 2017. As argued in Section 2.1, the CAM NC capacity allocation provisions do not apply to the EUGAL project.

Given that the CAM NC applies to all incremental capacity projects initiated on or after 6 April 2017, the German TSOs invited market participants to submit their non-binding demand indications for capacities to be created on the borders of German GASPOOL and NCG during 6 April-1 June 2017, in line with the CAM NC. Notably, non-binding demand indications made prior to CAM NC's entry into force were to be 're-submitted ... in order to be considered as part of the new market demand assessment process'. ${ }^{143}$ As a result of the process, two market participants have submitted eight requests, which extend to 2040 and relate to (a) the market area interconnection point between GASPOOL and NCG, and (b) the cross-border interconnection points between GASPOOL and Austria East, GASPOOL and Poland, GASPOOL and Russia, and GASPOOL and the Netherlands. ${ }^{144}$ During the non-binding stages the shippers have requested $26 \mathrm{GW}$ of transportation capacity, thus implying a total cost of $\sim 215$ million euros. The TSOs have subsequently conducted market demand assessment reports based on these non-binding demand indications, in order to determine demand for incremental capacity. These reports, which were published on 27 July 2017, have provided the basis for the subsequent development of technical studies by the TSOs, which took into account the existing and planned (in other words being part of the NDP) capacity as well as the incremental capacity requested during the demand assessment process. ${ }^{145}$ On 19 October 2017, the German TSOs published their proposals for incremental capacity projects for consultation in line with Art. 27.3 of the CAM NC, with market participants invited to submit their comments by 19 December 2017. ${ }^{146}$ Following the completion of consultation, the incremental capacity projects were to be submitted to the relevant regulatory authorities for approval.

\subsubsection{German and EU-level Network Development Plans: 'more capacity' projects}

\section{Legal basis for EU and National Network Development Plans (NDPs)}

EU energy law places a number of obligations on the EU-level European network of TSOs (ENTSOG), the regional groups' TSOs, and the national TSOs to develop various network development plans (NDPS).

\footnotetext{
140 'Germany grants permit for Nord Stream 2 Russian gas pipeline', Reuters, 31 January 2018.

141 'Germany fully approves Russia-built Nord Stream 2 gas pipeline', Reuters, 27 March 2018.

142 CAM NC (see Additional documents).

${ }^{143}$ FNB Gas (2017i).

${ }^{144}$ FNB Gas (2017f)

145 Ibid.

${ }^{146}$ FNB Gas (2017i).
} 

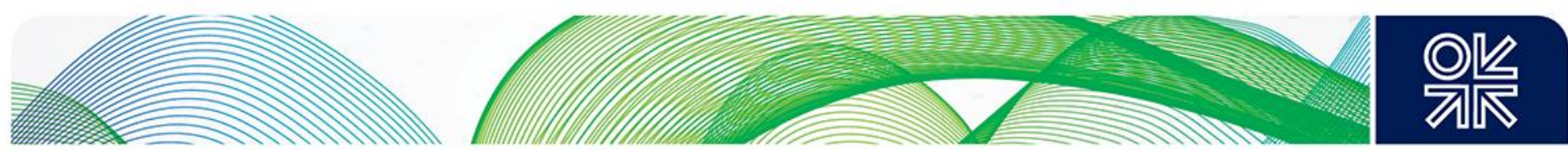

\section{EU level}

Under Gas Regulation 715 (Art. 8.3.b), ENTSOG is obliged to adopt a non-binding EU-level ten-year network development plan (EU TYNDP) every two years. The EU TYNDP must include 'the modelling of the integrated network, scenarios development, a European supply adequacy outlook and an assessment of the resilience of the system' (Art. 8.10) and 'build on national investment plans, taking into account regional investment plans'. Furthermore, 'if appropriate', the EU TYNDP must build on EU 'aspects of network planning, including the guidelines for trans-European energy networks in accordance with Decision N 1364/2006/EC'. ${ }^{147}$ Also, in respect of cross-border interconnections, the EU TYNDP must build on the 'reasonable needs of different network users and integrate long-term commitments from investors referred to in Art. 14 and 22' of the Third Gas Directive, and 'identify investment gaps, notably with respect to cross border capacities'. ENTSOG is obliged to submit the draft EU TYNDP to ACER for an opinion. ACER is obliged to produce 'a duly reasoned opinion as well as recommendations' to ENTSOG and the EC 'where it considers' that the draft EU TYNDP does not 'contribute to nondiscrimination, effective competition, the efficient functioning of the market or a sufficient level of crossborder interconnection open to third-party access' (Art. 9).

\section{Regional level}

The Third Gas Directive obliges member states and the regulatory authorities 'to cooperate with each other for the purpose of integrating their national markets at one and more regional levels' (Art. 7) thus promoting regional cooperation in respect of NDPs. Specifically, the Directive states that 'the regulatory authorities where member states have so provided or member states shall promote and facilitate the cooperation of TSOs at a regional level, including on cross-border issues'. The geographical areas covered by such regional cooperation must include 'cooperation in geographical areas defined in accordance with Art. 12.3 of Gas Regulation 715, which states that 'the geographical area covered by each regional cooperation structure may be defined by the [European] Commission, taking into account existing regional cooperation structures', while 'each member state shall be allowed to promote cooperation in more than one geographic area'. Furthermore, Gas Regulation 715 has obliged the TSOs to 'establish regional cooperation' within ENTSOG and in particular to 'publish a regional investment plan every two years', while also stating that the TSOs 'may take investment decisions based on that regional investment plan' (Art. 12.3).

\section{National level}

Under the Third Gas Directive (Art. 22.1), a TSO is obliged to submit to the national regulatory authority a ten-year network development plan (NDP) every year, 'based on existing and forecast supply and demand after having consulted all relevant stakeholders'. The plan must contain 'efficient measures in order to guarantee the adequacy of the system and the security of supply'. It must, 'in particular, (a) indicate to market participants the main transmission infrastructure that needs to be built or upgraded over the next ten years; (b) contain all the investments already decided and identify new investments which have to be executed in the next three years; (c) provide for a time frame for all investment projects' (Art. 22.2). Notably, the TSO is obliged to 'make reasonable assumptions about the evolution of the production, supply, consumption and exchanges with other countries, taking into account investment plans for regional and Community-wide networks, as well as investment plans for storage and LNG regasification facilities'. On its part, the national regulatory authority is obliged to examine whether the TSO's plan 'covers all investment needs identified during the consultation process'. The regulatory authority is also obliged to examine whether the plan is 'consistent' with the EU ten-year network development plan (EU TYNDP) and consult ACER in the event of 'any doubt' in respect of consistency. The regulatory authority may (but is not obliged to) require the TSO to amend its plan.

\footnotetext{
${ }^{147}$ Decision 1364/2006 established guidelines for trans-European energy networks with an objective to 'support the completion of the [European] Union internal energy market while encouraging the rational production, transportation, distribution and use of energy resources, to reduce the isolation of less-favoured and island regions, to secure and diversify the Union's energy supplies, sources and routes, including through cooperation with third countries, and to contribute to sustainable development and protection of the environment'.
} 

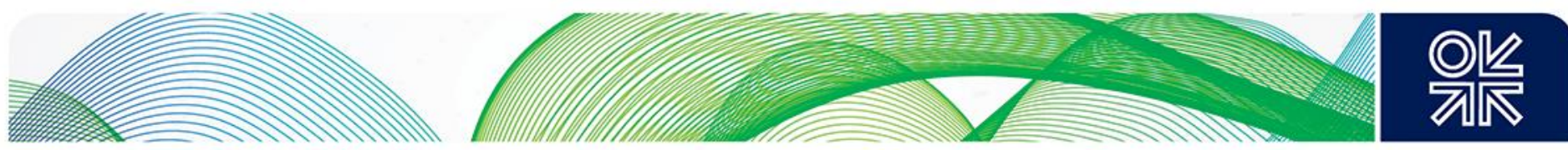

According to Gas Regulation 715, ACER is obliged to review the TSO's ten-year network development plans to 'assess their consistency' with the EU TYNDP. Should ACER identify inconsistencies between the two, it is obliged to 'recommend amending' the national plan or the EU TYNDP 'as appropriate'. (This suggests that ACER would be able to choose which plan to recommend for an amendment.) The Regulation says that if a national NDP was elaborated in accordance with Art. 22 of the Third Gas Directive, ACER is obliged to recommend that 'the competent national regulatory authority' amend the national ten-year NDP in accordance with Art. 22.7.

\section{German draft NDP 2018: 'more capacity' projects}

On 12 February 2018 the German TSOs published the draft German Gas Network Development Plan for 2018-2028 ('Draft NDP 2018'148) for consultation, with market participants being invited to submit their comments by 2 March 2018. ${ }^{149}$ The draft 2018 NDP is based on the scenario framework, which went through a consultation period ending on 14 July 2017 and was subsequently confirmed by the German regulatory authority (BNetzA) on 12 December $2017,{ }^{150}$ with the TSOs being obliged to model two different cases - base case and storage case - by 1 April 2018. ${ }^{151}$ The base case would determine the required additional capacity (projects) whereas the storage case determined the required storage capacity withdrawal in specific load situations arising towards the end of a winter period.

According to the scenario framework, the modelling was based on the existing capacity models of the two market areas - GASPOOL and NCG. It is the TSOs' expectation that the measures proposed in the draft NDP 2018 not only 'will continue to be required even after the market area merger' (GASPOOL and NCG are planned to be merged in one market area by 2022) ${ }^{152}$ but also 'will form the basis for a successful market area merger'. ${ }^{153}$ It is worth noting that the formation of a single German EE zone (a merger of GASPOOL and NCG) is believed to be 'a very political issue' and, even if embarked on, would be time consuming and fraught with serious difficulties. Both GASPOOL and NCG are each operated by six TSOs and, although BNetzA stated that it would see 'the increased benefits of a unified system', it has decided to leave it up to the 12 German TSOs to decide when and whether to proceed with the merger ${ }^{154}$ It would appear that the German TSOs are predominantly against the merger, arguing that its estimated cost of $€ 3$ billion (mostly due to additional transportation capacity that would need to be built for the merger to be possible) would by far outweigh the benefits. Nonetheless, it cannot be ruled out - and it seems likely that despite its high cost and the reluctance of the TSOs, BNetzA may push for the merger if it observes no voluntary action by TSOs in this direction, particularly if it is believed that the present zonal fragmentation might have made the German system's response to the February 2012 shortfall of Russian gas supply more challenging.

One of the main guiding principles for the scenario framework used for the draft NDP 2018 is the ongoing transition from L-gas to H-gas in Germany, which is set to become an increasingly important issue due to declining domestic production of L-gas and cuts in production of L-gas in the Netherlands. ${ }^{155}$ Notably both scenarios assume a reduction in overall gas demand due to efficiency improvements.

\footnotetext{
${ }^{148}$ For Draft NDP 2018 see FNB Gas (2018b).

${ }^{149}$ FNB Gas (2018a).

150 FNB Gas (2018c).

151 lbid.

${ }^{152}$ FNB Gas (2018b). (Draft NDP 2018).

153 lbid.

154 Heather (2012).

${ }^{155}$ Due to the Dutch government's decision to cut gas production ay Groningen towards $12 \mathrm{bcm}$ by $2022-23$ and stop it completely by 2030 , see 'Netherlands to halt gas production at Groningen by 2030 '. For a detailed account of Dutch gas production, see Honore (2017).
} 

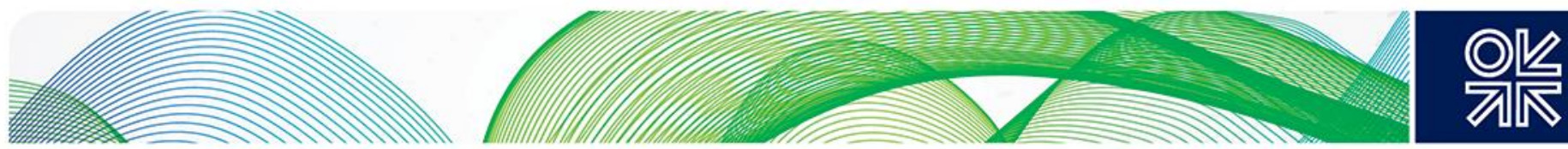

Figure 4: Coverage of additional European requirements to 2035

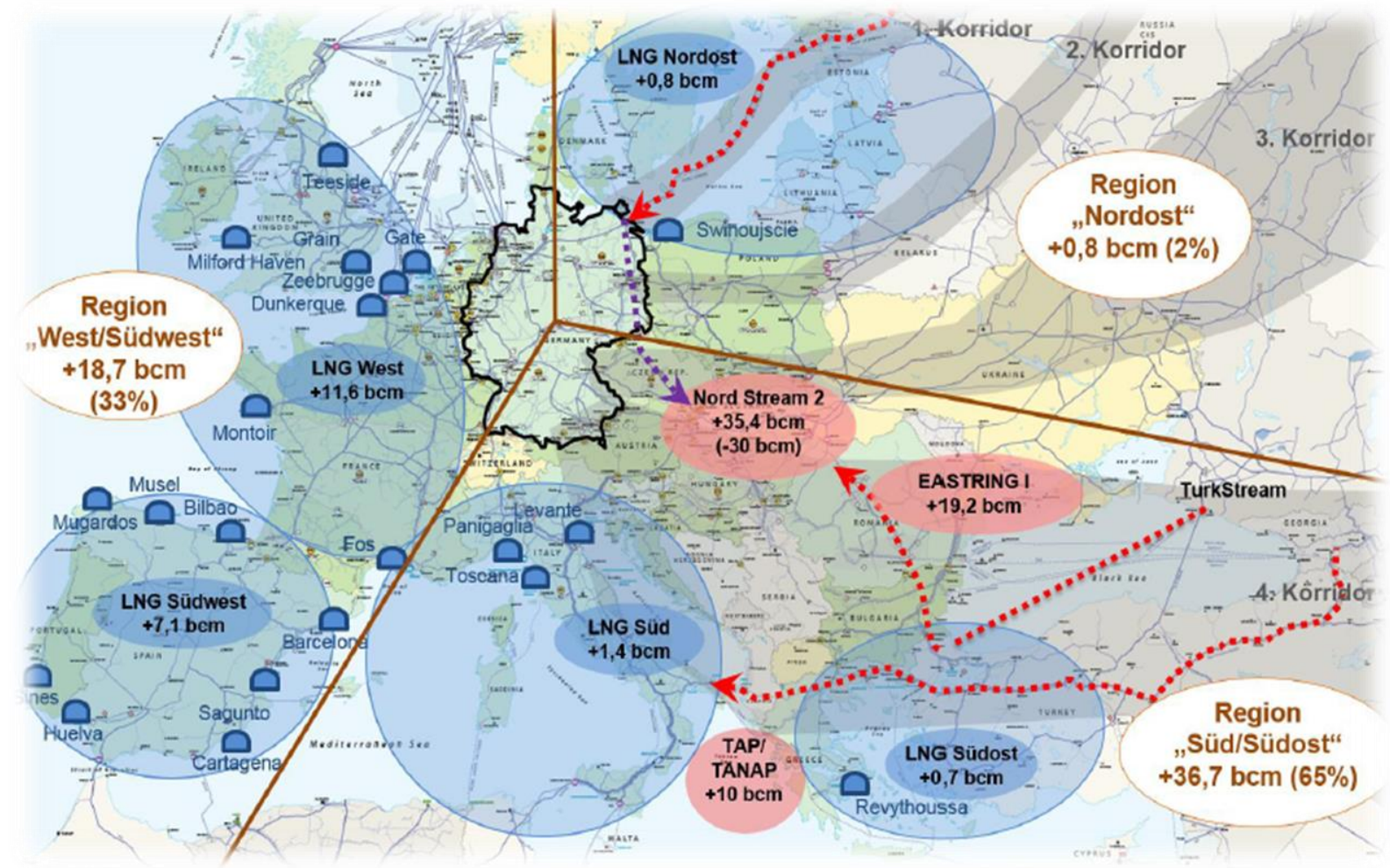

Source: German draft NDP 2018

The scenario modelling was based on the additional capacity requirements for distribution, storage, and gas-fired power plant for the years 2024 and 2029, identified in the draft NDP (Figure 5).

According to the German association of TSOs (FNB), the results of the modelling under the base case scenario have confirmed that while the NDP 2016 projects would allow stable network development, additional projects that were not part of the NDP 2016 will also be necessary during the 2018-28 period. Therefore, not only has the draft 2018 NDP confirmed the NDP 2016 projects (total cost estimated at $€ 3.9$ billion) but it also includes several additional projects, including the EUGAL pipeline. ${ }^{156}$ Overall, the TSOs have proposed the expansion of the existing network by adding $1,390 \mathrm{~km}$ of new pipeline, and installing $508 \mathrm{MW}$ of new compressor, capacity to meet 'the German and central European transportation needs'. ${ }^{157}$

\footnotetext{
156 The EUGAL pipeline project is being developed to transport Russian gas (to be delivered through the - yet to be built - Nord Stream 2 pipeline) from the interconnection point Lubmin II across Germany to the border with the Czech Republic.

${ }^{157}$ Most of these measures are planned to be implemented by 2024, whereas the EUGAL pipeline (and related projects) are planned to be implemented within the time range of end 2019-2022.
} 

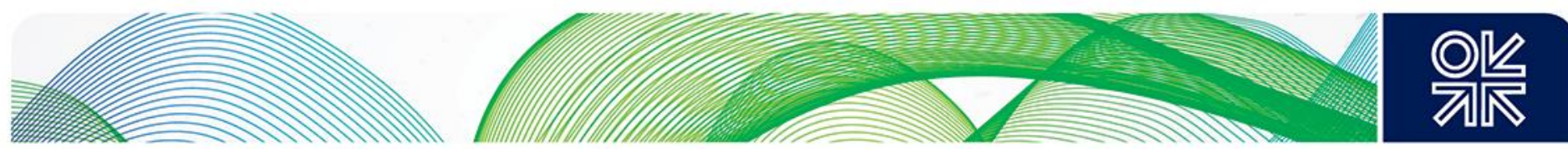

Figure 5: Additional capacity requirements in 2024 and 2029 (compared to 2018): gas-fired power plants, distribution and storage, $\mathrm{GWh} / \mathrm{h}$

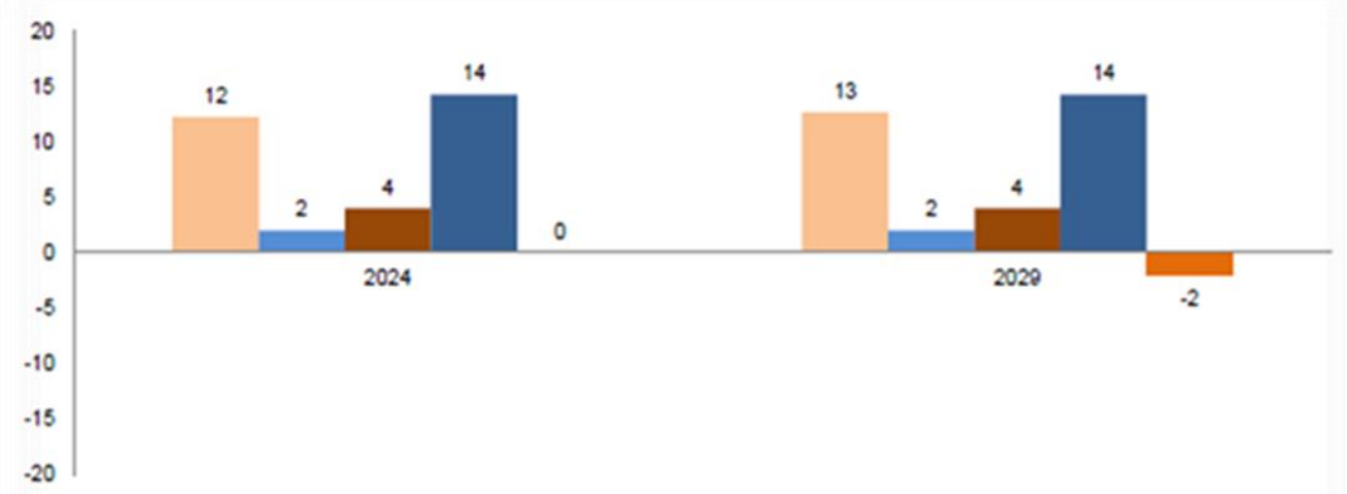

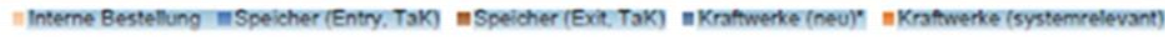

Distribution - Storage (Entry, TaK) - Storage (Exit, TaK) - Power Plants $(\mathrm{New})^{\star}-$ Power Plants (System-relevant) Source: draft NDP 2018, p. 122.

The majority of network expansion projects, which were not part of the NDP 2016, have been identified and proposed for inclusion in the draft NDP 2018 on the basis of market demand assessment and capacity auctions carried out during 2015-17 as part of the 'more capacity' process (see Sections 3.1.1 - 3.1.3). Thus, the draft NDP 2018 lists several 'more capacity' projects including inter alia: the EUGAL pipeline (ID 507-01a), the natural gas receiving station at Lubmin II (ID 412-03), the NEL connection line (ID 50701b), the compressor station VDS Radeland II, as well as several corresponding plants, systems, and facilities. Notably, no projects related to interconnection points between GASPOOL and NCG, GASPOOL and the Netherlands, GASPOOL and Poland have been included in the draft NDP 2018 (Fig. 6).

Thus the EUGAL pipeline (and its associated infrastructure) has emerged as a major addition compared to the NDP 2016, and it is one of the major parts of the draft NDP 2018, with EUGAL's cost being estimated at 2.27 billion euros. ${ }^{158}$ According to the 'more capacity' TSOs, their assumption is that 'the costs of EUGAL can be fully recovered through the capacity tariffs charged to shippers who have booked new capacity created as part of the project', provided that 'the long term capacity booking rate continues at the current level in the future'. 159

The total cost of all projects planned to be implemented under the draft 2018 NDP in the period to 2028 amounts to $\sim 7$ billion euros, of which 6.8 billion euros is to be invested for the requirements of the year 2024 and 0.2 billion euros for the requirements of the year 2029. New projects that are planned to be implemented as part of the draft 2018 NDP in the 2023 and 2028 timeframes are presented on Figures 6 and 7 respectively. Most of these measures are planned to be implemented by 2024, whereas EUGAL is planned to be implemented by the end of 2019 , while its related infrastructure is planned to be completed between the end of 2019 and 2022.

It is worth noting that the first German LNG terminal (Brunsbüttel, near Hamburg), to be operational from 2022 with planned capacity of $\sim 5 \mathrm{bcma}(8.7 \mathrm{GW})$, was also considered during the draft 2018 NDP consultation. ${ }^{160} \mathrm{It}$ was noted that for the terminal's capacity to be realized, an additional $50 \mathrm{~km}$ pipeline would have to be built. The pipeline (Brunsbüttel-Hetlingen) (502-01a), deemed to be an essential expansion measure for the integration of the terminal into the network, has been included in the draft

\footnotetext{
${ }^{158}$ FNB Gas (2018b) (Draft NDP 2018), p. 163.

${ }^{159}$ Transmission system operators expect that the costs of the EUGAL measures will be borne by the proceeds when updating the existing long-term booking level.

${ }_{160}$ More detail about the project is available at 'Vopak's German LNG Terminal': https://www.vopak.com/german-Ing-terminal
} 

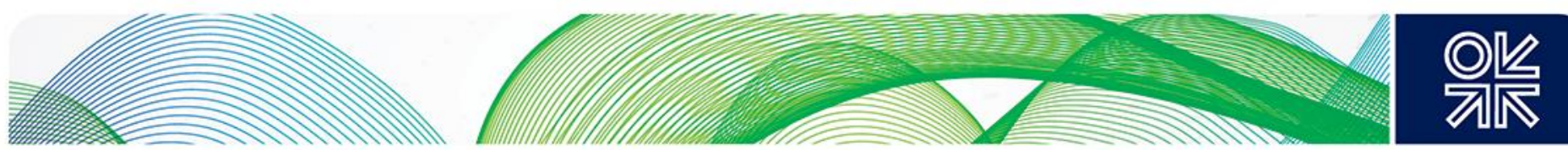

NDP 2018, with Gasunie Deutschland as an operator. The TSOs consider it to be essential that the draft NDP 2018 shows the need for expansion, to facilitate a timely discussion by all involved in the consultation process, as a FID has not yet been taken for the LNG terminal. The TSOs have also noted that further questions remain to be answered in respect of the LNG terminal, such as the choice of capacity products, necessary approvals, and cost. (However, given that at the time of writing the LNG terminal has not taken FID, the likelihood of it being operational from 2022 is low.)

Figure 6: The TSOs network expansion proposal: draft NDP 2018

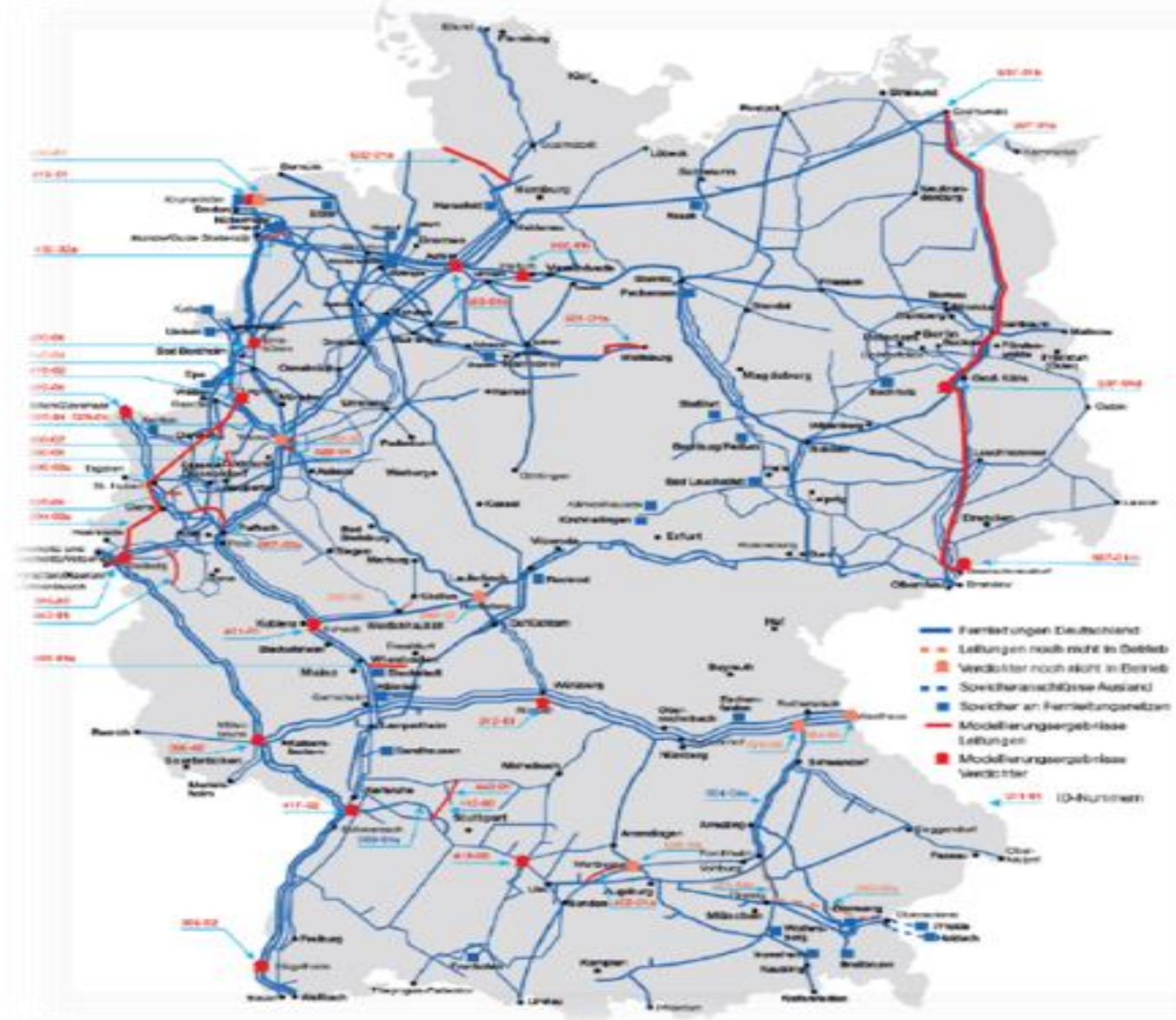

Source: German draft NDP 2018 (FNB Gas (2018b)), p. 166.

\section{German NDP 2016: 'more capacity' projects}

The draft NDP 2018, currently under development with a view of being finalized in late 2018 , is a successor of the NDP 2016, which was adopted in October 2017. The first draft NDP 2016 was published by the German association of TSOs (FNB) on 1 April 2016. ${ }^{161}$ It was preceded by publication of the draft for consultation during 15 February-4 March 2016. ${ }^{162}$ On 3 January 2017 BNetzA issued a decision amending the draft. This decision was based on the ruling, made by the German regional court in Dusseldorf, ordering two additional power plants in Altbach and Heilbronn am Neckar (southern Germany) to be taken into account, following a successful complaint by their operators. ${ }^{163}$ The German TSOs presented the revised draft for public consultation during 27 February-17 March 2017; eight responses

\footnotetext{
${ }^{161}$ FNB Gas (2016b) (First Draft NDP 2016).

162 FNB Gas (2016a) (First Consultation NDP 2016)

${ }^{163}$ FNB Gas (2017a)
} 

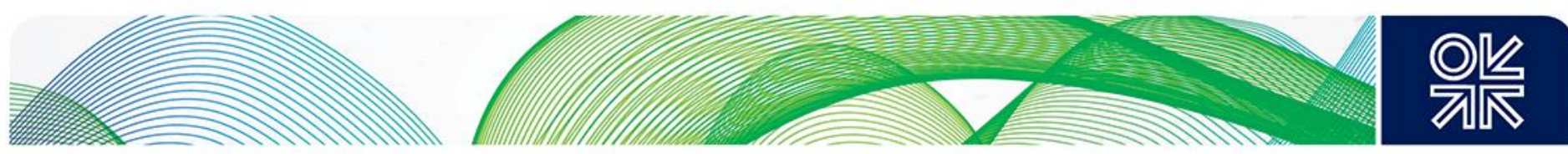

were received. ${ }^{164}$ On 5 April 2017, the second draft NDP 2016 was published and submitted to BNetzA for assessment. ${ }^{165}$ The second draft included an additional $25 \mathrm{~km}$ of pipelines and $16 \mathrm{MW}$ of compressor capacity needed for taking into account the two aforementioned power plants in southern Germany, thus increasing its total cost by 102 million euros, to a total cost of 4.5 billion euros. ${ }^{166}$ According to the existing procedure, BNetzA had run its own consultation on the second draft NDP 2016, after which it would have to be returned to the TSOs, which would then have three months for taking into account BNetzA's recommendations and finalizing the NDP 2016. The final (legally binding) NDP 2016 was published on 16 October 2017.167

The second draft NDP 2016, just like the first draft, was based on the scenario framework, which was initially confirmed by BNetzA on 11 December 2015 and subsequently amended on 3 January 2017, as explained above. ${ }^{168}$ This scenario framework included two cases envisaging different distribution of $\mathrm{H}$ gas supplies - the base case (Q.1) and the alternative case (Q.2). The main difference between the two cases was that Q.2, unlike Q.1, was based on the assumption that the total capacity of the Nord Stream pipelines would be expanded by 65 bcma. ${ }^{169}$ Table 3 demonstrates that case Q.2 provides a more balanced distribution of supplies than case Q.1, with each region (North East, West / South West, South / South East) accounting for around one third of supplies, whereas case Q.1 assumes that nearly 90 per cent of supplies will come from just two regions (West / South West and South / South East). The TSOs have concluded that case Q.2 provides a 'more robust level of supply security' than case Q.1, and argued that by selecting case $Q .2$ they would ensure that they can 'respond to future changes in the development of supply sources available to meet Europe's gas demand'. ${ }^{170}$ Therefore, the TSOs have proposed to implement the projects required under case Q.2, which is based on the additional capacity available after Nord Stream expansion, to meet the increased demand for H-gas in Germany.

Notably, although neither EUGAL nor other infrastructure projects related to it (for example the receiving terminal in Lubmin II and the connection to NEL) were made part of the final NDP 2016; the FNB has stated that 'in relation to the Nord Stream 2 project, the TSOs plan to publish an addendum to the NDP 2016 once all permits and approvals required for the construction and operation of the new pipeline are available (including planning approval for the project and permits under German federal mining law)'. ${ }^{171}$ (As noted earlier, the last required approval in respect of Nord Stream 2 pipelines was received on 27 March 2018.) It has further stated that the 'addendum will then include all those projects described in the previous draft [in other words the first draft NDP 2016] that were removed for the purposes of the final NDP 2016'. ${ }^{172}$

\section{Table 3: Supplies distribution in the NDP 2015 by region and the modelling cases for the NDP} 2016: Q.1 and Q.2

\begin{tabular}{|c|c|c|c|}
\hline Region & 2015 NDP. Per cent & Base case Q.1 & Alternative Case Q.2 \\
\hline North East & 11 & 7 & 42 \\
\hline West / South West & 30 & 34 & 32 \\
\hline South / South East & 59 & 59 & 26 \\
\hline
\end{tabular}

Source: adapted from the draft NDP 2016.

\footnotetext{
164 FNB Gas (2017b) (Second Consultation NDP 2016).

${ }^{165}$ FNB Gas (2017e) (Second Draft NDP 2016).

${ }^{166}$ FNB Gas (2017d).

167 FNB Gas (2017h) (NDP 2016).

${ }^{168}$ FNB Gas (2018c).

169 It is understood that this figure includes capacity expansion of the existing Nord Stream 1 pipelines by 5 bcma and new

capacity of the yet-to-be-built Nord Stream 2 pipelines.

170 FNB Gas (2018c)

${ }^{171}$ FNB Gas $(2017 \mathrm{~g})$.

172 lbid.
} 

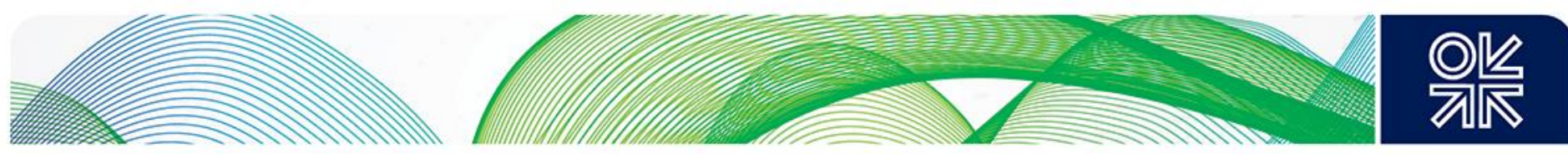

Notably, on 31 March 2017 the German TSOs published a report on implementation of the 2015 NDP and a statement on long-term capacity requirements in the GASPOOL and NCG market areas. ${ }^{173}$ The report provides information on the progress achieved in implementing the projects that were part of the NDP 2015 and the second draft NDP 2016 (as the final NDP 2016 was only published in October 2017 and hence not available when the implementation report was prepared). The statement provides an assessment of the development of capacity requirements in the GASPOOL and NCG market zones. Notably, the statement concluded that the results of the March 2017 auctions - where inter alia the EUGAL capacity was auctioned - confirm that it 'will be necessary' to build the planned EUGAL pipeline, which is 'to come online at the end of 2019'. ${ }^{174}$

\section{EU TYNDP 2017: the 'more capacity' projects}

Gas Regulation 715 (Art. 12) obliges the European Network of TSOs (ENTSOG) to adopt a non-binding Community-wide ten-year network development plan (TYNDP) every two years (Art. 12). The most recent TYNDP was published in April 2017. ${ }^{175}$

Despite the fact that projects developed as part of the 'more capacity' process had not been included into the final NDP 2016, they were included in TYNDP 2017 because they were part of the draft NDP 2016 and their importance was demonstrated through modelling of supply options under alternative scenario Q.2, which assumed the Nord Stream expansion. In particular, TYNDP 2017 includes inter alia the following projects (see Figure 7):

- $\quad$ EUGAL (TRA-N-763) (expected commissioning 2019, advanced non-FID),

- $\quad$ NEL expansion (TRA-N-807) (expected commissioning in 2020, advanced non-FID),

- $\quad$ transport of gas volumes to the Netherlands (TRA-N-808) (expected commissioning in 2021, advanced non-FID),

- $\quad$ upgrade of interconnections points at Deutschneudorf (German-Czech border) and Lasów (German-Polish border) (TRA-N-814) (expected commissioning in 2019, advanced nonFID), ${ }^{176}$

- $\quad$ extension of the receiving terminal at Greifswald (TRA-F-768) (expected commissioning in 2017),

- $\quad$ Nord Stream 2 (TRA-F-937) (expected commissioning in 2019, FID).

It is worth noting that several projects, for example NEL expansion and transport of gas volumes to the Netherlands (which are part of TYNDP 2017), have not been included into the draft 2018 NDP. (Notably, NEL expansion also does not appear to be part of the draft TYNDP 2018 project list. ${ }^{177}$ )

The TYNDP 2018 development process is ongoing and is expected to be completed by the end of 2018 . It is not clear whether the NDP 2018 will be completed prior to the completion of the TYNDP 2018. Should the NDP 2018 be completed ahead of the TYNDP 2018, and should the former include EUGAL (and its associated infrastructure), the latter would also include it. Should the NDP 2018 not be completed ahead of the 2018 TYNDP, the latter is also likely to include EUGAL (and its associated infrastructure), given its inclusion in the draft 2018 NDP and given the pending NDP 2016 addendum, which is expected to include EUGAL (and its related infrastructure).

\footnotetext{
${ }^{173}$ FNB Gas (2017c)

174 Ibid.

175 TYNDP 2017 (ENTSOG (2017a, Annex A - Project List); NW GRIP 2017 (ENTSOG (2017c), pp. 102-6).

176 TYNDP 2017 states that the project was not yet part of the draft German NDP 2016, whereas BNetzA by decree of 11

December 2015 had ordered the German TSOs to only model a $42 \%$ coverage of the expected additional national demand from

North East in the scenario Q2 including Nord Stream 2, but no further flows at IPs.

177 ENTSOG (2018), Annex A - Project List.
} 

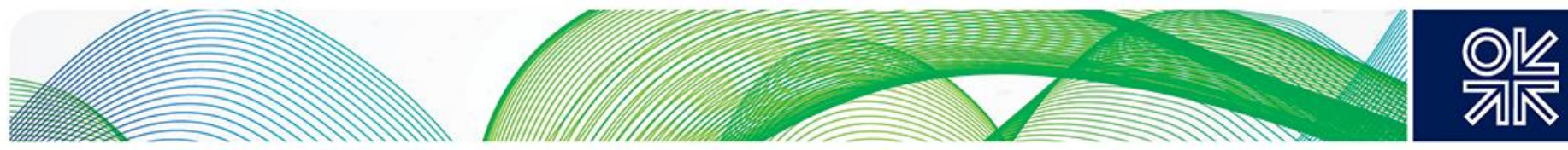

Figure 7: TYNDP 2017 project map Germany

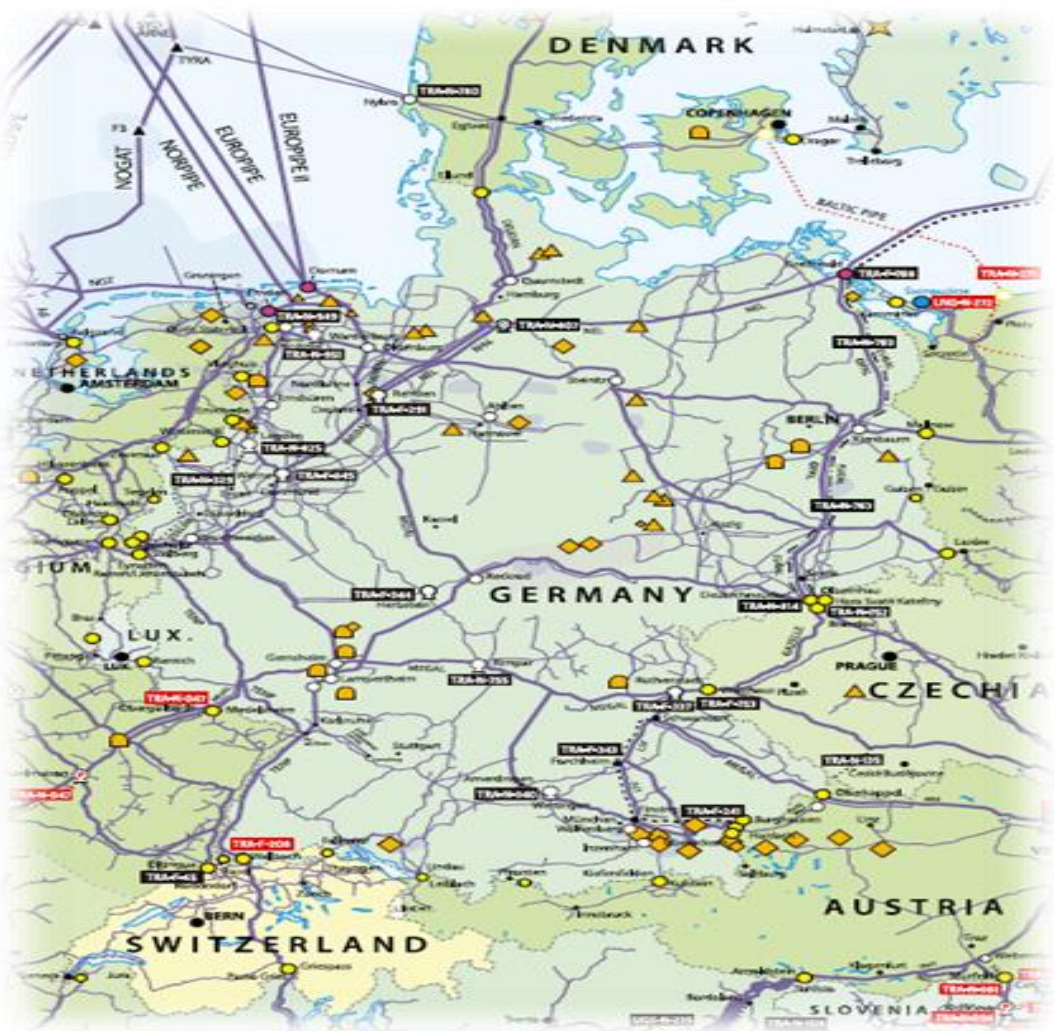

Source: ENTSOG (2017c) (NW GRIP 2017 Europe main report).

NWE and CEE Gas Regional Development Plans (GRIPs): 'more capacity' projects

Under the Third Gas Directive (Art. 7) and Gas Regulation 715 (Art. 12), the EU TSOs, from various EU regions are obliged to develop and publish Gas Regional Development Plans (GRIPs), every two years. The most recent set of GRIPs was published in 2017.178

The 2017 GRIPs were based on the TYNDP 2017 and on the existing national NDPs. As Germany is a member of both the North West European region (alongside Belgium, Denmark, France, Ireland, Luxembourg, the Netherlands, Sweden, and the UK) and the Central East European region (alongside Austria, Bulgaria, Croatia, the Czech Republic, Hungary, Poland, Romania, Slovakia, and Slovenia), its TSOs have participated in the development of both NWE and CEE GRIPs. Importantly, the 2017 GRIPs include the 'more capacity' projects. In particular, the German section of the NWE GRIP 2017 includes inter alia: ${ }^{179}$ EUGAL (TRA-N-763), the NEL expansion (TRA-N-807), the transport of gas volumes to the Netherlands (TRA-N-808), and the upgrading of interconnection points at Deutschneudorf and Lasów. The Dutch section of the NWE GRIP 2017 includes inter alia:180 the reinforcement investment in respect of interconnection point Oude Statenzijl at the Dutch-German border to increase the entry capacity of the Dutch gas transmission network (GTS), in order to accommodate increased gas flows. As noted above, the German draft 2018 NDP does not include either the project concerned with NEL expansion or the project involving the transport of gas to the Netherlands.

This analysis of the legal basis of EU-level, regional, and national NDPs suggests that the EU-level (TYNDP) and regional (GRIPs) NDPs are secondary to the national NDPs, as the former two are largely based on the latter. Although the EU acquis stipulates that the TYNDP and the national NDPs must be

\footnotetext{
178 ENTSOG (2017b).

${ }^{179}$ NW GRIP 2017 (ENTSOG (2017c)).

180 NW GRIP 2017, (ENTSOG (2017c), p. 114.
} 

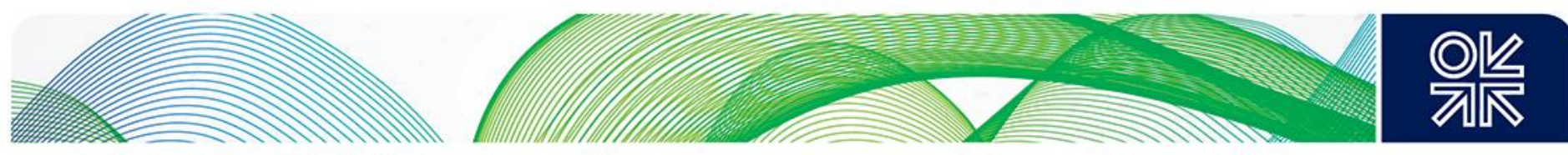

consistent, and envisages that both the NRAs and ACER will play a role in ensuring such consistency, it would appear that should the NRA approve the inclusion of any project into the national NDP, both ACER and the EC would only have very limited possibilities of preventing it from being included in the TYNDP. However, the opposite is not true, in other words it would appear to be impossible to include a project into the TYNDP (or GRIP) without the project being included into the national NDP. This suggests that should the EUGAL pipeline (and the associated 'more capacity' infrastructure) be made part of the German NDP 2018, it would be extremely difficult - most likely impossible - for either ACER or the EC to prevent it from being included in the TYNDP. Overall, should the EUGAL pipeline receive all the applicable approvals at the national level and should it be made part of the NDP 2018, it is difficult to imagine a scenario under which it would not be built, unless Nord Stream 2 (to which EUGAL connects and without which it has no rationale) is cancelled.

\section{Conclusions}

The EUGAL pipeline was developed under the 'more capacity' procedure, which appears to have been modelled closely on both the GGPOS and the available working drafts of the (then under development) CAM NC. As a result, the procedure is broadly in line with the final CAM NC, mirroring many of its provisions, including those on market survey, demand assessment, public consultation, design phase, and legally binding capacity auctions (Section 2.1). By the time the CAM NC entered into force on 6 April 2017, the 'more capacity' procedure had been completed, with legally binding auctions for existing and incremental capacity being held on PRISMA on 6 March 2017 - capacity in EUGAL from the end of 2019 until the end of 2039 was auctioned. This period tallies with a 20 -year booking period, consistent with the CAM NC (which stipulated a 15-year booking horizon but allowed this to be exceptionally extended by a further five years, where the alternative allocation mechanism is used and the economic test cannot be met otherwise). The usage of the 'more capacity' procedure - which is essentially a 'hybrid' auction procedure whereby an auction is preceded by an open season - prior to the CAM NC's entry into force was fully legitimate when no legally binding framework existed at the EU level. Notably, although it is understood that no regulatory approvals for capacity allocation procedures were required under German and EU law at the time, the 'more capacity' TSOs were coordinating with the German regulatory authority closely during all stages of the process. Neither the German regulatory authority nor the EC has raised any concerns in this respect. EUGAL is expected to be included in the German NDP 2018 and, subsequently, in the TYNDP. Its first string is scheduled to become operational at the end of 2019, thus tallying up with Nord Stream 2, the first string of which is also expected to become operational in this timeframe. Given that the capacity allocation provisions (stipulated by the 'more capacity' procedure) were in line with the GGPOS and were not vastly different from, and broadly consistent with, the procedures being developed as part of the (then under development) CAM NC, neither the EC nor the German regulatory authority would be in a strong position to request a significant change in the regulatory treatment of EUGAL.

\subsection{The Exemption Regime: the OPAL pipeline ${ }^{181}$}

\subsubsection{The Nord Stream 1 and OPAL pipelines}

Nord Stream 1 is a new gas export pipeline system, built in the early 2010s, which transports Russian gas from the St Petersburg region to northern Germany, under the Gulf of Finland and the Baltic Sea; it is a key element of Gazprom's transit diversification strategy, adopted in the early 2000s in respect of its gas exports to Europe. ${ }^{182}$ It is owned by Russia's Gazprom (51 per cent) and its European partners (Germany's E.ON (now Uniper) and Wintershall both 15.5 per cent, the Netherlands' Gasunie - 9 per cent, and France's Engie - 9 per cent). Nord Stream 1 consists of two offshore pipelines (27.5 bcm each) connecting Russia (Portovaya Bay near Vyborg) and Germany (Lubmin, near Greifswald). The first pipeline became operational in 2011 and the second in 2012 (Figure 8).

\footnotetext{
${ }^{181}$ This section provides a summary of the EC OPAL Exemption Decision (see EC, 2016a)), based on the detailed analysis of the EC OPAL Exemption Decision, Yafimava (2017a).

182 Blue Stream, Yamal-Europe, and South/Turkish Stream being the others.
} 

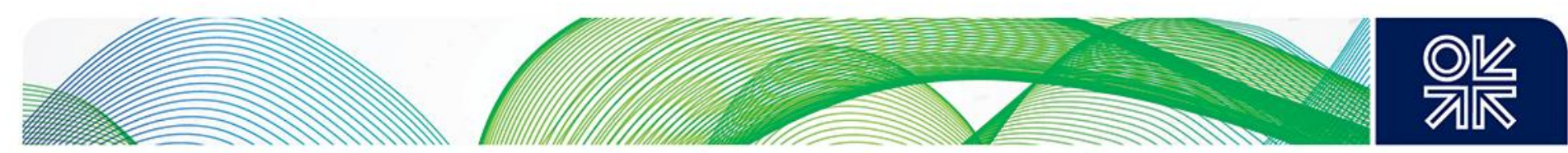

Figure 8: Nord Stream 1, OPAL, and NEL pipelines

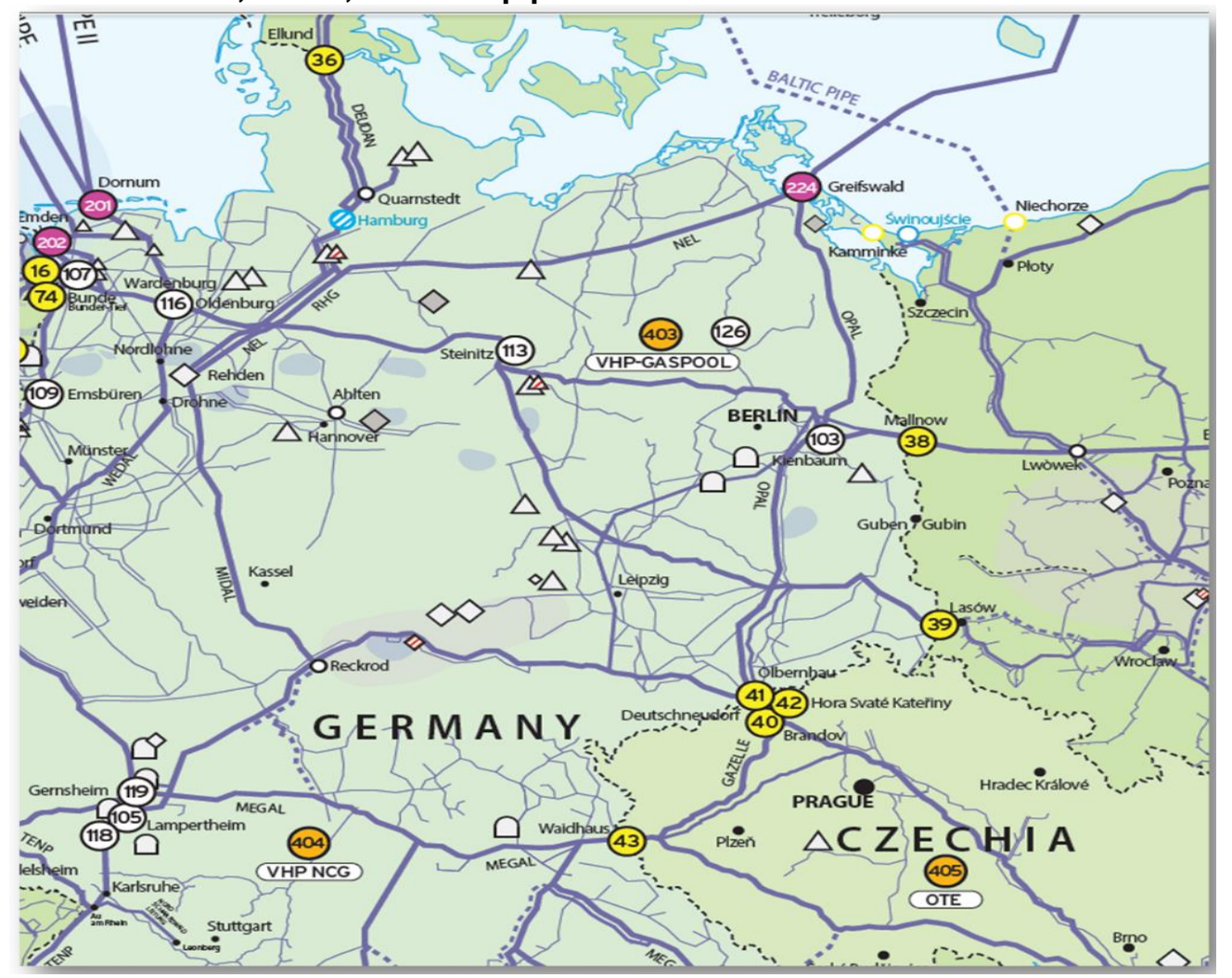

Source: ENTSOG website (adapted)

At the Greifswald receiving terminal, the Nord Stream 1 offshore pipelines connect with two onshore pipelines - OPAL and NEL - which transport gas from Russia onwards to European customers. The terminal consists of two sections: the 'offshore section' for the incoming Nord Stream 1 offshore pipelines and an 'onshore section' for OPAL and NEL. OPAL $(36.5 \mathrm{bcm})$ has been in operation from October 2011 and NEL (21.8 bcm) since late 2013 (Figure 8).

OPAL transports Nord Stream 1 gas $470 \mathrm{~km}$ southwards across Germany to Olbernhau/Brandov at the German-Czech border - from where it is transported by the Gazelle pipeline across the Czech Republic to Waidhaus at the Czech-German border. OPAL consists of two sections: OPAL-Nord and OPAL-Süd.

OPAL-Nord connects Lubmin/Greifswald to Groß Köris/Brandenburg (south of Berlin), where it links into the GASCADE Gastransport system.

OPAL-Süd connects Groß Köris/Brandenburg to Olbernhau/Brandov at the German-Czech border (Figure 8).

The entry capacity of OPAL-Nord is $36.5 \mathrm{bcm}$ whereas the exit capacity at Groß Köris/Brandenburg is $4.5 \mathrm{bcm}$, thus resulting in $32 \mathrm{bcm}$ entry capacity in OPAL-Süd.

NEL transports Nord Stream 1 gas from Lubmin $440 \mathrm{~km}$ westwards in Germany to Rehden, where it is linked with the Rehden-Hamburg pipeline (part of the MIDAL system), where it further connects to the gas transport networks of WIGA and Uniper. ${ }^{183}$

${ }^{183}$ Formerly E.ON Ruhrgas. 

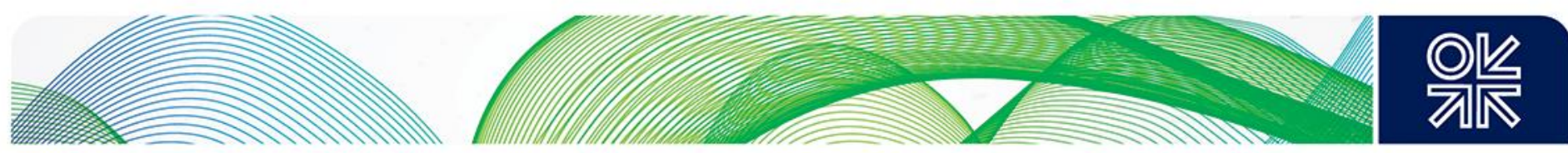

OPAL Gastransport is the operator of the OPAL pipeline and NEL Gastransport is the operator of the NEL pipeline. ${ }^{184}$ OPAL Gastransport is the majority shareholder in OPAL with an 80 per cent share, whereas the remaining 20 per cent share is owned by Lubmin-Brandov Gastransport (LBTG), which is an infrastructure affiliate of Uniper. NEL is owned by NEL Gastransport, Gasunie Deutschland (formerly GOAL), and Fluxys Deutschland. ${ }^{185}$ Gazelle, which connects with OPAL at Brandov at the German-Czech border and transports gas across the Czech Republic to Waidhaus at the Czech-German border before connecting into the GASCADE Gastransport system, is operated by RWE Transgas.

\subsubsection{The 2009 Exemption Decision and OPAL underutilization}

Although Nord Stream 1 has been in operation since 2011, Gazprom's ability to utilize its full capacity had remained limited for nearly seven years due to a regulatory cap, imposed by the European Commission (EC) by means of the exemption decision, adopted in June 2009, which prevented Gazprom from being able to utilize more than 50 per cent of OPAL capacity. ${ }^{186}$ The exemption decision is analysed below.

In 2008 OPAL NEL Transport and (then) E.ON Ruhrgas applied to the German regulatory (BNetzA) for two separate exemptions from regulated TPA (Art. 18) and tariffs (Art. 25.2, Art. 25.3, Art. 25.4) in respect of the OPAL and NEL pipelines under Art. 22 of the Second Gas Directive. On 25 February 2009 BNetzA issued two decisions: one to OPAL NEL Gastransport and another to E.ON. Ruhrgas. (Given that OPAL NEL Gastransport was later separated into OPAL Gastransport and NEL Gastransport, and E.ON Ruhrgas's shares in OPAL were transferred to Uniper's affiliated LBTG, this paper refers to these exemptions as 'OPAL Gastransport exemption decision' and 'LBTG exemption decision'.) BNetzA granted a partial exemption to OPAL - an interconnector - which was to apply to transportation of gas through OPAL from Nord Stream 1 directly to the German-Czech border at Olbernhau/Brandov and exclude 'domestic transports and possible reverse flow transports from the Czech Republic to Germany'. ${ }^{187}$ The exemption was granted for 22 years from OPAL's start of operation. NEL - being a domestic transmission pipeline as opposed to an interconnector - was refused an exemption and had to be operated as a fully regulated pipeline.

BNetzA's OPAL Gastransport decision covered 31,729,064 kWh/h ( 25.4 bcma) of entry capacity at Greifswald and exit capacity at Brandov (that would be offered as BZK, in other words coupled capacities) out of OPAL Gastransport's total technical capacity of $36,315,801 \mathrm{kWh} / \mathrm{h}(\sim 29.1 \mathrm{bcma})$. The remaining $4,586,737 \mathrm{kWh} / \mathrm{h}(\sim 3.7 \mathrm{bcma})$ would be regulated (and offered as DZK, in other words separately bookable dynamically allocable capacities). ${ }^{188}$

The LBTG exemption decision covered 7,932,260 kWh/h ( 6.3 bcma) of entry capacity at Greifswald and exit capacity at Brandov (that would be offered as BZK) out of LBTG's total technical capacity of $9,078,944$ $\mathrm{kWh} / \mathrm{h}(\sim 7.3 \mathrm{bcma})$. This suggests that the remaining 1,146,684 $\mathrm{kWh} / \mathrm{h}(\sim 1 \mathrm{bcma})$ would be regulated (and offered as DZK).

The combined OPAL Gastransport and LBTG exempted BZK capacities thus equals the exit capacity at Brandov $(31,729,064+7,932,260=39,661,324 \mathrm{kWh} / \mathrm{h} \sim 31.7 \mathrm{bcma})$. The combined OPAL Gastransport and LBTG regulated capacities equals the exit capacity at Groß Köris/Brandenburg $(4,586,737$ + $1,146,684=5,733,421 \mathrm{kWh} / \mathrm{h} \sim 4.6 \mathrm{bcma}$ ).

\footnotetext{
${ }^{184}$ OPAL Gastransport and NEL Gastransport - together with GASCADE Gastransport - are part of WIGA Transport, indirectly owned and jointly controlled by Wintershall and Gazprom.

185 Uniper sold its share in NEL Gastransport.

${ }^{186}$ EC (2016a) - EC OPAL Exemption Decision.

${ }^{187}$ Due to the fact that OPAL NEL Gastransport was later separated into OPAL Gastransport and NEL Gastransport, and E.ON Ruhrgas's shares in OPAL were transferred to Uniper's affiliate LBTG. This paper refers to these two exemptions as 'The February 2009 OPAL Gastransport exemption decision' and 'The February 2009 LBTG exemption decision' respectively. 188 The data on exempted capacities stated below reflects our understanding based on references made by the EC in its subsequent decisions.
} 

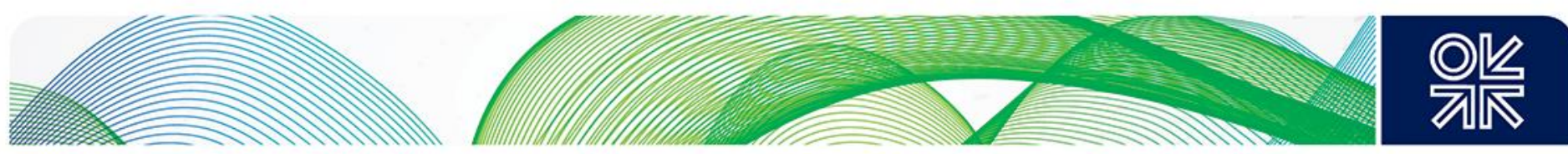

On 13 March 2009 BNetzA notified its draft decisions to the EC for assessment under Art. 4 of the Second Gas Directive. ${ }^{189}$ On 12 June 2009, after a three-month consideration period, the EC requested the draft OPAL Gastransport decision to be amended. ${ }^{190}$ While the EC accepted BNetzA's reasoning that OPAL meets most of the exemption criteria under Art. 22.1 of the Second Gas Directive, the EC disagreed with its reasoning in respect of the OPAL's impact on competition under Art. 22.1.a and Art. 22.1.e., which require enhancement of, and lack of detrimental effect on, competition. In its draft decision, BNetzA argued that the exemption would lead to improved competition in the Czech downstream wholesale gas market and would have no impact - positive or negative - on competition in the German market. However, the EC decided that the exemption would have a negative impact on competition in the Czech downstream wholesale market and alleged that BNetzA did not provide 'sufficient evidence' that competition there would improve. Furthermore, the EC concluded that the exemption could worsen competition in the Czech upstream wholesale market (based on the argument that no other producing countries apart from Russia would be able to supply gas to the Czech Republic at 'comparable conditions and without the difficulties of transport'), and that the exemption would reinforce Gazprom's position. In so doing, the EC rejected the argument that the producer (upstream) market should be considered as being at least EU-wide, on the basis that it would not take 'sufficient account of the different market conditions in Europe and obstacles facing Czech customers' in accessing non-Russian gas supplies. The EC also cited concerns expressed by the Czech regulatory authority (ERU) in this respect.

In short, the EC concluded that BNeztA's OPAL Gastransport draft decision did not provide 'sufficient evidence' that the exemption would have 'positive effects on competition' in the Czech downstream wholesale market and provided no 'required certainty' that it would not result in Gazprom's strengthened competitive position on the Czech upstream wholesale market. On that basis, it concluded that the draft decision did not meet the exemption criteria set under Art. 22.1.a and Art. 22.1.e, ${ }^{191}$ and requested it to be amended by imposing a 50 per cent cap on the amount of OPAL's exit capacity at Brandov $(31,729,064$ $\mathrm{kWh} / \mathrm{h}(\sim 25.4 \mathrm{bcma}))$ that could be booked by Gazprom (or any dominant undertaking), thus reducing it to $15,864,532 \mathrm{GWh} / \mathrm{h}(\sim 12.7 \mathrm{bcma}) .{ }^{192}$ The EC stated that the cap would be lifted should Gazprom agree to conduct gas and capacity release programmes - in other words, offering $3 \mathrm{bcm}$ of gas to a market in an open, transparent, and non-discriminatory manner while also guaranteeing corresponding transport capacity with a freely selectable exit point. On 7 July 2009, having decided to comply with the EC's request, ${ }^{193}$ BNetzA published an amended exemption decision, ${ }^{194}$ fully in line with the EC decision.

Given that OPAL entry capacity is only of interest to Gazprom - as it is the only shipper with gas at Greifswald - a significant part of capacity in OPAL, construction of which was completed in late 2011 in time to receive gas from the first string of Nord Stream1, remained underutilized due to Gazprom's use of OPAL's exit capacity at Brandov being capped at 50 per cent $(\sim 12.73 \mathrm{bcm})$. As demonstrated by this author previously, apart from short periods when restricted capacity was used, the overall median level of utilization of total technical capacity at Greifswald/OPAL in 2013 was around 52.9 per cent $(24 \mathrm{GWh} / \mathrm{h}$

\footnotetext{
${ }^{189}$ The two-month period stipulated by the Second Gas Directive (see Additional documents), was extended by one month, with the EC seeking additional information from BNetzA and the Czech regulatory authority (ERU) in the wake of third parties' negative comments on the draft decision.

${ }^{190}$ The EC has approved the February 2009 LBTG exemption decision in its entirety, which meant that NEL would be fully subject to regulation.

${ }^{191}$ As noted in Section 2.2, neither the Second Gas Directive (see Additional documents) - nor the Third Gas Directive (see Additional documents) which has subsequently repealed it - provided any quantitative criteria for granting an exemption -

including in respect of its impact on competition - thus enabling the EC to exercise a significant degree of discretion while making its assessment of the OPAL exemption's impact on competition.

${ }^{192}$ As long as gas entering OPAL at Greifswald was owned by Gazprom Export and there was no ownership change before the gas exited at Brandov, the cap, de facto, would have an effect only on Gazprom's capacity bookings.

${ }^{93}$ BNetzA had a choice of either complying with the EC request (thus amending its draft decision accordingly) or else cancelling an exemption altogether.

194 Notably, in 2011 Gazprom agreed the main principles of a gas release programme with BNetzA, but had subsequently decided not to participate.
} 

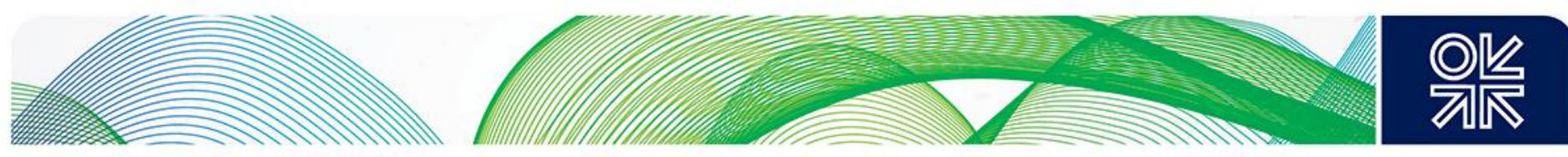

out of $45.4 \mathrm{GWh} / \mathrm{h}$ ) whereas the level of utilization of exempted and restricted technical capacity was 60 per cent $(24 \mathrm{GWh} / \mathrm{h}$ out of $39.7 \mathrm{GWh} / \mathrm{h}) .{ }^{195}$ Correspondingly, Nord Stream 1 itself - the first string of which became operational in late 2011 and the second in late 2013 - also remained underutilized.

\subsubsection{The October 2013 settlement agreement: failed attempt to find a solution}

Persistent underutilization of OPAL's entry capacity in 2012-13 enabled Gazprom to argue that the EC decision to deny it full access to OPAL capacity was illogical, because no other supplier had additional gas available at Greifswald to deliver into OPAL. As demonstrated by this author previously, data on physical flows supported Gazprom's argument. ${ }^{196}$ After nearly three years of negotiations, the EC and Gazprom reached a compromise solution that would have allowed Gazprom to use 100 per cent of OPAL capacity - without triggering the release programme - unless it was required by third parties. The interest of third parties was to be determined through an auction on the European capacity trading platform, PRISMA, where both Gazprom and third parties would be allowed to bid.

On 31 October 2013 BNetzA, OPAL Gastransport, Gazprom, and Gazprom Export concluded a settlement agreement to this effect. The agreement had to be approved by the EC so that the June 2009 exemption decision could be amended accordingly. By that time, the Second Gas Directive - under which the exemption was granted - had been repealed by the Third Gas Directive. Therefore, the EC had to assess the settlement agreement under Art. 36 of the Third Gas Directive rather than under Art. 22 of the Second Gas Directive as had been done previously. Notably, the Third Gas Directive allows more time for assessment - at least four months but potentially more (Art. 36.9) compared to the Second Gas Directive (Section 2.2). Nonetheless, despite the ample time provided, the EC repeatedly delayed its assessment. On 28 February 2014, OPAL Gastransport announced postponement of OPAL capacity auctioning on PRISMA - originally scheduled for 3 March 2014 - with no new date being provided. Meanwhile the EC continued to postpone its decision, citing unspecified 'technical aspects' but providing no specific reasons for the delay. This was especially puzzling given that the EC is understood to have participated in negotiations of the substantive changes, incorporated into the settlement agreement, and had verbally approved it. With the agreement set to expire at the end of 2014, Gazprom - by then having waited more than a year for the EC's assessment - decided not to extend the deadline, thus causing the agreement to lose validity. In turn, the agreement's expiry enabled the EC to consider the substantive changes made to the agreement void, and subsequently terminate the process of its assessment. It is possible that the EC - well aware of the agreement's expiry date - was postponing its assessment until that date to avoid making any decision.

It is open to interpretation why the EC took more than a year to conduct the assessment, which it ultimately failed to complete. This could be due to a sharp deterioration of political relations between the EU and Russia in the aftermath of the 2014 Ukraine political and security crisis. In particular, the EC might have been unwilling to approve the amended exemption decision, which would have been seen as a benevolent gesture towards Russia, at a time when the EU was introducing various political and economic sanctions and declaring a policy of reducing its dependence on Russian gas. However, the EC has repeatedly denied that politics was a reason for delays. Notably, had the EC been willing to approve the October 2013 settlement agreement, it had ample time to do so before March 2014, when the EU-Russia political relationship deteriorated. It is possible that commercial considerations were also at play as, due to Gazprom's limited ability to utilize OPAL capacity in full, European traders were able to transport gas from GASPOOL and utilize exit capacity at Brandov at a time (2014) when there was a growth of commercial gas flowing into the Czech Republic, when Gazprom's long-term contract gas exports to the Czech Republic fell sharply. ${ }^{197}$

The Gazprom rationale for deciding not to extend the settlement agreement deadline is also unclear. It is possible that Gazprom had interpreted the EC's prolonged delay in making the assessment of the

\footnotetext{
195 Yafimava (2017a), pp. 8-9, 12-13.

${ }^{196}$ Ibid.

${ }^{197}$ Due to the suspension of the long-term contract which was subsequently reinstated.
} 

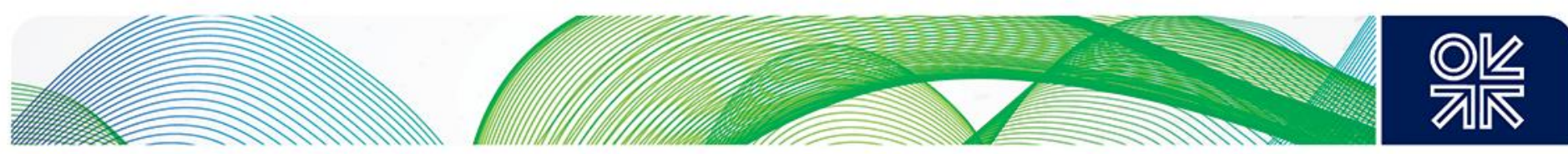

agreement as a de facto refusal to approve it before the end of 2014, and simply decided to accept it as such. Given that the EC's approval would have allowed Gazprom to re-route some of its European exports via Nord Stream 1 in the event of a transit crisis with Ukraine during the winter of 2014-15, by deciding not to extend the agreement, Gazprom might have wanted to signal to the EC that should there be such a crisis, the EC would bear significant responsibility, as it would be seen as having failed to approve the agreement, which would have significantly reduced the impact of any such crisis. The likelihood of such a crisis was not insignificant at the time, given that a trilateral EC-Russia-Ukraine 'winter package', signed in October 2014, was deemed to be necessary.

Due to the EC's failure to approve the October 2013 settlement agreement, Gazprom continued to be unable to use more than 50 per cent of OPAL capacity, even though there was no other demand for this capacity on the part of third parties. In 2014, physical flows via OPAL's entry at Greifswald were mostly at the level of 24-25 GWh/h, which corresponded to the level of combined exempted capacity for OPAL Gastransport and LBTG, thus suggesting that OPAL Gastransport's restricted entry capacity at Greifswald was hardly used. In 2014, as in 2013, physical flows exiting Brandov were still largely within the 25-34 GWh/h range, suggesting that the level of capacity utilization remained within $~ 63-83$ per cent. ${ }^{198}$ Exit flows out of Brandov remained higher than entry flows into Greifswald by some $5-9 \mathrm{GWh} / \mathrm{h} .{ }^{199}$

\subsubsection{The 2016 Exemption Decision: reaching the settlement and increased OPAL utilization}

As Gazprom failed to secure an amendment of the July 2009 exemption decision, it decided to hold an auction for its gas to be sold at Greifswald during 7-10 September 2015. Out of $3.2 \mathrm{bcm}$ offered, around $1.2 \mathrm{bcm}$ was sold, of which only $0.17 \mathrm{bcm}$ was sold with delivery via OPAL. This result provided Gazprom with additional evidence of the lack of third-party interest in entry capacity at Greifswald. Gazprom held another auction during 31 August-2 September 2016 which displayed similar results. According to Gazprom's deputy CEO, Alexander Medvedev, out of around $2 \mathrm{bcm}$ being sold 'not a single lot was sold at the OPAL direction'. 200

Given that the EC's raison d'être for the 50 per cent cap on Gazprom's access to OPAL capacity was to promote competition and allow access for third parties, the results of the auctions made the EC decision look increasingly illogical, strongly suggesting that it was based on non-regulatory considerations. Meanwhile, in 2015 the level of utilization of OPAL's entry capacity at Greifswald remained largely at (and at times below) the level of the combined exempted capacities of OPAL Gastransport and LBTG (24 $\mathrm{GWh} / \mathrm{h}$ ). Capacity utilization at Brandov increased compared to 2014 and was within the range of 30-40 $\mathrm{GWh} / \mathrm{h}$, averaging $\sim 35 \mathrm{GWh} / \mathrm{h}$ but occasionally reaching $\sim 40 \mathrm{GWh} / \mathrm{h}$, in other words, the level of combined technical exit capacities of OPAL Gastransport and LBTG at Brandov. ${ }^{201}$ In 2016, the situation remained essentially the same until it changed at the end of the year, when the amended OPAL Gastransport exemption decision was approved.

As the September 2015 auction demonstrated the strength of Gazprom's argument by showing no thirdparty interest in OPAL's capacity, Gazprom made another attempt to find a solution that would allow it an increased degree of utilization of OPAL and, subsequently, of Nord Stream 1. This proved successful and resulted in the conclusion of a new settlement agreement between BNetzA, OPAL Gastransport, Gazprom, and Gazprom Export on 11 May 2016, which was largely identical to the expired October 2013 agreement.

The May 2016 settlement agreement divides 31,729,064 kWh/h (around $25.4 \mathrm{bcma}$ ) of OPAL's 'transit' capacity into two groups:

\footnotetext{
198 Yafimava (2017a)

199 Ibid.

200 Gazprom Export (2016)

201 Yafimava (2017a).
} 

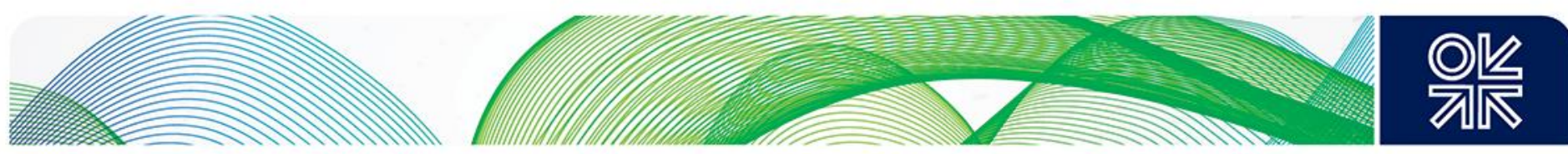

- $15,864,532 \mathrm{kWh} / \mathrm{h}$ (12.7 bcma) of coupled (bundled) interconnection capacity (BZK capacity), which can only be used for entry at Greifswald and exit at Brandov, and

- $15,864,532 \mathrm{kWh} / \mathrm{h}$ (12.7 bcma) of decoupled (unbundled) interconnection capacity, which is in turn divided into two groups:

- DZK: separately bookable dynamically allocable capacity (which is firm if gas entered at Greifswald and exited at Brandov and is interruptible if gas entered/exited at the GASPOOL hub),

- FZK: separately bookable freely allocable capacity (which is firm capacity that can be used unrestrictedly to transport gas from GASPOOL to the exit point of Brandov).

In line with the agreement, the $15,864,532 \mathrm{kWh} / \mathrm{h}$ (12.7 bcma) of coupled interconnection capacity (BZK) that could only be used for entry at Greifswald and exit at Brandov would be exempt from TPA for 22 years (although specific CMP would apply). Another 15,864,532 kWh/h (12.7 bcma) of DZK and FZK capacity would be partly regulated; more specifically, such capacity would be auctioned on the PRISMA platform in the following way (Art. 1.d.aa):

- entry capacity at Greifswald is only supplied as DZK in the amount of $15,864,532 \mathrm{kWh} / \mathrm{h}(12.7$ bcma);

- exit capacity at Brandov is only supplied as DZK in the amount of $14,064,532 \mathrm{kWh} / \mathrm{h}$ (11.3 bcma), or $\sim 4.3$ per cent;

- exit capacity at Brandov is only supplied as FZK in the amount of $1,800,000 \mathrm{kWh} / \mathrm{h}$ (1.4 bcma), or $\sim 5.7$ per cent.

The May 2016 agreement also stated that if demand for FZK capacity at Brandov exceeded supply of $1,800,000 \mathrm{kWh} / \mathrm{h}$ in two consecutive annual auctions for annual capacities, the supply of FZK capacity must be increased by the extent necessary to satisfy demand, up to a maximum of $3,600,000 \mathrm{kWh} / \mathrm{h}(2.9$ bcma, or $\sim 11.3$ per cent), provided that such an increase is 'economically reasonable'. Should the supply of FZK capacity be increased, the supply of DZK capacity could only be decreased - by a maximum of $1,800,000 \mathrm{kWh} / \mathrm{h}-$ if and to the extent that such a reduction was technically necessary. Importantly, the agreement stated that OPAL Gastransport was not only entitled, but also obliged, to supply DZK capacities of at least $12,264,532 \mathrm{kWh} / \mathrm{h}$ at the Brandov exit point and at least $15,864,532 \mathrm{kWh} / \mathrm{h}$ at the Greifswald entry point, thus suggesting that these could not be decreased in the future. The agreement also stated explicitly that Gazprom, Gazprom Export, and associated companies may participate in capacity auctions for partly regulated decoupled capacity, and book and utilize such capacity on the same terms as third parties. Both unregulated BZK and partly regulated DZK and FZK capacities would be exempt from the tariff provisions applied to fully regulated capacity. Tariffs charged to all users for DZK and FZK capacities must be non-discriminatory and transparent and must correspond exactly to the charges applied to BZK capacity (unless differences are technically justified with regard to the capacity product concerned and the particular form it takes).

BNetzA had subsequently notified the May 2016 settlement agreement to the EC for assessment under the exemptions procedure set out by the Third Gas Directive (Art. 36). In July 2016, the EC announced that it had sent a request for additional information to BNetzA, thus extending its initial two-month consideration period. The delay gave rise to doubts over whether the EC was ever going to make a decision, or would continue to postpone, as had been the case with the October 2013 settlement agreement. However, on 28 October 2016, the EC made a decision to approve the May 2016 settlement agreement, subject to amendments. The decision, once adopted, became binding on BNetzA with immediate effect. ${ }^{202}$ The EC has approved the agreement in principle, thus allowing Gazprom (and any

202 The EC published a press release to this effect, but the decision itself was only published on 9 January 2017 - in other words more than two months after the decision was adopted. Although a failure to publish the decision on the day of adoption appears to 

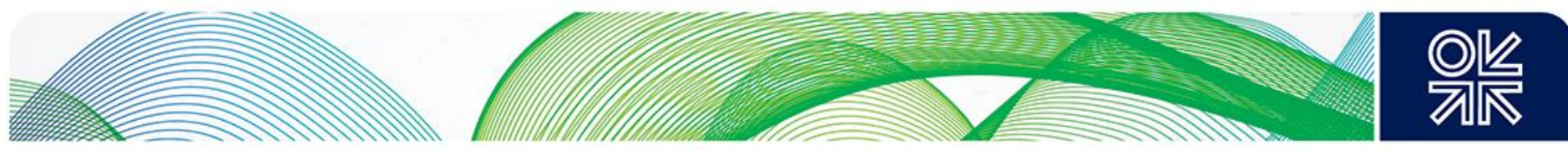

other undertakings with a dominant position in the Czech Republic) to access more than 50 per cent of OPAL capacity through participation at auctions organized at the PRISMA platform alongside third parties (without conducting a gas release programme). However, it also imposed additional conditions aimed at safeguarding the interests of third parties, which would not only enable but also guarantee their access to 20 per cent of OPAL (FZK) capacity in the event of demand.

Firstly, the EC requested that the minimum level at which FZK capacities are to be offered to third parties must be set at $3,200,000 \mathrm{kWh} / \mathrm{h}$ (10 per cent of the total capacities) thus suggesting an increase from the figure of $1,800,000 \mathrm{kWh} / \mathrm{h}$ set in the May 2016 settlement agreement. The EC stated that such an increase reflects the increased liquidity of GASPOOL and would serve to improve the functioning of the EU internal market through increased trading and arbitrage between hubs. The EC also stipulated a mechanism for further increases of FZK capacities from the level of 3,200,000 kWh/h, depending on demand by third parties (Art. 2). In particular, it specified that if, at an annual auction, the demand for FZK capacities was 'equal or greater than 90 per cent of the offer', the total amount of FZK capacities offered in subsequent annual auctions was to be increased by $1,600,000 \mathrm{kWh} / \mathrm{h}$ 'in an economically feasible way' and 'up to a maximum of' $6,400,000 \mathrm{kWh} / \mathrm{h}$ (20 per cent of the total capacities). This suggests that such capacity increases are to be made in one $(3,200,000+1,600,000=4,800,000 \mathrm{GWh} / \mathrm{h})$ or two $(4,800,000+$ $1,600,000=6,400,000 \mathrm{GWh} / \mathrm{h}$ ) subsequent steps, each allowing for a 5 per cent increase. Notably, although the EC decision states that capacity increases are to be offered 'in an economically feasible way' (Art. 2), the decision's preamble (paragraph 147) notes that it is the EC's view that provision of additional FZK capacities, at least up to the limit of 20 per cent, should 'in principle always be economically feasible'. The EC argued that the imposition of the 20 per cent cap is justified due to:

a) a restrictive definition of firm capacity used by the German regulatory authority 203 as a result of which the not placing of a cap might lead to economically unjustified investment in additional pipeline infrastructure, and

b) the fact that a 20 per cent capacity reservation for short-term and annual capacity products is required by the EU Capacity Allocation Mechanism (CAM) network code (Section 2.1).

Notably, the EC exemption is not clear in respect of what happens if demand for FZK capacities exceeds $6,400,000 \mathrm{kWh} / \mathrm{h}$ (20 per cent of the total capacities) and, as argued by this author elsewhere, is open to multiple interpretations. ${ }^{204}$ The exemption states that 'if demand for FZK capacities at an annual auction exceeds 6,400,000 kWh/h (or the current threshold, if it has been increased before), the threshold for FZK capacities under Art. 2 shall be increased by $3,200,000 \mathrm{kWh} / \mathrm{h}$ in the following annual auction provided a further increase in FZK capacities is technically feasible, the changes to the competitive situation are such as to justify an increase, and the benefits of an increase outweigh the costs thereof' (Art. 3). One interpretation would suggest that the exemption established a mechanism which simply allows for a steeper increase of FZK capacities from the level of $3,200,000 \mathrm{kWh} / \mathrm{h}$ up to the level of $6,400,000 \mathrm{kWh} / \mathrm{h}$ in the following annual auction, thus sidestepping the 5 per cent annual incremental increases and reaching the same maximum level of $6,400,000 \mathrm{kWh} / \mathrm{h}$ sooner. In this case, it would not be possible for the EC to request an increase in FZK capacities beyond $6,400,000 \mathrm{kWh} / \mathrm{h}$ (20 per cent). Another interpretation would suggest that the exemption established a mechanism which allows for FZK capacities to increase above $6,400,000 \mathrm{kWh} / \mathrm{h}$ (or the current threshold, if it has been increased before) by requesting an increase in these capacities from that level by a further $3,200,000 \mathrm{kWh} / \mathrm{h}$, thus resulting in FZK capacities above 6,400,000 kWh/h (and therefore removing the 20 per cent cap). In this case, it would be possible for the EC to request an increase in FZK capacities beyond $6,400,000 \mathrm{kWh} / \mathrm{h}$ if such an increase is 'technically feasible, the changes to the competitive situation are such as to justify an

be a departure from the EC's usual practice, publication was not required for such a decision to be valid. Nonetheless, several third parties, in particular central European member states, voiced their concerns about the lack of publication. Moreover, the Polish $100 \%$ state-owned gas company, PGNiG, formally appealed to the EC to publish the decision.

${ }^{203}$ Yafimava (2017a), p. 5.

204 Yafimava (2017a), p. 16 

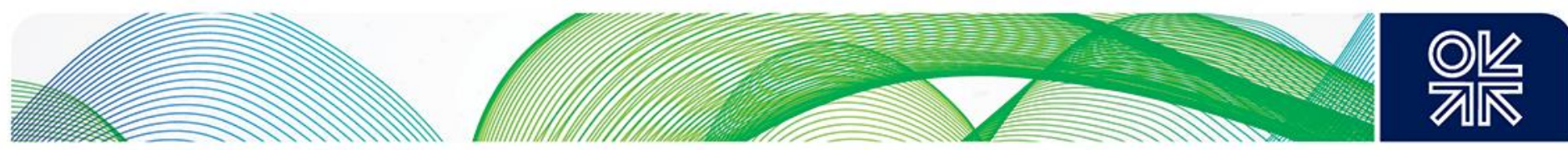

increase, and the benefits of an increase outweigh the costs thereof' and in theory there would be no limitation on an FZK capacity increase beyond 20 per cent and potentially up to 50 per cent. ${ }^{205}$ There are legal arguments in support of both interpretations, and hence it is not possible to confirm definitively which one is 'correct'. Furthermore, it is possible that the EC might have deliberately allowed for this ambiguity. In any event, irrespective of which interpretation of the decision is 'correct', it appears certain that it guarantees third parties' access to FZK capacities in OPAL to the amount of at least 20 per cent.

Secondly, the EC ruled that Gazprom (and any other undertakings with a dominant position in the Czech Republic or which control more than 50 per cent of gas arriving at Greifswald) could 'submit their bid for FZK capacities on OPAL only at the base price' (albeit excluding any successful bidding in the case of congestion) thus suggesting that such bids would only participate in the first bidding round and hence would be unable to outbid third parties' bids. According to the decision, the base price 'shall not be set higher than the average base price of regulated tariffs on transmission networks from the GASPOOL area to the Czech Republic in the same year for comparable products' (Art. 4). The EC justified this ruling on the basis that it would prevent Gazprom from excluding third parties from booking FZK capacities and using them for accessing the Czech market.

Thirdly, the EC required OPAL Gastransport to be certified under the provisions of the Third Gas Directive and Gas Regulation 715 (Art. 3), ordering BNetzA to assess OPAL Gastransport's compliance with the unbundling rules envisaged in the Second Gas Directive (in other words functional and legal unbundling) and with the exemption decision itself (provisions concerning the unbundling requirements aimed at safeguarding a degree of independence between the OPAL Gastransport management and its shareholders). The EC requested BNetzA to notify its certification decision by 28 February 2017 so that a certification procedure could be completed prior to the first general annual auction. ${ }^{206}$

In order to become legally binding on its parties, the May 2016 settlement agreement - as approved by the EC subject to the aforementioned changes - had to be signed by all of them (BNetzA, OPAL Gastransport, Gazprom, and Gazprom Export). Although Gazprom invested significant time in attempting to reach a settlement, its initial reaction was cautious, if not outright negative as, according to Gazprom's deputy CEO Alexander Medvedev, the substantive changes requested by the EC had changed the terms of the settlement agreement and had not been discussed when the agreement was signed in May 2016. Eventually Gazprom accepted the changes and agreed to amend the agreement in line with the EC's decision. The amended agreement was signed on 28 November 2016.

The November 2016 agreement divides 31,729,064 kWh/h (around $25.4 \mathrm{bcma}$ ) of OPAL's 'transit' capacity into two groups:

- $15,864,532 \mathrm{kWh} / \mathrm{h}$ (12.7 bcma) of BZK capacity, which is fully exempt for 22 years, and

- $15,864,532 \mathrm{kWh} / \mathrm{h}$ (12.7 bcma) of decoupled capacity (divided into two groups: DZK capacity and FZK capacity) which is partly regulated, and would be auctioned on the PRISMA platform in the following way:

- entry capacity at Greifswald is only supplied as DZK in the amount of $15,864,532$ $\mathrm{kWh} / \mathrm{h}$ (12.7 bcma) (hence no change compared to the May 2016 settlement agreement);

○ exit capacity at Brandov is only supplied as DZK in the amount of 12,664,532 kWh/h (10.1 bcma), or 40 per cent (hence a decrease compared to the May 2016 settlement agreement);

\footnotetext{
${ }^{205}$ However, in practise, it is unlikely that demand for FZK capacities would increase beyond (or even up to) 6,400,000 kWh/h Therefore, it is unlikely that the EC would request OPAL Gastransport to offer FZK capacity in excess of 6,400,000 kWh/h, unless this capacity is needed on a long-term basis, thus allowing OPAL Gastransport enough time to demonstrate whether such an increase would be technically feasible and whether its costs would not be disproportionate.

206 The first annual auction for OPAL capacity was held by OPAL Gastransport in March 2017.
} 

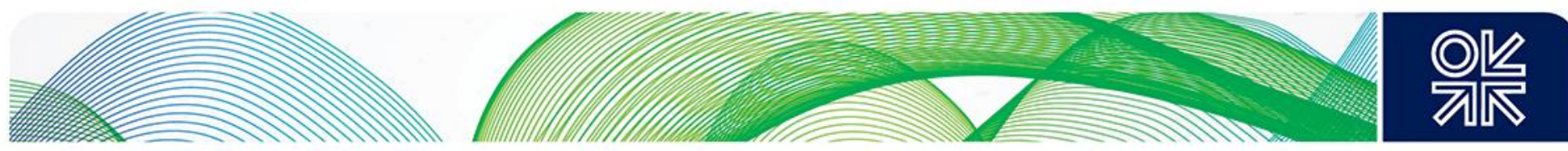

exit capacity at Brandov is only supplied as FZK in the amount of $3,200,000 \mathrm{kWh} / \mathrm{h}$ (2.6 bcma), or $\sim 10$ per cent (hence an increase compared to the May 2016 settlement agreement).

Furthermore, the November 2016 agreement states that if demand for FZK capacity at Brandov constitutes at least 90 per cent of the offer of FZK capacity at Brandov in an annual auction where annual capacity is offered, the overall offer of FZK capacity at later annual auctions must be increased by $1,600,000 \mathrm{kWh} / \mathrm{h}$ 'in an economically reasonable way', but at most to $6,400,000 \mathrm{kWh} / \mathrm{h}$, thus bringing the maximum amount of FZK capacity to 20 per cent of OPAL's 'transit' capacity. This is a significant difference compared to the May 2016 settlement agreement, which set a maximum amount of FZK capacity at a level of $3,600,000 \mathrm{kWh} / \mathrm{h}$, or 11.3 per cent of OPAL's 'transit' capacity. An increase stipulated by the May 2016 agreement was also subject to stricter conditions; for example, demand for FZK capacity at Brandov had to exceed supply in two consecutive auctions rather than be at least 90 per cent of supply in one auction. Furthermore, while the May 2016 agreement stated clearly that any such increase could only be made if it was 'economically reasonable', the November 2016 agreement appears to suggest that it should always be economically feasible to offer an increase, up to 20 per cent of OPAL capacity.

The November 2016 agreement further states that if demand for FZK capacity in the annual auction exceeds $6,400,000 \mathrm{kWh} / \mathrm{h}$ (or the current threshold value if it had been previously increased), the offer of FZK capacity should be increased at the following annual auction by a further $3,200,000 \mathrm{kWh} / \mathrm{h}$, 'insofar as' a further increase is 'technically feasible, changes to the competitive situation are such as to justify an increase, and the benefits of an increase outweigh the costs thereof'. The November 2016 settlement agreement preserved the ambiguity of the EC October 2016 exemption decision in respect of whether it would be possible for the EC to request an increase in FZK capacities beyond 6,400,000 kWh/h (20 per cent).

The agreement stated that, subject to the EC decision, OPAL Gastransport is entitled (but not obliged) to supply DZK capacities of at least $9,464,532 \mathrm{kWh} / \mathrm{h}$ at Brandov (thus suggesting that they could potentially be reduced in the future).

In summary, under the November 2016 settlement agreement, Gazprom would be guaranteed 50 per cent (as exempt) of OPAL's 'transit' capacity (not offered at an auction) and guaranteed either:

a) a further 40 per cent (if it outbids third parties for DZK capacity and if there is low demand on the part of third parties for FZK capacity) or

b) a further 30 per cent (if it outbids third parties for DZK capacity and there is high demand on the part of third parties for FZK capacity),

in other words:

a. $\quad 12.7 \mathrm{bcma}+10.1 \mathrm{bcma}=22.8 \mathrm{bcma}$, or

b. $\quad 12.7 \mathrm{bcma}+7.6 \mathrm{bcma}=20.3 \mathrm{bcma}$.

While the November 2016 agreement upheld the terms of the May 2016 settlement agreement, envisaging that decoupled DZK and FZK capacities are to be auctioned on PRISMA where Gazprom, Gazprom Export, and their associated companies would be able to book and utilize these capacities, it also introduced a new requirement, in line with the October 2016 EC exemption decision. According to this, any undertaking (or groups of undertakings) which have a dominant position in the Czech Republic, or which controls more than 50 per cent of gas entering at Greifswald, will not be allowed to bid for FZK capacity at a price other than the base price. The exemption decision notes that 'the base price for partlyregulated decoupled capacities awarded at the auctions is determined by non-discriminatory, transparent pricing' whereas 'non-discriminatory means that the prices must correspond exactly to the charges for the exempted, coupled interconnection capacities [BZK], unless departures from those charges are technically justified'. It further states that the base price for FZK capacity must not be set lower than the 

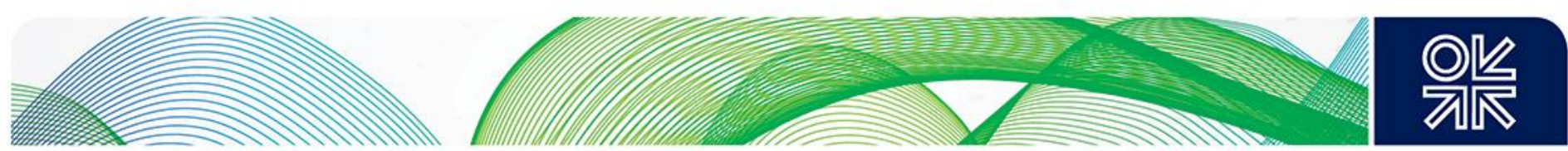

average base price, which applies to comparable regulated capacity products from the GASPOOL area to the Czech Republic in the same year. Effectively, this means that Gazprom would not be able to outbid third parties in their demand for FZK capacity.

Importantly, whereas the May 2016 settlement agreement stated that OPAL Gastransport is obliged to supply DZK capacities at the Greifswald entry point of at least 15,864,532 kWh/h, the November 2016 settlement agreement states that OPAL Gastransport is entitled but not obliged to do so, thus suggesting that this figure could potentially be reduced in the future.

As the November 2016 settlement agreement was signed, OPAL Gastransport announced that 'the way has been cleared for the full use of transit capacities that have been only partially available in the past'. ${ }^{207}$

On 19 December 2016, OPAL Gastransport held an auction on the PRISMA capacity platform for OPAL's capacity in line with the amended exemption decision. As of 23 December 2016, gas flows entering at Greifswald began to increase and continued to increase steadily (though levelling off slightly over 31 Dec 2016), reaching $44.8 \mathrm{GWh} / \mathrm{h}$ on 5 January 2017 (having been at the level of $26 \mathrm{GWh} / \mathrm{h}$ throughout 2016). Notably, as of 1 January 2017, gas flows entering at Greifswald were above gas flows exiting at Brandov, for the first time since 2014. This suggests that gas flows entering at Greifswald started to exit not only at Brandov but also into GASPOOL, thus confirming that gas entering at Greifswald is competitive with gas that otherwise would have entered the Czech Republic from GASPOOL.

Notably, as gas flows via OPAL/Greifswald started to increase in late December 2016 following the removal of the cap, gas flows arriving via the Ukrainian gas system at Velke Kapusany decreased accordingly. As flows via Greifswald stabilized in early January 2017, flows at Velke Kapusany started to increase and nearly reached their mid-December 2016 level, as overall exports increased. This suggests that Gazprom has a preference for exporting its gas via Nord Stream 1 rather than via the Ukrainian corridor and is also a useful indicator of its future preferences in respect of Nord Stream 2 and its onshore extensions (if and when built). The strength of such preferences will ultimately be based on the cost of transportation via each corridor.

\subsubsection{The legal action against the 2016 OPAL Exemption Decision: interim decision of the CJEU and implications for final judgement}

Although the October 2016 exemption decision established a fine balance between the interests of all parties involved, in line with the EU acquis, it was met with an avalanche of criticism from several central and eastern EU countries such as Poland and Lithuania, which argued that Gazprom's increased access to OPAL capacity would undermine their energy security. Particularly sharp criticism came from Poland and its 100 per cent state-owned gas company, PGNiG, which filed several complaints in the Court of Justice of the EU (CJEU) during December 2016-March 2017, calling for the exemption decision to be temporarily suspended and eventually annulled. 208 In parallel, on 15 December 2016 PGNiG and its German subsidiary, PGNiG Supply \& Trading, filed a complaint at the German Higher Regional Court in Düsseldorf in respect of the November 2016 settlement agreement (which brought the rules of access to OPAL capacity in line with the 2016 exemption decision) also calling for its temporary suspension.

On 27 December 2016 the General Court of the CJEU issued a decision to provisionally suspend execution of the October 2016 exemption decision, requesting:

(a) the EC to present 'detailed explanations with respect to the proposed procedure of capacity allocation on the OPAL pipeline' and

(b) PGNiG Supply \& Trading to submit 'an in-depth analysis of the EC's decision impact on the security and competitiveness of gas supplies to Poland'.

\footnotetext{
207 Yafimava (2017a), p. 23

${ }^{208}$ PGNiG's German subsidiary (PGNiG Supply \& Trading GmbH) vs EC (4 December 2016, case T-849/16); Poland vs EC (16 December 2016, case T-883/16); PGNiG vs EC (1 March 2017, case T-130/17). Notably, Lithuania has supported Poland in its application as an 'intervener in support of the applicant'.
} 

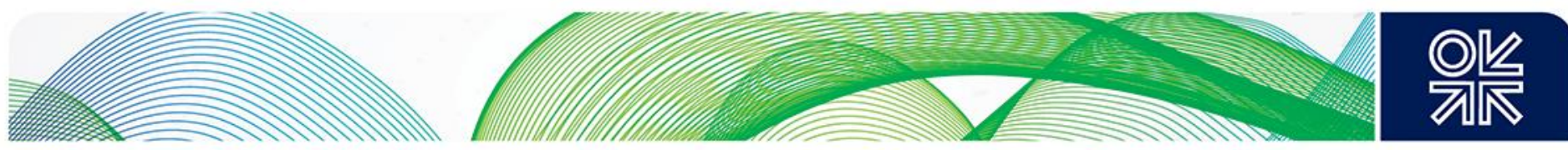

In January 2017 the CJEU stated that the suspension would be in place until other interim measures had been decided or the President of the General Court lifted it. On 30 December 2016, the Düsseldorf Court followed suit and adopted an interim decision to provisionally suspend the November 2016 settlement agreement with immediate effect. This suggested that the June 2009 exemption decision - under which Gazprom was unable to utilize more than 50 per cent of OPAL capacity - remained in force. Consequently, the Düsseldorf Court ordered BNetzA to suspend any further auctions for the remaining (in other words non-exempted) 50 per cent of OPAL capacity. Contrary to the gas community's expectations, the CJEU did not clarify its position in respect of interim measures and made no decision during the first quarter of 2017. Consequently, the Düsseldorf Court decided to keep the suspension in place until March-April 2018.

Finally, on 21 July 2017 - just before the CJEU closed for the summer holidays - the President of the General Court issued an Order, stating that he 'rejects the applications for a stay of execution of the Commission's decision that 50 per cent of the transport capacities of the OPAL gas pipeline are to be subject to a bidding procedure'. ${ }^{209}$ In so doing, the Order lifted the suspension of the October 2016 exemption decision until judgements were made by the General Court on the applications for its annulment. The Order indicated that such judgements 'will probably be delivered during 2019'. This means that the October 2016 exemption decision will continue to apply and remain valid at least until the Court makes its final judgement in 2019. On 27 July 2017, the Düsseldorf Court followed suit and repealed its previous December 2016 decision (which ordered BNetzA to suspend the November 2016 settlement agreement), confirming the continued validity of the October 2016 exemption decision.

Subsequently, BNetzA withdrew its provisional order to implement the December 2016 decision, thus enabling OPAL Gastransport to re-start the auctioning of OPAL's capacity in line with the November 2016 settlement agreement with immediate effect. The first auctions for daily capacity were held on the PRISMA platform on 1 August 2017. The timing of both the CJEU and the Düsseldorf Court decisions was important, as it allowed the suspension to be lifted before 31 July 2017, thus enabling Gazprom to utilize spare capacity in OPAL at quarterly auctions held on 7 August 2017 for the third and fourth quarters of 2017 and the first and second quarters of 2018. On 2 August 2017, flows via OPAL increased by approximately 25 per cent, thus confirming Gazprom's keenness to use OPAL capacity. On 9 August 2017 Gazprom announced that it was using the OPAL pipeline to full capacity for the first time since the suspension had been lifted.

\subsubsection{Reasons and likely final judgement of the Court in $\mathbf{2 0 1 9}$}

It is important to understand the reasons for the Court's rejection of the application for a stay of execution, as they provide some guidance on the Court's reasoning and an indication of what its final decision on the exemption, expected in 2019 , is likely to be. The Court rejected the application as it had not passed the threshold for granting the suspension, ${ }^{210}$ according to which two requirements must be met, that it:

'is established that to grant it is, prima facie, justified in fact and in law';

'is a matter of urgency that it be granted in order to avoid the party seeking it suffering serious and irreparable harm before the decision in the main proceedings is made'.

The CJEU refrained from explicitly expressing a view on whether the first requirement - prima facie justification in fact and in law - had been met (although the wording of the Order suggested that the

\footnotetext{
209 The President's Order (see Additional documents). The President's Order and its implications for final judgment are analysed in Yafimava (2017c), p. 9.

${ }^{210}$ We disagree with the argument advanced by some experts that the CJEU's grant of a provisional suspension in December 2016 implied that PGNiG had demonstrated it had a prima facie case and it will suffer serious and irreparable damage if the suspension was not granted. On the contrary, had the CJEU believed this to be the case it would not have made such suspension provisional. By granting a provisional suspension the CJEU had simply allowed itself sufficient time for assessment of whether a suspension was justified, following which it ruled definitively that it was not. Furthermore, the Court's decision not to introduce any other interim measures in respect of how the exemption decision could be applied before a judgement is made on the substance, suggests that the Court has no reason to believe that the exemption decision is not in line with the EU acquis.
} 

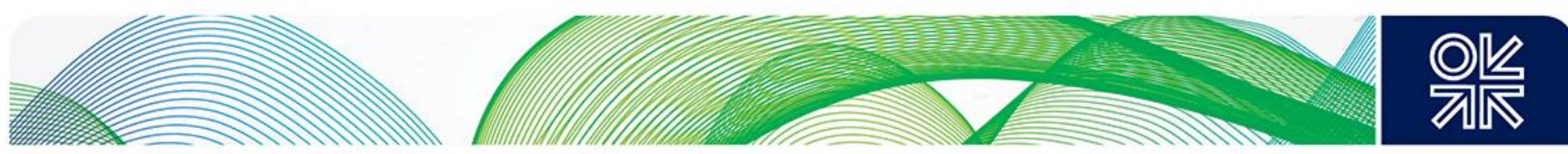

certainty of the alleged harm - threat to the security of supply or reduction of competition - had not been sufficiently demonstrated). The Court was unequivocal that the second requirement - urgency - had not been met. Notably the Order states that 'the use of the transport capacity of the Polish section of the Yamal-Europe pipeline and Gazprom's deliveries to the Polish market are, prima facie, guaranteed' under the existing transit contract which does not expire until 2020 and the existing supply contract which does not expire until 2022 - 'until the aforementioned dates'. The Court thus believed that even if the certainty of the alleged harm were sufficiently demonstrated, such harm 'could occur at the earliest only on expiry of those [supply and transit] contracts', thus suggesting that there was no reason for granting a stay of execution prior to their expiry. ${ }^{211}$

This demonstrated that the Court viewed the presence of commercial contracts in place, under which Gazprom is obliged to transit and supply gas across, and to, Poland, as a guarantee for continued supply to Poland and use of capacity in the Yamal-Europe pipeline until these contracts expire. This suggests that the CJEU, when making its final judgement in 2019, is likely to consider contractual arrangements which might replace the existing contracts upon their expiry. Given that Gazprom's contractual obligations and European buyers' gas demand are such that capacity in the Yamal-Europe pipeline would need to be utilized post-2019 either by Gazprom (if delivery points in its existing LTSCs remain unchanged) or by its European buyers (if renegotiated or new supply contracts specify the Polish-Belarusian border as a new delivery point), new transportation contracts would have to be concluded for Yamal-Europe capacity, even if the 2016 OPAL exemption decision is upheld. Therefore, the CJEU is likely to take the view in its 2019 judgement that upholding the 2016 exemption decision will not necessarily lead to a reduction of gas transport via the Yamal-Europe pipeline, as new transmission contracts would provide a prima facie guarantee of continued transit, and hence is likely to reject the application for its annulment.

In making its final judgement on the OPAL exemption decision in 2019, the CJEU is likely to take into consideration progress made on the construction of Nord Stream 2 (planned to be completed by the end of 2019 and to run parallel to Nord Stream 1) and EUGAL (planned to be completed by the end of 2019 and run parallel to OPAL) pipelines. Should Nord Stream 2 and EUGAL proceed on schedule, Russia's export pipeline capacity towards Europe would expand significantly by 2020 . Should this be the case, the CJEU might want to assess the OPAL exemption decision in this context. ${ }^{212}$ In particular, it might decide to assess its potential impact on the utilization of the Yamal-Europe pipeline (given the future availability to Gazprom of significant additional export capacity in the form of Nord Stream 2), and its potential impact on competition and on security of gas supply to Poland. In our view, the result of such an assessment is unlikely to lead the CJEU to annul the exemption decision, as even if both the Nord Stream 2 and EUGAL pipelines are built by the end of 2019 - though they are more likely to be delayed by a year or two ${ }^{213}-$ this would not necessarily result in the reduction of gas transit across Poland. Both Gazprom's contractual commitments under its European LTSCs and European gas demand strongly suggest that the utilization of the Yamal-Europe pipeline will continue to be necessary. However, the degree of its utilization will depend on the commercial attractiveness of the transportation tariff offered by Yamal-Europe's operator, Gaz-System, as well as on the degree of utilization of the Ukrainian transit system (which will also depend on the commercial attractiveness of the tariff offered by the Ukrainian TSO). ${ }^{214}$ By the time of the CJEU making its final judgment, there will be more clarity in respect of the degrees of utilization of both the Yamal-Europe and the Ukrainian systems post-2019. ${ }^{215}$ Clearly, should new contracts underpinning

\footnotetext{
${ }^{211}$ Given that the Court's judgement on substance is expected sometime during 2019 (in other words before the expiry of the transit contact), the requirement of urgency would continue to be unmet by the time such judgement is made, thus giving the Court no reason to revise its decision until the end of the proceedings. (This suggests that the 2016 exemption decision would continue to remain in force at least until the Court's final judgement.)

212 Conversely, a delay in Nord Stream 2 and / or EUGAL implementation beyond 2020 would increase the likelihood of the CJEU upholding the 2016 EC OPAL Exemption Decision (see EC, 2016a)).

${ }^{213}$ Yafimava (2017b).

214 Just as Gazprom's contract governing the transit of gas across Poland expires at the end of 2019, Gazprom's transit contract governing the transit of gas across Ukraine also expires at the end of 2019.

${ }^{215}$ As this paper goes to print, neither the Polish nor the Ukrainian transit contract has been negotiated or extended for the post2019 period.
} 

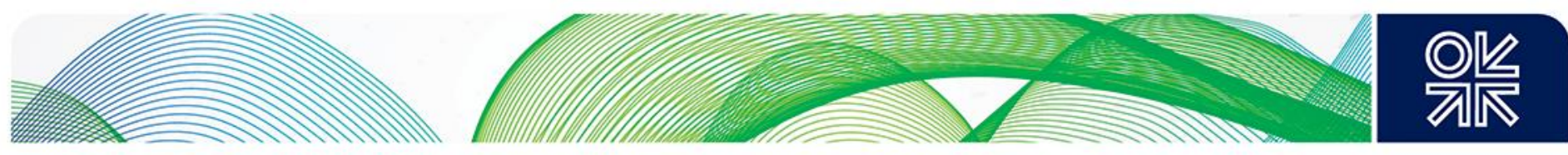

transit of gas across Poland (and across Ukraine) post-2019 be concluded prior to its final judgement, the CJEU would be more likely to uphold the exemption decision, as its interim judgement suggested that it views the presence of transit contracts as a guarantee of continued transit. On the other hand, should new transit contracts not be concluded prior to its final judgment, the CJEU would likely also uphold the exemption - as it would not necessarily lead to reduction of transit across Poland because of the reasons outlined above - but the court could choose to introduce a safeguard in the exemption decision. For example, the CJEU could request making a floating cap part of the exemption decision - a cap that could be activated should the utilization of the Yamal-Europe system decrease beyond a certain level once, and if, Nord Stream 2 and EUGAL are built. However, the CJEU might conclude that the exemption decision already contains strong safeguards, under which the EC has a significant degree of flexibility in respect of limiting the utilization of OPAL capacity by Gazprom, by being able to guarantee third parties' access to FZK capacities in OPAL in the amount of at least 20 per cent. As argued above, under the exemption decision, at least 20 per cent of OPAL capacity is 'ring-fenced' for third parties, and arguably - under one interpretation - up to 50 per cent. The CJEU might decide to clarify and strengthen this provision.

Importantly, the CJEU's judgment on the OPAL exemption decision might also serve as guidance for regulatory treatment of EUGAL - the capacity in which has been allocated in line with the 'more capacity' procedure, which closely but not completely mirrors the CAM NC (as the former was developed earlier than the latter, see Section 2.1). In particular, the CJEU judgement could be used by the EC, or the German regulatory authority, in order to justify the introduction of a floating cap on EUGAL capacity which could be activated in the event of a reduction in the utilization of Polish (and potentially Ukrainian) systems beyond a certain level.

In our view, the acceptance on 24 May 2018 by the EC Directorate for Competition (DG COMP) of Gazprom's commitments in respect of its sales to central and eastern European countries (made in the course of the EC anti-trust investigation) and their adequate implementation by Gazprom, will have increased the likelihood of the CJEU upholding the 2016 OPAL exemption decision. ${ }^{216}$ Given that the EC's Directorate General for Energy (DG ENER) adopted the exemption decision in October 2016, in other words shortly before the EC's Directorate General for Competition (DG COMP) had come to a provisional agreement with Gazprom on their commitments in December 2016, the impact of the commitments on both Polish security of supply (as Poland was one of the six countries assessed during the investigation) and competition must have been taken into account in the process of finalizing the exemption decision. DG COMP was in favour of the draft commitments, acknowledging that their acceptance and implementation would improve competition in central and eastern Europe. The draft commitments were strengthened further, following the results of the market test, with the EC acknowledging that the final commitments - as accepted by the EC on 24 May 2018 - 'address' its competition concerns and achieve its objectives of 'enabling the free flow of gas in central and eastern Europe at competitive prices'. ${ }^{217}$ Given the expected positive impact of Gazprom's commitments (which will be in force during 24 May 2018-24 May 2026) on the functioning of the internal market and on competition in central and eastern Europe - including Poland - the CJEU is unlikely to view Gazprom's increased utilization of OPAL under the 2016 exemption decision as a threat to security of supply and competition.

The approach taken by the President of the CJEU in his judgement to reject the stay of execution, due to the continued validity of both long-term transit and supply contracts, suggests that the CJEU is unlikely to annul the exemption decision. ${ }^{218}$ This is because Gazprom's contractual obligations and European buyers' projected gas demand in the 2020 time frame will require capacity in the Yamal-Europe pipeline to continue to be utilized post-2019, either by Gazprom or by its European buyers, thus necessitating the conclusion of new transportation contract(s). Annulment of the exemption decision would be groundless,

\footnotetext{
${ }^{216}$ EC (2018b).

217 Ibid.

${ }^{218}$ Yafimava (2017c).
} 

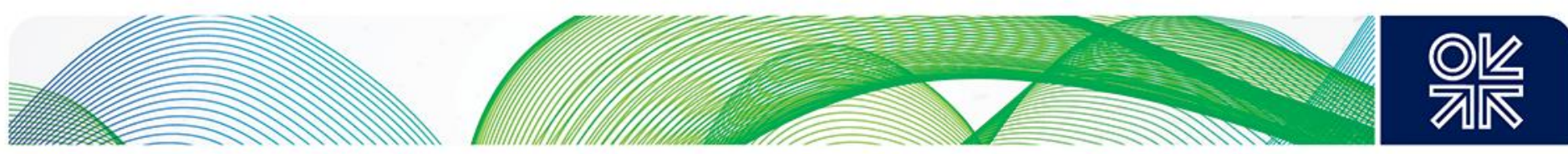

as the future presence of such contracts would mean that the exemption decision would not necessarily lead to a reduction of flows via Poland, thus refuting Poland's main argument against the exemption. Poland's official position not to renew the long-term supply contract with Gazprom upon expiry and make post-2019 contractual arrangements for transit conditional on a gas price reduction, further undermines its argument. ${ }^{219}$ Should the CJEU uphold the October 2016 exemption decision, the latter will continue to apply until 2033,220 thus enabling Gazprom's continued utilization of more than 50 per cent of OPAL capacity. In the unlikely event of the CJEU not upholding the 2016 exemption decision, Gazprom's utilization of OPAL capacity would be capped at 50 per cent as it was under the 2009 exemption decision.

\section{Conclusions}

The June 2009 EC exemption decision granted to OPAL - an interconnector transporting Russian gas delivered by Nord Stream 1 at Greifswald in Germany to the German-Czech border at Olbernhau / Brandov - prevented Gazprom from being able to utilize more than 50 per cent of OPAL capacity for more than five years, despite the lack of third-party demand for OPAL capacity. As result, both OPAL and Nord Stream 1 - remained heavily underutilized. The cap placed on Gazprom's access to OPAL favoured traders shipping gas from GASPOOL to Brandov as, even had Gazprom priced its gas at the same level as GASPOOL (or below), it would not be able to compete with the traders due to its access to capacity at Brandov being artificially constrained. Although capacity available to the traders at Brandov was interruptible rather than firm, the cap made the probability of interruption negligible. Ultimately, this led to a situation where European buyers were getting their gas at prices that were potentially higher than might have been the case had it not been for the OPAL cap, thus going against its original raison d'être of preserving and enhancing competition.

As maintaining the OPAL cap became increasingly illogical and unjustifiable on the grounds of the acquis, and prone to criticisms of having been imposed on political grounds, in October 2016 the EC adopted a significantly more balanced decision. The October 2016 exemption decision removed the cap and allowed Gazprom to bid for the remaining 50 per cent of OPAL's capacity - alongside third parties - on the PRISMA capacity trading platform. This allowed Gazprom to utilize at least 80 per cent (and possibly more) of OPAL's capacity, thus enabling it to achieve higher utilization of Nord Stream 1 capacity. Importantly the October 2016 decision struck a fine balance between the interests of all parties involved, in line with the acquis. While it allowed Gazprom to have in excess of 80 per cent of OPAL capacity, it also effectively guaranteed access by third parties to at least 20 per cent of capacity (as Gazprom is not allowed to outbid third parties for that share), and possibly more.

The October 2016 decision manifests a (belated and not openly acknowledged) recognition on the part of the EC that there was no rationale, either in the energy or competition acquis, for not allowing Gazprom to utilize more than 50 per cent of OPAL's capacity when a) capacity at OPAL's entry point, Greifswald, was of no interest for third parties which did not - and could not - have the gas available at Greifswald, and b) provided that Gazprom's gas would be competing with third parties shipping their gas from GASPOOL to OPAL's exit point at Brandov. The decision ended more than seven years of negotiations and many failed attempts to find a mutually acceptable solution that would be compliant with the EU acquis. Having recognized that politicization threatens to undermine the credibility of the EU regulatory gas framework - which it has spent decades to establish - the EC moved back into the comfort zone of rules-based regulatory decision-making, of which the October 2016 decision is an example. Poland's legal challenge to this decision was an attempt to move in the opposite direction and risked creating a precedent in which political objectives are allowed to override regulatory rules. However, as argued above, this challenge is unlikely to succeed.

Overall, the OPAL exemption decision-making process - lasting from June 2009 to October 2016 - serves as an example of the politicization of regulatory process, and demonstrates that highly unfavourable treatment could be granted by the EC to any new pipeline project under the exemption regime, despite a

\footnotetext{
${ }^{219}$ Ibid, p. 9.

220 The date until which the exemption was granted.
} 

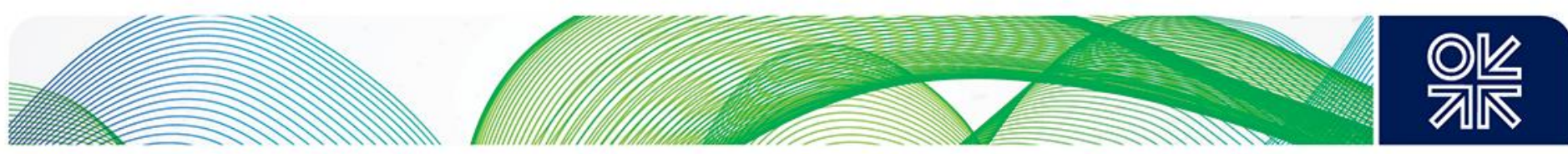

lack of justification on regulatory grounds. As a result, it undermined the value of the exemption procedure as an attractive legal / regulatory framework within which to develop new pipeline capacity in the future.

\subsection{The Exemption Regime: the TAP pipeline}

The Southern Gas Corridor (SGC) is an EU initiative aimed at bringing natural gas by pipeline from the Caspian region (initially from Azerbaijan but also potentially from Turkmenistan, Iran, and Iraq) to Europe. ${ }^{221}$ The EC has invested significant time and effort in supporting this initiative from the mid-2000s when it was seen as the major instrument for reducing Europe's dependence on Russian gas - it was seen as a quest on which the EC embarked after the series of transit disputes between Russia and Ukraine (but also Belarus and Moldova) in the 2000s. ${ }^{222}$ The concept of the SGC has changed significantly since its inception, both in respect of potential sources of gas and routes via which it could be delivered to Europe. ${ }^{223}$ The initial intention had been to build a three pipeline corridor to bring around $100 \mathrm{bcm} /$ year of Azeri, Turkmen, Iranian, and Iraqi gas to Europe. A combination of unfavourable politics, economics, and regional security issues substantially reduced the scale of the initiative to just bringing Azeri gas from the Shah Deniz 1 (SD1) and Shah Deniz 2 (SD2) fields, the latter starting in 2019/20.

At present, the SGC initiative centres around bringing Azeri gas to Europe via the following pipelines (Figure 9):224

South Caucasus pipeline (SCP) - an existing pipeline, which transports gas from Azerbaijan across Georgia to Turkey;225

Trans Anatolian Pipeline (TANAP) - a new pipeline, which was launched on 12 June $2018^{226}$ and will transport Azeri gas to, and across, Turkey to European border(s), with an initial capacity of 16 and expandable to $32 \mathrm{bcma} ; 227$

Trans Adriatic pipeline (TAP)228 - a new pipeline under construction, which will transport gas from the Turkish-Greek border across Greece, Albania, and the Adriatic Sea to southern Italy, where it will connect to the Italian domestic transmission network, with an initial capacity of 10 and expandable to 20 bcma. ${ }^{229}$

\footnotetext{
${ }^{221}$ Several studies were published by the OIES Gas Programme on the Southern gas corridor for example Rzaeva (2015) and Pirani (2016).

${ }^{223}$ Southern Gas Corridor ('SGC') describes 'infrastructure for the transmission of gas from the Caspian Basin, Central Asia, the Middle East, and the Eastern Mediterranean Basin to the [European] Union to enhance diversification of gas supply', see TEN-E Regulation (see Additional documents), Annex 1.

${ }^{224}$ Several pipeline projects for transporting SD2 gas to Europe were under consideration, including Nabucco and TAP.

${ }^{225}$ SCP has been operational since late 2006 transporting gas to Azerbaijan and Georgia, and starting from July 2007 to Turkey from SD1. On 17 December 2013 an FID was taken on the South Caucasus Pipeline Expansion (SCPX) project with a view of tripling its capacity to $20 \mathrm{bcma}$ (this would involve construction of a new pipeline across Azerbaijan and two compressor stations in Georgia)

226 'TANAP to supply gas to TAP in mid-2019', Interfax Natural Gas Daily, 29 June 2018. (see Journal articles)

227 TANAP website.

${ }^{228}$ Initially several pipeline projects other than TAP were originally under consideration for transporting SD2 gas to Europe; these included Nabucco and the Interconnector Turkey-Greece-Italy (ITGI).

${ }^{229}$ The pipeline in Greece will be approximately $550 \mathrm{~km}$ long, starting at Kipoi near the Turkish-Greek border and finishing at the Greek border with Albania, south-west of leropigi. The pipeline in Albania will be approximately $215 \mathrm{~km}$ long, starting at Bilisht Qendër in the Korça region, on the border with Greece. TAP's landfall in Albania will be located $17 \mathrm{~km}$ north-west of Fier, up to 400 metres inland from the shoreline. The offshore section in Albanian territorial waters will be about $37 \mathrm{~km}$. TAP's route across the Adriatic Sea will take the pipeline approximately $105 \mathrm{~km}$ along the seabed from the Albanian to the Italian coast. TAP will make landfall in southern Italy, in Lecce, municipality of Melendugno, near San Foca. The offshore pipeline through Italian territorial waters will be about $25 \mathrm{~km}$ long, while the onshore section will be approximately $8 \mathrm{~km}$.
} 

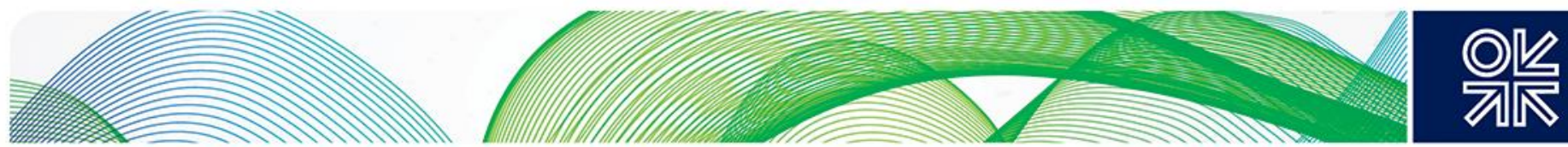

Figure 9: The Southern Gas Corridor pipelines

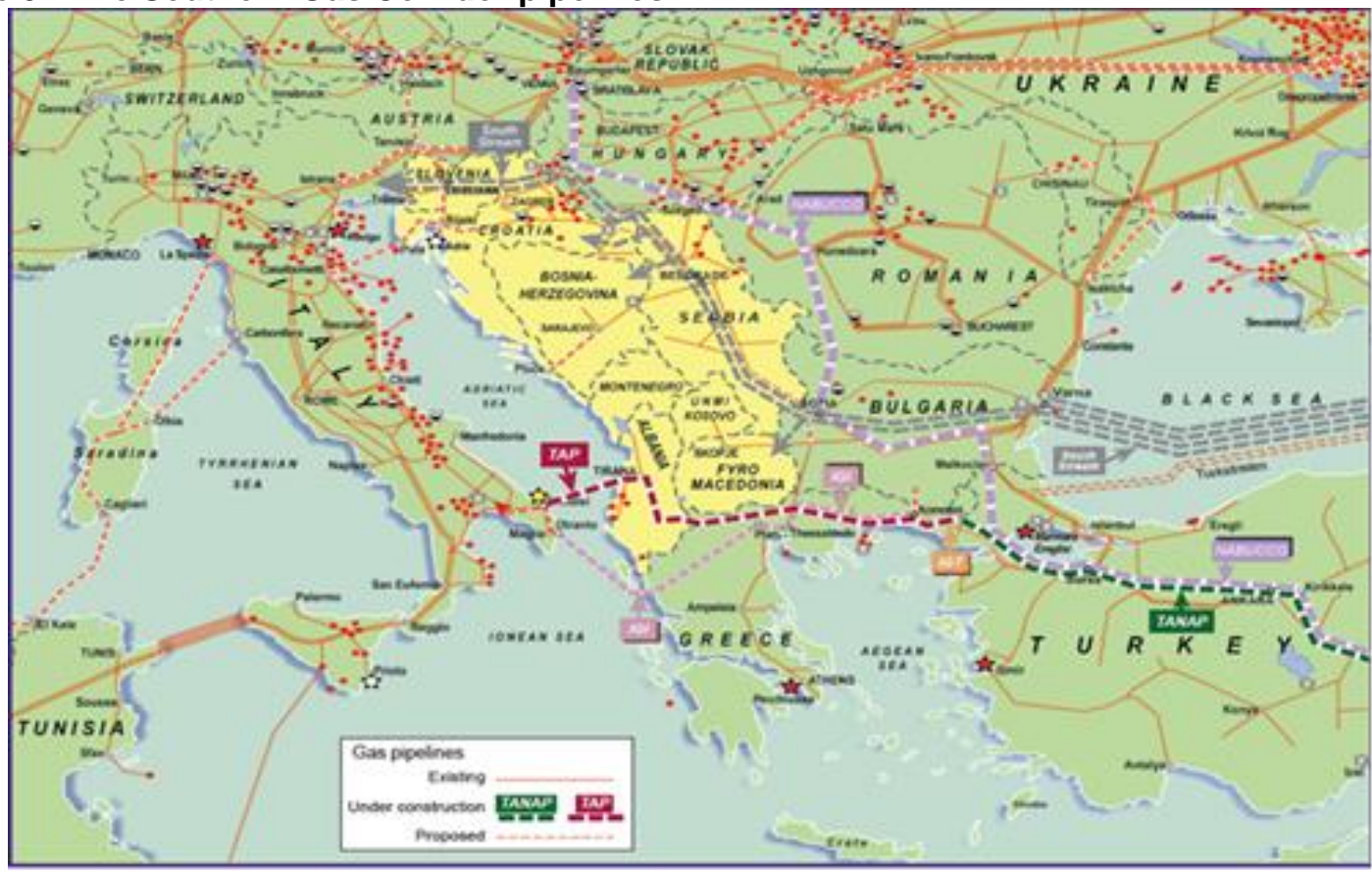

Source: OIES.

This paper focuses on the European part of the Southern Gas Corridor - the TAP pipeline - and specifically on its regulatory treatment under an Exemption Regime.

\subsubsection{TAP: the route and the interconnection points}

TAP is being developed by the TAP consortium. Its shareholders' composition has changed over time and at the time of writing stands as follows: BP ( 20 per cent), SOCAR ( 20 per cent), SNAM (20 per cent), Fluxys (19 per cent), Enagas (16 per cent), and Axpo ( 5 per cent). ${ }^{230}$ TAP's ownership structure has changed significantly since its inception, as it originally consisted of Statoil (42.5 per cent), EGL (Axpo's subsidiary) (42.5 per cent), and E.ON (15 per cent). However, Statoil and E.ON have left while Axpo (which absorbed EGL in 2012 231 ) has significantly reduced its share. ${ }^{232}$

The TAP is planned to start at Kipoi on the Turkey-Greece border, where it is expected to be connected to TANAP (Figures 10 and 11). ${ }^{233}$ During the project's earlier stages, TAP's entry point had been expected to be located at Komotini in Greece (87 km from the Greece-Turkey border), to which point gas would have been transported through the Greek section of the existing Greece-Turkey Interconnector (ITG). ${ }^{234}$ The ITG connects the Turkish transmission system - owned and operated by Botas ${ }^{235}$ - with the Greek transmission system - owned and operated by DESFA. ${ }^{236}$ It has been in operation since 2007,

\footnotetext{
230 TAP website.

231 'Switzerland: EGL Becomes Axpo', 1 October 2012, LNG World News.

${ }^{232}$ EC (2013), p. 4

${ }^{233}$ According to MoU on TAP-TANAP (see Additional documents), November 2012, also see EC (2013), p. 5

${ }^{234}$ However, as acknowledged by the Italian, Greek and Albanian regulatory authorities, TAP could be connected directly to TANAP thus bypassing the existing Interconnector Turkey-Greece, in which case the entry point of TAP will be transferred to the Greek-Turkish border, see TAP Joint Opinion, pp. 2, 29

${ }^{235}$ Botas is a 100 per cent state-owned Turkish gas company.

${ }^{236}$ DESFA is a 100 per cent subsidiary of DEPA, in which the Greek state owns 65 per cent and the Hellenic Petroleum (a private fund) owns 35 per cent of shares, http://www.desfa.gr/?page_id=2463\&lang=en. DESFA has been undergoing privatization since 2016 as part of the EU/IMF bailout programme, with a view of selling 66 per cent of its shares (including all the Hellenic Petroleum shares). It was reported in August 2017 that the following players submitted their expressions of interest: a consortium of Italy's
} 

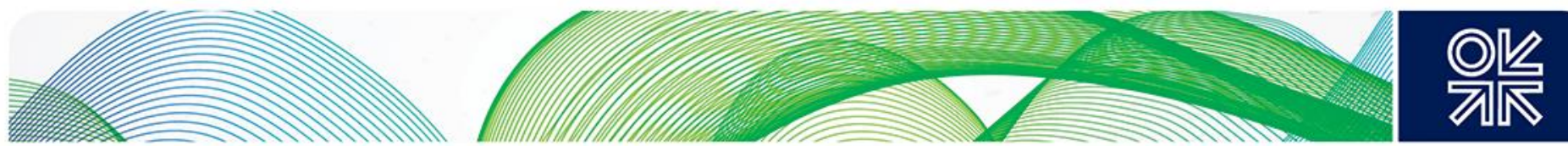

transporting Azeri gas to Greece via Turkey. ${ }^{237}$ Given that the ITG's capacity is only $48.6 \mathrm{GWh} / \mathrm{d}(\sim 1.5$ bcma), its Kipoi-Komotini section (on both the Greek and Turkish parts of the border) would have had to be expanded significantly in order to ensure reservation of sufficient capacity for TAP shippers at Kipoi. ${ }^{238}$ However, it was later agreed that SD2 gas would be transported across Turkey through the new standalone pipeline - TANAP - rather than through the existing Turkish system. ${ }^{239}$ As TAP would be connected directly to TANAP at Kipoi, bypassing the existing ITG, 240 a new pipeline section of $87 \mathrm{~km}$ with a capacity matching that of TANAP would have to be built to connect TANAP with the Greek transmission system, following consultation with DESFA and the Greek regulatory authority (RAE). ${ }^{241}$

At the time when the Joint Opinion on the TAP exemption was adopted by the authorities of Greece, Italy, and Albania, there was no certainty on whether TAP would start at Komotini and connect with the existing Turkish system via the ITG, or whether it would start at Kipoi and connect with the newly built TANAP. Importantly, the Joint Opinion states that the Exemption Decision will not be affected by the decision on whether to connect TAP to TANAP or to the existing Turkish system. ${ }^{242}$

\section{Figure 10: Trans Adriatic Pipeline (TAP) and Trans Anatolian Pipeline (TANAP)}

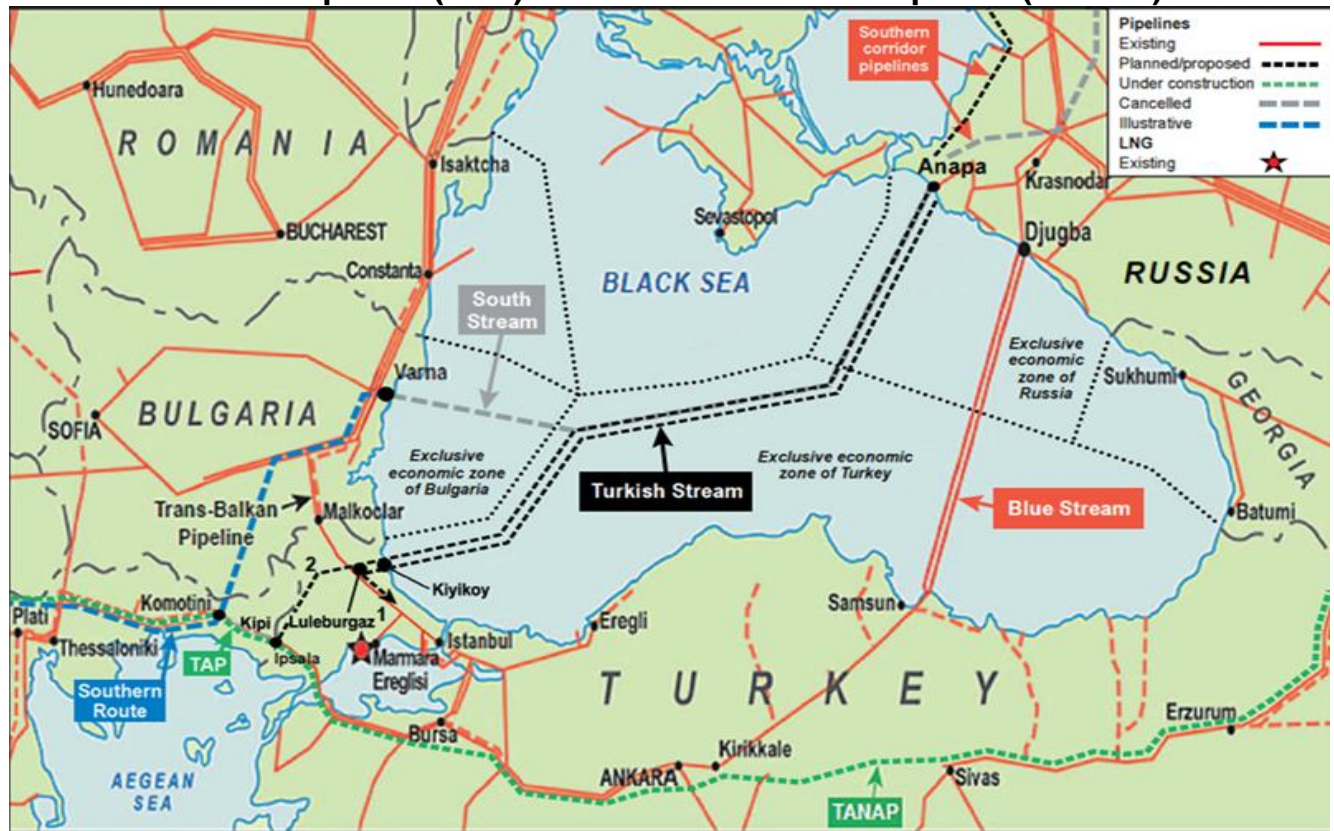

Source: OIES

SNAM, Spain's ENAGAS, Belgium's Fluxys, and the Netherlands' Gasunie, a consortium of Romania's Transgaz and France's GRTgaz, as well as Spain's Reganosa, US' Integrated Utility Services, Australia's Macquarie Infrastructure and Real Assets, and Qatar's Powerglobe, see 'A look at the six suitors for Greece's gas grid DESFA', The National Herald, 8 August 2017. In December 2017 it was reported that the following potential buyers qualified for submitting bindings bids: Reganosa and a consortium of Italy's SNAM, Spain's ENAGAS, Belgium's Fluxys, and the Netherlands' Gasunie, see 'Greece to push back DESGA gas grid privatization deadline: source', Reuters, 18 December 2017. It was announced in April 2018 that two different consortia - one of SNAM, ENAGAS, and Fluxys, and another of Reganosa, Romania's Transgaz, and EBRD - submitted their bids, see 'Greece gets two binding bids in gas grid sale', Reuters, 16 February 2018. The former has won the tender thus clearing the way for acquisition of 66 per cent of DESFA for 535 million euros, see 'SNAM-led consortium wins DESFA tender', Ekathimerini, 19 April 2018. Notably ENAGAS and Fluxys are shareholders of TAP.

237 DEPA website.

${ }^{238}$ There is also the existing interconnection point at the Greece-Bulgaria border (IGB) at Kulata-Sidirokastron: Bulgaria $\rightarrow$ Greece capacity is $108 \mathrm{GWh} / \mathrm{d}(\sim 3.4 \mathrm{bcma})$, Greece $\rightarrow$ Bulgaria capacity is $10 \mathrm{GWh} / \mathrm{d}(\sim 0.3 \mathrm{bcma})$.

${ }^{239} \mathrm{It}$ is not clear whether a connection(s) between TANAP and the existing Turkish system is planned.

${ }^{240}$ TAP Joint Opinion, see Additional documents, p. 2.

${ }^{241}$ The Greek legislation provides for virtual reverse flow in the domestic transmission system, meaning that every entry point is simultaneously an exit point too.

${ }^{242}$ TAP Joint Opinion, see Additional documents, p. 29. 

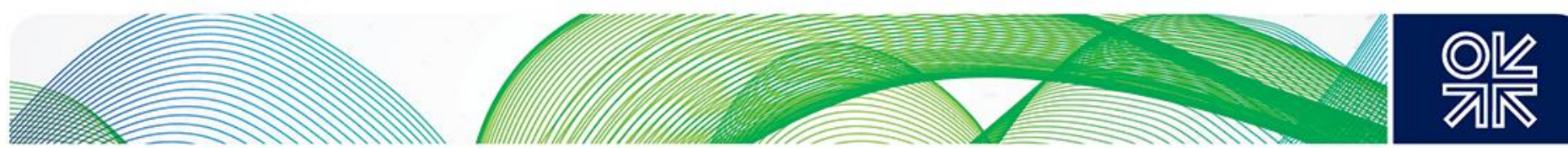

Figure 11: The Trans Adriatic Pipeline (TAP)

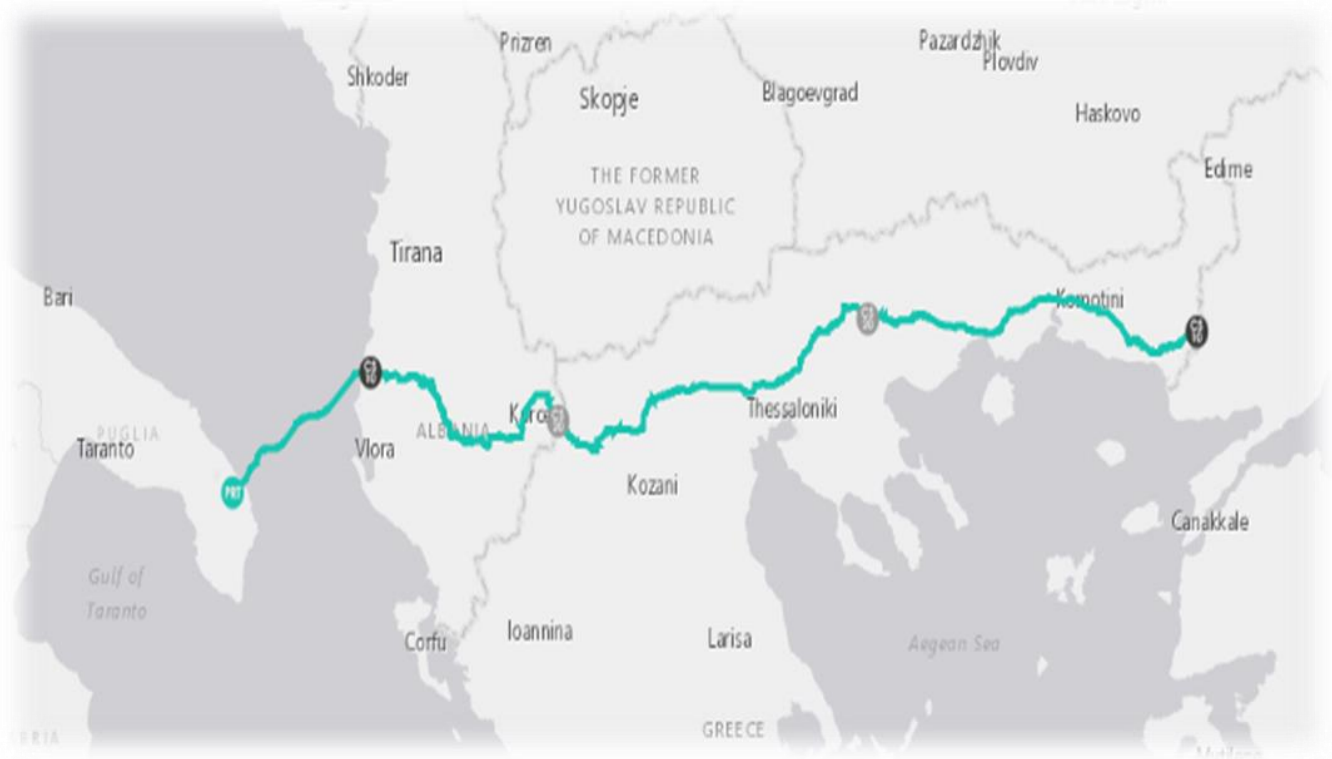

Source: BP

The intention to build a new pipeline - TANAP - which would carry Azeri gas from SD2 across Turkey, was confirmed in the Turkish-Azeri Intergovernmental Agreement on TANAP ('The Turkish-Azeri IGA'), signed on 26 June 2012. ${ }^{243}$ In November 2012, TAP and TANAP signed a memorandum of understanding ('TAP-TANAP MoU'), which established technical and commercial cooperation and formalized a framework for information exchange. In particular, the TAP-TANAP MoU specified that TAP and TANAP would be directly connected at Kipoi at the Greece-Turkey border. In November 2015, TANAP and TAP signed an agreement for cooperation during construction ${ }^{244}$ which stipulated 'the responsibilities for constructing the interconnection and the technical specifications for connecting the two pipelines' and specified 'the exact terms for connecting the two projects'.

The Turkish-Azeri IGA on TANAP states that apart from a domestic exit point in Turkey (thus connecting to the Turkish domestic transmission system as $6 \mathrm{bcm}$ of SD2 gas is to be delivered to Turkey), TANAP could have several external exit points, including at the Turkey-Greece border, the Turkey-Bulgaria border, or any other point as agreed by Turkey and Azerbaijan. ${ }^{245}$ As noted earlier, there is an existing interconnection point on the Turkey-Greece border (the ITG) as well as an existing interconnection point on the Turkey-Bulgaria border located at Standhza-Malkoclar with a capacity of $468 \mathrm{GWh} / \mathrm{d}(\sim 14.8$ bcma), connecting the Trans Balkan pipeline system with the Turkish domestic system. (At present, the Trans Balkan system is predominantly used for Russian gas deliveries to western Turkey, but utilization will decline as Russian gas deliveries to western Turkey will be re-routed to the first string of Turkish Stream as of $2020 .{ }^{246}$ )

While TANAP envisages the possibility of having several external exit points, TAP envisages only one entry point, where it is planned to connect to TANAP - Kipoi at the Turkey-Greece border. ${ }^{247}$ TAP will have exit points in Greece, Albania, and Italy. In Italy a new entry point to the Italian transmission system

\footnotetext{
243 The Turkish-Azeri IGA.

244 TAP (2015).

245 The Turkish-Azeri IGA, preamble.

246 The Russian-Turkish IGA (see Additional documents)

247 TAP Joint Opinion (see Additional documents).
} 

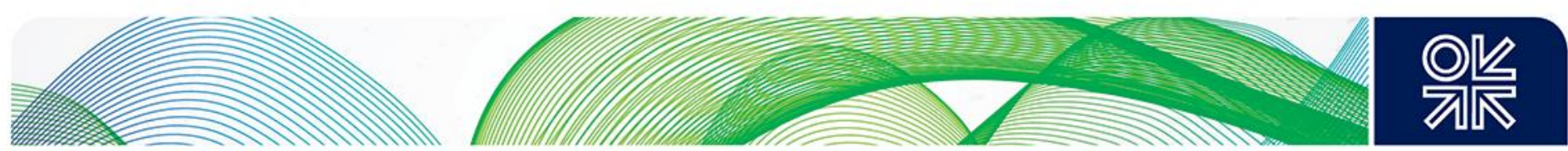

- owned and operated by SNAM Rete - will connect with TAP at San Foca in southern Italy. In addition, the Italian system will be expanded to allow SD2 gas flow from the south to the north of Italy. ${ }^{248}$

The TAP is being built in two stages:

1. a pipeline with capacity of 10 bcma ('Initial Capacity'),

2. an expansion of capacity by a further 10 bcma ('Expansion Capacity') by means of adding compressor stations along the pipeline built during the first stage, thus achieving a total capacity of 20 bcma ('Total Capacity').

According to the TAP consortium's announcement made in January 2017, the project's cost is estimated at 4.5 billion euros. ${ }^{249} \mathrm{It}$ is understood that this estimate relates to the first stage, during which the pipeline with the Initial Capacity of 10 bcma would be built, whereas the addition of Expansion Capacity of a further 10 bcma during the second stage would increase the cost by 18 per cent. ${ }^{250}$ As this paper is being completed, the financing of the TAP is understood to be ongoing and yet to be finally decided. ${ }^{251}$ Notably, although TAP is $~ 70$ per cent complete, it is under review in Italy, where the new government, which came to power following the May 2018 elections, has expressed doubts about the need for it. 252 However, the government appears to have since softened its position, with one of its senior officials, Guglielmo Pichhi, was quoted in June 2018 as saying that it is the government's 'intention to put it [TAP] in place'. ${ }^{253}$

\subsubsection{Shah Deniz 2 gas sales agreements (contracts) 254}

The SD consortium, which owns the gas to be transported through TAP, is led by the UK's BP with a 28.8 per cent share. BP has a number of partners: the Turkish state-owned company, TPAO (19 per cent), the Azeri state-owned company, SOCAR (16.7 per cent), the Malaysian state-owned company, Petronas of Malaysia (15.5 per cent), ${ }^{255}$ the Russian private company, LukOil (10 per cent), and the Iranian stateowned company, NIOC (10 per cent). The consortium's ownership structure has changed significantly since its inception: previous stakeholders included Total, ENI, and Statoil, all of which have since left the consortium. . $^{256}$

On 19 September 2013 the SD consortium announced the conclusion of 25-year sales agreements for 'just over 10 bcma of gas' to be produced from SD2. ${ }^{257}$ The SD press release lists the following buyers: Switzerland's Axpo, Bulgaria's Bulgargaz, Greece's DEPA, Italy's Enel, Germany's E.ON (now Uniper), Spain's Gas Natural, France's GDF SUEZ (now ENGIE), Hera Trading Srl, and Shell Energy Europe. Of the total $10 \mathrm{bcma}$, around $1 \mathrm{bcma}$ was contracted by DEPA and around $1 \mathrm{bcma}$ by Bulgargaz for supplies to Greece and Bulgaria respectively, and the remaining $8 \mathrm{bcm}$ by buyers intending to supply Italy and 'adjacent market hubs'. Notably, the SD agreements with European buyers were concluded only after the TAP had been granted an exemption by the EC in June 2013 ('EC TAP Exemption Decision') (Section 3.3.6), ${ }^{258}$ and after SD had concluded agreements with Botas to sell 6 bcma to Turkey in 2011. Overall, $16 \mathrm{bcma}$ of SD2 gas has been contracted, of which $10 \mathrm{bcma}$ is intended to be sold in Europe and $6 \mathrm{bcma}$ in Turkey. These agreements completed the SD2 gas sales process and entered into force following the SD2 Final Investment Decision (FID), which took place on 17 December 2013. ${ }^{259}$

\footnotetext{
248 The TAP-SNAM Rete construction contract was signed in December 2007

249 'Trans Adriatic Pipeline to cost 4.5 billion euros: project chief', Anadolu Agency, 31 January 2017.

${ }^{250}$ EC TAP Exemption Decision (EC 2013), p. 5.

${ }^{251}$ Prospective lenders include the EIB, the EBRD, export credit agencies, as well as commercial banks.

252 'Exclusive: Italy's new government to review TAP gas pipeline', Reuters, 6 June 2018.

253 'Italy intends to endorse new chapter in NATO-Russia ties: Under-Sec of State, Sputnik, 25 June 2018.

${ }^{254} \mathrm{BP}(2013 \mathrm{a})$.

${ }^{255}$ Acquired Statoil's share in November 2014.

${ }^{256}$ Rzayeva (2015).

${ }^{257}$ Shah Deniz Stage 2 will add a further 16 bcma of production to the $\sim 9$ bcma produced by Shah Deniz 1 .

${ }^{258}$ EC (2013).

${ }^{259} \mathrm{BP}(2013 b)$.
} 

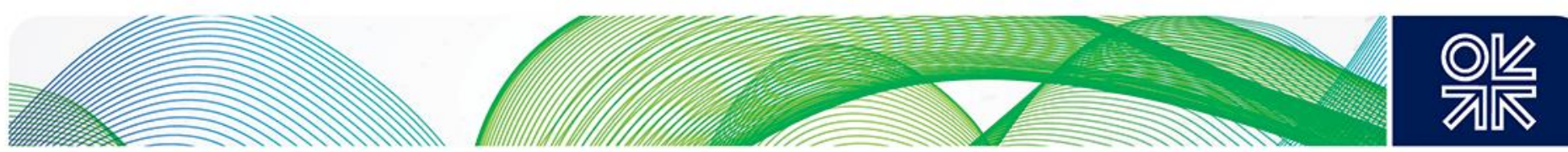

\subsubsection{The TAP legal / regulatory framework}

The major element of the legal / regulatory framework governing the TAP is an exemption from certain provisions of the Third Gas Directive and Gas Regulation 715. The exemption was granted by the national regulatory (competent) authorities of Italy, Greece, and Albania - countries in which the TAP would be located - and approved by the EC in 2013 , subject to additional conditions such as inter alia:

- development of the TAP Tariff Code (setting the rules of tariffs);260

- development of the TAP Network Code (setting the rules on capacity allocation and management); 261

- establishment of the Regulatory Compliance Programme (RCP);262

- certification of the TAP under an ad hoc ITO model;

- development of the First Market Test guidelines (developed by the national regulatory authorities).

Other elements of the legal / regulatory framework include the following:

- A trilateral Intergovernmental Agreement (IGA) between Greece, Albania and Italy (signed on 13 February 2013 and ratified by the national parliaments of Albania in March 2013, Greece - April 2013, Italy - December 2013);263

- Host Government Agreements (HGAs) between TAP and Greece (signed 26 June 2013264) and TAP and Albania;265

- Environmental and Social Impact Assessments (ESIAs), approved in Italy, Greece, and Albania.

The TAP exemption decision is analysed in Section 3.3.6, with the focus on capacity allocation, tariffs, and unbundling provisions.

\subsubsection{TAP's Exemption Application: capacity allocation and tariff principles}

During August-September 2011, the TAP consortium submitted an application for an exemption from certain provisions of the Third Gas Directive and Gas Regulation 715 to the Italian Ministry of Economic Development (MSE) ${ }^{266}$, the Greek regulatory authority (RAE), and the Albanian regulatory authority (ERE).

It requested an exemption for the period of 25 years from the date of commercial operation - thus matching the duration of SD2 gas supply contracts (Section 3.3.2) - as follows:

- In respect of Initial Capacity: from third-party access (TPA) (Art. 32) and from regulated tariffs (Art. 41.6, 41.8, 41.10).

- In respect of Expansion Capacity: from regulated tariffs (Art. 41.6, 41.8, 41.10).

\footnotetext{
260 The TAP Tariff Code was approved by the authorities in November 2013, see TAP Joint Certification Opinion, p. 4. The code must be published before the start of TAP's commercial operation; as this paper is being completed, the code is not available in public domain.

${ }^{261}$ As this paper is being completed, the TAP Network Code is under development and has not been finalized yet.

262 The compliance programme was approved by the authorities in February 2014, see TAP Joint Certification Opinion, p. 4.

${ }^{263}$ TAP (2013a). Having been signed and ratified by all host countries, the IGA has become part of their national legislation.

264 TAP (2013c); Greece-TAP HGA.

265 TAP (2013b). No HGA was signed between TAP and Italy as the latter's legislation does not envisage / necessitate such a possibility.

${ }^{266}$ Under Italian legislation the MSE is responsible for granting exemptions under a non-binding opinion of the Italian regulatory authority (AEEG).
} 

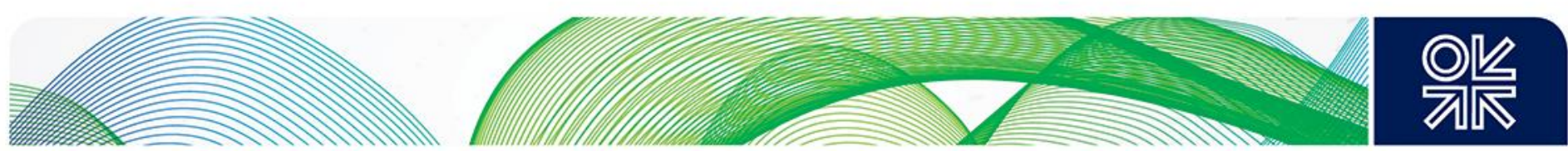

- In respect of both Initial and Expansion Capacity: from regulated tariffs for reverse flow (Art. 41.6, $41.8,41.10$ ), from the unbundling provisions (Art. 9), and from all provisions of Gas Regulation 715 except Art. 19.4. ${ }^{267}$

In its application for an exemption, TAP offered to allocate the Initial Capacity to its own shareholders on a pro rata basis under ship-or-pay contracts. ${ }^{268}$ It has also proposed to offer the Expansion Capacity to 'all interested parties in full to the market, at the TAP tariff, in a non-discriminatory manner and on the basis of prevailing European capacity management rules and prevailing regulation on capacity allocation', as firm capacity and under contracts of duration not longer than the requested exemption period of 25 years. ${ }^{269}$ As far as the Reverse Capacity ${ }^{270}$ is concerned, TAP has also proposed to offer it to the market.

The TAP consortium developed several scenarios of capacity allocation and tariff setting under different regulatory conditions, in order to justify its request for an exemption.

- In its first - 'base case' - scenario, all 10 bcma of the Initial Capacity would be exempted from TPA for 25 years and an (unregulated) uniform tariff would be applied to all shippers (irrespective of whether capacity is used for forward or reverse flow), with the tariff being set to ensure the target revenue as set by TAP. TAP argued that unless the tariff is uniform (rather than differentiated), the Initial Capacity shippers would be disadvantaged compared to the Expansion Capacity shippers, as the former would not sign long-term ship-or-pay contracts if they knew in advance that the latter would be able to transport their gas through the Expansion Capacity at a lower tariff and for a shorter period.

- The second - 'regulated' - scenario envisaged that all 10 bcma of the Initial Capacity would be exempted from TPA and offered at a regulated tariff (as opposed to an unregulated tariff under the first scenario).

- The third - 'hybrid' - scenario envisaged that 80 per cent of the Initial Capacity (in other words 8 bcma) would be exempted from TPA and offered at an unregulated tariff (as in the first scenario) whereas the remaining 20 per cent of the Initial Capacity (in other words 2 bcma) would be offered to third parties at a regulated tariff (as in the second scenario).

- The fourth scenario envisages a shorter duration for an exemption - 20 years (compared to 25 in all other scenarios).

As part of its analysis of the scenarios, the consortium concluded that the project would only be viable under the 'base case' scenario - offering the entire Initial Capacity of 10 bcma to its shareholders at an unregulated tariff - while expressing 'significant doubts' about the project's financial viability under all other scenarios.

The uniform TAP tariff ('TAP Tariff) and the methodology used for its calculation, as suggested by the TAP consortium, is explained in detail below. The consortium suggested the use of tariff methodology based on an entry-exit system whereby the target revenue would be split equally between an entry fee and an exit fee. ${ }^{271}$ The entry fee is to be allocated 'in proportion to all volumes entering TAP (only one entry point is planned [at Kipoi on the Greece-Turkey border]), unrelated to the distances for which such volumes will be shipped'. The exit fee is to be allocated to the volumes exiting TAP at various exit points (of which there are several), 'in proportion to volumes and travelled distance'. ${ }^{272}$ The tariff would also

\footnotetext{
${ }^{267}$ TAP Joint Opinion (see Additional documents), pp. 4-5.

${ }^{268}$ A 'ship-or-pay' contract is a transportation (capacity) contract whereby a shipper commits to pay for capacity it has booked irrespective of whether or not it has used it, so that a pipeline company (a TSO) can remunerate its investment, TAP Joint Opinion (see Additional documents) p. 5.

269 TAP Joint Opinion, see Additional documents, p. 5.

270 In other words, the Initial and the Expansion Capacity used for reverse flow.

271 TAP Joint Opinion, see Additional documents, p. 8.

272 Ibid.
} 

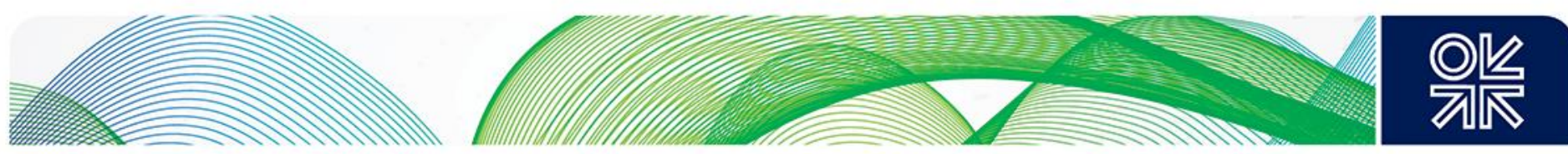

apply to short-term products as a floor price 'to the extent products are offered though auctions' whereas 'further provisions could be made for products with a duration shorter than one year'. Once a binding offer (which would contain a specified tariff model) to the SD consortium is completed, the cost estimate underlying the tariff calculation would be revised. In respect of the allocation of risk, associated with changes in the planned costs, the TAP consortium offered to accept technical risk with a view that the SD consortium was to accept 'market risk, as well as the risk of [unspecified] certain changes outside TAP AG's control'. Once the exact level of tariff is finally determined, changes would only come from annual escalation and expansion cases, with the tariff also being adjusted on an annual basis to account for inflation.

TAP proposed to offer firm capacity to all interested parties on a non-discriminatory long-term basis at a uniform tariff which means that all shippers would be charged the same tariff in respect of Initial and Expansion Capacity, irrespective of whether they use it for forward or reverse flow. The main principle according to which it was suggested the tariff be calculated, is to ensure that 'all investments costs are recovered and the minimum requirement from lenders and shareholders is fulfilled'. The resulting target revenue is distributed to all firm capacity products that can be sold. An Initial Capacity tariff is calculated to cover all the costs of realizing the initial capacity of $10 \mathrm{bcma}$, as well as those associated with recovering the pre-investments undertaken for the Expansion Capacity.

When only the Initial Capacity is built, the TAP tariff is thus calculated as follows:

TAP Tariff = Targeted Revenue / Initial Capacity .

When the Expansion Capacity is developed or Reverse Capacity is booked, the TAP tariff is re-calculated following the same methodology, while taking into account the additional costs of the Expansion Capacity. If Reverse Capacity is booked, the additional revenues above target revenue are re-distributed, thus lowering the tariff:

TAP Tariff $=$ Targeted Revenue $/($ Initial Capacity + Expansion Capacity + Reverse Capacity).

Any additional income received from selling Expansion Capacity or Reverse Capacity would thus reduce the tariff for all shippers.

\subsubsection{The TAP First Market Test procedure: Expression of Interest and Booking Phases}

\section{First Market Test Guidelines}

As explained in Section 2.2, according to the Third Gas Directive (Art. 36), prior to deciding on the exemption, the regulatory authorities of the countries on whose territories the new infrastructure is envisaged to be built - Greece, Italy, and Albania in the TAP case 273 - are obliged 'to decide upon the rules and mechanisms for management and allocation of capacity'. These rules must 'require that all potential users of the infrastructure are invited to indicate their interest in contracting capacity before capacity allocation in the new infrastructure, including for own use, takes place'. The Italian, Greek, and Albanian authorities decided that 'to this end, a Market Test should be implemented, inviting all potential users' of new infrastructure 'including its shareholders, to indicate their interest in contracting capacity' in new infrastructure in respect of which an exemption is sought.

In April 2012 the Italian, Greek, and Albanian regulatory authorities - AEEG, RAE, and ERE respectively - jointly developed the Guidelines for management and allocation of capacity in TAP ('First Market Test Guidelines'). ${ }^{274}$ These Guidelines stipulated that the Market Test must be conducted in two phases (Art. 2.2):

\footnotetext{
${ }^{273}$ Albania is not an EU member state but is a Contracting Party of the Energy Community Treaty (https://www.energycommunity.org/aboutus/whoweare.html) and is therefore obliged to comply with some of the EU energy acquis, including the Third Gas Directive (see Additional documents)

${ }^{274}$ First Market Test Guidelines (see Additional documents).
} 

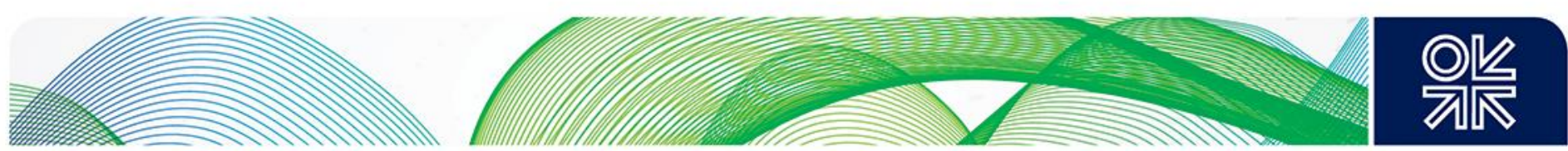

- non-binding Expression of Interest (EI) phase, and

- binding Booking phase.

The First Market Test Guidelines provided a general framework for capacity allocation and management procedures. In particular, they stipulated a detailed procedure for conducting the Expression of Interest phase and outlined general principles for conducting the Booking phase. A detailed procedure for conducting the Booking phase of the first Market Test was set in the separate guidelines approved by the authorities in March 2014 - Booking Phase Guidelines. ${ }^{275}$

Also, as this paper is being completed, a new set of Guidelines for the future market tests is under development ('Subsequent Market Test Guidelines'). It is not clear whether and how the Subsequent Market Test Guidelines might be different from the First Market Test Guidelines (governing the first market test), including in respect of the procedure and capacity allocation provisions.

The First Market Test Guidelines stipulated the following conditions to be observed while issuing a positive opinion on the exemption:276

- in expressing a positive opinion, the authorities will consider the need to impose conditions regarding, for example, the duration of the exemption and non-discriminatory access to the infrastructure (Art. 3.4);

- the positive opinion may also be conditional on the TAP being obliged to offer the Expansion Capacity in the Booking phase and to build it if allocated, in so far as it is technically and economically feasible to do so (Art. 3.4);

- the exemption 'may also include an obligation' on the TAP to 'run further market tests in subsequent years, with the view of investigating the willingness of potential users to contract additional capacity' (Art. 3.6).

\section{The Expression of Interest (EI) Phase: a procedure}

The First Market Test Guidelines obliged TAP to propose procedures for conducting the expression of interest (EI) phase within 20 days of the Guidelines being issued. Within 15 days, the authorities were required to verify whether these procedures are 'open, non-discriminatory, transparent and in accordance with EU and national legislation'. Once the procedures were approved by the authorities, TAP was obliged to conduct the El phase. Notably, the El phase neither binds participants to book the capacity in the TAP for which they have expressed interest, nor does it bind the TAP to offer such capacity.

Procedures for conducting the El phase must also include the expression of interest notice, which should provide the following information (Art. 4.3):277

- the pipeline's intake and offtake points, route, alternative designs;

- technical specifications;

- a description of proposed connections to other networks in Greece, Albania, and Italy, as well as information on how TAP will 'pursue with the corresponding expansion of capacity in those other networks';

- transportation services proposed in the exemption application, the contractual intake and offtake points, date, and duration for each service;

- additional transportation services (firm forward transportation from the intake point in Greece (Komotini278) to any point in Greece, Albania, and Italy, including the offtake point in Italy (San

\footnotetext{
275 Booking Phase Guidelines.

${ }^{276}$ First Market Test Guidelines (see Additional documents), pp. 5-6.

${ }^{277}$ First Market Test Guidelines (see Additional documents), pp. 7-9.

${ }^{278}$ Komotini has since been replaced by Kipoi on the Greece-Turkey border as the TAP's entry point, see Section 3.3.1.
} 

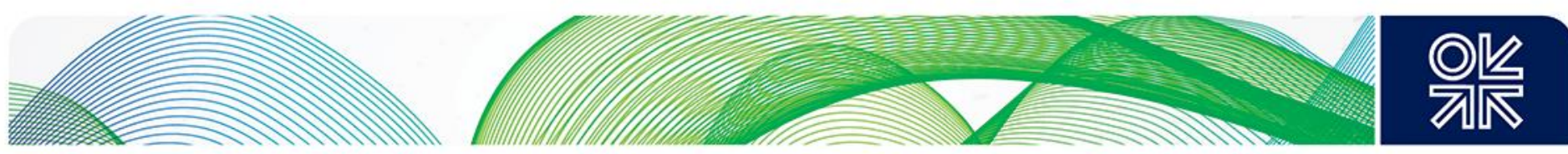

Foca), firm and/or interruptible reverse flow transportation from the intake point in Italy to any point in Italy, Albania, and Greece, up to the offtake point in Greece);

- estimate of investment and operating costs (CAPEX and OPEX);

- summary of authorizations, licenses, and regulatory approvals and their timetable)

- declaration that participation in the Expression of Interest phase is 'a prerequisite for participation at the Booking phase that might follow' (Art. 4.4). ${ }^{279}$

The Guidelines stated that 'all interested parties including TSOs and relevant institutions (governments, ministries of EU member and non-member states, financial institutions) as well as market operators, may participate in the El phase' under equal terms (Art. 6.1). With this aim, all potential users, institutions, and TSOs ${ }^{280}$ were invited to express their interest in 'contracting capacity or in connecting to the infrastructure', and submit their application forms to the regulatory (competent) authorities and TAP, together with the relevant information for assessment of compliance with the exemption criteria (Art. 2.3). Participants were invited to indicate their interest in the type, start date, duration, and amount of capacity for each transportation service. They were allowed to suggest modifications to TAP's proposal - for example additional intake and offtake points, different start and end dates, duration of services, interruptible services (Art. 6.4).

Importantly, market operators were obliged to submit a declaration to TAP stating that 'sanctioned gas will not be imported or transported through any part of the TAP project'. 281 'Sanctioned gas' is defined as natural gas which '(a) has been extracted from petroleum deposits in a sanctioned jurisdiction (restricted gas); or (b) will have been made available to the shipper of that gas as a direct or indirect result or consequence of any contractual or other arrangement to which the shipper, or any of its affiliates or related persons (the offtaker), is a party whereby the offtaker purchases restricted gas; or will have been made available to the shipper as a direct or indirect result or consequence of any other arrangement having a similar economic or practical effect'. 282 In turn, 'sanctioned jurisdiction' is defined as 'any jurisdiction in respect of which any commercial, import or export activities with that jurisdiction or persons resident in that jurisdiction and subject to sanctions imposed by any of the EU, the UN, or the USA, in each case in relation to terrorist activities or sponsorships, or the acquisition or possession of WMD'.

Market operators were also asked to provide as part of their application (to the authorities only, not to TAP) ${ }^{283}$ information on the upstream and downstream transportation systems that they will rely upon for their usage of TAP, whether they have already booked capacity in these systems or whether they have signed transportation contracts matching the required capacity, information on the source and origin of gas (in particular, whether the requested capacity is to be used for transportation of SD2 gas), and information on the status of their agreements with upstream suppliers (Art. 6.5).

The Expression of Interest phase: the results and the implications for an exemption

Following the preparation by the TAP consortium of the Expression of Interest (EI) notice and its approval by the authorities, the El phase was conducted during 15 June-15 August 2012.284 In line with the First Market Test Guidelines, 15 days after the El phase was completed, TAP submitted a report evaluating the results and their implications for the TAP project. The national regulatory authorities provided their

\footnotetext{
$279 \mathrm{lbid}, \mathrm{p} .9$.

${ }^{280}$ While the Third Gas Directive (see Additional documents) makes it mandatory that 'all potential users' are invited to indicate their interest, the TAP First Market Test Guidelines (see Additional documents) allows the invitation of not only all potential users but also institutions and TSOs that might not be potential users.

${ }^{281}$ TAP Joint Opinion, p. 63.

282 First Market Test Guidelines (see Additional documents), p. 2.

${ }^{283}$ TSOs and institutions participating in the Expression of Interest phase should express their interest both to the authorities and to TAP.

${ }^{284}$ The Expression of Interest notice was prepared by TAP and approved by the authorities in May-June 2012.
} 

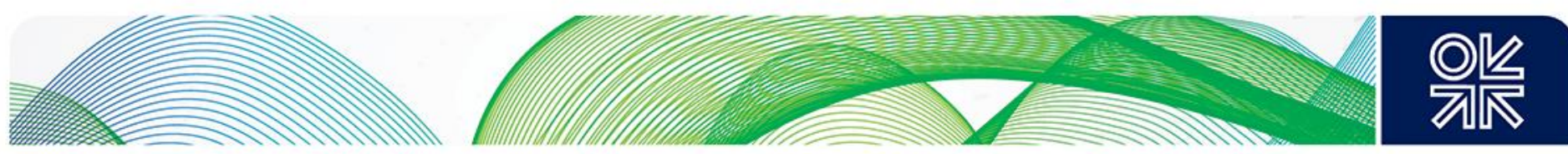

opinion on the results of the El phase within 30 days of receiving the TAP report, while also assessing the TAP's compliance with the exemption criteria.

Among 19 companies which had registered for the El phase, thus formally expressing their interest in TAP capacity, 'most were energy traders and suppliers' whereas an unnamed entity had also participated by submitting an 'institutional expression of interest'. ${ }^{285}$ As far as forward flow capacity is concerned, the main expressed interest related to long-term capacity from the TAP's initially planned entry point at Komotini (which has subsequently changed to Kipoi, see Section 3.1.1286) to the exit point in Melendugno (Italy), subject to 'ship-or-pay' transportation agreements as of the commercial operation date, until 2036 to $2042 .{ }^{287}$ The total capacity required for this product was $40 \mathrm{bcma}$, whereas the total long-term capacity requests from the TAP entry point to its exit point were $41.5 \mathrm{bcma}$. Interest was also expressed in longterm capacity from Komotini to the exit point in Fier (Albania) totalling $1.45 \mathrm{bcma}$, as well as in long-term capacity from Komotini to one or more TAP exit points in Greece totalling $3.52 \mathrm{bcma}$. As far as the reverse flow capacity is concerned, interest was expressed in respect of capacity from Melendugno to an exit point in Albania in the amount of $1.44 \mathrm{bcma}$ and to an exit point in Greece in the amount of $9.53 \mathrm{bcma}$. No interest was expressed in the short-term capacity (up to one year). The shortest duration product for which interest was expressed was for five years; the shortest-term products in respect of which interest was expressed were forward capacity from Komotini to Melendugno and also, optionally, to an exit point in Albania or Greece (all as secondary products). No additional entry points were requested (thus suggesting that TAP would only have one entry point), while two additional exit points in Albania and three additional exit points in Greece were requested. Given that one of the requested additional exit points in Greece is in the Komotini region, ${ }^{288}$ it might suggest that the participants were also interested in supplying the gas to the Turkish market.

Based on the results of the El phase, the authorities concluded that TAP is being considered by its shareholders, as well as by the market, mostly as the route for transporting Azeri gas from SD2 to Italy on a long-term basis, with some demand present for forward and reverse flow to Albania and Greece and with only low demand expressed for shorter-term (less than 25 years) products. At the same time, the authorities have acknowledged the possibility of potential demand which would also cover some or all of the Expansion Capacity. Interestingly, some (unnamed) institutions showed an interest in TAP as a way of developing new markets.

The Market Test resulted in an overall demand of $\sim 46.4$ bcma from shippers, which would rely either on SD gas or on gas from new (unspecified) sources. The regulatory authorities concluded that the amount of SD2 gas available for transportation to Europe via TAP 'will be no more than $10 \mathrm{bcma}$ - and could be less - it was 'reasonable to assume' that the Initial Capacity of 10 bcma would be sufficient, as this capacity would cover all the requests made during the El phase. Furthermore, the authorities concluded that the Expansion Capacity of an additional $10 \mathrm{bcma}$ would be sufficient for transportation of 'all gas quantities with sources other than SD2 ... especially if not all the participants of the El phase participate in the Booking phase ... should they not feel in a strong position to commit capacity on a long-term basis for gas quantities that might come from non-specified (and, therefore potentially not secured) sources'. ${ }^{289}$ TAP would be obliged to offer the Expansion Capacity to all other participants of the El phase who were still willing to reserve capacity in TAP for the transportation of non-SD2 gas.

\footnotetext{
285 TAP Joint Opinion (see Additional documents), p. 12.

${ }^{286}$ At the time when the Expression of Interest phase was carried out there was no certainty in respect of whether Komotini or a point at the Greece-Turkey border would be the TAP's entry point, hence all the references were made to Komotini.

${ }^{287}$ Initially, the TAP's commercial operation date was expected to be 1 January 2019 at the latest (and the exemption was to lose its validity on 16 May 2019). TAP has subsequently changed to a date within the range1 January 2020-31 December 2020.

288 In the following regions: western Macedonia, Nea Mesimvria, and Komotini.

${ }^{289}$ TAP Joint Opinion, see Additional documents, p. 21
} 

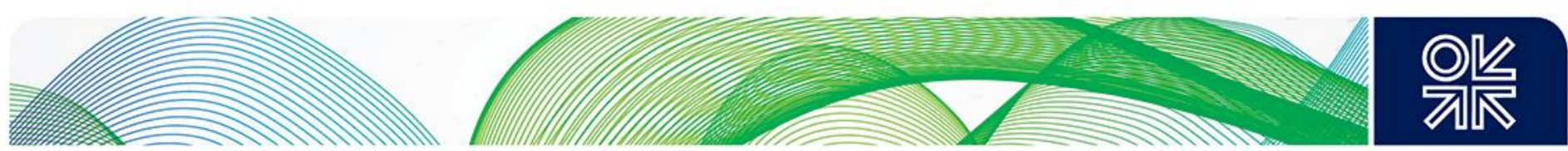

The Booking phase

The Booking phase is the second - binding - phase of the Market Test. The First Market Test Guidelines stipulated that during that phase 'potential users are requested to bid and subscribe for capacity' in TAP so that 'long-term capacity is allocated under ship-or-pay contracts, subject to the final investment decision by TAP AG and its shareholders leading to the actual realization of the infrastructure'.290

The First Market Test Guidelines established the following general principles to be applied during the Booking phase in respect of capacity allocation and tariffs:

- capacity allocation through auctions;

- cost-reflective and non-discriminatory tariffs.

They have also set out the following general principles governing capacity management:

- to include Congestion Management Procedures (CMP), Use-it-or-Lose-it (UIOLI) arrangements, secondary capacity trading arrangements, balancing regimes, capacity overruns, and nomination and re-nomination rules compliant with relevant EU provisions as they will be established, amended, or integrated;

- TAP is to develop its own network code ('TAP Network Code') compliant with the aforementioned rules, subject to the authorities' approval, which will provide for a harmonized regime for capacity allocation for the entire TAP route.

The First Market Test Guidelines stated that, should there be a need for a Booking phase, the authorities were to issue separate Booking Phase Guidelines, ${ }^{291}$ outlining detailed design, and the amount of capacity available for booking, in line with the general principles of the First Market Test Guidelines. Notably '[d]etailed rules, products, tariffs and duration of contracts of capacity allocation, as well as mechanisms to deal with cost-overruns and penalties applied to TAP if capacity is not delivered on time' were to be decided by the authorities before the Booking phase, taking into account the exemption criteria (Art. 36.1) and the results of the El phase.

Having evaluated the results of the El phase as part of their Joint Opinion on the TAP's exemption request (Section 3.3.6), the authorities decided to impose an obligation on the TAP consortium to launch the Booking phase of the first Market Test no later than three months after the TAP's Final Investment Decision (FID) date. On 17 December 2013, following the announcement on the SD2 FID, the TAP shareholders confirmed that they had passed the 'Resolution to Construct'. Three months later, on 17 March 2014, TAP launched the Booking phase of the first Market Test by sending the notice, specifying the details for participation and providing relevant information, to all registered participants. All participants of the El phase were allowed to participate in the Booking phase (subject to capacity caps for the Italian, the Greek, and the Albanian markets as set in their respective exemption decisions (see Section 3.3.7))..$^{292}$

On 1 December 2014 TAP announced the closure of the Booking phase and the completion of the Market Test. The TAP press release states that as a result of the Market Test 'additional capacity will be provided at TAP's entry point at the Turkey-Greece border and additional exit points will become available along the route'; no further details have been published. ${ }^{293}$ In February 2017, one of TAP's directors, Ulrike

\footnotetext{
290 First Market Test Guidelines (see Additional documents).

291 These guidelines were issued in March 2014, Booking Phase Guidelines (see Additional documents).

${ }^{292} \mathrm{~A}$ party is also considered to have participated in the El phase if another party has expressed interest for the benefit of the party that wishes to participate in the Booking phase.

${ }^{293}$ This suggests that bookings made during the first market test were made in respect of the TAP's entry point at the Greece-

Turkey border rather than at Komotini, see TAP $(2014 b)$. Although the press release did not specify the name of the entry point it

is understood to be Kipoi.
} 

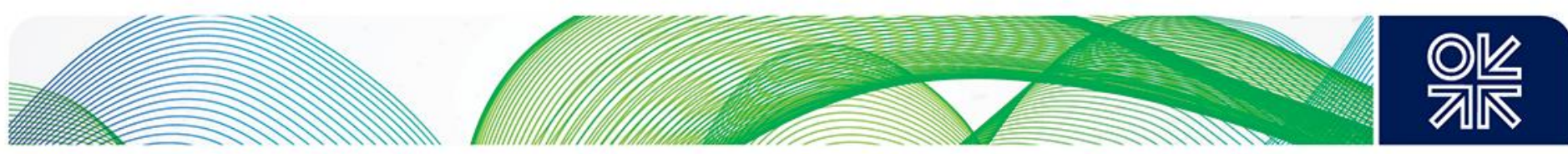

Anders, confirmed that 'all of the Initial Capacity (10 bcm per year)' has been booked on 'ship or pay, long-term contracts' for 25 years, while also saying that 'a minor amount of capacity' is 'available for short term (annually and less than one year in duration) transportation' and that 'capacity might be made available on the secondary market, should there be demand from shippers' ${ }^{294}$ TAP will offer available short-term capacity to the market according to the ENTSOG auction calendar, with the first regular auction expected to be conducted in November 2019. It is understood that some Expansion Capacity has also been booked although there is no information in public domain on either the amount of capacity or the shippers that have booked it. ${ }^{295}$

\subsubsection{The TAP Exemption Decision: key provisions}

Having decided 'upon the rules and mechanisms for management and allocation' of TAP capacity - as required by the Third Gas Directive - by means of the First Market Test Guidelines, according to which the El phase was held during 15 June-15 August 2012, the Italian, Greek, and Albanian regulatory authorities issued their Joint Opinion on the TAP's exemption request ('TAP Joint Opinion'), taking into account the results of the El phase. ${ }^{296}$ This Joint Opinion is an integral part of the national - Italian, ${ }^{297}$ Greek, ${ }^{298}$ and Albanian ${ }^{299}$ - exemption decisions, the former two of which were notified to the EC, and the latter to the Energy Community Secretariat, ${ }^{300}$ in early March 2013 for assessment. In their Joint Opinion, the national regulatory authorities have approved the TAP's request for an exemption - but only in part and subject to additional conditions, which must be fulfilled by the TAP consortium for the exemption to be granted.

For its part, on 16 May 2013, the EC adopted its own TAP Exemption Decision ${ }^{301}$ ('EC TAP Exemption Decision') based on the review and assessment of national exemption decisions, including the Joint Opinion. ${ }^{302}$ The EC confirmed that the TAP - an interconnector - would enhance security of supply in Italy, Greece, and Albania, and would enhance, and would not be detrimental to, competition in Italy and Greece (the Energy Community Secretariat concluded that the TAP would enhance competition in Albania), subject to additional conditions imposed in the EC Exemption Decision, thus confirming the TAP's adherence to the exemption criteria. ${ }^{303}$ It is worth noting, however, that one of the exemption criteria - that the infrastructure must be owned by a person who is separate, at least in terms of that person's legal form, from the system operators in whose systems it will be built - might have to be revisited once the procedure of acquisition by a consortium of SNAM, Enagas, and Fluxys of the 66 per cent stake in the Greek TSO, DESFA, is finalized, following their successful bid in April 2018. ${ }^{304}$ As part of its Exemption Decision, the EC recommended further conditions - in addition to those requested by the national regulatory authorities in the Joint Opinion - to be imposed on TAP.

\footnotetext{
294 'TAP first phase sold out, Russia, Eastmed could piggybank on expansion', New Europe, 6 February 2017.

295 TAP shareholders were informed about the results of the Booking Phase while only aggregated bookings were communicated but not the names of a relevant shipper or the amount of capacity it had booked, see TAP Joint Certification Opinion, p. 26.

296 TAP Joint Opinion, see Additional documents.

297 MSE (2013)

298 RAE (2013)

${ }^{299}$ ERE (2013).

${ }^{300}$ As Albania is not an EU member state but is a contracting party to the Energy Community Treaty.

${ }^{301}$ EC (2013) (the EC TAP Exemption Decision)

${ }^{302}$ EC Exemption Decision applies to TAP only and does not - and cannot - impose 'conditions upon the operators of other projects, even if potentially interconnecting with TAP, such as TANAP', see EC (2013), p. 20.

303 EC (2013), pp. 25, 27, 30, 32-3, 35-7.

304 'SNAM-led consortium wins DESFA tender', Ekathimerini, 19 April 2018
} 

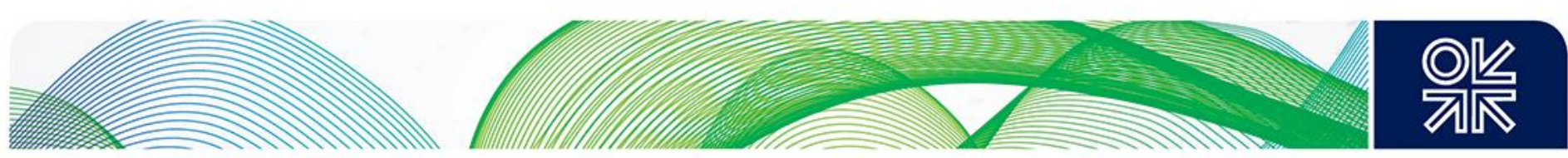

Subsequently, in June 2013, the Italian Ministry of Economic Development (MSE) and the Greek regulatory authority (RAE) adopted finalized Exemption Decisions, which were modified to the extent requested by the EC Exemption Decision, ${ }^{305}$ including amendments made to the Joint Opinion. ${ }^{306}$

The summary of the TAP exemption - as stipulated in the EC Exemption Decision and mirrored in the amended TAP Joint Opinion and the national Exemption Decisions - is as follows. TAP was granted an exemption according to which its Initial Capacity was to be exempted from TPA. Its Expansion Capacity as well as its Residual Initial Capacity (in other words part of the Initial Capacity up to $10 \mathrm{bcm}$ that remained unallocated for the transportation of SD2 volumes) was to be offered and allocated through the binding Booking phase of the first Market Test, in which both TAP shareholders and third parties would be able to participate. TAP is obliged to build any capacity reserved during the Booking Phase of the first Market Test and make it available no later than 6 months after TAP's commercial operation date. In the event of TAP capacity not being fully allocated (up to the Total Capacity), it is to be offered during subsequent Market Tests. TAP is under obligation to build additional capacity, above the Initial Capacity and up to the Total Capacity, in order to accommodate the binding capacity requests made during subsequent Market Tests, subject to economic viability test. The expansion is to be considered economically viable if 'the incremental revenues from capacity resulting from each Market Test is (sic) equal or larger than the efficient incremental costs' defined according to the TAP Tariff Code. ${ }^{307}$ Expansion beyond the Total Capacity is to be 'investigated' by TAP and to be undertaken if 'economically and technically feasible'. The key provisions of the TAP exemption are analysed in detail below.

\section{Exemption granted for the Initial Capacity from TPA}

The exemption has been granted in respect of the Initial Capacity for forward flow from the actual TAP entry point in Greece to its exit point in Italy from TPA rules (Art. 32) for 25 years from the date of commercial operation, subject to the following conditions:

- The Initial Capacity is to be allocated to TAP shareholders in proportion to their shares and dedicated to the transportation of SD2 gas; any deviation from this principle is not allowed without prior approval of the regulatory (competent) authorities.

- The volume equivalent to 5 per cent of the Initial Capacity for short-term products (less than one year duration) would also not be subject to TPA. ${ }^{308}$

- The TAP shareholders are obliged to 'undertake all appropriate legal actions' - procedures for which are to be developed by TAP and approved by the regulatory (competent) authorities - 'to transfer, in part or as a whole, as the case may be', their capacity rights and obligations to buyers of SD2 gas volumes (or their nominated shippers) once the SD consortium has announced its final decision regarding buyers of SD2 gas.

- TAP is obliged to disclose to the authorities how much of the Initial Capacity was allocated for transportation of SD2 gas, the final list of buyers and shippers, and the amount of capacity allocated to each of them.

In summary, the EC decision to exempt the forward Initial Capacity from TPA would 'secure transportation capacity of the gas produced in SD2, which would be sold under 25-year gas supply contracts'. ${ }^{309}$

\footnotetext{
${ }^{305}$ EC (2013)

${ }^{306}$ TAP Joint Opinion (see Additional documents) has remained unchanged apart from Part 4 'Authorities' final joint opinion', which was amended in line with the EC request.

${ }^{307}$ TAP Joint Opinion, pp. 57-58. According to the authorities, the details of economic viability test for investment in Expansion

Capacity are specified in Art. 3.3.1 of the TAP Tariff Code (at the time of writing not available in public domain), see TAP Joint Certification Opinion, p. 7.

${ }^{308}$ EC (2013), p. 42.

${ }^{309} \mathrm{EC}(2013)$, p. 41.
} 

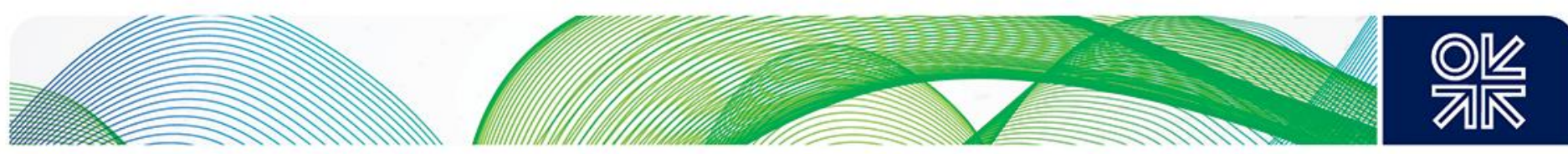

If not all of the Initial Capacity is allocated for SD2 gas, its remaining part (up to $10 \mathrm{bcma}$ ) - Residual Initial Capacity - is to be made available to the market through the Booking phase of the first Market Test. ${ }^{310}$ The Expansion Capacity and the Residual Initial Capacity are to be allocated through auctions. These auctions are to be conducted in line with the Booking Phase Guidelines, approved by the authorities (Section 3.3.5). The Joint Opinion stipulates that the first Booking phase must be conducted no later than three months after the date of the FID. ${ }^{311}$ As TAP has passed its 'Resolution to Construct' on 17 December 2013 - on the day of SD2 FID announcement - the first Booking phase was launched on 17 March 2014. TAP is obliged to ensure that any capacity reserved as a result of the first Booking phase will be built and become available no later than six months after the commercial operation date. ${ }^{312}$ All participants of the El phase are allowed to participate in the first Booking phase, subject to capacity caps. Certified TSOs from Greece, Italy, and Albania can participate irrespective of their participation in the El phase.

Notably, the EC has rejected the national regulatory authorities' view as expressed in the draft Joint Opinion that the forward Expansion Capacity allocated during the first Booking phase would only be allocated to third parties (thus excluding TAP shareholders) and only for transportation of non-SD2 gas. ${ }^{313}$ The EC concluded that such limitations were not justified ${ }^{314}$ thus enabling both TAP shareholders and third parties to participate in the first Booking phase, irrespective of whether their gas was of SD2 origin.

In addition to being obliged to conduct the first Market Test, consisting of the El phase and the Booking phase in line with the First Market Test Guidelines and the Booking Phase Guidelines, TAP is obliged to perform subsequent Market Tests 'on a regular basis starting from no later than the commercial operations date and, subsequently, at least every two years' under the guidelines approved by the authorities 'with the view to offer to all interested parties additional available capacity up to the Total Capacity'. All these subsequent market tests would have to be conducted in line with the new set of Guidelines ('Subsequent Market Tests Guidelines') and the TAP Network Code. As this paper is being completed, both documents are under development and must be finalized before the TAP's commercial operation date. This date is expected to be within the 1 January-31 December 2020 range, ${ }^{315}$ which means that the latest possible start date for the second Market Test would be within the range of 1 January 2020 to 31 December 2020. Notably, there are no conditions in place that would oblige TAP to launch the second market test before the start of commercial operation date. In fact, TAP has stated that it has 'no plans to perform the next Market Test earlier than required, i.e. starting from no later than COD [commercial operation date]'. ${ }^{316}$

As TAP is obliged to conduct subsequent Market Tests at least every two years, each Market Test consisting of two phases - cannot be conducted for longer than two years, as one Market Test must be completed before another can be started. This suggests that if the second Market Test is started on 1 January 2020, it will have to be completed (including its binding Booking phase) by 1 January 2022 at the latest. Likewise, if the second Market Test is started on 31 December 2020, it will have to be completed by 31 December 2022.

Notably, TAP is under obligation to build additional capacity, above the Initial Capacity and up to the Total Capacity, in order to accommodate the binding capacity requests made during subsequent Market Tests, subject to economic viability test. The expansion is to be considered economically viable if 'the incremental revenues from capacity resulting from each Market Test is (sic) equal or larger than the

\footnotetext{
310 The first Market Test on TAP was conducted over the period 2012-14, with the first (non-binding) phase being conducted in 2012 and the (binding) booking phase in 2014

311 TAP Joint Opinion (see Additional documents), p. 56.

312 TAP Joint Opinion (see Additional documents), p. 57.

313 TAP Joint Opinion (see Additional documents), p. 21.

314 EC (2013), p. 52.

315 The exemption will expire on the 31 December 2020 (unless renewed)

${ }^{316}$ TAP Joint Certification Decision (see Additional documents), p, 26
} 

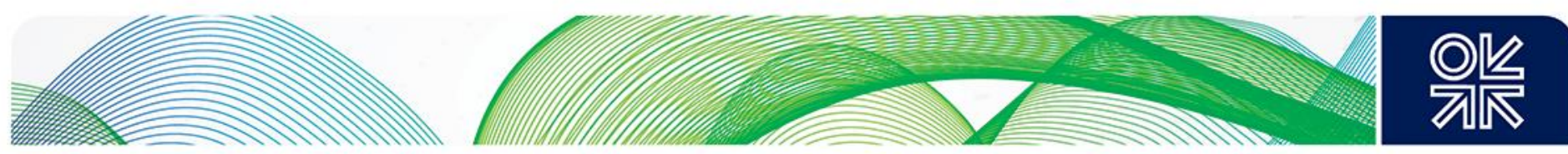

efficient incremental costs' defined according to the TAP Tariff Code. ${ }^{317}$ The economic viability test is specific for TAP and would need to be approved by the national regulatory authorities. TAP is obliged to conclude a binding agreement to have such capacity built no later than two months after the closing date of the Market Test in which a binding request was made. This suggests that the date by which TAP would have to conclude a binding agreement to have such capacity built would be within the range of 1 March 2022-1 March 2023. The exemption does not specify within which period TAP would have to build and make such capacity available; presumably, this will be defined in the Subsequent Market Test Guidelines and the TAP Network Code, both of which are under development as this paper is being completed. ${ }^{318}$

If TAP considers that such capacity expansion is not economically viable, it is obliged to demonstrate this to the authorities not later than one month after the closing date of the Market Test (1 February 2022-1 February 2023) and provide an opinion by a third party (if so requested by the authorities) in which case the deadline is extended by two months (1 April 2022-1 April 2023). The authorities will decide whether the expansion is economically viable within one month of TAP's report or of the third-party opinion (1 May 2022-1 May 2023). Should the authorities decide that the expansion is economically viable, TAP is obliged to conclude a binding agreement to have the capacity constructed no later than two months after such decision. The expansion is to be considered economically viable if the incremental revenues resulting from each Market Test are equal to or larger than the efficient incremental costs, according to the tariff methodology set in the TAP Tariff Code. This suggests that should the authorities consider expansion to be economically viable, the latest date by which TAP would have to build additional capacity would be within the range of 1 July 2022-1 July 2023.

Furthermore, TAP is obliged to investigate a possibility of further expansion of its capacity beyond the Total Capacity of $20 \mathrm{bcma}$, and to expand it 'if economically and technically feasible', with a view to meeting all requests for long-term capacity (in other words more than 15 years), although the way of determining such feasibility is not specified. ${ }^{319}$

As far as short-term capacity is concerned, TAP is obliged to make available short-term capacity (up to one year) to the market by methods 'similar to those applicable to short-term products offered on nonexempted capacity' and 'of a volume that at least amounts to' 5 per cent of the Initial Capacity and 10 per cent of the actually built Expansion Capacity.

\section{Exemption granted for the Initial Capacity from regulated tariffs}

The exemption has been granted in respect of the Initial Capacity from regulated tariffs (Art. 41.6, 41.8, 41.10), subject to the following conditions:

- TAP is obliged to submit the final tariff methodology to the authorities within three months after the exemption decision becomes effective.

- The tariff must be defined by the TAP Tariff Code $^{320}$ and reflect efficient costs, be transparent, nondiscriminatory, and follow the principles described in the exemption application.

- TAP is also obliged to ensure that balancing service charges will be objective, transparent, costreflective, non-discriminatory, and be published.

- The methodology must define the pricing mechanism for all forward capacity products offered by TAP and be such that for any further capacity product offered, in addition to the initial forward capacity, the TAP Tariff will be reduced.

\footnotetext{
317 TAP Joint Opinion, pp. 57-58. According to the authorities, the details of economic viability test for investment in Expansion Capacity are specified in Art. 3.3.1 of the TAP Tariff Code (at the time of writing not available in public domain), see TAP Joint Certification Opinion, p. 7.

${ }^{318}$ Presumably this will be defined in the Subsequent Market Test Guidelines and the TAP Network Code, both of which are under development and of which no detail is available in public domain as this paper is being completed.

${ }^{319}$ TAP Joint Opinion, p. 58.

${ }^{320}$ Already developed and approved by the authorities but not yet publicly available.
} 

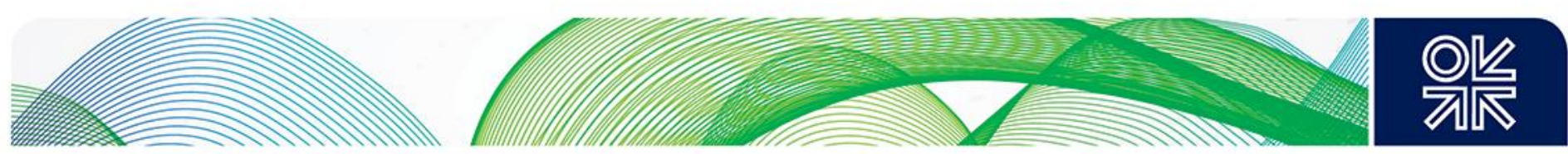

- In deciding on the final tariff structure when approving the Tariff Code, the authorities are to take into account the different risks levels attached to TAP's investments in the Initial and Expansion Capacity.

\section{Exemption granted for the Expansion Capacity from regulated tariffs}

The exemption has been granted in respect of the Expansion Capacity (for forward flow only) from regulated tariffs (Art. 41.6, Art. 41.8 and Art. 41.10), subject to following conditions:

- Capacity products will be offered through auctions as a result of a market test;

- As TAP will offer different products - in other words different duration and different entry or exit points - each product should be priced;

- For each capacity product offered, the reserve price at the auction will be equal to the TAP Tariff, according to the TAP Tariff Code;

- Users of the Expansion Capacity will pay the reserve price (in other words the TAP Tariff) plus the auction premium, the latter to be transferred by TAP to a special fund which will be at the authorities' disposal to be distributed to final customers in line with procedures to be defined by the authorities.

TAP advocated a uniform tariff to be applied to all TAP capacity, irrespective both of whether it was its Initial or Expansion Capacity and of flow direction, arguing that this was necessary to avoid discrimination between the Initial Capacity shippers and the Expansion Capacity shippers, as unless the tariff is uniform there would be a reduced incentive to book the Initial Capacity (Section 3.3.4). However, the authorities decided that the allocation of Expansion Capacity should be made according to market procedures, with the users paying a market price for the Expansion Capacity rather than the TAP tariff. In order to address TAP's concerns in respect of potential discrimination, the authorities stipulated that the reserve price of the auction should be set at the level of the TAP Tariff. In this case, users of the Expansion Capacity will be paying at least the TAP tariff or possibly more if auctions demonstrate congestion. Revenues above the TAP tariff must be collected by the authorities and redistributed to end users according to criteria decided by the authorities.

Exemption rejected for the Initial and Expansion Capacity from regulated tariffs in respect of reverse flow

The exemption was rejected in respect of reverse flow - both for Initial and Expansion Capacity - from regulated tariffs (Art. 41.6, Art. 41.8, Art. 41.10) as the authorities decided that granting it would likely have a negative impact on completion. Therefore, the authorities prescribed that the reverse flow capacity is to be regulated according to the EU acquis, with the following restrictions:

- Reverse flow products will be offered through auctions in the Booking phase of the Market Test and in any subsequent market tests;

- The tariff for reverse flow product cannot be higher than 5 per cent of the tariff of an equivalent forward flow product and is to be approved by the authorities as part of the TAP Tariff Code;

- The reserve price for each reverse flow product in the auction will be set equal to the applicable tariff of that product;

- Users of the reverse flow products will pay the reserve price plus the auction premium (the latter to be transferred to the special fund, which redistributes surplus revenues to final customers);

- TAP will ensure that at least $5 \mathrm{bcma}$ is provided for physical reverse flows for emergency and that at least 5 bcma is provided for reverse flows for commercial operations.

\section{Exemption granted from the unbundling requirements}

The exemption was granted from the ownership unbundling (OU) provisions (Art. 9.1) for 25 years from the commercial operation date, subject to the following conditions: 

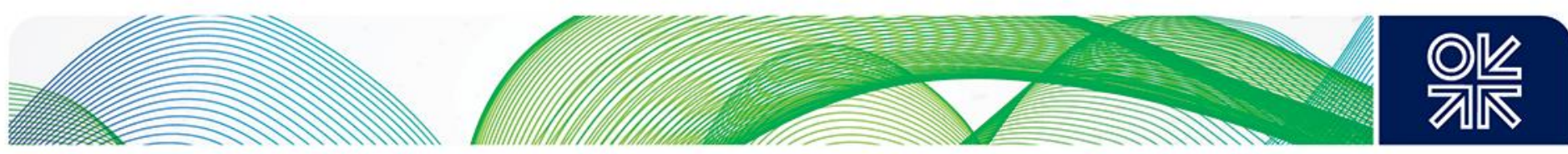

- TAP functional unbundling is to be implemented prior to capacity allocation during the first Booking phase, ${ }^{321}$ based on a compliance programme; 322

- TAP certification as an ad hoc Independent Transmission Operator (ITO) unbundling regime ${ }^{323}$ is to be completed before the start of construction ${ }^{324}$ and not later than 1 January $2018 .^{325}$

The authorities concluded that OU - just as for TPA and regulated tariffs - may undermine the commercial viability of TAP. If OU were to be applied to TAP, its shareholders - major energy players, performing functions of production or supply (directly or through subsidiaries) in the European gas and electricity markets - would be forced to sell their shares in TAP to a third party. As the outcome of the sale could not be predicted with sufficient certainty, investors may refrain from investing in TAP. The authorities concluded that 'at this stage, the implementation of OU provisions would indeed heavily undermine the basic business model of the project and as a consequence the shareholders would not be prepared to commit to the investment' thus suggesting that the exemption from the OU provisions was a prerequisite for investors to make the investment decision. However, the authorities have also stated that an unconditional exemption from OU would have negative effects on the third parties' ability to gain nondiscriminatory access to TAP, which is owned and operated by TAP AG, which is itself a part of a vertically integrated undertaking (VIU) (Art. 2.1.20 of Third Gas Directive). ${ }^{326}$ Therefore, the authorities prescribed the application of a different unbundling regime in order to break the inherent conflict of interest.

The regulators' Joint Opinion prescribed that TAP should apply a tailor-made ad hoc Independent Transmission Operator (ITO) unbundling regime, such that it must comply with all conditions for an ITO as set in Chapter IV of Third Gas Directive (except Art. 22), as well as with the following additional conditions: 327

- TAP's management must not participate in any company structures of TAP's shareholders responsible for day-to-day production and supply;

- Evidence is required that the professional interests of persons responsible for the management of TAP are taken into account in a manner that ensures their capacity to act independently;

- A supervisory body, charged with all financial supervision allowed under legal and functional unbundling, may not interfere with TAP's day-to-day activities and operation of the pipeline;

- Evidence should be shown that TAP has the necessary resources, including financial, to have effective decision-making rights;

- Evidence that TAP will have a compliance programme adequately monitored by a compliance officer employed by TAP should be shown.

TAP has been obliged to be certified under the aforementioned 'ad hoc ITO model' before the start of construction and not later than 1 January 2018, in each member state whose territory it crosses, as a condition for an exemption from OU provisions to be granted. ${ }^{328}$ The TAP certification is analysed in Section 3.3.8.

\footnotetext{
321 The first Booking phase was conducted during 17 March 2014 - 1 December 2014.

${ }^{322}$ EC (2013), p. 52. The requirement to establish a compliance programme - absent in the national regulatory authorities exemption decisions - was made by the EC, which required it to be adopted within six months after the adoption of the EC exemption decision (in other words by 16 November 2013).

${ }^{323}$ EC Exemption Decision stipulated that TAP is to comply with all ITO requirements as set in Chapter IV of the Third Gas

Directive (see Additional documents) apart from Art. 22.

${ }^{324}$ Construction of TAP started 17 May 2016, see TAP (2016b).

${ }^{325}$ EC (2013), p. 53.

326 TAP Joint Opinion (see Additional documents), p. 41. TAP shareholders are either vertically integrated undertakings with interests in supply and production, or certified TSOs.

327 TAP Joint Opinion (see Additional documents), p. 61

${ }^{328}$ EC (2016b), also see TAP (2016a).
} 

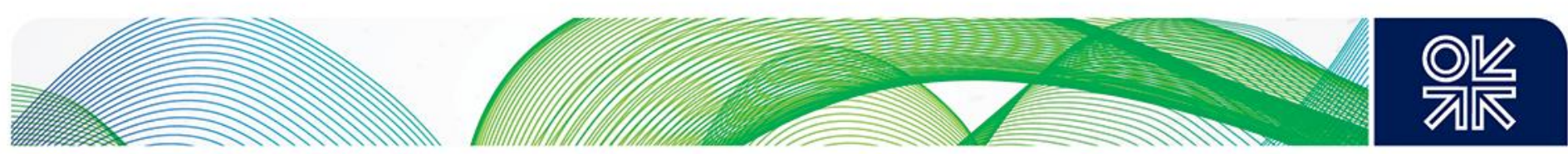

\section{Exemption rejected from Gas Regulation 715}

The TAP's request for an exemption from all provisions of Gas Regulation 715 was rejected as the authorities believed that it 'might have a negative impact on the transparency of access ... as well as on the operation of the regulated systems to which TAP will be connected' and stated that TAP 'will have to comply with the provisions of Gas Regulation, as long as they are not in conflict' with the Exemption Decision.

\subsubsection{The TAP Exemption Decision additional conditions: TAP Network Code, capacity caps, monitoring changes in TAP shareholding}

In addition to the general provisions outlined and analysed in Section 3.3.6, the Exemption Decision has imposed several additional specific conditions in order to ensure the TAP's full compliance with the exemption criteria (Art 36.1 of Third Gas Directive). These conditions are as follows.

\section{Establishment of the TAP Network Code}

TAP is obliged to develop and submit to the authorities the TAP Network Code no later than 12 months prior to the TAP's commercial operation date; this is to be compliant with Gas Regulation 715 and with all the EU Network Codes that will be in force at the time ${ }^{329}$ as long as these are not in conflict with the exemption. (Given that TAP is planned to start operations between 1 January 2020 and 31 December 2020, the TAP Network Code would need to be in place between 1 January 2019 and 31 December 2019.) The TAP Network Code would have to be revised every time any new EU Network Code enters into force, ensuring that the former incorporates the latter's provisions. ${ }^{330}$

The TAP Network Code must be published on the TAP's website and include the following:

- detailed operational procedures (including procedures for secondary trading),

- Congestion Management Procedures (CMPs) and Use-it-or-Lose-it (UIOLI) arrangements,

- procedures for the publication of operational data and capacity availability,

- declaration that sanctioned gas will not be imported or transported through any part of TAP.

\section{Establishment of capacity caps for dominant players (competitiveness issues)}

In stipulating the additional conditions to be imposed on TAP as part of the Exemption Decision, the regulatory authorities wanted to ensure that no market player who was dominant on the Greek, the Italian, or the Albanian gas markets would become 'the capacity holder of all or of a large part of the gas' transported by TAP to the relevant markets leading to a situation where TAP could not be considered as enhancing competition. ${ }^{331}$ The authorities noted that while at the time the exemption was granted none of the TAP (BP, SOCAR, SNAM, Fluxys, ENAGAS) or SD (BP, TPAO, SOCAR, Petronas, LukOil, NIOC) shareholders had been dominant on any of the aforementioned markets; this could change in the future. ${ }^{332}$

As far as the Italian gas market is concerned, the regulatory authorities stated that it would have a positive impact but they considered it necessary to impose additional conditions as part of the exemption such that would 'ensure that a dominant market player cannot book a share of capacity in the TAP which would reinforce its position'. The authorities argued that should such conditions not be imposed, the positive

\footnotetext{
${ }^{329}$ EC TAP Exemption Decision (EC (2013)) refers to EU network codes which are listed in Regulation 715/2013 some of which have already been developed and entered into force and some might be in the future.

${ }^{330}$ It is worth noting that with the four EU Network Codes already in force - CAM NC, Tariffs NC, Interoperability NC, Balancing NC (see Additional documents) - and no new EU Network Codes envisaged to be developed before the TAP's commercial operation date, the TAP Network Code will have to comply with the aforementioned four codes (insofar as they are not in conflict with the exemption decision).

${ }^{331}$ TAP Joint Opinion (see Additional documents), p. 27.

${ }^{332}$ Notably, the Greek TSO DESFA is being privatized as part of the EU/IMF bailout programme, with a view of selling $66 \%$ of shares, with two binding bids having been submitted in early 2018: (a) a consortium of SNAM, ENAGAS, and Fluxys (all of which are TAP shareholders) and (b) a consortium of Reganosa, Transgaz, and EBRD.
} 

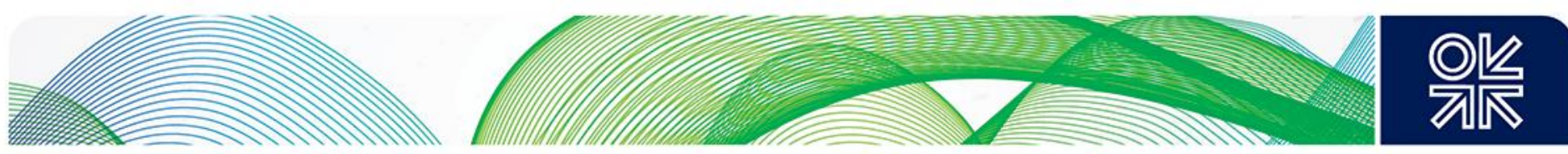

effects on competition would be reduced should 'an undertaking with a significant degree of market power' reserve 'a substantial part' of capacity on a long-term basis via 'either subletting the TAP exempted capacity or booking the available capacity through auctions'. ${ }^{333}$ The Italian authorities also stipulated that such companies (or any affiliated companies) should not be allowed to reserve capacity 'on the long-term basis only' and that their short-term bookings (less than one year) should be limited to 25 per cent of the available capacity. Furthermore, these restrictions were to apply to any undertakings with a dominant position in any of the Italian wholesale and retail markets.

The exemption decision thus introduced the following capacity caps for dominant players in Italy such that:

'any undertaking with a share of 40 per cent or larger in any relevant product market for the supply of gas in Italy, or on the upstream market of supplying gas for Italy, shall not be allowed to reserve more than 50 per cent of the capacity at the exit point it Italy;

'in the event that two or more undertakings together hold a market share of at least 80 per cent and each of these undertakings have a market share of more than 20 per cent in any relevant product market for the supply of gas in Italy, or on the upstream market of supplying gas for Italy', the Italian regulatory authority will have the right to impose a capacity cap on these undertakings at the TAP exit point in Italy;

Importantly, where 'due to lack of interest by other parties' these capacity caps prevent the expansion of the pipeline or cause the existing capacity to remain idle, a derogation from these caps shall apply on the condition that the undertaking(s) concerned offer to the market the entire volume of gas in excess of the capacity that the undertaking(s) hold in an open, transparent, and non-discriminatory procedure whereas this gas volume released shall be followed by a corresponding capacity release. However, if the imposition of the aforementioned gas and capacity release leads to a situation where the undertaking(s) concerned has no incentive to utilize the capacity above the cap imposed (and under no other circumstances), the Italian regulatory authority - at its own initiative or on request of the undertaking(s) can provide a temporary derogation, subject to conditions that competition is maintained in consultation with the Italian competition authority.

As far as the Greek market is concerned, the authorities have imposed obligations on TAP to develop 'one or more' connections with the existing Greek transmission system (other than TAP's entry point) with all related costs to be financed by the Greek TSO DESFA. ${ }^{334}$ In defining the location and the capacity of such interconnections, TAP and DESFA may perform a market test, subject to approval by the Greek regulatory authority. The authorities have also stated that TAP can enhance competition if capacity at its exit points in Greece could be booked either by new entrants or by existing suppliers with a limited market share, while adding that competition would 'arguably be compromised' if all of the available capacity at one or more potential TAP exit points were to be reserved by a single undertaking with a high market share. The authorities stated that 'currently this would arguably be the case of DEPA', which is a dominant gas supplier to the Greek market. ${ }^{335}$ Thus conditions have been imposed on TAP to prevent any supplier

\footnotetext{
${ }^{333}$ Notably, the Italian legislation does not allow a transfer of exempted capacity to third parties without the ex ante approval of the Italian Ministry of Economic Development (MED) which can only be granted if changes 'do not negatively affect competition and the functioning of the Italian gas market'. The MED is the same ministry which has the power to grant an exemption, based on the opinion of the national regulatory authority.

${ }^{334}$ TAP Joint Opinion (see Additional documents), p. 64

335 Although since April 2010 the third parties (power and industry sectors) have begun importing LNG on a spot basis, mostly for their own consumption, DEPA remains the dominant gas supplier to the Greek market. Pipeline gas imports are controlled by two dominant suppliers - Gazprom and BOTAS - both of which have LTSCs with DEPA, whereas access to import pipelines is forbidden for all Greek gas market participants. In December 2012 the Greek competition authority obliged DEPA to implement a gas release programme at both interconnection points with Bulgaria and Turkey, as well as gradually reducing its share of booked capacity on all existing and future import interconnection points to less than $55 \%$ of technical capacity, thus enhancing competition on the Greek domestic market.
} 

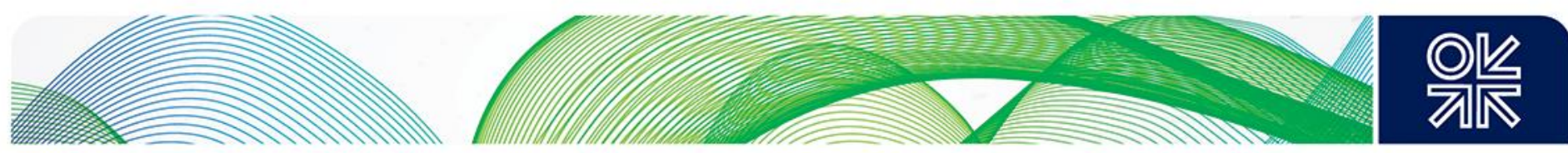

to the Greek market with a share higher than 40 per cent in the relevant market - including DEPA - from obtaining more than 50 per cent of new gas supplies from any future TAP exit points on Greek territory.

Similar to measures taken in respect of the Italian market, the authorities have introduced the following capacity caps to prevent the reinforcement of existing dominant players and the development of new dominant players:

'any undertaking with a share of 40 per cent or larger in any relevant product market for the supply of gas in Greece, or on the upstream market of supplying gas for Greece, shall not be allowed to reserve more than 50 per cent of the capacity' on any of the aforementioned points (in other words additional entry and exit points and connection points with the existing Greek system);

'in the event that two or more undertakings together hold a market share of at least 80 per cent and each of these undertakings have a market share of more than 20 per cent in any relevant product market for the supply of gas in Greece, or on the upstream market of supplying gas for Greece', the Greek regulatory authority will have the right to impose a capacity cap on the aforementioned points;

Also, similarly, the exemption has envisaged the possibility of granting a derogation from the aforementioned caps, where due to lack of interest by other parties, these caps prevent the expansion of the pipeline or cause the existing capacity to remain underutilized, conditional on the implementation of gas and capacity release. Furthermore, the Greek regulatory authority (on its own initiative or at the request of the undertaking(s)) would have a right to grant a temporary derogation if the implementation of a release programme leads to a situation where the undertaking(s) concerned has no incentives to utilize the capacity above the cap imposed, subject to conditions that competition is maintained (in consultation with the Greek competition authority).

It is important to note that while the national regulatory authorities of Italy and Greece considered that it would be sufficient to apply the aforementioned caps only as far as downstream supply and retail markets in Italy and Greece were concerned, the EC Exemption Decision prescribed the application of these caps in respect of upstream supplies to Italy and Greece. ${ }^{336}$

As far as the Albanian market is concerned, the Exemption has obliged TAP to build at least one exit point in Albania and to expand existing, and/or build additional, entry and exit points in Albania. It also introduced capacity caps for dominant players in Albania.

\section{Monitoring changes in TAP shareholding}

The Exemption has also obliged TAP to notify a change in its shareholding - if 'directly or indirectly, an undertaking acquires joint or sole control over or mergers with' TAP or one of its shareholders - to each of the relevant national regulatory authorities which must assess - if deemed necessary in cooperation with the national competition authorities - whether the conditions under which the exemption was granted are still met. ${ }^{337}$

\subsubsection{TAP certification}

It its application for certification, TAP has argued that it does not constitute a typical case for an ITO model application, as its activities at the time of application solely related to the construction of infrastructure, as opposed to its management and operation, while it was required to be certified prior to the start of construction (in other words four to five years before the commercial operation was planned to start in 2020), and that it would not be controlled by a single undertaking or VIU; it was suggested that this should limit the full applicability of ITO provisions. For example, TAP argued that it is necessary for it to receive engineering services from its shareholders for the purpose of building the pipeline, despite the fact that no rendering of services to the ITO is allowed by any other part of the VIU. TAP also requested to be allowed to conclude service agreements with those of its shareholders that are certified TSOs. It also

\footnotetext{
${ }^{336}$ EC (2013)

${ }^{337}$ EC (2013), p. 54.
} 

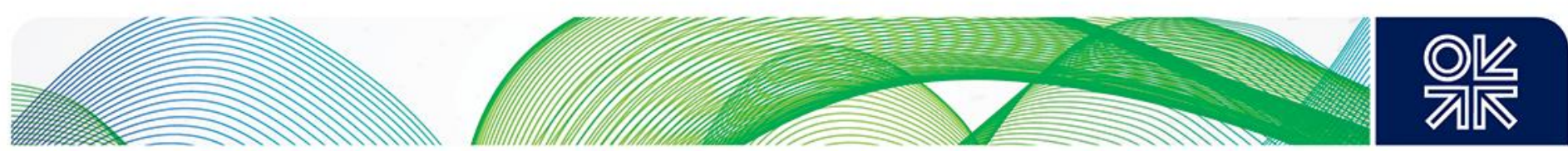

requested to be able to outsource some of its technical operation and maintenance during the operation phase to adjacent certified TSOs. TAP also asked to be allowed not to comply fully with all the ITO requirements on financial autonomy (as set by Art. 17 and 18), on the basis that the immediate implementation of such provisions might endanger the project's bankability and completion.

\section{National Regulatory Authorities TAP Certification Decisions}

Having received the TAP's application for certification under the ITO model, the Italian and Greek regulatory authorities prepared their preliminary certification decisions jointly ('Draft Joint Certification Decision') with the involvement of the Albanian regulatory authority (under supervision from the EnCT secretariat). The authorities came to the conclusion that TAP complies with ITO requirements and adopted a draft decision having regard to the requirements that have already been fulfilled and the commitments undertaken by TAP to fulfil the remaining requirements by the commercial operation date including inter alia:

- provision of 'all the necessary information on the definitive financial arrangements made for the construction of the pipeline' and of 'the financial arrangements made, before the start of commercial operations to ensure TAP's financial independence';

- obligation to review the compliance programme pursuant to the draft Joint Decision;

- obligation to notify the authorities of any change in the ownership structure that would result in a person acquiring control of TAP in order to evaluate whether the certification procedure needs to be re-opened.

The authorities have agreed that TAP shareholders should be allowed to continue providing engineering services. TAP is allowed to manage the offshore pipeline construction directly, whereas a third-party company without any shareholding in TAP will be in charge of the construction of the onshore part. The Joint Opinion says that full compliance with ITO requirements on financial autonomy can be deferred until the commercial operation start date, on the grounds that shareholder involvement in TAP financing will not lead to conflict of interest.

The authorities adopted their final decision on TAP certification on 18 April 2016 ('TAP Joint Certification Decision'), taking into account the EC opinion, analysed below. ${ }^{338}$ In line with their Draft Joint Certification Decision, the authorities decided to certify TAP as an ITO, subject to its full compliance with specific commitments made by TAP, ${ }^{339}$ whereby all ITO requirements set out in Chapter IV of the Third Gas Directive (except Art. 22) would be met by TAP by the start of commercial operation.

\section{The EC TAP Certification Opinion}

Having received the authorities' preliminary certification decisions on 2 December 2015, the EC issued its own opinion on TAP certification on 28 January 2016. ${ }^{340}$ In its Exemption Decision of 16 May 2013, the EC had left national regulatory authorities to decide whether certification of TAP was to be carried out under Art. 10 (designation and certification of TSOs) or Art. 11 (certification in relation to third countries) of the Third Gas Directive. In its opinion on certification, the EC agreed to TAP's certification under Art. 10 rather than under Art. 11, stating that the latter was not applicable, despite some of TAP's shareholders being from third countries, given that none of them 'solely or jointly, have control over' TAP in the meaning of the EU Merger Regulation. ${ }^{341}$

The EC has also confirmed that TAP's application for certification under a tailor-made ad hoc ITO model is legitimate, as it was imposed on TAP by the Exemption Decision. While the EC acknowledged that TAP does not constitute a typical case for an ITO model, it stressed that, given that its obligation to be certified as an ITO stems from the Exemption Decision rather than from the Third Gas Directive, the fact

\footnotetext{
338 AEEG, ERE, RAI (2016); TAP Joint Certification Decision.

${ }^{339}$ TAP Joint Certification Opinion, pp. 15-16.

${ }^{340}$ EC (2016b).

${ }^{341}$ EU Merger Regulation (see Additional documents).
} 

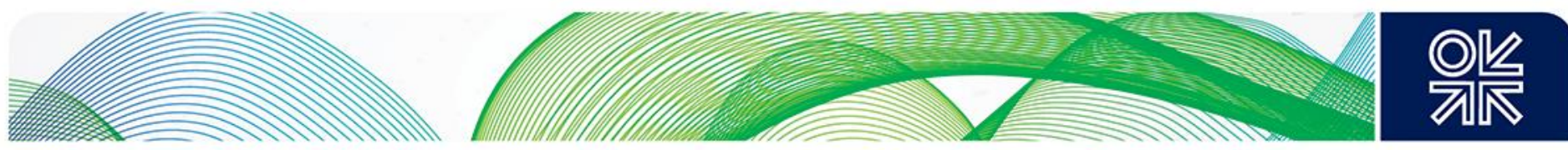

that TAP is not controlled by a single undertaking or VIU cannot per se be construed as limiting the full applicability of ITO provisions. In this respect the EC noted that the TAP's shareholders are 'either vertically integrated energy undertakings, with interests in supply and production of electricity and gas' (such as BP and SOCAR) 'or certified gas transmission system operators' (such as SNAM, Fluxys and ENAGAS). The EC noted that the general objective of unbundling under an ITO is to constrain the incentives and the abilities of a VIU to use its control over transmission infrastructure to prevent competitors from using it. It stressed that such concerns 'may arise with regard to the construction of the Expansion Capacity and the manner in which it is operated, as TPA rules would apply'. The EC noted that although TAP will not be providing gas transportation services during the construction phase, it has already engaged in commercial activities such as the first allocation of capacity (which is a TSO task). It has further noted that some TAP shareholders have contracted TAP capacity while also having contracted gas to be transported through TAP. Therefore, there exists a possibility of a conflict of interest, implying the need for unbundling measures to be implemented prior to the start of commercial operation. The EC has also noted that TAP has carried out various commercial operations prior to the operation stage, such as the management of all previously agreed shipping contracts, the management of information gathered in the previous Market Test, and the execution of further Market Tests. A deferred implementation of ITO requirements can therefore only be justified where its immediate application would be incompatible with the specific circumstances under which TAP is being developed and where any conflict of interest is neutralized by the specific regulatory measures in force. The EC has invited the national authorities to assess, in their final certification decisions, whether the grounds for a deferred ITO implementation are justified, and also to assess whether the additional regulatory safeguards currently in place provide a sufficient protection against the risks of undue shareholder interference. It has requested the imposition of additional conditions and safeguards should this not be the case.

The EC has agreed that the TAP shareholders should be allowed to continue to provide engineering services to TAP (despite this being prohibited by the Third Gas Directive) but invited the regulatory authorities to assess whether sufficient measures are in place to ensure that the provision of such services might not jeopardize the confidentiality of commercially sensitive information accessible to TAP. In respect of TAP's request to be allowed to conclude services agreements with its shareholders that are certified TSOs, the EC has stated that the regulatory authorities have not assessed the compatibility of such a request with unbinding requirements during the operation phase. The EC has also stated that the provision of services by TAP shareholders certified under an OU model could be possible, provided they are rendered under market conditions and do not undermine confidentiality. The EC has also invited the authorities to assess compatibility with the unbundling requirements of TAP outsourcing technical operation during the operation phase to adjacent certified TSOs.

In respect of TAP's argument that full compliance with requirements on the financial autonomy of an ITO from a VIU would endanger the project, the EC has noted that without this requirement, the VIU 'could continue to control' the ITO 'in particular in relation to investment decisions by withholding the necessary funding in order to obstruct building of additional capacity or new connections with a view of hindering its competitors' thus suggesting that the arrangement ensuring financial independence is relevant. In this regard, the EC has noted that TAP will 'in principle be able to raise funding independent from its shareholders' and that 'sufficient assurances exist that shareholders take the required measures including financial decisions to realize TAP investments'. The EC has also noted that any loans provided by TAP shareholders 'are likely to be compatible with the financing requirements as third-party lenders and TAP shareholders will subscribe by the nature of the financing process to the same conditions, and in view of third party participation can be presumed to be based on market terms'. In connection with this, the EC has invited the national authorities to assess whether the conditions under which TAP shareholders intend to participate in the financing of TAP can be considered as compliant with the financing requirements (Art. 18.6).

The EC has noted that while the incentives to foreclose could be based on TAP shareholders' willingness to protect their potential supply activities in the Italian and Greek markets, at the time of application for certification, they had 'no or only insignificant interests' in these markets, thus suggesting no existing incentive for market foreclosure. However, such incentives could appear if TAP's existing or new shareholders (should the TAP ownership structure change) enter these markets in the future. The EC 

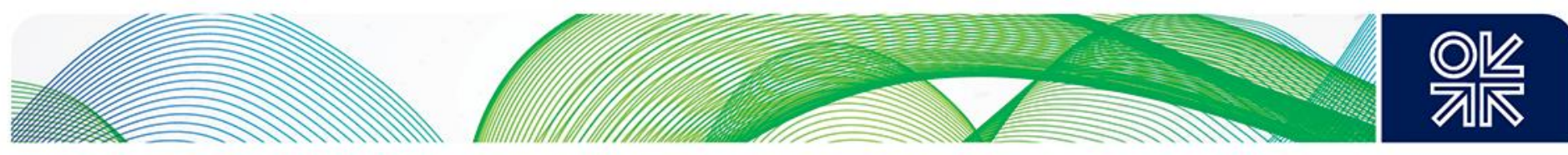

has therefore recommended the national authorities to monitor the development of the TAP's ownership structure and take 'all steps' should changes in the ownership structure lead to a risk of market foreclosure.

In conclusion, the EC has noted that the specific TAP regulatory framework - consisting of the TAP Tariff Code, the TAP Network Code, the TAP Regulatory Compliance Programme (RCP), and the First Market Test Guidelines - 'has elements that go beyond those usually applied to an ITO' and provides the safeguards against market foreclosure by reducing both the incentives and the abilities of TAP's shareholders to engage in it. In particular, this framework places an obligation on TAP to build the Expansion Capacity, stipulates how such a decision is to be made, and establishes a regime of regulatory oversight while also approving the tariff structure that would significantly mitigate any incentive to foreclose.

\subsubsection{The TAP Exemption Decision: the timeline and duration}

The EC Exemption Decision, issued on 16 June 2013, stated that the EC's approval of the decision 'shall lose its effect 3 years from its adoption [in other words 16 May 2016] in the event that construction of TAP has not yet started, and 6 years from its adoption [in other words 16 May 2019] in the event that the infrastructure has not become operational', unless the EC decides that any further delay is due to major obstacles beyond TAP's control. The EC decision also stated that 'in any event, TAP shall be put in operation no later than 1 January 2019'. On 27 June 2014, TAP requested a postponement of the commercial operation date to 31 December 2022, and of the date by which construction has to start to 1 January 2018. On 17 December 2014, TAP modified its request and asked for the date by which commercial operation had to start to be 31 December 2020 (but made no change to the earlier requested date of 1 January 2018, by which construction has to start).

The reasons for the TAP's request are related to a change in the anticipated timing of the first gas deliveries by the SD consortium to Europe. It was only after the EC approved the exemption that TAP and the SD consortium (which controls the project) agreed on a contractual mechanism ('funnelling mechanism') for aligning the planned commercial operation date and the availability of SD2 volumes, by which TAP is notified by the SD consortium on 'more narrow time frames' within which the commercial operation date has to take place. It is understood that at the time of applying for an exemption TAP had a more optimistic view on the commercial start of operations compared to the range of dates which became known through the funnelling mechanism (initially 1 January 2020-31 December 2022 and subsequently 1 January 2020-31 December 2020). According to TAP, no contractual mechanism allows for a change of the latter range and hence it is considered final.

This delay has resulted in a discrepancy between the date when the original Exemption Decision would lose its validity - 16 May 2019 - and the earliest date of SD2 gas availability for Europe - 1 January 2020 - as set by the funnelling mechanism. The Italian and the Greek authorities have recommended that the TAP request for postponement is to be granted on both accounts (in other words, the commercial operation date and the start of construction date). However, the EC has only agreed to grant the TAP's request to postpone the latest date by which the commercial operation date has to take place until 31 December 2020 - so that the EC's approval of the exemption and the national exemption decisions are to retain their effect. The EC refused to postpone the latest date (16 May 2016) by which the construction had to start (on the grounds of the TAP's own estimate that at least five years would be needed to complete construction). In line with the EC Exemption Decision, the TAP construction started in May 2016. As requested by TAP, the exemption has been granted for the entire period of 25 years from the date of commercial operation. Any infringement by TAP of the conditions of the exemption may result in a penalty imposed by the authorities. Serious violation of the conditions may result in withdrawal of the exemption. ${ }^{342}$

\footnotetext{
342 Should the Italian government, which expressed doubt about the need for, and launched a review in respect of, TAP in June 2018, decide to prevent the completion, it would have an impact on the exemption. However, it is understood that the government has since softened its position.
} 

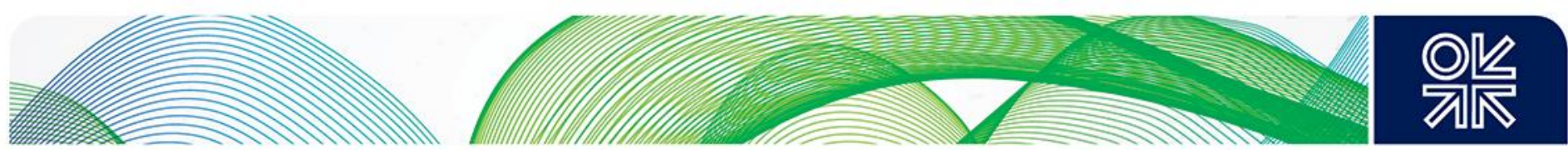

\section{Conclusions}

The May 2013 Exemption Decision granted to TAP, under which all of its $10 \mathrm{bcm}$ capacity (in other words the Initial Capacity, nearly all of which has been booked under 25 year ship-or-pay contracts), necessary for transporting around $10 \mathrm{bcm}$ of Azeri gas sold by the supplier (the SD consortium) under 25 year contracts, has been exempted from TPA and regulated tariffs (with the tariff to cover inter alia all costs of realizing this capacity), serves as an example of a very favourable regulatory treatment under the exemption regime. Although no exemption from TPA was granted in respect of its Expansion Capacity (a further $10 \mathrm{bcm}$, additional to the Initial Capacity) the TAP consortium is only obliged to build it if there is a request made for such capacity during the Booking Phase of the first (and subsequent) Market Tests at an auction, where the TAP shareholders are able to participate alongside third parties. Expansion beyond the Total Capacity of $20 \mathrm{bcm}$ (the sum of Initial and Expansion Capacities) is possible, subject to a commercial viability test and it would be built 'with a view to fulfil all requests for long-term capacity' (more than 15 years). The TAP Exemption Decision has thus created a very stable and supportive regulatory environment for TAP.

As such, the TAP Exemption Decision is in sharp contrast with the 2009 OPAL Exemption Decision, under which an exemption was only granted from TPA and regulated tariffs in respect of half of its capacity, necessary for the supplier (Gazprom) to supply its gas to Europe. As the lack of regulatory and competition logic for the 2009 OPAL decision had become increasingly evident, with OPAL being severely underutilized, that decision was ultimately revised in 2016. Comparison of the TAP and OPAL decisions demonstrates that a new pipeline project could be awarded a very different regulatory treatment under the same exemption regime under Art. 36, largely depending on the EC's attitude towards the project. This attitude could be subject to a broad set of considerations ranging from regulatory to political. Although it is a national regulatory (competent) authority (with the possible involvement of ACER) which prepares a draft Exemption Decision, it is the EC which ultimately determines the conditions of the exemption. As the criteria set in Art. 36 for granting an exemption are broad and unquantified, the EC has significant discretion over the terms of an exemption. This suggests that any project developer, considering a regime under which to develop a new pipeline in the EU, would be well advised to seek a preliminary clarification from the EC on whether the project is likely to encounter regulatory obstacles.

\subsection{The CAM NC Incremental Process: the Baltic Pipe}

On 6 April 2017 the CAM NC, which for the first time has provided a set of legally binding regulatory procedures in respect of incremental (new) capacity, entered into force. The Baltic Pipe - connecting the Norwegian offshore transmission system with the Polish transmission system and crossing the North Sea, Denmark, and the Baltic Sea - is one of the biggest infrastructure projects that is being developed under the new CAM NC (Figure 12). This section analyses the process under which the Baltic Pipe is being developed and evaluates its compliance with the CAM NC, in particular its provisions governing the incremental capacity process. 

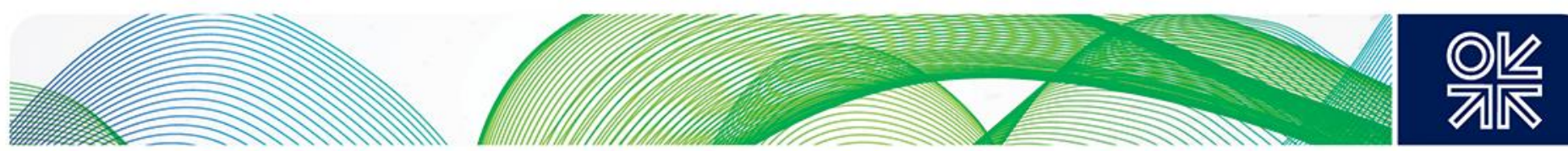

Figure 12: The Baltic Pipe Gas Pipeline

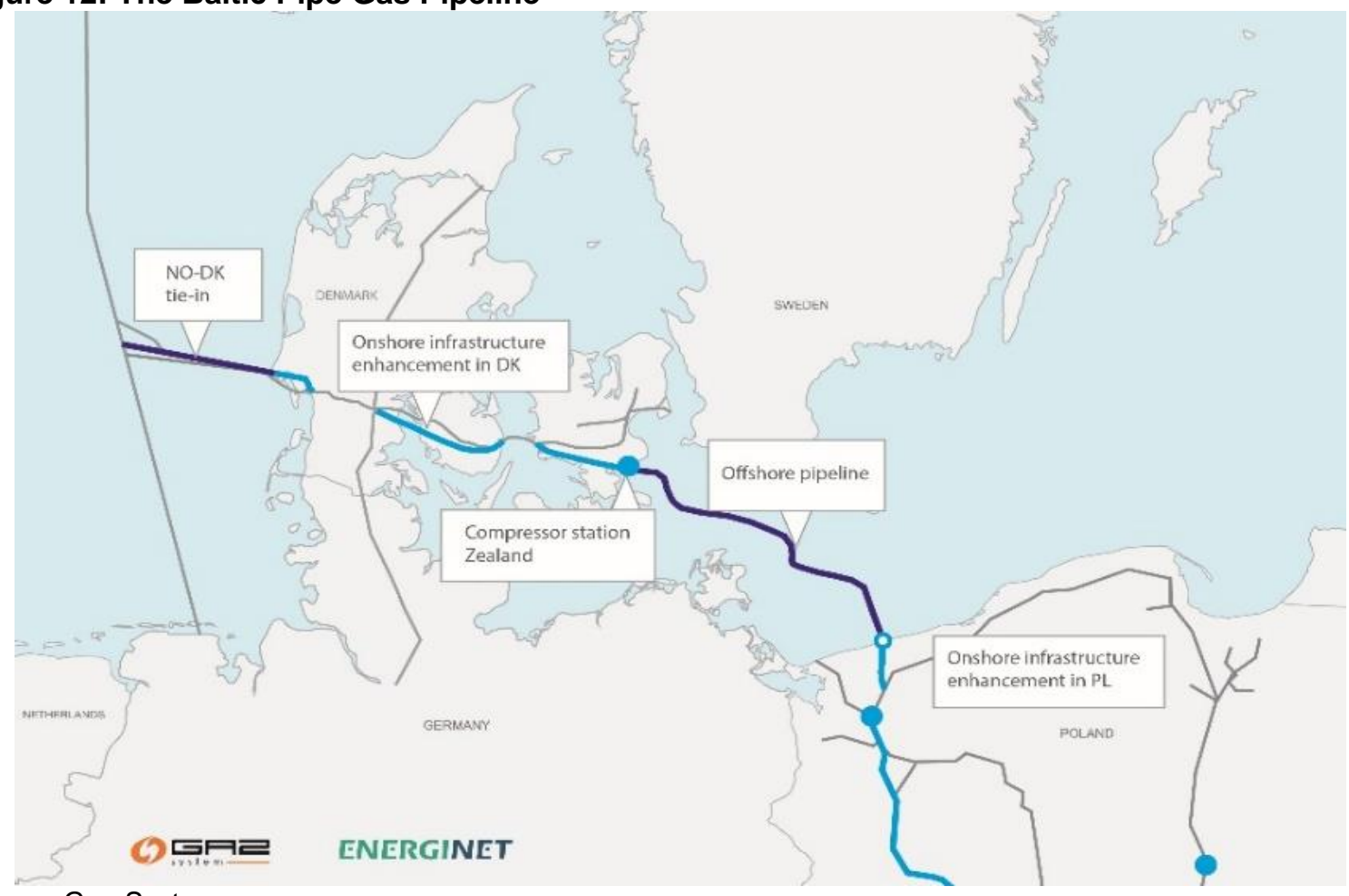

Source: Gaz-System.

\subsubsection{The Baltic Pipe project}

In March 2016 the Polish and Danish TSOs - Gaz-System ${ }^{343}$ and Energinet respectively -started to investigate the possibility of establishing a pipeline connection between the Polish and Danish gas transmission systems, including a possible offshore connection from the Norwegian offshore gas system to Denmark. ${ }^{344}$ The Gaz-System-Energinet joint initiative has become known as the Baltic Pipe project, for which a framework agreement was signed in June 2017. The stated aim of the project is to 'create a new supply corridor for gas ... to enable transport of gas directly from Norway to the markets in Denmark and Poland together with the neighbouring markets ... enable shippers to flow gas bidirectional[lly] from Poland to the Danish and Swedish markets, and thus allow Denmark and Sweden access to LNG through the LNG import terminal in Poland'. 345

The Baltic Pipe has been defined as upstream and transmission infrastructure which consists of the following components: ${ }^{346}$

- new Danish offshore upstream tie-in pipeline $(\sim 120 \mathrm{~km})$ - to be owned by Energinet - connecting the Norwegian offshore upstream pipeline, Europipe II (25 bcma $)^{347}$ in the North Sea with a receiving gas terminal in Denmark. A direct pipeline connection to the Nybro entry point ashore and

\footnotetext{
343 Until 31 December 2030

${ }^{344}$ Energinet (2016a).

${ }^{345}$ Abstract of feasibility study, April 2017 (see Additional documents).

${ }^{346}$ OS 2017 Rules (see Additional Documents). The Baltic Pipe project should not be - but often is - confused with the Denmark-Poland interconnector, which is only one part of the project. This confusion is partly due to the fact that the PolandDenmark interconnector is referred to as 'The Baltic Pipe' on several EU PCI lists.

${ }^{347}$ Both Europipe and Europipe II were built with a view of supplying increasing gas demand in Germany. The actual transport capacity, available for potential users of these pipelines, could be influenced by such factors as pressure dependencies between different pipelines, temperature, gas quality, and operational constraints.
} 

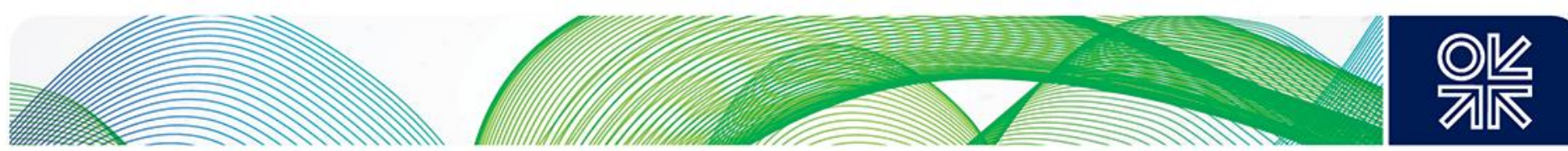

to the existing gas receiving terminal at Nybro (or to a yet to be built new terminal at another location ${ }^{348}$ ) with no connections either to existing offshore upstream pipeline infrastructure, owned and operated by Ørsted, ${ }^{349}$ or with production platforms operated by other producers, is considered the preferred solution. 350

- $\quad$ expansion of the Danish onshore transmission system including construction of new onshore pipelines ( 200-220 km) enabling the Danish system (which at present transports $\sim 3.5$ bcma of gas to customers in Denmark and Sweden) to transport up to an additional $10 \mathrm{bcma}$ in the west to east direction;

- construction of a gas compressor station (GCS) in Denmark near Zealand, capable of bidirectional compression;

- $\quad$ offshore interconnector - an offshore transmission pipeline from Denmark to Poland ( 227-286 $\mathrm{km}): 351$

- two alternative routes - through the Swedish or the German Exclusive Economic Zones (EEZ) - are considered, with both having to be routed through corridors of heavy commercial traffic, environmentally sensitive areas, ${ }^{352}$ a number of EU member states' territorial seas, and a number of infrastructure crossings. ${ }^{353}$

- construction of infrastructure necessary for allowing the gas delivered through the interconnector to enter the Polish gas transmission system and expansion and reinforcement of the existing Polish gas transmission system, including:

- construction of a receiving terminal on the Polish shore;

- construction of an onshore transmission pipeline from the terminal to the Polish gas transmission system (for example the Niechorz-Płoty gas pipeline) and a receiving terminal;

- extension of CS Gustorzyn;

- Goleniów-Lwówek gas pipeline;

- extension of CS Goleniów;

- CS Odolanów.

The Baltic Pipe is planned to be implemented by Energinet and Gaz-System.

- Energinet is a 100 per cent state-owned Danish company which owns the Danish gas (and electricity) transmission systems. In 2011 it was certified by the Danish regulatory authority as a TSO under the ownership unbundling (OU) model.

- Gaz-System is a 100 per cent state-owned Polish company which owns the Polish gas transmission network (with the exception of the Yamal-Europe pipeline). ${ }^{354}$ In 2014 Gaz-System was certified by the Polish regulatory authority as a TSO under an OU model in respect of the gas transmission system owned by Gaz-System. As of December 2008, Gaz-System is also an owner of Polskie

\footnotetext{
348 The existing Nybro terminal, owned by Ørsted (known as DONG Energy until November 2017), is a preferred location but an alternative location is also considered as restoration works at the Tyra platform, operated by Ørsted, may impact the Nybro terminal.

349 Ørsted Annual Report 2017.

350 This is the cheapest solution (2.8 bn DKK + 40 million DKK * 15 years) with others being 1.6-2.6 times more expensive. Gassco (Europipe II) conceptual studies of NO-DK tie-in and Energinet conceptual studies of Nybro expansions have been awarded.

${ }^{351}$ Baltic Pipe Project: Shipper information meeting, Stavanger 20 June 2017

352 Both alternatives pass the Ankora basin, the geological specificities of which might impact a technical solution.

353 Baltic Pipe Project: Shipper information meeting, Stavanger 20 June 2017.

${ }^{354}$ It was previously known as PGNiG-Transmission, originally a constituent part of the Polish $100 \%$ state-owned company

PGNiG. In April 2005 PGNiG transferred its shares in Gaz-System to the Polish state treasury.
} 

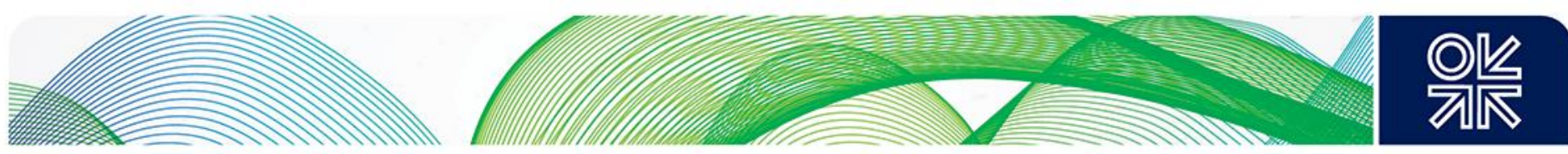

LNG, the company set up to build and operate the Polish LNG terminal. In 2015 Gaz-System was certified by the Polish regulatory authority as a TSO under an ISO moderl in respect of the Polish section of the Yamal-Europe pipeline.

The division of responsibilities between Gaz-System and Energinet in respect of Baltic Pipe is as follows. Energinet is in charge of establishing the first three components (the offshore tie-in pipeline, expansion of the Danish system, and construction of the compressor station) of the Baltic Pipe project whereas GazSystem is responsible for the last two components (an offshore interconnector and expansions in Poland).

Gaz-System and Energinet announced that the planned start date for the Baltic Pipe project would be October 2022. The timeline, although not impossible from the technical point of view, appears to be extremely ambitious given the complexity of the project. According to Energinet, the Environmental Impact Assessment (EIA) process is considered to be the main risk to the project's schedule. ${ }^{355}$ The EIA was launched in January 2017, with Gaz-System submitting the requests to Poland's ministry of maritime economy and the Polish maritime office for administrative decisions (location permits), agreeing the conditions for laying and maintaining the offshore pipeline in Poland's territorial waters and its EEZ, in respect of the three different routes under consideration. ${ }^{356}$

It is worth noting that several projects aimed at the establishment of offshore connections between Poland and Denmark with a view of transporting Norwegian gas to Poland across Denmark have been considered in the past - in 2005 (DONG-PGNiG JV), 2007, and 2009 - but these schemes failed to progress due to lack of market interest. However, the new feasibility study, which was conducted in 2015 and was financed by the EU under CEF funding, ${ }^{357}$ concluded that the project was feasible 'from a technical, environmental and economic point of view'. It has also identified market 'interest in the project', stating that market players expressed an interest in 'capacity of (more than) $10 \mathrm{bcm}$ '. 358 This preliminary conclusion was in sharp contrast to several previous studies which found no economic rationale for this type of project.

The Baltic Pipe feasibility study provides the following cost estimates: 359

- CAPEX: 1,585-2,060 million euros;

- OPEX: $\left(52.3 \times 20^{360}\right)=1,046$ million euros;

thus suggesting a total cost $2,631-3,106$ million euros (or 2.6-3.1 billion euros). The study noted that the estimate is given with 30 per cent accuracy, which changes the range to $1.8-4$ billion euros. ${ }^{361}$ The feasibility study notes that no exact division of cost between Gaz-System and Energinet has yet been determined, although the Energinet website suggests that the costs 'are split equally' between Energinet and Gaz-System. ${ }^{362}$

\footnotetext{
${ }^{355}$ Energinet (2017b), pp. 1-2.

356 The issue is to be coordinated with several governmental agencies as well as the local authorities of the regions where the pipeline could be built. The procedure will confirm whether or not the considered routes impact on other uses of the sea. In addition to securing a location permit, other permits will be necessary: for example a decision on environmental conditions, a decision on location of the pipeline in the designated corridor, and a construction permit.

357 The Polish-Danish interconnector is a PCl project and is therefore eligible for CEF funding, see Section 2.3.

358 The study was performed by Ramboll Denmark, Gazrprojekt, and EY Poland, and included technical and economic aspects of the project, see Abstract of feasibility study (see Additional Documents).

${ }^{359}$ Abstract of feasibility study (see Additional Documents)

360 The OPEX is estimated is for 20 years (2023-42) of operation.

${ }^{361}$ Although the feasibility study refers to these figures as cost estimates for the Baltic Pipe project, it is not clear whether they refer to all five components of the project (Norwegian tie-in, Danish system expansion, CS, offshore interconnector (offshore pipeline and onshore infrastructure allowing connection to the existing Polish system), and Polish system expansion), or only to one part of it, namely the offshore interconnector. In our view the estimates appear to be too low to refer to the entire project.

362 Energinet, 'Baltic Pipe: Gas pipeline, connecting Denmark and Poland with Norway's gas fields'.
} 

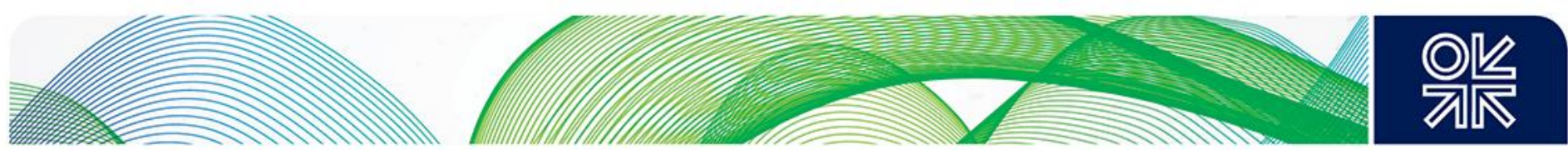

In its information manuals 1 and $2^{363}$ Energinet specifies that it is responsible for three out of five components of the Baltic Pipe project: the Norwegian tie-in, expansion of the Danish system, and CS Zealand. It will cover the costs of the Norwegian tie-in and expansion of the Danish system fully. It will cover part of the costs of CS Zealand as follows:

- 36 per cent of CAPEX up to 140 million euros and all CAPEX above 140 million euros;

- 50 per cent of fixed OPEX;

- all ABEX;

- variable OPEX related to flows above 7.5 bcma.

Furthermore, if the sum of 50 per cent of fixed OPEX plus variable OPEX related to flows of $7.5 \mathrm{bcma}$ or below exceeds 10-12 million euros per year, Energinet will pay the difference. ${ }^{364}$ In other words, as far as CS Zealand is concerned, Energinet agreed to paying around a third of CAPEX, half of fixed OPEX, and all variable OPEX related to annual flow of $7.5 \mathrm{bcma}$. Correspondingly, Gaz-System will cover the costs of the offshore interconnector and the expansion of the Polish system fully, and will also pay the costs of CS Zealand not covered by Energinet.

It is understood that the Baltic Pipe feasibility study has not assessed either the issue of Norwegian gas production (the availability of non-contracted gas that could be transported through the Baltic Pipe) or the issue of the Norwegian transportation capacity (the availability of non-contracted transmission capacity in the Norwegian offshore pipeline system). Thus Energinet and Gaz-System have asked Gassco, the operator of the Norwegian offshore gas system, to perform its own pre-feasibility study. The results of this pre-feasibility study were not publicly available at the time this study was completed.

As the Baltic Pipe includes the offshore tie-in pipeline, which would connect the Baltic Pipe to the offshore pipeline Europipe 2 (part of the Norwegian gas transmission system, Gassled) as one of its key components, Energinet would need to have approval from the Gassled operator, Gassco, before it can proceed with building the tie-in pipeline. It is understood that Energinet would be its sole owner and operator. Importantly, any shipper willing to use capacity in Europipe 2 would need to book both entry and exit capacity from Gassco. Gassco is the operator of the integrated system for transporting gas from the Norwegian continental shelf to other European countries (Figure 13).

As of 1 January 2003, virtually all of Norway's gas transport systems were integrated in a major new JV, Gassled. Gassco is responsible for running the Norwegian transportation system on behalf of its owners. Gassled serves as the formal owner of the Norwegian gas transport infrastructure and it is owned by several entities, the biggest share ( 46,7 per cent) being owned by Petoro, which serves as the licensee for the Norwegian state's direct financial interest in petroleum activities. The Norwegian government determines the framework conditions for Gassco, which also apply to the relationship between Gassco and the owners of the transport system. The main legal documents governing Gassco's operations are the Norwegian Petroleum Act and agreements with the transport system owners. The Gassled owners finance most of the major investments in the transport system. The cost of operating the transport system is met by users through tariff payments, which cover investment made by the owners. Gassco has the right and the duty to pursue unified further development of the gas infrastructure. Gassco does not make a profit or a loss from its own operations.

\footnotetext{
363 Energinet (2017a).

${ }^{364}$ Energinet (2017b).
} 

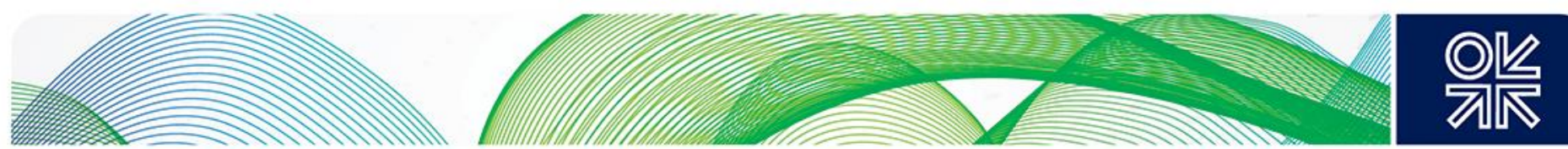

Figure 13: The Norwegian offshore transmission network Gassled

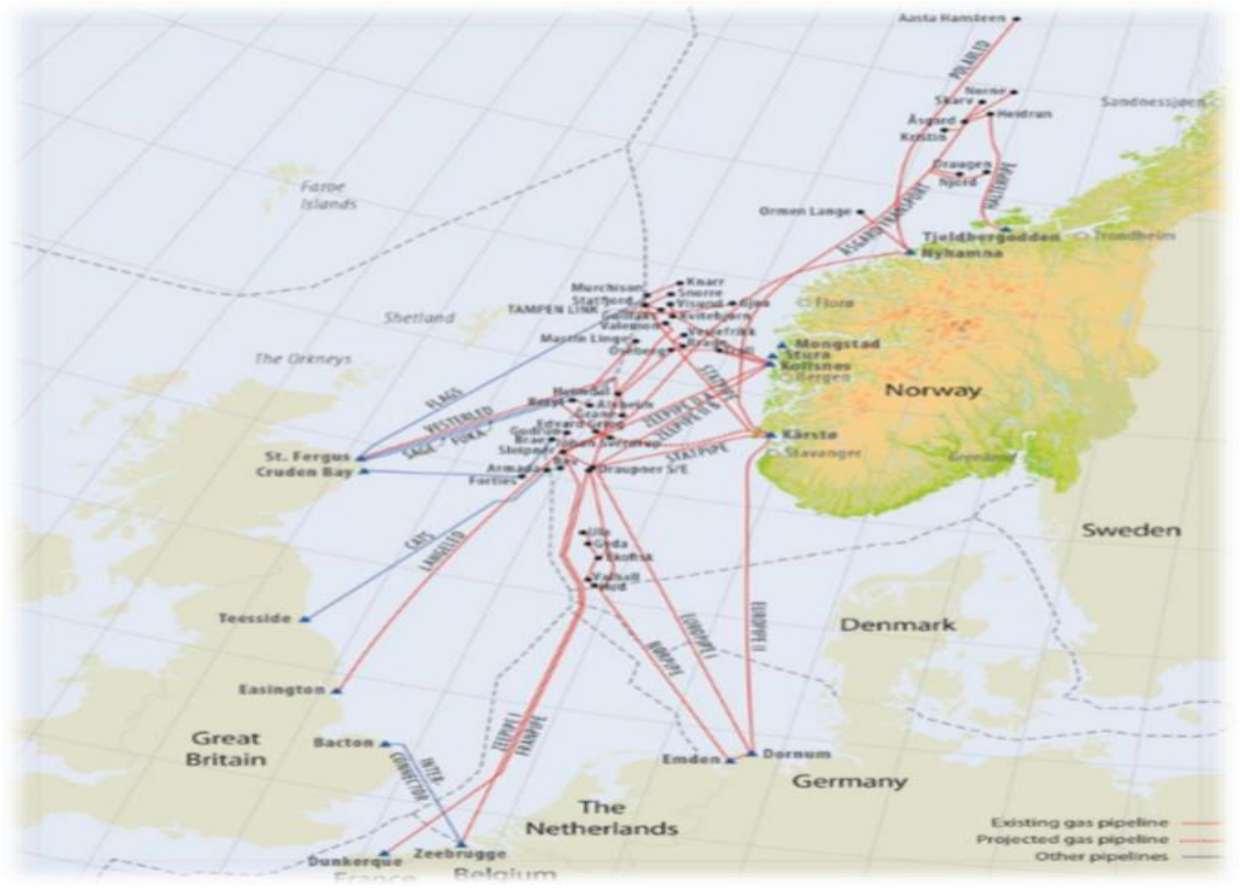

Source: Norwegian Petroleum Directorate.

Gassco is responsible for initiating and coordinating development processes for the gas pipeline network and related facilities (process plants and receiving terminals) and makes its own assessments and recommendations for infrastructure development. While Gassco does not own the infrastructure, it is required to present recommendations and investment proposals. Whether these recommendations are accepted, and proposals approved, depends on the willingness of the network owners and resource owners engaged on the Norwegian continental shelf. Gassco also carries out feasibility studies and conceptual designs for improvements and expansions of the upstream pipeline networks. Gassco coordinates and develops plans for future new capacity on the basis of the annual transport plan (Gassco does not appear to have the transport plan on its website and advises those interested to contact it directly). Gassco, in cooperation with the industry, has established a process for developing the annual transport plan to ensure that:

(a) all relevant information needed for continuous improvement of the gas transport network is collected,

(b) all participants involved in this process act in accordance with agreed procedures,

(c) the upstream pipeline networks are developed in line with established procedures.

This process aims to ensure efficient use of existing infrastructure and to recommend necessary capacity expansions on the basis of the annual transport plan. The work process is intended to secure efficient and commercial infrastructure development and to ensure neutrality and confidentiality in all phases of such activities. It also provides independent assessments and secures the necessary involvement of relevant stakeholders, including infrastructure owners, gas shippers, field operators, government agencies, and other affected parties. It would thus appear that the decision on construction of the Norwegian tie-in would need to be approved by the Norwegian government.

Gassco states that Gassled capacity is allocated to shippers 'in a transparent, fair and equitable manner, and in compliance with an agreed set of rules'. In particular, Gassco holds booking rounds twice a year 

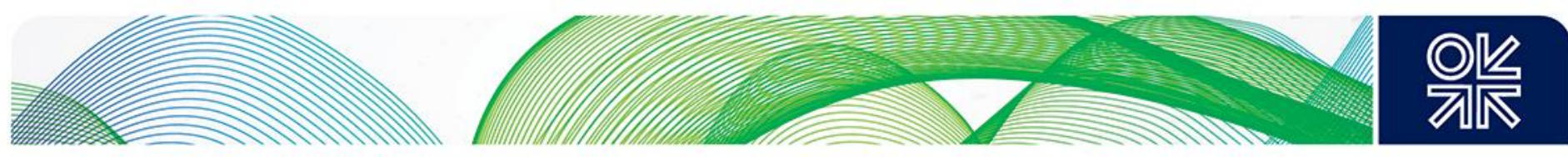

in which shippers can request spare capacity in the transport system for the medium and long term. ${ }^{365}$ Prior to these rounds, it collects data which forms the basis for estimating transport capacity requirements. Gassco also handles daily requests from shippers for additional capacity when and if this is available. Only authorized shippers - "companies with a duly substantiated need to transport gas from the Norwegian continental shelf' - are able to book capacity. While it is not specified what us meant by 'a duly substantiated need', it is reasonable to assume that a party requesting capacity in the system has confirmation of ownership of gas produced in the Norwegian continental shelf, such as a purchase contract or a production agreement. It is not clear whether the participant(s) which have booked capacity during the legally binding phase of the Baltic Pipe Open Season (OS) have also requested capacity in the Gassled system (in other words in Europipe 2), which is planned to be connected to the Danish upstream/transmission network.

\section{The Baltic Pipe rationale}

The main driving force behind the Baltic Pipe (whose main use was to import Norwegian gas to Poland via Denmark) is Poland's desire 'to completely exclude the use of Russian gas in Poland', on which it depends for two-thirds of its demand. Poland wants the Baltic Pipe to become operational by 2022, just as its long-term supply contract with Gazprom - under which it receives Russian gas at the PolishRussian border - expires at the end of 2021. (Notably, the long-term transit contract under which Russian gas is transited across Poland to Germany, expires at the end of 2019.)

However, the project's commercial rationale is not obvious, as the Norwegian gas could be brought to Poland across Germany through existing infrastructure. The existing infrastructure (in particular, the Polish-German interconnection point at Mallnow, which has a capacity of 27.9 bcma for forward flow and $5.4 \mathrm{bcma}$ for reverse flow) would have to be expanded to accommodate higher volumes, but such expansion would be less expensive by an order of magnitude than construction of the Baltic Pipe. As for Denmark, its demand is primarily satisfied by the Danish offshore field Tyra, located in the Danish EEZ and connected to the gas-receiving terminal at Nybro by an offshore pipeline, ${ }^{366}$ while it also imports small quantities from Germany (via Ellund at the Danish-German border).

The Baltic Pipe would enable Denmark to import pipeline gas from Norway (via the Norwegian tie-in) and also to import gas from Poland delivered to the Polish LNG terminal. However, there appears to be no need for additional imports as Denmark has been phasing gas out of its energy balance as a matter of government policy, thus suggesting continued decline in demand. (This has been confirmed during the Baltic Pipe binding capacity auctions, as no capacity was booked in the direction from Poland to Denmark.) Notably, the Danish regulatory authority has stated that 'the Danish infrastructure is already well-developed ... the Danish/Swedish market is an integrated part of the north western European market and ... the current transmission capacity is sufficient to cover the future demand for gas in Denmark and Sweden'.

\subsubsection{The Baltic Pipe regulatory procedure: 'Open Season 2017 Rules'}

Gaz-System and Energinet have developed a set of rules - the Open Season 2017 General Rules ('OS 2017 Rules') $)^{367}$ - to conduct an open season (OS) procedure as the means of assessing demand for, and allocating capacity in, the Baltic Pipe project. As noted earlier, the CAM NC, which established a set of legally binding regulatory procedures in respect of incremental (new) capacity, was adopted in March 2017, in other words at the time when Gaz-System and Energinet started to investigate the possibility of establishing an offshore connection between Denmark and Poland, including a possible offshore connection with the Norwegian offshore system. As our analysis in Section 2 demonstrated, the CAM NC made auctions the only capacity allocation mechanism that could be applied by TSOs in respect of

\footnotetext{
365 Gassco website.

366 The Tyra platform will be temporarily shut down for renovation from November 2019 to July 2022 . The primary source of supply for Danish and Swedish consumers during the renovation period will be gas from Germany combined with gas from the Danish gas storage facilities.

${ }^{367}$ OS 2017 Rules (see Additional documents).
} 

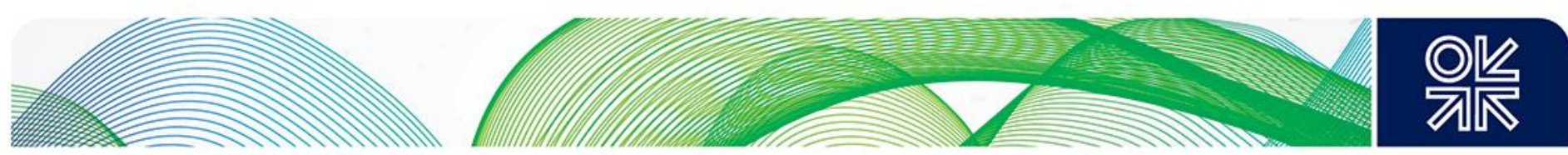

incremental capacity involving only two entry-exit systems, as is the case with the Baltic Pipe project. Therefore, the application of the OS procedure to the Baltic Pipe in respect of incremental capacity between two entry-exit zones - Danish and Polish - would appear to run contrary to the CAM NC. The fact that the Baltic Pipe project envisages an offshore connection to the Norwegian upstream pipeline system (the Norwegian tie-in) does not change this argument, because such an offshore connection would be made to an upstream (as opposed to transmission) pipeline (system), thus suggesting that it could not be considered an interconnector connecting Denmark with Norway. Furthermore, if one were to make an argument that after having been produced offshore, the Norwegian gas has left the upstream network and entered the Norwegian transmission system for processing, the Norwegian tie-in would still not be considered an interconnector because it would not be connecting two EU transmission entry-exit zones. This is because the Norwegian transmission system cannot be considered a transmission entryexit zone in the meaning of the EU acquis, because Norway is not an EU member. Nonetheless, GazSystem and Energinet maintain that the OS 2017 Rules respect the provisions of the CAM NC as well as those of the Third Gas Directive and Gas Regulation 715, while also noting that 'in addition' to these, the Rules are also based on the principles of the ERGEG's Guidelines for Good Practice for Open Season Procedures (GGPOS) (see Sections 2.1 and 2.4). This could be explained by the fact that the Polish regulator has granted its approval in respect of capacity allocation in the Baltic Pipe on 27 March 2017 thus allowing it to deviate from some of CAM NC's provisions under transitional arrangements (Art. 31).

Gaz-System and Energinet have listed several Open Seasons; some held by Energinet (for example in respect of expanding the Danish system from Germany (Ellund) to Denmark (Egtved) in 2009) and some by Gaz-System (for example an interconnector between Poland and the Czech Republic in 2011 and an interconnector between Poland and Slovakia in 2016). They have stated that 'it is on this background' provided by the OS - that Energinet and Gaz-System decided to conduct the Open Season in respect of the Baltic Pipe project. Interestingly, Gaz-System and Energinet have failed to mention that all the aforementioned projects were conducted before the entry into force of the CAM NC, which provided a legally binding set of procedures for the construction and allocation of incremental (new) capacity, thus dramatically reducing the importance of GGPOS as an applicable framework.

The 'OS 2017 Rules': detailed analysis

The OS 2017 Rules stipulate the following points at which capacity in the Baltic Pipe is offered:

- Entry Point North Sea - the delivery point at which transport through the Danish upstream and transmission system commences and where the shipper contractually delivers the gas to Energinet;

- Entry Point Baltic Pipe (DK $\rightarrow \mathrm{PL}$ ) (Gaz-System) - the delivery point at which transport through the Polish transmission system commences and where the shipper contractually delivers the gas to Gaz-System;

- Entry Point Baltic Pipe (PL $\rightarrow$ DK) (Energinet) - the delivery point at which transport through the Danish transmission system commences and where the shipper contractually delivers the gas to Energinet;

- Exit Point Baltic Pipe (DK $\rightarrow \mathrm{PL})$ (Energinet) - the delivery point at which transport through the Danish transmission system ends and where Energinet contractually redelivers the gas to the shipper;

- Exit Point Baltic Pipe (PL $\rightarrow$ DK) (Gaz-System) - the delivery point at which transport through the Polish transmission system ends and where Gaz-System contractually redelivers the gas to the shipper.

Capacity at the following pairs of interconnection points is offered as bundled capacity:

(a) Entry Point Baltic Pipe (DK $\rightarrow P L)$ and Exit Point Baltic Pipe $(D K \rightarrow P L)$ as Interconnection Point Baltic Pipe (DK $\rightarrow$ PL);

(b) Entry Point Baltic Pipe $(\mathrm{PL} \rightarrow \mathrm{DK})$ and Exit Point Baltic Pipe $(\mathrm{PL} \rightarrow \mathrm{DK})$ as Interconnection Point Baltic Pipe (PL $\rightarrow$ DK). 

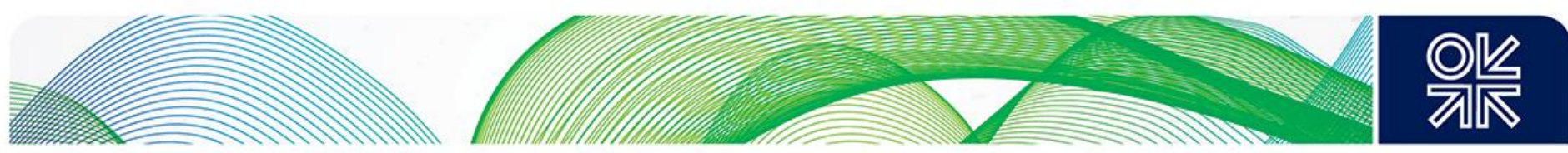

Capacity at the Entry Point North Sea, is offered as unbundled firm capacity on the Danish side of the Norwegian tie-in, thus suggesting that the booking of capacity in the Baltic Pipe does not include capacity in the Norwegian upstream system. ${ }^{368}$

According to the Rules, technical capacity to be offered at these points is as follows:

- North Sea Entry Point (entry to the Danish system): up to $14,201,000 \mathrm{kWh} / \mathrm{h}$;

- Interconnection Point Baltic Pipe (DK $\rightarrow P L)$ : up to $13,411,000 \mathrm{kWh} / \mathrm{h}$;

- Interconnection Point Baltic Pipe (PL $\rightarrow$ DK): up to $3,852,740$ kWh/h.

The OS 2017 Rules stipulate that 90 per cent of technical capacity at the relevant points will be offered as long-term capacity (in other words for a period from one to 15 years), whereas the remaining 10 per cent will be reserved for short-term capacity (in other words less than one year ${ }^{369}$ ) to be offered 'in the ordinary auctions'. The Rules further stipulate that the long-term capacity that has been offered but not allocated will also be offered in the auctions. According to the OS 2017 Rules, capacity is to be offered as long-term (more than one year) and short-term (less than one year) with a pro rata mechanism to be applied for capacity allocation in case of over-demand.

\subsubsection{The incremental process}

A market test was conducted to assess the interest of third parties in the project; according to GazSystem, the result of the market test was positive. In December 2016 Gaz-System and Energinet developed the 'Draft OS 2017 Rules' 370 in respect of the Baltic Pipe project and held a market consultation during 6 December 2016-6 January 2017. Following its conclusion, Gaz-System and Energinet adopted the 'OS 2017 Rules' on 6 June 2017 (these were subsequently amended on 10 July and 5 September 2017). ${ }^{371}$

The CAM NC, which entered into force on 6 April 2017, has stipulated that 'the first demand assessment shall be conducted in 2017 as from the entry into force'. It has also stated that market demand assessment reports must be produced no later than eight weeks after the start of the annual yearly capacity auction. ${ }^{372}$ The Gaz-System and Energinet interpretation of these provisions was such that the non-binding demand indications for incremental capacity had to be submitted to them by 1 June 2017 at the latest (in other words eight weeks after 6 April 2017) and market demand assessment reports had to be produced by 27 April (in other words 16 weeks after 6 April 2017).

On 6 June 2017 Gaz-System and Energinet published the OS 2017 Rules $^{373}$ and launched the OS 2017 procedure, enabling submission of the binding bids. ${ }^{374}$ The OS 2017 procedure was conducted in two phases: Phase 1 - non-binding; Phase 2 - binding.

\section{Phase 1}

Gaz-System and Energinet conducted Phase 1 during 6 June 2017-25 July 2017, with market participants being invited to submit non-binding bids for new capacity, and bids from associated

\footnotetext{
${ }^{368}$ OS 2017 Rules (see Additional Documents), p. 10.

369 Unlike the CAM NC, the OS 2017 Rules (see Additional Documents) do not provide a further breakdown of short-term capacity - in other words quarterly, monthly, daily, and within day.

${ }^{370}$ Draft OS 2017 Rules (see Additional Documents).

371 OS 2017 Rules (see Additional Documents).

${ }^{372}$ In 2017 the annual capacity auction was conducted on the first Monday of March 2017, according to the CAM NC 2013 (see Additional documents), whereas the CAM NC (2017) (see Additional documents) prescribed that the annual capacity auction would be conducted on the first Monday of July, as of 2018, see Section 2.1.

${ }^{373}$ OS 2017 Rules. Also see Appendix 3 to OS 2017 Rules and Appendix 4 to OS 2017 Rules (see Additional Documents) for additional rules applicable to the Danish and Polish participants respectively.

${ }^{374}$ Gaz-System (2017a).
} 

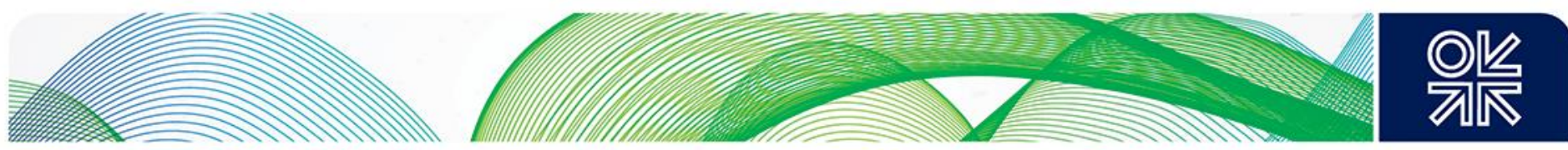

participants being prohibited. ${ }^{375}$ Bids could be submitted for a maximum of 15 years (October 2022September 2037). Phase 1 bids for Entry and Exit Point Baltic Pipe (DK $\rightarrow P L)$ and for Entry and Exit Point Baltic Pipe $(\mathrm{PL} \rightarrow \mathrm{DK})$ were to be submitted to both Energinet and Gaz-System, whereas Phase 1 bids for Entry Point North Sea were only to be submitted to Energinet.

The bids submitted during Phase 1 were considered by both TSOs to be sufficient for pursuing the fasttrack project for the implementation of the Baltic Pipe project, which would enable provision of capacity as of October 2022. ${ }^{376}$ The fast-track project can be pursued by Gaz-System if the total amount of capacity of the Entry Point Baltic Pipe (DK $\rightarrow \mathrm{PL})$ demanded by the participants in Phase 1 bids is, at least, at the level of $10,058,250 \mathrm{kWh} / \mathrm{h}(7.5 \mathrm{bcma})$ for each gas year. If this level is not reached, Gaz-System may still decide, at its sole discretion, to pursue the fast track project, but the fast track shall only be pursued if both TSOs decide to do so; in other words, Energinet would not be obliged to proceed if the total amount of capacity requested was below $10,058,250 \mathrm{kWh} / \mathrm{h}$. If the total amount requested is at least $10,058,250 \mathrm{kWh} / \mathrm{h}$ Energinet will continue the fast-track project.

The Phase 1 bid constitutes 'an order to proceed', in other words it is a binding offer from a participant to enter into a capacity agreement, thus suggesting that if the TSOs decide to proceed with the project, the participant is bound by its Phase 1 bid. As the order to proceed is binding, the participant is obliged to submit an offer for at least the same amount of capacity in its Phase 2 bid as it requested in the order to proceed. If the participant does not place a Phase 2 bid, if the Phase 2 bid is not complete, or the Phase 2 bid contains less capacity than was requested in the order to proceed, the participant is considered to have breached its obligations and is liable to pay liquidated damages to Energinet. ${ }^{377}$

The OS 2017 Rules stipulate that should the fast-track procedure be pursued:

- the Danish OS 2017 capacity agreement(s) will be concluded following the positive outcome of the Economic Test for each of the TSOs, and

- the Polish OS 2017 capacity agreements will be concluded following the positive outcome of the Economic Test for each of the TSOs and procurement of the corporate approvals of Gaz-System (management board, supervisory board, or the general assembly).

Given that capacity for pairs of interconnection points (Entry Point Baltic Pipe (DK $\rightarrow P L)$ and Exit Point Baltic Pipe $(\mathrm{DK} \rightarrow \mathrm{PL}))$ and (Entry Point Baltic Pipe $(\mathrm{PL} \rightarrow \mathrm{DK})$ and Exit Point Baltic Pipe $(P L \rightarrow D K)$ ) are offered as bundled, such capacity is identical in the given flow direction. Therefore, identical capacity must be requested for each of these pairs in a given year. If capacity requested is different for one or more years, the bid with the highest requested capacity in the given year shall be reduced by the relevant TSO to the bid with the lowest requested OS 2017 capacity for the given year.

Having received the Phase 1 bids, Energinet has assessed whether the total requested capacity for Entry Point North Sea and Exit Point Baltic Pipe $(D K \rightarrow P L)$ is sufficient to pursue the fast-track project. GazSystem has assessed whether the requested capacity for Entry Point Baltic Pipe (DK $\rightarrow P L)$ is sufficient in order to pursue the fast-track project. If both TSOs assess that the requested capacity in Phase 1 is sufficient for the fast-track procedure, it will be pursued, with participants being obliged to submit Phase 2 bids. If at least one TSO assesses that the requested capacity is not sufficient for the fast-track

\footnotetext{
${ }^{375}$ Rules application to participation in the Danish part of OS 2017 (Appendix 3 to OS 2017 Rules, see Additional documents) has an extensive section defining as associated participant as 'directly or indirectly controls the other participant, directly or indirectly is controlled by the other participant, directly or indirectly is under the control of the same third party'. Appendix 3 to OS Rules, p. 6. It further notes that if a participant establishes control or, comes under the control of another participant, or under common control with another participant during the Open Season 2017, Energinet 'may at its sole discretion' revoke the registration and disregard any bids from the participant.

${ }^{376}$ Fast track procedure means that parties will initiate scoping of the Baltic Pipe design and reducing the number of possible technical solutions at an early stage of the Open Season 2017.

377 30,000,000 DKK
} 

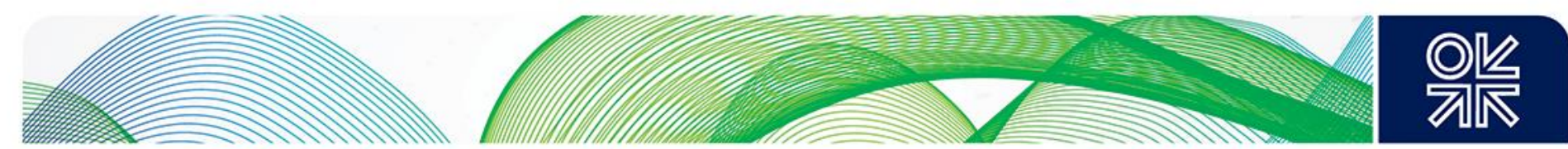

procedure, it will not be pursued, with participants not being obliged to submit Phase 2 bids. The OS 2017 Rules stipulate that should the fast-track project not be pursued, Energinet and Gaz-System may 'in their sole discretion decide to change certain elements' of the OS 2017 Rules.

\section{Phase 2}

Gaz-System and Energinet conducted Phase 2 during 5 September 2017-31 October 2017, with participants being invited to submit their final (binding) bids for the final allocation of capacity for a maximum of 15 years (October 2022-September 2037) (Figure 14). ${ }^{378}$

\section{Figure 14: The open season time schedule for the Baltic Pipe project}

\section{THE OPEN SEASON TIME SCHEDULE FOR THE BALTIC PIPE PROJECT}

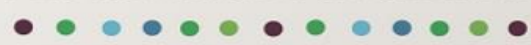

PHASE 2

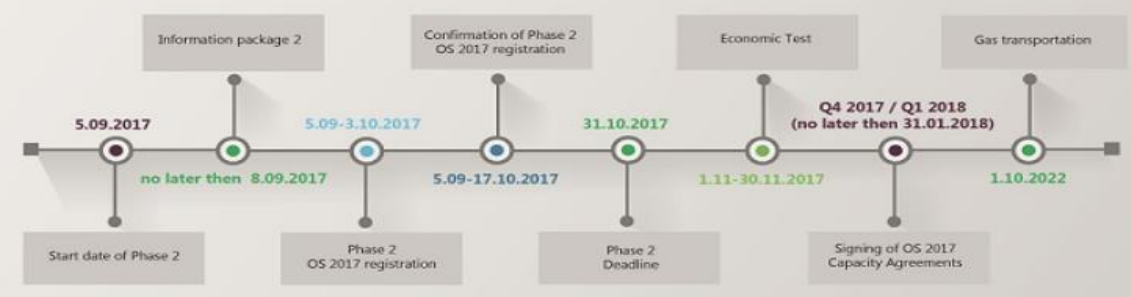

C) GR्= ENERGINET

Source: Gaz-system, Energinet.

While participation in Phase 1 was not a precondition for participation in Phase 2, participants in Phase 1 were obliged to submit bids in Phase 2 for at least the same amount of capacity as they did in Phase 1. A participant who has submitted a Phase 1 bid does not have a preferential status compared to a participant who only submitted its bid in Phase 2. As was the case for the bids submitted in Phase 1, the Phase 2 bids for Entry and Exit Point Baltic Pipe (DK $\rightarrow P L)$ as well as Entry and Exit Point Baltic Pipe $(\mathrm{PL} \rightarrow \mathrm{DK})$ were to be submitted to both Energinet and Gaz-System, whereas the Phase 2 Bid for Entry Point North Sea was only to be submitted to Energinet. Bids submitted for the Entry/Exit Point Baltic Pipe were considered as bundled in the same direction between Energinet and Gaz-System. According to a Gaz-System press release, market participants have confirmed their interest in new capacity demonstrated during Phase 1, by submitting binding bids for capacity for 15 years. ${ }^{379}$

Having received the Phase 2 bids Energinet and Gaz-System have conducted their evaluation. According to the OS 2017 Rules, in the event of capacity being over-subscribed at one or more points, ${ }^{380}$ capacity will be allocated in line with the priority of the Phase 2 bids. For a particular gas year, priority shall be given to the Phase 2 bids which cover the level of capacity requested for the highest number of years. The priority of a particular Phase 2 bid shall be given only within the level of capacity requested for the highest number of years, and not for the total level of the capacity requested for the particular gas year

\footnotetext{
${ }^{378}$ In order to participate, the interested shippers have to be registered as a shipper and as a participant at Energinet.dk and GazSystem.

${ }^{379}$ Gaz-System (2017b).

${ }^{380}$ Defined as capacity requested in phase 2 bids in the same direction at a given point for a given yearly standard product exceeds the capacity offered at that point
} 

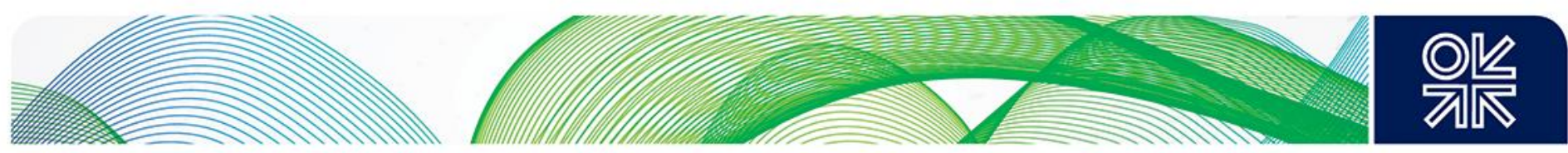

in this Phase 2 bid. This demonstrates that the Rules stipulate prioritization by duration. ${ }^{381}$ If over-demand occurs within a certain priority level, the Phase 2 bids within this priority level will be subject to the pro rata mechanism (in other words allocation of capacity proportionally to the requested capacity for the given yearly standard products in the Phase 2 bids of the same priority level). If application of the pro rata mechanism results in a discrepancy between the allocated capacity at the Entry Point North Sea, Exit Point Baltic Pipe $(D K \rightarrow P L)$, and Entry Point Baltic Pipe $(D K \rightarrow P L)$, a participant who has submitted identical bids for these three points shall be entitled to reduce its allocation to the allocated capacity at the point with the lowest allocation of the three points. A participant is obliged to state in its Phase 2 bid that the three points are interdependent, in order to be able to make use of this reduction, and is obliged to inform both TSOs within 10 days from the announcement of allocation results whether it wishes to exercise this right - the reduction will be conducted by the TSOs only upon receipt of a request from the participant. The Rules thus stipulate the possibility of conditionality of bids. In the event that capacity is not over-subscribed, the participant is to be allocated capacity equal to its Phase 2 bid.

It is understood that demand was within capacity limits and the participants were allocated their Phase 2 bids.

\subsubsection{The economic test}

The OS 2017 Rules stipulate that the economic test must be concluded following the evaluation of the Phase 2 bids and the final allocation result. The positive outcome of the economic test for each TSO is a necessary - but not a sufficient - condition for the conclusion of capacity agreements (contracts). Notably the Rules allow for the technical parameters of the Baltic Pipe project - in particular, the technical capacity - to be changed should the received Phase 2 bids imply a negative outcome of the test under the project's original parameters. If such a change requires a proportionate reduction of bids, the participants would be entitled to reject the reduced allocation, and the TSOs would be entitled to terminate an OS.

The Rules stipulate that if the outcome of the economic test for each TSO is positive, Energinet will conclude the Danish capacity agreement(s) with the participants (if the total capacity requested in Phase 1 bids is not sufficient to pursue the fast-track project, conclusion of the Danish agreement(s) must await approval by the supervisory board of Energinet) and Gaz-System will conclude the Polish capacity agreements, subject to 'the obtainment (sic) of the corporate approvals of the relevant body of GazSystem'. ${ }^{382}$

Notably, the commencement of gas transmission services is subject to the conditions precedent set out in the relevant capacity agreement(s). In particular, Energinet has stated that as it foresees 'some uncertainty as to the expansion of the transmission system and the Norwegian tie-in', and as the Baltic Pipe project also envisages construction of the Baltic Pipe pipeline (offshore interconnector), its capacity agreements include a conditions precedent which 'may relieve or delay obligations for the participant and/or Energinet.dk' under a capacity agreement.

\section{Tariffs and the tariff principles}

The Danish part of the OS 2017 Rules stipulates that the tariffs for allocated incremental OS 2017 capacity will be governed by the Danish Rules for Gas Transport (RfG) and as such will be identical to the tariffs for existing capacity. The participants will thus not be offered fixed tariffs for OS 2017 capacity, the tariffs will not be determined until this capacity is made available to the participant, and this may change during the time covered by the capacity agreement. Tariffs will be determined in line with the tariff methodologies in force during the period of the capacity agreement.

Notably, should the existing Danish (entry-exit) tariff principles and market design remain unchanged, the Baltic Pipe would have a significant impact on tariffs and their cost-reflectivity. If built, the Baltic Pipe

\footnotetext{
${ }^{381}$ Thus, giving priority to the participants who submitted the phase 2 bids for the longest duration - in other words for the allocation for a given point, in a given direction, within a higher number of gas years.

382 OS 2017 Rules (see Additional documents), p. 12.
} 

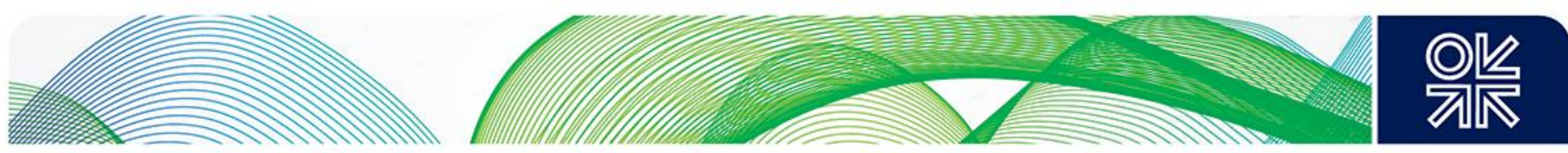

would effectively turn Denmark into a transit territory for gas from the Norwegian shelf to Poland, thus making transit predominant in overall transmission. ${ }^{383}$ In November 2016. Energinet prepared a memorandum on the new market design and tariff principles ('The Tariff Principles') that would mitigate this impact and aim 'among others' to support the feasibility of the Baltic Pipe project while also conforming to the Tariffs NC. ${ }^{384}$

The main principles of the tariff structures and market design as proposed by Energinet are as follows: ${ }^{385}$

- a common entry point for the Norwegian-Danish tie-in in the North Sea and the Danish transmission system, on the basis that it would allow for harmonization of capacity products, balancing the terms and tariff structures between the upstream and transmission systems of Denmark, whose operators are subject to different regulatory regimes (for example negotiated access to upstream systems as opposed to regulated access to transmission system, non-application of the EU NCs to upstream, and application of the EU NCs to transmission systems);

- uniform cost allocation of CAPEX and OPEX at points in the Danish transmission system (in other words socialization of costs), on the basis that it would constitute a 'fair, objective and transparent cost-allocation principle' given the anticipated change of flows as a result of the Baltic Pipe construction, and stating that it is 'a requirement for a positive transit business case';

- extension of uniform cost allocation to the joint entry point in the North Sea (in other words socialization of costs to include entry point(s) in the North Sea), provided that this is compliant with regulations for upstream tariff setting.

If adopted, these tariff principles would mean a very significant change in comparison to the present regime. Under the current system - in other words with no common entry point from the Norwegian tie-in and the Danish transmission system - a shipper needs to conclude a separate entry-exit capacity contract with an upstream operator(s), thus booking the capacity in the upstream network, in addition to booking the entry-exit capacity in the transmission network (for example at the Entry Point North Sea and the Interconnection Point Baltic Pipe (DK $\rightarrow \mathrm{PL})$. Energinet notes that creation of a common market zone would allow for one capacity booking to give access to both the upstream and the transmission systems, thus removing the need for multiple capacity contracts with upstream and transmission operators and reducing the risk of upstream and transmission capacity mismatch. Energinet thus suggests the creation of a common market zone by moving the entry point into the offshore transmission system to the Norwegian tie-in. This would mean that a shipper would only need to conclude one contract for entry and exit capacity (as upstream and transmission would be integrated into one common entry point).

As of 2012, Energinet has applied an entry-exit differentiated tariff. For example, CAPEX related to an incremental capacity project (capacity expansion at the interconnection point on the Danish-German border at Ellund, also carried out under open season procedure ${ }^{386}$ ) built in 2012 is allocated to individual points, whereas other CAPEX is uniformly allocated to all points in the system. It is worth noting that the TEP, adopted in 2009, has made an entry-exit tariff mandatory in the EU. However, in its new tariffs and market design proposal, Energinet suggests abolishing differentiated tariffs, arguing that their application 'impose[s] disproportionate costs on new shipper' and 'may risk jeopardizing' the Baltic Pipe project and 'the entire project's feasibility' whereas uniform tariffs provide 'a more transparent pricing principle'. Furthermore, while Energinet argues that the change is needed to make the tariff methodology compliant

\footnotetext{
${ }^{383}$ Notably, the Second Energy Package eliminated a legal distinction between the categories of 'transit' and 'transmission' whereas the Tariffs NC appears to have (at least partly) re-introduced it by defining the 'intra-system network use' and 'crosssystem network use' categories, see Tariffs NC (see Additional documents).

${ }^{384}$ Energinet (2016b), Tariff Principles. The memorandum was presented for public consultation during 2-15 November 2016 and 18 November 2016-2 December 2017.

${ }^{385}$ Energinet (2016b) Tariff Principles, pp. 3-4.

${ }^{386}$ The OS procedure for Ellund IP expansion offered capacity for 10 years (not 15 as had been the OS procedure for the Baltic Pipe); more than half of incremental (new) capacity was allocated as short-term capacity.
} 

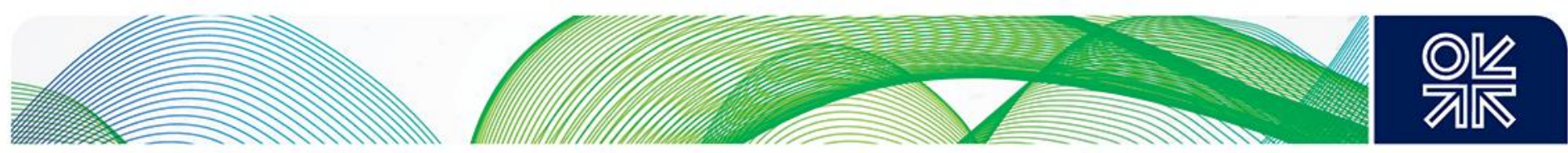

with the Tariffs NC, it does not elaborate on why it believes the current (differentiated) tariff methodology is not compliant with the Tariffs NC. Instead Energinet offers to apply a principle of uniform entry and uniform exit tariffs as the basis of cost allocation. In other words, all CAPEX related to new and existing infrastructure is merged into a single tariff cost base, with the tariff being calculated as 'the sum of all CAPEX divided by the sum of expected capacity reservations in all entry and exit points'. This suggests that all project-related costs would be fully socialized at all points in the system, and uniform tariffs will be the same at all entry and exit points irrespective of route (path) and destination of gas. (Energinet notes that due to a 50:50 entry-exit split of the cost base - in other words half of the cost base is allocated to entry and the other half to exit - and due to the fact that more exit capacity is normally booked, the resulting exit tariffs would be lower than the entry tariffs.) Energinet states that the uniform tariff principle is 'arguably' 'more cost-reflective' and is 'certainly more transparent and predictable' and argues that application of a uniform tariff will not lead to cross-subsidization.

In its first Information Package, which provides the OS 2017 guidance, Energinet defines a uniform tariff as follows: ${ }^{387}$

\author{
Uniform Tariff $=$ Volume Tariff + Entry Capacity Tariff + Exit Capacity Tariff \\ Volume Tariff $=$ Total OPEX $/$ Total Volume \\ Entry Capacity Tariff $=0.5 \times$ Total CAPEX / Total Entry Capacity Booking \\ Exit Capacity Tariff $=0.5 \times$ Total CAPEX / Total Exit Capacity Booking \\ Uniform Tariff $=$ Total OPEX / Total Volume $+0.5 \times$ Total CAPEX / Total Entry Capacity Booking +0.5 \\ $\times$ Total CAPEX / Total Exit Capacity Booking
}

In its subsequent Information Package 2, Energinet has changed a formula which it uses to calculate the tariff (which it no longer refers to as a Uniform Tariff but as a Transportation Tariff); the difference being that the tariff will be identical for all (in other words entry and exit) points, while the previous formula ensured that the tariff would be the same for all entry points and the same for all exit points, but that there would be a difference between the tariff charged at all entry points compared to the tariff charged at all exit points. ${ }^{388}$

\title{
Transportation Tariff $=$ Commodity Tariff + Entry Capacity Tariff + Exit Capacity Tariff \\ Commodity Tariff $=$ Total OPEX / Total Flow \\ Entry Capacity Tariff = Exit Capacity Tariff = Total CAPEX $/$ Total Capacity Booking
}

It is argued here that in advocating a uniform tariff, Energinet proposes a de facto postal tariff system, not an entry-exit system. ${ }^{389}$ It is worth noting that the Tariffs NC stipulated that the default cost allocation principle is one of capacity-weighted distance tariffs, not uniform (postal) tariffs. Energinet acknowledges this, but argues that a uniform tariff could be used (as long as it is approved by the Danish regulatory authority and the difference with capacity-weighted distance tariffs is accounted for) as a capacityweighted distance tariff is not mandatory under the Tariffs NC.

On 31 January 2017 the Danish regulatory authority provided a positive (not legally binding) opinion on the Energinet proposal on the tariff principles. ${ }^{390}$ It stated that the uniform tariff principle 'may be designed in such a way that it facilitates the realization of the project, while also giving existing shippers the possibility of benefitting in the form of generally lower transmission tariffs than they would otherwise be charged'.391 No formal (legally binding) decision has yet been made by the Danish regulatory authority, as it requires a formal notification of tariff methodology by Energinet, which has not yet happened. ${ }^{392}$

\footnotetext{
387 Energinet, (2017a).

388 Energinet (2017b).

${ }^{389}$ Energinet, Tariffs and fees on the Danish gas market, https://en.energinet.dk/gas/tariffs-and-fees

390 DERA (2017a).

391 DERA (2017a).

392 Ibid.
} 

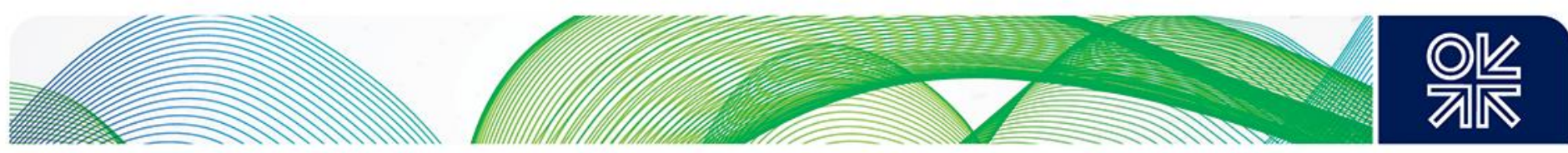

Subject to the approval of the Danish regulatory authority, the tariff principles are expected to be implemented by October 2018. Energinet has also stated that it will implement the Tariffs NC by 1 October $2019 .{ }^{393}$

As it expects the tariff will be uniform from 1 October 2022 (the planned start date of Baltic Pipe operation) - assuming that the Danish regulatory authority will have approved it - Energinet has used a uniform tariff (and not the existing differentiated tariff) in its tariff simulation for the Baltic Pipe OS 2017. For conducting a tariff simulation, Energinet included all the costs related to its components of the Baltic Pipe project (Norwegian tie-in, onshore expansion, and compressor station) as well as its existing cost base associated with the existing infrastructure.

\section{Economic test parameters: Danish and Polish regulatory authorities' decisions}

On 28 November 2017, the Danish regulatory authority approved the economic test parameters. ${ }^{394}$ It has approved the estimated future reference prices (capacity tariffs) in the range of $0.23-0.28$ euros/MWh for the 2022-37 period of binding commitments for OS2017 capacity. By multiplying the estimated reference prices and 10,058 MWh (7.5 bcma) of binding commitments made in Phase 2 of OS 2018, Energinet has calculated a present value of the binding commitments of 428 million euros and estimated a present value of the allowed increase of revenue of 693 million euros. The Danish regulatory authority has approved the f-factor at 0.6 , which means that only 60 per cent of the increase in allowed revenue should be covered by binding commitments for the economic test to provide a positive result. Under these parameters, the economic test has been passed with a positive outcome, albeit very narrowly:

Present value of binding commitments $>=f$-factor $\times$ Present value of the allowed revenue increase 428 million euros $>0.6 \times 693$ million euros $=415.8$ million euros

The f-factor of 0.6 is understood to be considered low by gas industry standards. However, the Baltic Pipe project would not have passed the economic test should the f-factor have been significantly higher, unless significantly higher reference prices were to be approved.

The Polish regulatory authority has set the same f-factor of 0.6 as the Danish regulatory authority. ${ }^{395}$ Polish tariffs are significantly higher, in the range of 1.4-1.7 euros/ $\mathrm{MWh}$, with the allowed revenue close to the Danish level at $\sim 750$ million euros.

\section{Signature of capacity agreements}

On 30 November 2016, it was reported that the economic test - conducted by Gaz-System and Energinet, pursuant to the requirements of their respective regulatory authorities, ERO and DERA, had yielded a positive result. On 30 January 2018, Gaz-System issued a press release stating that 'a positive result of the economic test together with the fulfilment of the other conditions set forth in the OS 2017 Rules allowed both TSOs, in other words Gaz-System and Energinet to enter into the capacity agreements with the market participants to whom the capacity of the Baltic Pipe project was allocated' while adding that the 'relevant capacity agreements were concluded'. ${ }^{396}$

On 22 January 2018, Gaz-System spokesperson, Mariusz Kozlowski, announced that Gaz-System had signed a transmission contract (capacity agreement) with PGNiG in respect of capacity in the Baltic Pipe allocated during the OS 2017. It is not clear whether any other party has booked capacity and whether any other capacity agreement was signed.

According to Gaz-System, the total technical capacity booked during the OS is as follows:

- North Sea Entry Point (NO $\rightarrow$ DK): 10,600 MWh/h; ( 75 per cent of technical capacity);

\footnotetext{
${ }^{93}$ Energinet (2017b).

${ }^{394}$ DERA (2017b).

${ }^{395}$ ERO (2017), Decision of the President of the Energy Regulatory Office.

${ }^{396}$ Gaz-System (2018b).
} 

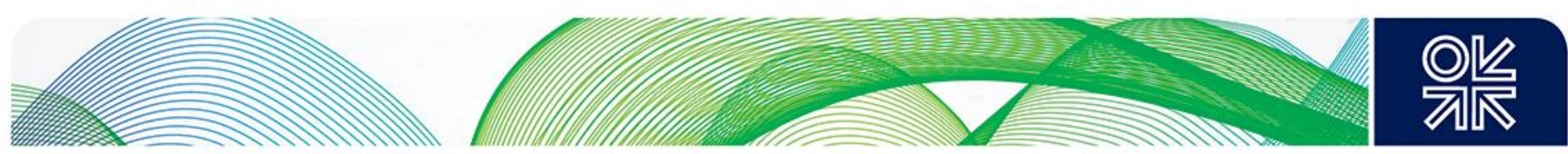

- Entry Point Baltic Pipe (DK $\rightarrow \mathrm{PL})$ and Exit Point Baltic Pipe (DK $\rightarrow \mathrm{PL}): 10,600 \mathrm{MWh} / \mathrm{h} ;(\sim 79$ per cent);

- Entry Point Baltic Pipe (PL $\rightarrow$ DK) and Exit Point Baltic Pipe (PL $\rightarrow$ DK): 0 MWh/h. (0 per cent).

Given that, according to the Rules, technical capacity offered at these points is as follows:

- North Sea Entry Point (entry to the Danish system): up to $14201 \mathrm{MWh} / \mathrm{h}$;

- Interconnection Point Baltic Pipe (DK $\rightarrow \mathrm{PL})$ : up to $13411 \mathrm{MWh} / \mathrm{h}$;

- Interconnection Point Baltic Pipe (PL $\rightarrow$ DK): up to $3852 \mathrm{MWh} / \mathrm{h}$.

The press release notes that 10 per cent of the planned technical capacity has been reserved for shortterm products, and that it is 'expected that the remaining technical capacity ... will be offered as part of regular auctions' in accordance with the CAM NC.

The results of the Baltic Pipe OS suggest that $\sim 75$ per cent of capacity at the Entry Point North Sea and $\sim 79$ per cent of capacity at the Interconnection Point Baltic Pipe (DK $\rightarrow \mathrm{PL}$ ) (in other words towards Poland) was booked, whereas no capacity at the Interconnection Point Baltic Pipe ( $P L \rightarrow D K$ ) (in other words towards Denmark) was booked. Notably the amount of capacity booked at the Entry Point North Sea is equal to the amount of capacity booked at the Interconnection Point Baltic Pipe (DK $\rightarrow P L)-10600 \mathrm{MWh} / \mathrm{h}$ - which suggests that all of this capacity was booked exclusively for supplies to Poland (and not to Denmark). This confirms the lack of market interest in supplying Danish (and Swedish) consumers from Europe via the North-South gas corridor. ${ }^{397}$ The results of the Baltic Pipe capacity allocation - both amount and direction - thus suggests that the only party (parties) interested in Baltic Pipe capacity are those willing to transport the Norwegian gas to Poland.

It is not clear which parties have booked capacity in the Baltic Pipe. On 31 October 2017, PGNiG stated that it had submitted an 8.1 billion zloty ( $\$ 2.2$ billion) binding offer to book capacity on the Baltic Pipe, but did not say how much of the pipeline's capacity it has booked. Neither Gaz-System nor Energinet have said whether companies other than PGNiG have booked the capacity. ${ }^{398}$ But it is worth noting that GazSystem has only announced a capacity agreement with PGNiG and not with any other party. While this announcement on its own is not sufficient to conclude whether PGNiG is the only party which has booked the capacity in the Baltic Pipe, the lack of any mention of other parties strongly suggests that this might be the case. If true, this would confirm - with both Gaz-System and PGNiG being 100 per cent stateowned Polish entities - that the Polish government is the only interested party in this project.

According to the Danish part of the OS 2017 Rules, the capacity agreement is conditional on a positive business case calculation for the Norwegian tie-in and the expansion of the Danish network. The business case calculation is defined as 'a socio-economic test', measuring the impact of the Baltic Pipe project 'for Danish society' and is conducted by Energinet based on comparison of the total costs of the Danish part of the project with the socio-economic benefits in Denmark, 'such as (but not limited to): producer and consumer surplus, impact on transportation costs, effects on security of supply, effects on competition'. ${ }^{399}$ In March 2018, Energinet's supervisory board approved the business case for the Danish part of the Baltic Pipe project and submitted an application for investment approval to the Danish energy ministry (as the investment requires approval by the minister). ${ }^{400}$ Given that both the Danish regulatory and competition authorities have provided their (as yet) provisional approvals - with the regulatory authority being willing to agree to an overhaul of the existing tariff methodology so that the Baltic Pipe could be commercially viable - it is logical to assume that the minister is also likely to approve.

\footnotetext{
${ }^{397}$ North-South gas corridor - a project promoted by Gaz-System - is envisaged to connect the Polish LNG terminal is Świnoujście, through central Poland, the Czech Republic, Slovakia and Hungary with the proposed LNG terminal in Croatia. 398 'Poland's PGNiG confirms interest in gas transit via Baltic Pipe', Reuters, 31 October 2017 (Journal articles).

${ }^{399}$ Appendix 3 to OS 2017 Rules (see Additional Documents), p. 20.

${ }^{400}$ Energinet (2018).
} 

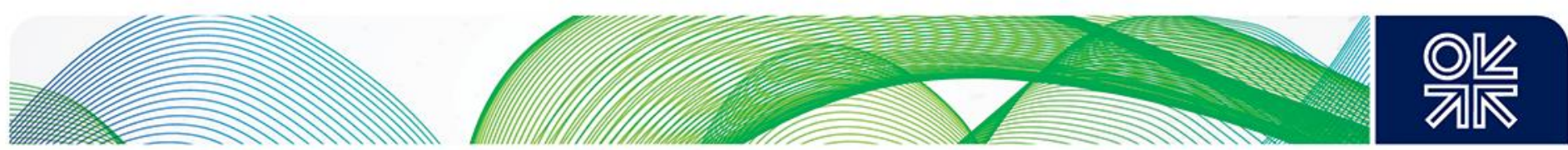

\section{Conclusions}

Overall, although some uncertainty remains in respect of the Baltic Pipe project - mostly stemming from the availability of sufficient volumes of Norwegian gas and the infrastructure necessary for carrying this gas through the Norwegian tie-in - there appears to be a clear political will on the part of both Poland and Denmark and their stated-owned TSOs (Gaz-System and Energinet) to proceed with the project. Notably, the project is pursued irrespective of the fact that Poland is already connected via the GASPOOL hub to various sources and suppliers (including Norway). ${ }^{401}$ Notably in late December 2017, Gaz-System approved its national network development plan covering the 2018-27 period; this was also confirmed by the Polish regulatory authority in October 2017. This plan includes the Denmark-Poland interconnector (10 bcma) and the expansion of the existing Polish LNG terminal (from 7.5 to $10 \mathrm{bcma}$ ). ${ }^{402}$ The final investment decision (FID) on the Baltic Pipe project is expected to be made in 2018.403

In addition to being supported by Poland and Denmark, the Baltic Pipe project is supported by the EC; this is illustrated by the fact that the Denmark-Poland interconnection has been included in all the EU PCl lists - the first (2013), the second (2015), and the third (2017) as part of the priority corridor 'Baltic energy market interconnection plan in gas' (BEMIP). ${ }^{404}$ Furthermore, EC support appears to have increased over time as, in addition to the Denmark-Poland interconnection, the $2017 \mathrm{PCI}$ list also includes a project on reinforcement of 'interconnection between the Danish Nybro gas treatment plant and Poland/Denmark interconnection'. ${ }^{405}$ In 2015, the Baltic Pipe project received EU financial assistance for a feasibility study under the CEF, and also in 2018 for preparatory works. ${ }^{406}$ However, it is not known whether the EC will contribute towards co-financing of construction works.

\subsection{Intergovernmental Agreements: Yamal-Europe and South Stream}

Several new pipeline projects have been - or have attempted to be - developed in the EU under the framework provided by intergovernmental agreements (IGA). IGAs have been concluded between the governments of European host countries and the governments of third countries, in respect of construction and operation of new cross-border pipelines, with a view of developing bespoke frameworks for their regulatory treatment at a time when legally binding regulatory procedures for new capacity did not exist at the EU level.

For example, the Yamal-Europe pipeline, bringing Russian gas to Europe across Belarus and Poland, was developed under The Russian-Polish IGA, ${ }^{407}$ which was signed in 1993 and subsequently amended in 2003 and 2010.408 When the Yamal-Europe pipeline became operational in 2006, ${ }^{409}$ the EU energy acquis for gas comprised the Second Energy Package (in other words the 'Second Gas Directive' and 'Gas Regulation 1775'), which did not contain either general rules or specific regulatory procedures in respect of new capacity. On 13 July 2009, the Third Energy Package (TEP) (in other words the 'Third Gas Directive' and 'Regulation 715') was adopted, subsequently becoming part of the acquis on 3 March 2011.410 The TEP outlined the general rules (TSO unbundling, tariff regime, TPA) but did not

\footnotetext{
${ }^{401}$ There is existing exit capacity of $7,700,000 \mathrm{KWh} / \mathrm{h}$ from GASPOOL to Poland at Mallnow, see Table 2

402 Gaz-System (2018a)

403 Gaz-System (2017c)

${ }^{404}$ First PCI List, Second PCI List, and Third PCI List (see Additional documents).

405 Third PCI List (see Additional documents). See also Baltic Pipe Project: Shipper Information meeting, Stavanger.

406 Gaz-System (2018)

407 The Russian-Polish IGA (see Additional documents).

408 See The 2003 Additional Protocol, The 2010 Protocol amending the 2003 Additional Protocol, and The 2010 Protocol amending the Russian-Polish IGA (Additional documents)

409 The Yamal-Europe has been repeatedly delayed and downscaled, for details see Stern and Yafimava (2017b).

410 The Third Gas Directive (see Additional documents) was adopted on 13 July 2009 and entered into force on 3 September 2009, with member states being obliged to transpose it into their national legislation, thus making it fully applicable, by 3 March 2011 - the date from which the Second Gas Directive (see Additional documents) would be repealed. Gas Regulation 715 (see Additional documents) was also adopted on 13 July 2009 and entered into force on 3 September 2009, fully applicable as of 3 March 2011, the date from which Gas Regulation 1775 (see Additional documents) would be repealed.
} 

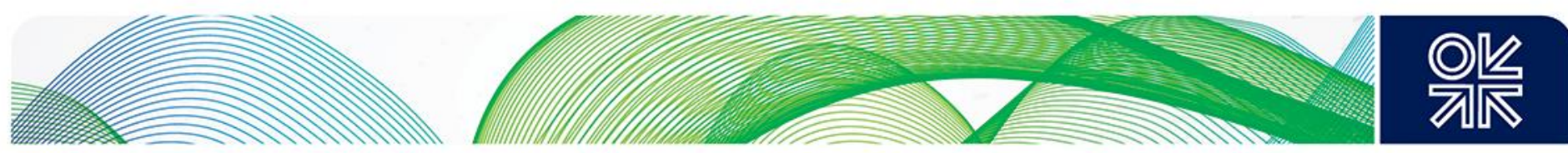

include detailed procedures for new pipeline capacity. In the interim, significant changes had been made to the IGA, aimed at making it compatible with the TEP.

The South Stream pipeline, which was planned to bring Russian gas to Europe across the Black Sea, coming ashore in Bulgaria and proceeding to Austria and / or Italy, ${ }^{411}$ was planned to be developed on the basis of several IGAs between Russia and several EU and non-EU host countries. Such IGAs were signed by the Russian government with the governments of Austria, Bulgaria, Hungary, Slovenia, Croatia, Greece, and Serbia during 2008-10. Thus, while some of these IGAs were signed before, and some after, the TEP's adoption, all of them were signed before the TEP became part of the acquis. Despite the significant preparatory work accomplished on the South Stream project (including inter alia production of pipe and signature of pipe-laying contract), it was cancelled in December 2014 by Gazprom, due to unresolved regulatory issues with Bulgaria and the EC, in particular due to the latter's position that the South Stream IGAs were incompatible with the TEP. ${ }^{412}$

The Turkish Stream pipeline - initiated as a replacement for South Stream - the first string of which is planned to bring Russian gas to Turkey and the second to Europe via Turkey, by transporting it across the Black Sea, ${ }^{413}$ has proceeded under The Russian-Turkish IGA. ${ }^{414}$ As this IGA was concluded between the governments of two countries in which the EU acquis does not apply, the question of its compatibility with the TEP is irrelevant.

This paper overviews the main provisions of the Yamal-Europe and South Stream IGAs in order to explain the regulatory treatment provided by them for new pipeline capacity in the EU and assess its compatibility with the treatment provided by the TEP. This paper does not analyse the Turkish Stream IGA, as although the second string of Turkish Stream is planned to bring gas to Europe, it terminates at the EU border, thus having no impact on the regulatory treatment of new pipeline capacity in the EU. Although neither the Yamal-Europe nor the South Stream projects constitutes a 'perfect' case study - as the Yamal-Europe IGA was signed before the TEP was adopted and became part of the acquis, whereas the South Stream IGAs have been rendered irrelevant due to the project's cancellation - both provide useful insights into the future relevance of the IGA framework for new pipeline capacity in the EU.

\subsubsection{The Polish-Russian IGA and the Yamal-Europe pipeline}

The Yamal-Europe pipeline was the first export pipeline initiated by Gazprom in the early 1990s for exports of Russian gas to north-western and central-eastern Europe. It aimed to reduce Gazprom's transit dependence on Ukraine - the relationship with which was becoming increasingly problematic due to disagreements over gas prices and non-payments. ${ }^{415}$ The Yamal-Europe pipeline, which became operational in 2006, transits Russian gas across:

- Belarus - where it runs in parallel with the existing Gazprom Transgaz Belarus (formerly known as Beltransgaz) pipeline system ${ }^{416}$; to

- Poland (at the entry point Kondratki at the Poland-Belarus border); and then to

- Germany (at the interconnection point Mallnow at the Poland-Germany border).

\footnotetext{
${ }^{411}$ Two routes - the northern to Austria and the southern to Italy - have been originally envisaged.

412 Stern, Pirani, and Yafimava (2015).

${ }^{413}$ With both strings coming ashore in Turkey. The first string will connect to the Turkish transmission network and the second will proceed to an (unspecified) Turkish-EU border (thus suggesting it could arrive at either the Turkish-Greek or the Turkish-

Bulgarian border).

414 The Russian-Turkish IGA. For analysis, see Yafimava (2016).

${ }^{415}$ Yafimava (2011).

${ }^{416}$ Gazprom Transgaz Belarus was initially owned by the Belarusian state but by 2011 was acquired by Gazprom, see Gazprom, Gazprom Transgaz Belarus (company websites). For details on the Russia-Belarus gas relationship, see Yafimava (2010) and Stern and Yafimava (2007).
} 

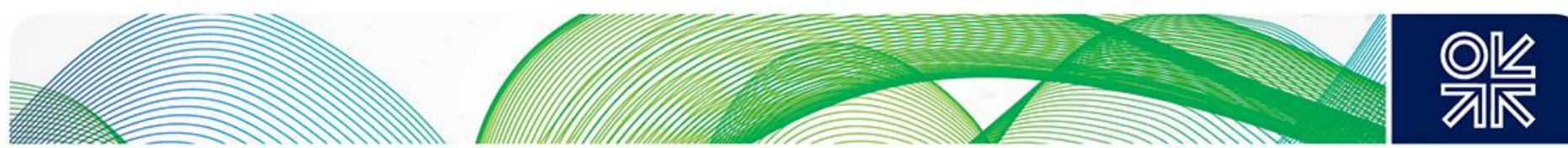

The pipeline's capacity is 33 bcma (Figure 15) ${ }^{417}$ In Germany, the Yamal-Europe pipeline connects to the GASCADE Gastransport system which, together with OPAL Gastransport and NEL Gastransport, is part of the WIGA Group, indirectly owned and jointly controlled by Wintershall and Gazprom.

Figure 15: The Yamal-Europe Pipeline

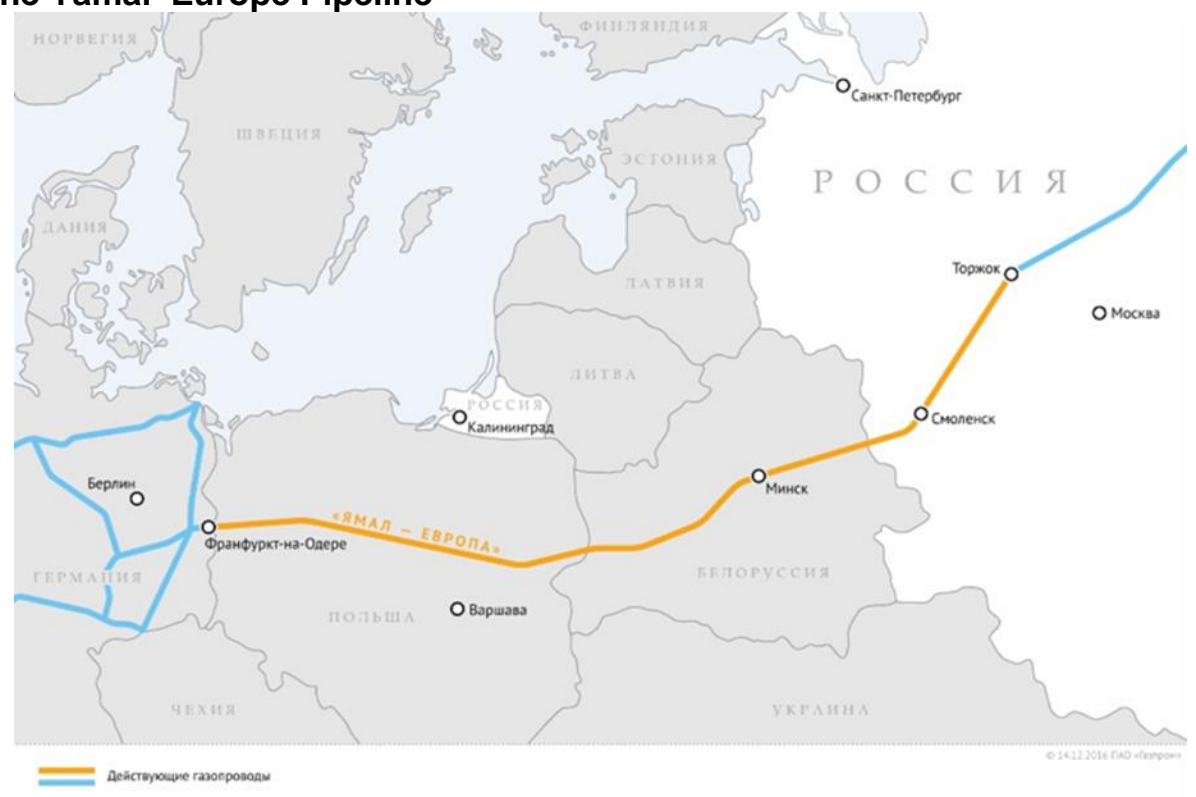

Source: Gazprom.

The EU (Polish) section of the Yamal-Europe project was developed on the basis of 'The RussianPolish IGA', ${ }^{418}$ signed on 25 August 1993, which was subsequently amended by:

- - the additional protocol, signed on 12 February 2003 ('The 2003 Additional Protocol'419) as amended by,

- the protocol, signed on 29 October 2010 ('The 2010 Protocol amending the 2003 Additional Protocol'420),

- the protocol, signed on 29 October 2010 ('The 2010 Protocol amending the Russian-Polish IGA'421).

The 1993 IGA outlined ownership and operatorship provisions as follows: the Polish section of the pipeline was to be built and operated by a new joint venture (JV) - EuRoPol Gaz - which was to be jointly owned by the Polish state-owned company (PGNiG) and Gazprom, holding 50 per cent each (Art. 1 and Art. 2). In 2010, the IGA was amended to include a provision under which it would be operated by the Polish TSO, Gaz-System, which was designated by the Polish regulatory authority as its only national gas TSO on 13 October 2010. In $2014 \mathrm{Gaz}$-System was certified under the ownership unbundling (OU) model in respect of the national gas transmission network and in 2015, under the independent system operator (ISO) model in respect of the Polish section of the Yamal-Europe pipeline. Gaz-System was to operate the latter on the basis of a new contract with EuRoPol Gaz, signed on 25 October 2010. This amendment

\footnotetext{
417 Yafimava (2009).

418 The Russian-Polish IGA (see Additional documents).

419 The 2003 Additional Protocol (see Additional Documents).

420 The 2010 Protocol amending the 2003 Additional Protocol (see Additional Documents)

421 The 2010 Protocol amending the Russian-Polish IGA (see Additional Documents).
} 

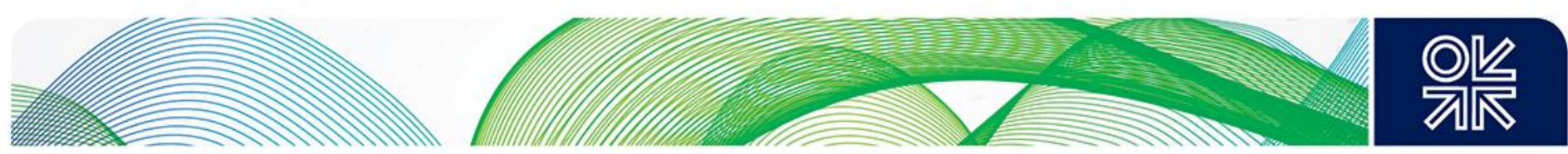

brought the IGA in line with the TEP as far as the TSO unbundling and certification requirements were concerned.

This amendment has also brought the ownership of EuRoPol Gaz in line with the IGA. Although the 1993 IGA stipulated that EuRoPol Gaz was to be owned by PGNiG and Gazprom in equal shares of 50 per cent each, it transpired that it was owned 48 per cent by PGNiG, 48 per cent by Gazprom, and 4 per cent by a third company, Gaz Trading. In turn, Gaz Trading was owned 43 per cent by PGNiG, 16 per cent by Gazexport, 2.73 per cent by Wintershall, 2.27 per cent by Weglokoks, and 36 per cent by Bartimpex (a trading company with close historical links to Gazprom). It is not clear why the lack of compliance with its ownership provisions had persisted for many years after the IGA was signed. Notably, such an ownership structure has led some Polish politicians to claim that EuRoPol Gaz was 'majority Russian-owned - or at least Russian-influenced' and thus not under the Polish government's control. While it is impossible to ascertain whether this was the case, it certainly became a contentious issue in the Polish-Russian gas relationship. The amendment has rectified this irregularity by stipulating the following:

- by 1 December 2010, PGNiG and Gazprom were to start the process of implementing their mutually agreed plan, aimed at ensuring that EuRoPol Gaz was 50 per cent owned by PGNiG and 50 per cent by Gazprom, and to complete it as soon as possible once all the necessary procedures were accomplished, and

- by 1 March 2011, to enshrine the principle of parity management in the EuRoPol Gaz statute, ensuring in particular that all relations with third parties are undertaken jointly by PGNiG and Gazprom. ${ }^{422}$

Although the 1993 IGA did not contain any provisions on transportation tariffs, such provisions have since been incorporated by means of The $\mathbf{2 0 0 3}$ Additional Protocol, which stipulated that a tariff charged by EuRoPol $\mathrm{Gaz}^{423}$ (the operator of the Polish section of the Yamal-Europe pipeline before operatorship was transferred to Gaz-System) both for transit of Russian gas across Poland and for transportation to Polish consumers, must provide for continuous operation of the system, ensuring that no losses were incurred (Art. 4). The tariff had to ensure that EuRoPol Gaz would be able to cover its operational costs, carry out an investment programme agreed with its main shareholders, honour its loan commitments and taxes, and accumulate free cash in line with (but not in excess of) its business plan (Art. 4). A progressively decreasing tariff for the 2002-19 period was also set. ${ }^{424}$ The 2003 Additional Protocol was amended in October 2010, abolishing as of January 2010 the specific tariff rates and specifying no new rates. ${ }^{425}$ The amendment largely preserved the tariff principles established in 2003, while also adding a new provision, ensuring EuRoPol Gaz's annual net profit of $\sim 7$ million US dollars (21 million Polish zloty (Art. 4). EuRoPol Gaz was obliged to calculate its tariffs in accordance with these principles and submit them to the head of the national energy regulatory authority (or other competent regulatory authority) for approval and was not allowed to set the tariff at a higher level than that approved by the regulator.

The amendments made by means of The 2003 Additional Protocol and The 2010 Protocol amending the 2003 Additional Protocol brought the IGA in line with the Third Gas Directive requirement for tariffs - or at least with their methodologies - to be approved by the national regulatory authority and to be published in advance. They also brought it in line with Gas Regulation 715 requirements on tariff costreflectivity and on a reasonable rate of return. Prior to being amended in 2010, the IGA had set specific tariffs for the 2009-19 period based on a point-to-point tariff regime. This was not in line with Gas Regulation 715, which effectively prescribed an entry-exit tariff regime. As the amended IGA has not stipulated any specific tariff regime and set no tariffs, EuRoPol Gaz would then be able to set - and the

\footnotetext{
422 The 2010 Protocol amending the Russian-Polish IGA (see Additional documents), Art. 2.1.

${ }^{423}$ A pipeline operator prior to operatorship being transferred to Gaz-System in 2010, see above.

${ }^{424}$ An annex to The 2003 Additional Protocol (see Additional Documents).

425 The 2010 Protocol amending the 2003 Additional Protocol (see Additional Documents).
} 

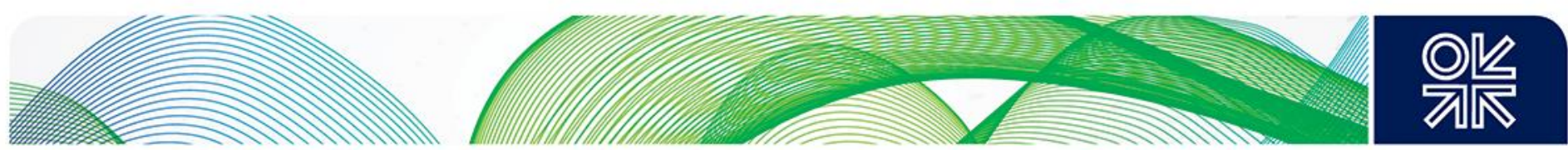

Polish regulatory authority to approve - any tariff consistent with Gas Regulation 715 requirements (including an entry-exit tariff). This suggests that the amended IGA is not incompatible with the TEP in respect of tariffs.

Neither the 1993 IGA (The Russian-Polish IGA) nor its subsequent amendment 2003 (The 2003 Additional Protocol) outlined specific provisions in respect of TPA to the Polish section of the YamalEurope pipeline, apart from saying that full utilization of its capacity was assumed and the transportation tariff was set accordingly. ${ }^{426}$ However, as Gaz-System replaced EuRoPol Gaz as an operator of the Polish section of the Yamal-Europe pipeline - in line with the amendment made to the IGA in 2010 - it would be obliged (being a certified ISO) to provide non-discriminatory TPA, despite the IGA not having a TPA provision. It could thus be argued that in so doing, the 2010 amendment also served to bring the IGA in line with the TEP requirements in respect of TPA.

Overall, this analysis suggests that the Yamal-Europe IGA - as amended in 2003 and 2010 - was made compatible with the TEP ('Third Gas Directive' and 'Gas Regulation 715'), particularly in respect of TSO unbundling and certification, transportation tariffs, and TPA. Notably, since the Yamal-Europe IGA was signed in 1993 (well before the start of EU gas market liberalization, which began with the adoption of the 'First Gas Directive' in 1998), the EU has made significant progress in liberalizing its gas market - the most recent wave of liberalization taking place in 2009, when the TEP was adopted. It is worth noting that in $\mathbf{2 0 1 0}$ the Russian government, although continuously maintaining the IGA's prevalence over the EU acquis (including the TEP), adopted a cooperative stance towards the Polish government and agreed to renegotiate the Yamal-Europe IGA to bring it in line with the (by then adopted but not yet applicable) TEP. The EC had also participated in renegotiating the IGA. As explained above, several substantial amendments had resulted in making the IGA compatible with the TEP. This assessment was shared by the (then) EU Energy Commissioner, Gunter Oettinger, who stated that the EC had 'managed to ensure that the intergovernmental agreement between Russia and Poland was brought in line with EU law'.

\subsubsection{The South Stream IGAs and the South Stream pipeline}

The South Stream pipeline was another new export pipeline, initiated in the mid-2000s with an aim of reducing Ukraine's monopoly on transit of Russian gas to southern Europe; Gazprom attempted but failed to carry out this project due to unresolved regulatory issues.

In 2006, Gazprom and Italy's ENI announced a joint venture (JV) to build the South Stream pipeline system across the Black Sea. Its original projected capacity was 31 bcma (two strings), but it was subsequently decided to increase this to $63 \mathrm{bcma}$ (four strings) (Figure 9). ${ }^{427}$ In 2010 the project was joined by France's EdF and Germany's Wintershall. The pipeline system was to be laid from Anapa on the Russian Black Sea coast to Varna on the Bulgarian Black Sea coast. The plan was to flow gas through the first pipeline in the fourth quarter of 2015 , with full capacity of the first two lines to be reached by the end of 2017, and four lines by 2020 . Once onshore in Bulgaria, the pipeline was originally envisaged to take the following routes:

- northern (Bulgaria-Serbia-Hungary, with two possible branches past Hungary - one to Austria and another to Italy and Slovenia),

- southern (Bulgaria-Greece-Italy).

During 2008-10, Russia had signed several IGAs for onshore European sections of South Stream with the following host countries: ${ }^{428}$

\footnotetext{
${ }^{426}$ Noting that $4 \%$ of its capacity was booked by Gaz-Trading, at the time, a minority owner of EuRoPol Gaz.

${ }^{427}$ Yafimava (2011).

${ }^{428}$ All these IGAs are available on the Russian Ministry of Foreign Affairs website.
} 

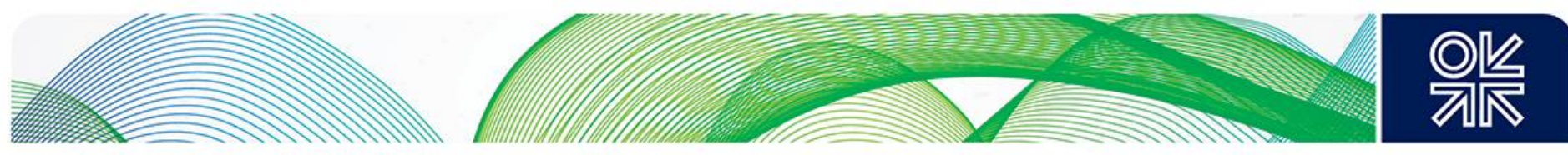

- EU member states:

- Bulgaria - signed on 18 January 2008 and entered into force on 12 August $2008,{ }^{429}$

- Hungary - signed and entered into force on 28 February 2008,430

- Slovenia - signed on 14 November 2009 and entered into force on 1 August 2010,431

- $\quad$ Croatia - signed on 2 March 2010 and entered into force 1 October 2010,432

- $\quad$ Austria - signed 24 April 2010 and entered into force 1 March 2011,433

- Greece - signed on 29 April 2008 and entered into force 16 October 2008;434

- non-EU countries

$\circ \quad$ Serbia - signed on 25 January 2008 and entered into force on 30 September $2008 .{ }^{435}$

Notably, the IGAs with Bulgaria, Hungary, Greece, and Serbia had been signed and entered into force nearly a year before the Third Gas Directive and Regulation 715 were adopted. The IGAs with Slovenia, Croatia, and Austria had been signed and entered into force after the Third Gas Directive and Regulation 715 were adopted but before they became fully applicable on 3 March 2011.

Despite the fact that all South Stream IGAs were signed before the TEP became part of the acquis in 2014 - in other words three years after the latest IGA (with Austria) was signed - the EC decided to conduct an assessment of their compatibility with the TEP. It concluded that the IGAs were not compatible with the Third Gas Directive and Gas Regulation 715 - in particular, with TSO unbundling, tariff and TPA provisions - and raised objections to South Stream. The EC subsequently called on member states to renegotiate or renounce their IGAs, otherwise threatening to open infringement procedures. Unilateral renunciation of an IGA by a member state would necessitate a payment of compensation to a counterparty - in other words the Russian government - whereas renegotiation would require the counterparty's consent. On its part, the Russian government refused to re-negotiate and maintained that - irrespective of their compatibility - the IGAs must prevail over the TEP. It also stressed that the IGAs were concluded prior to the TEP becoming part of the EU acquis. EU member states thus faced a stark choice of either renouncing their IGAs (thus making themselves liable to penalties imposed by the Russian government) or retaining their IGAs intact (thus making themselves liable to penalties imposed by the EC).

At the time the IGAs were signed and ratified, the EC had no legal right to conduct an assessment of their compatibility with the acquis - either ex ante (before signature and ratification) or ex post (after signature and ratification). It was not until 2012 that the EC acquired the right to conduct an ex post assessment (when 'Decision 994/2012' was adopted ${ }^{436}$ ) and not until 2017 when it acquired the right to conduct an ex ante assessment (when 'Decision 2017/684' was adopted ${ }^{437}$ ). Having acquired the right of ex post assessment in 2012, the EC appears to have waited for two years before announcing the results of its assessment (in 2014), declaring the incompatibility of the IGAs with the TEP. ${ }^{438}$ In December 2014, the DG Energy's Director for Internal Energy Market (IEM), Klaus-Dieter Borchardt, stated during a presentation at the European Parliament (in the presence of the Russian deputy energy minister, Anatoly Yanovsky, and Gazprom's deputy CEO, Alexander Medvedev) that 'none' of the South Stream IGAs were 'in compliance with EU law', 439 in particular, with provisions on TSO unbundling, TPA, and tariffs.

\footnotetext{
${ }^{429}$ The Russian-Bulgarian IGA see Additional documents.

430 The Russian-Hungarian IGA see Additional documents.

431 The Russian-Slovenian IGA see Additional documents.

432 The Russian-Croatian IGA see Additional documents.

433 The Russian-Austrian IGA see Additional documents.

434 The Russian-Greek IGA see Additional documents.

435 The Russian-Serbian IGA see Additional documents.

${ }^{436}$ Decision 994/2012 (see Additional documents).

437 Decision 2017/684 (see Additional documents).

438 'South Stream bilateral deals breach EU law, Commission says', EurActive, 4 December 2013.

439 Ibid.
} 

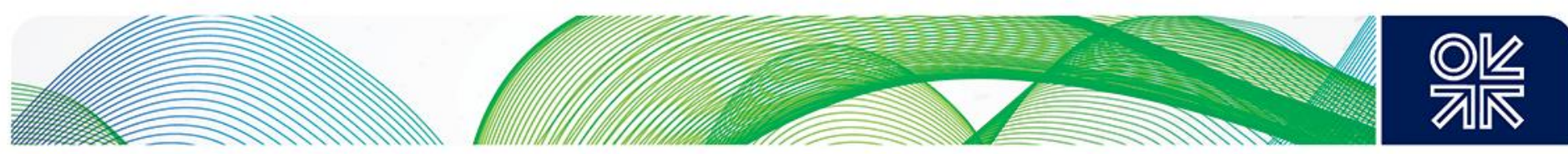

Interestingly, while declaring the IGAs incompatible with the TEP, the EC encouraged Gazprom to apply for an exemption from the TEP, which could have enabled South Stream to proceed under the Exemption Regime (see Section 2.2). ${ }^{440}$ However, this ran contrary to the logic of why Gazprom had decided not to apply for an exemption in respect of South Stream when first embarking on the project. Gazprom's decision to develop South Stream solely on a set of IGAs rather than by applying for an exemption to the regulatory authorities of individual EU member states (such an exemption would ultimately have to be approved by the EC) is understood to have been largely due to its negative experience when obtaining an exemption for the OPAL pipeline (the onshore extension of Nord Stream). The EC OPAL Exemption Decision - which appeared to have been political - left Gazprom unable to use more than 50 per cent of OPAL's capacity for more than five years (Section 3.2). It is argued here that the EC, by making sure that it had the final say in deciding on the TSO unbundling, TPA and tariff provisions of the exemption (at a time when the TEP itself did not contain any specific procedures in respect of new capacity) could have made a similar decision in respect of South Stream to that made on OPAL (based on considerations other than purely regulatory). By not applying for an exemption and proceeding on the basis of IGAs instead, Gazprom might have hoped that South Stream would be given a regulatory treatment similar to what it could have normally expected under an exemption regime, issued on the basis of purely regulatory considerations and without unduly undermining its commercial viability.

Eventually, in 2014 the EC initiated an infringement procedure against Bulgaria (the EU member state where the South Stream pipeline would first come ashore) on the grounds of incompatibility of its IGA with the TEP, as well as alleged irregularities in procurement procedures. Subsequently, in June 2014 Bulgaria halted construction of South Stream on its territory. Bulgaria had also failed to provide the necessary regulatory approvals, thus breaking its commitments under the IGA. Although no Bulgarian regulatory approval was needed for construction of the offshore section of South Stream, that project was judged as too risky to proceed in the absence of regulatory approval in respect of its onshore section. In December 2014, the Russian president, Vladimir Putin, and the Gazprom CEO, Alexei Miller, announced that the South Stream project was cancelled.

\section{The South Stream IGAs: compatibility with the TEP}

Although the South Stream project was stopped, this paper overviews its IGAs, in particular in respect of TSO unbundling, TPA, and tariffs provisions, with the view of assessing their compatibility with the TEP and concluding whether these IGAs - in their current or revised form - could be used for developing new pipeline capacity in Europe.

The South Stream IGAs concluded between the Russian government and the governments of several EU (Bulgaria, Hungary, Greece, Slovenia, Croatia, Austria) and non-EU (Serbia) host countries have many similarities as well as differences. As far as TSO unbundling and certification requirements are concerned, all IGAs stipulated that the respective onshore sections of South Stream were to be owned and operated jointly by newly established joint ventures (JV) between Gazprom (or an entity designated by Gazprom) and a host country's counterparty. Gazprom's counterparties in host countries were defined as follows:

- Bulgargaz Holding in Bulgaria, ${ }^{441}$

- the Hungarian Development Bank (HDB) in Hungary, ${ }^{442}$

- DESFA in Greece, ${ }^{443}$

\footnotetext{
440 'EC: Russia should apply for South Stream exemption', Natural Gas Europe, 7 December 2013.

${ }^{441}$ Bulgargaz Holding is a Bulgarian state-owned vertically integrated gas company.

442 Hungarian Development Bank is a state-owned Hungarian bank.

${ }^{443}$ DESFA is a Greek TSO and a 100\% owned subsidiary of the Greek gas company DEPA, in which the Greek state owns $65 \%$ and Hellenic Petroleum (a private fund) owns 35\% of shares. DESFA has been undergoing privatization since 2016 as part of the EU/IMF bailout programme, with a view of selling $66 \%$ of its shares (including all of Hellenic Petroleum shares). A consortium of Italy's SNAM, Spain's ENAGAS, Belgium's Fluxys has won the tender in April 2018.
} 

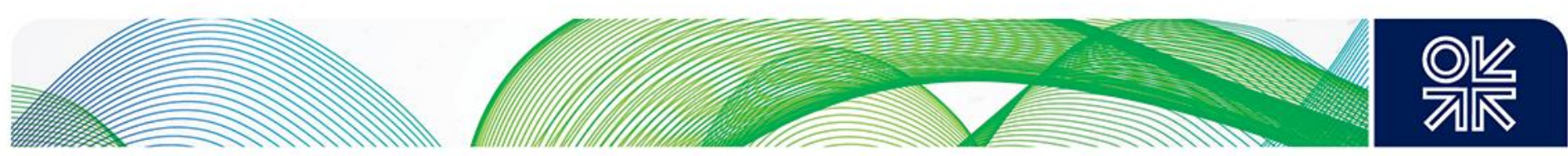

- Plinovodi in Slovenia, ${ }^{444}$

- Plinacro in Croatia, ${ }^{445}$

- $\mathrm{OMV}$ in Austria, ${ }^{446}$

- Srbijagaz in Serbia. 447

Under the majority of IGAs - in other words with Bulgaria, Hungary, Greece, Slovenia, and Croatia (Art. 3 in all five IGAs) - Gazprom and its host country counterparty were to have 50 per cent of shares each. Under the IGA with Serbia, Gazprom was to have at least 51 per cent whereas its Serbian counterparty (Srbjiagaz) was to have at most 49 per cent (Art. 3). Under the IGA with Austria, no specific shares for Gazprom and its Austrian counterparty (OMV) were specified (Art. 1).

Although the Third Gas Directive does not mandate the ownership unbundling (OU) model where the transmission system belongs to a vertically integrated company, on 3 September 2009 (the date of the Third Gas Directive's entry into force), it required that the transmission system be operated by a TSO which is either a certified independent transmission operator (ITO) or an independent system operator (ISO). ${ }^{448}$ Therefore, to be compatible with the TEP in respect of ownership unbundling provisions, the JVs between Gazprom and the counterparties of host countries (Bulgargaz Holding-Gazprom, HDBGazprom, DESFA-Gazprom, Srbjiagaz-Gazprom, 449 Plinovodi-Gazprom, Plinacro-Gazprom, OMVGazprom) would have had to be certified as new TSOs by the respective host countries' regulatory authorities. Otherwise, the IGAs would have to be amended to stipulate that the respective sections of South Stream would either be operated by the existing certified TSOs (Bulgartransgaz, Hungarian TSO, DESFA, Plinovodi, Plinacro, Gas Connect Austria) or by the yet-to-be established new TSOs (which would also have to be certified). Notably, under the TEP, TSOs are required to be certified under Art. 10 unless they are 'controlled' by third parties, in which case they are required to be certified under Art. 11 . It is argued here that given that the aforementioned JVs were jointly controlled by Gazprom and a host country's counterparty - as opposed to being under the sole control of Gazprom - certification under Art. 10, rather than Art. 11, could be sufficient.

As far as tariffs (or tariff methodologies) are concerned, all IGAs stipulated that the transportation tariff in respect of each onshore section of South Stream would be set by the aforementioned JVs between Gazprom and each host country's counterparty - although the exact wording differs. The Bulgarian IGA states that its JV would have an 'exclusive competence' over the tariff (Art. 8), whereas the tariff must ensure that no losses are incurred, a 'reasonable rate of return' is generated, and a payback period of 15 years is ensured. Likewise, the Hungarian (Art. 7), the Serbian (Art. 8), and the Croatian (Art. 6) IGAs state that their JVs would have an 'exclusive competence' in respect of setting the tariff. The Greek IGA states that its JV's competence over setting the tariff 'cannot be limited' (Art. 6). Unlike the Bulgarian IGA, none of the Hungarian, Greek, Serbian, or Croatian IGAs specify any requirements that the tariff should meet. Interestingly, both the Austrian and Slovenian IGAs, while acknowledging the JVs' competence over setting the tariff, made references to their national laws governing the tariff-setting process. The Austrian IGA stated that 'setting the tariff ... is within competence' of the JV but 'in accordance with procedures and principles of tariff setting in Austria'. The Slovenian IGA similarly stated that the tariff will

\footnotetext{
444 Plinovodi is a Slovenian TSO which was certified as an ITO in 2012 and is 100\% owned by Plinhold. (Geoplin d.o.o. Ljubljana established a subsidiary company Geoplin plinovodi d.o.o. in 2004 and transferred into its ownership the entire energy infrastructure. The company Geoplin plinovodi d.o.o. began with carrying out the activities of a System Operator of the gas pipeline transmission network on 1 January 2005.)

445 Plinacro is a Croatian TSO.

${ }^{446} \mathrm{OMV}$ is an Austrian oil and gas producing and marketing company, which holds $51 \%$ of Gas Connect (one of the Austrian TSOs).

${ }^{447}$ Srbijagaz is a Serbian state-owned vertically integrated gas company

448 Or else meets requirements more stringent than those.

${ }^{449}$ As Serbia is a contracting party to the Energy Community Treaty, the Third Gas Directive and Gas Regulation 715 (see Additional documents) apply.
} 

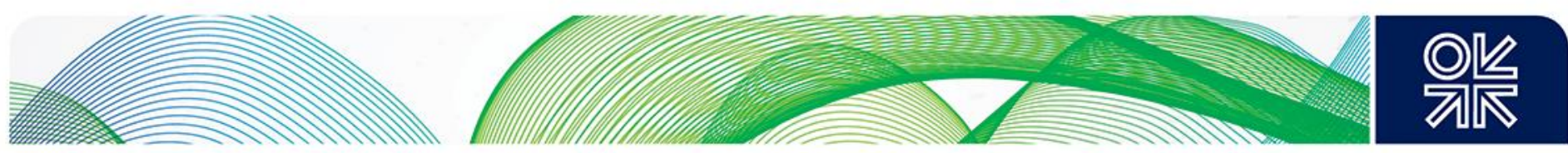

be determined by the $\mathrm{JV}$ ' in accordance with the Slovenian law'. Other IGAs had no references to national laws as far as tariff setting is concerned.

It could be argued that there was no direct contradiction between any of the IGAs and the TEP in respect of tariff provisions. Under the TEP it is for the national regulatory authority to decide whether to fix or approve the methodologies or the tariffs themselves. Although the majority of IGAs stated that setting the tariff was an 'exclusive competence' of the respective JV, none of them precluded the possibility of a national regulatory authority being able to fix or approve their underlying methodology. This is even more the case in respect of the Austrian and the Slovenian IGAs, both of which stipulated that the tariff setting was to be done in accordance with national laws (which incorporate the energy acquis, including the TEP). Furthermore, under the TEP, the tariff must meet certain requirements such as cost reflectivity and a reasonable rate of return. Although the majority of IGAs did not contain any requirements in respect of tariffs (except the Bulgarian IGA), none of them contained any tariff requirements contrary to the TEP's requirements.

The IGAs are most diverse in respect of their TPA provisions, particularly in respect of which entities hold capacity rights in respective sections of South Stream and whether some (or all) of the capacity rights could be assigned (and if so how) to a third party. For example, the Bulgarian (Art. 9) and the Greek (Art. 6) IGAs stipulated that it is the JVs between Gazprom and its Bulgarian and Greek counterparties that would hold capacity rights. The Bulgarian IGA states that Gazprom guarantees full capacity utilization by means of a long-term transportation contract, which was to be concluded between the JV and Gazprom (or a company designated by Gazprom), and which would include inter alia a 'ship-or-pay' clause. Similarly, the Greek IGA states that Gazprom provides for full utilization of the pipeline by means of concluding a long-term contract between the Gazprom-DESFA JV and Gazprom (or a company designated by Gazprom). The Bulgarian IGA also states that capacity rights 'can be assigned' fully or partly to a third party. Similarly, the Greek IGA states that 'the rights to use capacity in the pipeline fully or in part can be provided to a third party'. However, neither of these IGAs stipulates a mechanism through which capacity could be allocated to a third party. The Austrian and the Slovenian IGAs are similar to the Bulgarian and the Greek IGAs, in that both state that the JV had the right to allocate 'capacity' (the Slovenian IGA) or 'all capacity' (the Austrian IGA). However, neither of them states whether such a right is exclusive, whereas the Bulgarian and the Greek IGAs seem to imply exclusivity. Also, unlike the Bulgarian and the Greek IGAs, neither the Austrian nor the Slovenian IGAs contain any provisions on whether capacity could be assigned to third parties. Interestingly, however, the Austrian IGA envisages the conclusion of a long-term transportation contract between Gazprom and the JV between Gazprom and its Austrian counterparty (OMV). The Hungarian (Art. 7) and the Serbian (Art. 8) IGAs are quite different from the four aforementioned IGAs, in that they both stipulate that it is not the JV between Gazprom and the host country's counterparty, but Gazprom itself that holds all capacity rights in the respective sections of South Stream. Unlike the Bulgarian and the Greek IGAs, the Hungarian and the Serbian IGAs are silent on the possibility of assigning capacity rights to third parties and do not contain any provision in respect of Gazprom guaranteeing full capacity utilization by means of long-term ship-orpay transportation contracts.

Notably, all three South Stream IGAs (with Austria, Slovenia and Croatia) which were signed and entered into force after the Third Gas Directive and Gas Regulation 715 were adopted (but before they became part of the acquis) declare the host countries' support for an exemption from the TEP's provisions, should an exemption request be made. In particular, the Slovenian IGA states that Slovenia undertakes to provide 'all necessary support in receiving an exemption' in respect of TPA, tariff regulation, and TSO unbundling to ensure the project's development (Art. 7). Notably, it states further that should an exemption request be received, if and when the Slovenian law so requires, the JV between Gazprom and the Slovenian counterparty (Plinovodi) would carry out the TSO functions. The Croatian IGA states that, at the request of the JV between Gazprom and its Croatian counterparty (Plinacro) or its parties, Croatia undertakes to provide 'all necessary support in receiving an exemption' in respect of TPA, tariff regulation, and TSO unbundling to ensure the project's development (Art. 5). Similarly, the Austrian IGA states that 

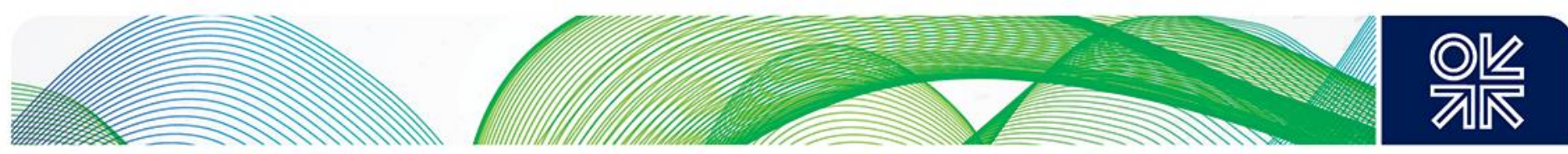

'in respect of TPA ... tariff regulation, unbundling of system operators and ownership rights over the pipeline, envisaged by the Austrian law, if necessary provided that' the JV between Gazprom and its Austrian counterparty (OMV) or its parties 'has made a corresponding request, an exemption will be granted ... in order to ensure economic profitability of the project by means of concluding a long term transportation contract between Gazprom and the company' (Art. 5). Furthermore, the IGA states that Austria would 'welcome' an exemption request and 'undertake' to provide 'corresponding support' while also, it would not 'initiate an adoption of specifically designated law which could have a negative impact on the project or its payback period' (Art. 8).

Overall, our analysis of the South Stream IGAs' compatibility with the TEP suggests that on many issues both frameworks - although not entirely consistent with each other - nonetheless share a significant degree of similarity and compatibility. On one hand, this suggests that it would have been possible for the EC not to start infringement procedures against Bulgaria on the grounds of alleged incompatibility of its IGA with the TEP, thus allowing the South Stream project to proceed under the IGA framework, especially given that the TEP did not contain any specific regulatory procedures in respect of new capacity, whereas the CAM NC, which included such procedures, was only adopted in 2017. On the other hand, there certainly was scope for renegotiating the IGAs, to align them more closely with the TEP to the mutual satisfaction of all the IGAs' counterparties - Russia and the European host countries - and also that of the EC. Renegotiation of the IGAs would have provided the least confrontational, as well as the least costly, solution, potentially enabling South Stream to proceed. The example provided by the YamalEurope IGA, which was signed in 1993 but was amended in 2010 to make it compatible with the TEP, demonstrates that the same procedure in respect of re-negotiating the South Stream IGAs could have been followed. The Russian government might have agreed to renegotiations (as it did in respect to the Yamal-Europe IGA) had it had a reasonable expectation that following re-negotiation, either South Stream would be granted regulatory treatment amounting to an exemption (which would not unduly restrict Gazprom's ability to utilize capacity - as in the case of the first OPAL exemption) or a bespoke regulatory regime would be developed (for example similar to the 'more capacity' procedure, followed by EUGAL). However, as the EU-Russia political relationship worsened dramatically over the course of 2014 (due to the Ukraine security crisis and Russia's role in it), the EC's attitude towards South Stream turned distinctly negative, undermining any expectation on the part of the Russian government that the EC's assessment of South Stream IGAs (or exemptions) would be based on purely regulatory considerations, as allowing the project to procced would decrease transit across Ukraine and hence its leverage against Russia.

\section{Conclusions}

New pipelines have been built (the Yamal-Europe pipeline) or have been attempted to be built (the South Stream pipeline) in the EU under the IGA framework. As long at the EU energy acquis did not contain any legally binding detailed regulatory procedures for new pipeline capacity (which only became available when the CAM NC became part of the acquis in March 2017), the framework provided by IGAs allowed their parties a significant degree of freedom in respect of designing regulatory procedures for new capacity, including on ownership, operatorship, capacity allocation, congestion management, and tariffs. Such flexibility first began to decrease when the EC secured a right to check the IGAs' compatibility with the acquis, initially ex post in 2012 and subsequently ex ante in 2017. The right of ex post assessment allowed the EC to require a member state to re-negotiate or renounce its (signed and/or ratified) IGA deemed incompatible with the acquis. The right of ex ante assessment enabled the EC to prevent a member state concerned from signing such an IGA in the first place. The EC's ability to check an IGA's compatibility with the acquis would make it impossible for the parties to include any procedures in their IGAs which could be deemed by the EC as being incompatible with the acquis. Given that prior to March 2017, the energy acquis (as represented inter alia by the TEP) only contained general rules but no detailed regulatory procedures for new capacity, the EC had a significant degree of discretion in deciding whether any given IGA was compatible with the acquis. 

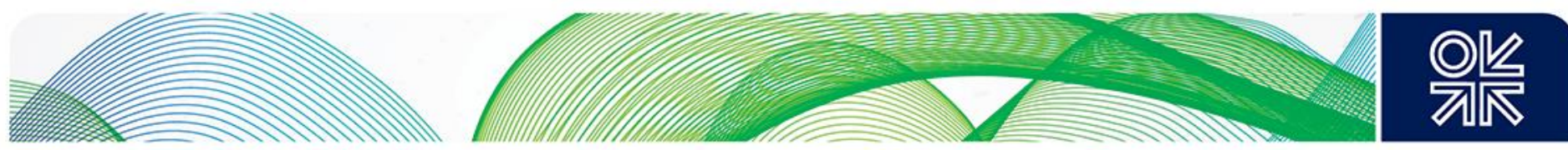

The importance of the IGA framework for the development of new capacity in the EU is set to decline further as the EU network codes - in particular, the CAM NC - became part of the acquis in March 2017. As the CAM NC stipulated detailed regulatory procedures for new capacity, the IGA parties' degree of freedom in respect of designing regulatory provisions for new capacity will decline, due to becoming constrained not only by the TEP's (general) provisions but also by the CAM NC's (detailed) regulatory procedures for new capacity. Although the CAM NC allows for significant discretion on the part of TSOs and NRAs in respect of capacity allocation mechanisms for new pipelines (for example designing the AAM for complex projects, see Section 2.1), it is argued here that the EC would be able to maintain a significant degree of discretion in deciding whether any given IGA is compatible with the acquis (including both the TEP and the NCs).

Thus, although it is possible that the IGA framework could continue to be used for construction of new capacity in the EU, the IGAs underpinning new pipelines would come under increased scrutiny from both the EC and the member states' regulatory authorities, such that it would become impossible for an IGA to contain provisions that either the EC or the national regulatory authorities deem to be incompatible with the acquis. Interestingly, most of the IGAs underpinning South Stream appear to have remained in force (and have not been renounced by either party) despite the project being cancelled. This suggests that should any pipeline project, involving Russian gas export to Europe across the Black Sea be revived, these IGAs could become instrumental. However, like the Yamal-Europe IGA, they would have to undergo significant adjustments, with a view of making them fully compatible with the acquis, including the TEP and the NCs.

Finally, if the EC's proposal to amend the Third Gas Directive succeeds and the EC receives a mandate from the Council to negotiate an international agreement between the EU and the Russian government in respect of Nord Stream 2 (Section 4.3), the importance of IGAs between EU member states and third parties in respect of pipelines would decline further, potentially to the point of becoming irrelevant. This is because, according to the European Council's legal service's assessment, should the EC acquire the right to negotiate an international agreement with a third country in respect of an import pipeline, EU member states might lose their right altogether to conclude IGAs with third countries in respect of import pipelines. ${ }^{450}$ Consequently, the importance of international agreements between the EC and the governments of third parties - as opposed to IGAs between the governments of member states and those of third countries - would become the dominant regulatory framework.

\section{Energy Union legal initiatives: potential impact on construction and utilization of incremental capacity}

In 2014, in response to the worsening relationship between the EU and Russia over the Ukraine's political and security crisis and Russia's role in it, the EU developed a new European Energy Security Strategy ${ }^{451}$ and the Energy Union Strategy policy concept ${ }^{452}$ - the main overarching goals of which were to reduce EU dependence on Russian gas imports and increase resilience in the event of potential interruptions. These moves followed the EU's earlier initiatives, such as the Security of Supply Regulation 2010453 (which had introduced supply and infrastructure standards) and the IGA Decision (2012), launched in the aftermath of the 2006 and 2009 gas transit crises between Russia and Ukraine, and pursuing similar aims.

\footnotetext{
${ }^{450}$ Council Legal Service's Opinion - Competences (see Additional documents).

${ }^{451}$ EC (2014a) (Energy Security Strategy) and EC (2014b).

${ }^{452}$ EC (2015a), Energy Union Strategy.

${ }^{453}$ See Additional documents (Security of Supply Regulation 994/2010).
} 

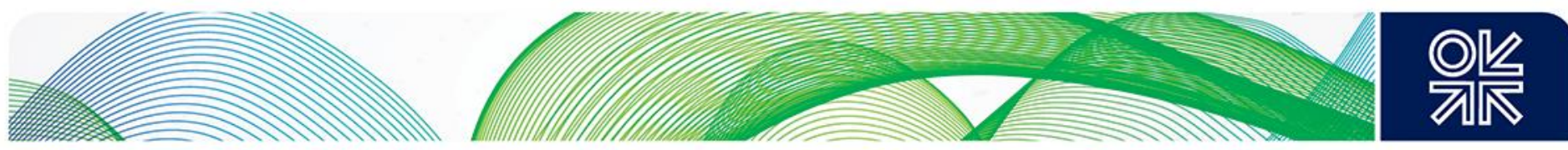

'A framework strategy for a resilient Energy Union with a forward-looking climate change policy'454 lists the following dimensions of the Energy Union:

- 'energy security, solidarity and trust',

- 'a fully integrated European energy market',

- 'energy efficiency contributing to moderation of demand'; 'decarbonizing the economy'; 'research, innovation, competitiveness'. 455

During 2015-17 the EC prepared three annual State of the Energy Union reports, assessing the progress made towards creating the Energy Union. Measurement of progress is not easy given that the Energy Union objectives do not appear to be defined explicitly and clearly in any of the documents. The Council's conclusions on the Energy Union governance system (see Section 4.1) only mention that it aims at affordable, secure and sustainable energy' ${ }^{\prime 256}$ whereas the Energy Security Strategy only says that the Energy Union dimensions are 'designed to bring greater energy security, sustainability and competitiveness' thus only indirectly implying that the latter constitutes its objectives. The Strategy also notes that 'diversification of energy sources, suppliers and routes' is 'crucial for ensuring secure [...] energy supplies'. It is possible - and likely - that the Energy Union objectives have been deliberately left vague to allow the EC more leeway in interpreting and assessing the progress made towards reaching them.

As part of its First Energy Union Report, ${ }^{457}$ the EC proposed an overall monitoring approach and methodology for measuring the progress made towards meeting the Energy Union objectives - as distilled above. This includes a set of specific indicators to be used to measure progress made in respect of each of the dimensions of the Energy Union. The set has been subsequently updated in the Second Energy Union Report. ${ }^{458}$ In particular, it is suggested that progress made in respect of the energy security, solidarity and trust' dimension is measured by net import dependence, supply concentration index (SCI), and $\mathrm{N}-1$ rule, ${ }^{459}$ whereas it is suggested that progress made in respect of the fully integrated European energy market' dimension is measured by market concentration index, wholesale gas prices, and switching rates (households). ${ }^{460}$

The EC has started translating the Energy Union concept into legislation, including inter alia by developing the new Draft Governance Regulation ${ }^{461}$ (Section 4.1), adopting the revised 'Security of Supply Regulation 2017'462 (Section 4.2), and proposing to amend the 'Third Gas Directive' (2017-18) (Section

\footnotetext{
${ }^{454}$ EC (2015a), p. 4

${ }^{455}$ EC (2015a), p. 4

${ }^{456}$ Council Governance Conclusions (see Additional documents)

${ }^{457}$ EC (2015b), First Energy Union Report.

458 See Additional documents.

${ }^{459}$ EC (2017b), Commission Staff Working Document, Second Energy Union Report, Monitoring progress towards the Energy Union objectives - key indicators.

${ }^{460}$ See Second Energy Union Report.

461 The final text of the Governance Regulation was agreed in late June 2018 (see Council (2018)), as this paper was nearing completion and entering the editing stage, and hence too late for this paper to be revised and based on the analysis of the final text. Therefore the paper is based on the analysis of the Draft Governance Regulation, as proposed by the EC on 30 November 2016 (see Additional documents). Since being proposed on 30 November 2016, the Draft Governance Regulation has undergone multiple changes; for example, it was corrected on 23 February 2017 thus resulting in COM(2016) 759 final/2, amendments made by the European Parliament, resulting in provisional text adopted on 17 January 2018 (doc 5351/18); amendments made by the Council during several trilogies (docs 15235/17 and 15891/17). For comparative overview of different drafts see Council Note (Additional documents). A preliminary - and very cursory - reading of the finalized text of the Governance Regulation suggests that the conclusions reached in this paper (as based on the analysis of the Draft Governance Regulation) would not appear to be materially different had the analysis been based on the finalised Gas Regulation. Notably, as this paper is going to print, the Regulation has not yet been published in the Official Journal of the EU, thus suggesting that further changes could have been made to it prior to publication.

${ }^{462}$ See Additional documents (Security of Supply Regulation 2017/1938).
} 

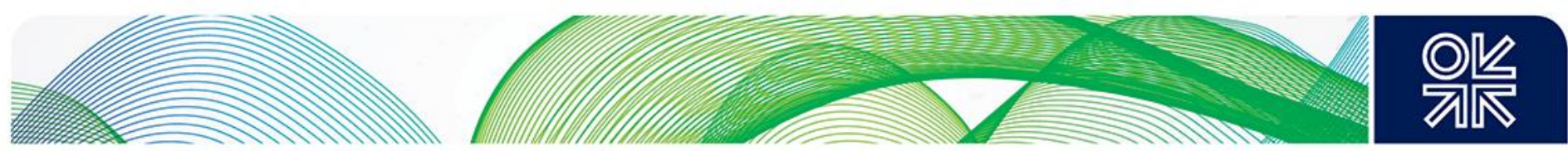

4.3). These legislative initiatives are analysed below, with a focus in particular on those provisions that could have an impact on the development and utilization of new pipeline capacity in the EU.

\subsection{Draft Governance Regulation}

Following the adoption on 26 November 2015 of the Council's conclusions on the governance system of the Energy Union - described as 'an essential tool for the efficient and effective construction of the Energy Union and the achievement of its objectives' 463 - the EC presented a proposal for the Governance Regulation in November 2016. ${ }^{464}$ In April 2018 the draft Regulation secured unanimous support in the first trilogue of the Council, held on 21 February 2018, with approval being granted to proceed to the second trilogue, which took place on 26 April, the third trilogue followed on 23 May. Finally, the Governance Regulation has been agreed during fourth (and last) trilogue on 19-20 June 2018. ${ }^{465}$

The Draft Governance Regulation is an important EU legislative initiative, designed specifically to 'operationalize' the Energy Union objectives by making them part of the acquis. The draft Regulation aims to do this through the establishment of 'a governance mechanism' ensuring that the Energy Union objectives are 'collectively' achieved and adhered to by the EU and its member states. ${ }^{466}$ It stipulates that the mechanism will be based on:

- integrated national energy and climate plans (ECPs) covering ten-year periods (prepared by member states every ten years),

- corresponding integrated national energy and climate progress reports (ECPRs) (prepared by member states bi-annually),

- integrated monitoring between the EC and member states, including 'with regard to regional cooperation and corresponding action' by the EC.

The draft Regulation states that the governance mechanism is to be used for meeting 'the objectives and targets of the Energy Union, and for the first ten-year period from 2021 to 2030 in particular the EU's 2030 targets for energy and climate' (Art. 1.1.a). The latter meaning:

- 'the Union-wide binding target of at least 40 per cent domestic reduction in economy-wide GHG emissions as compared to 1990 to be achieved by 2030 ,

- the Union-level binding target at least 27 per cent ${ }^{467}$ for the share of renewable energy consumed in the EU in 2030,

- the Union-level target of at least 27 per cent for improving energy efficiency in 2030 (to be reviewed by 2020 having in mind an EU level of 30 per cent),

- the 15 per cent electricity interconnection target for 2030 ,

or any subsequent targets in this regard agreed by the European Council or Council and Parliament for the year 2030'.468

Thus, although the draft Regulation does not define the objectives and targets of the Energy Union, it implies that the EU's 2030 climate and energy targets on GHG emissions, renewables, efficiency, and electricity interconnection are part of them. Although the EU's 2030 targets do not include any explicit targets on gas infrastructure (as opposed to electricity infrastructure), meeting these targets (some of which are legally binding) might have an impact on the construction and utilization of new gas pipeline infrastructure. In some member states, more gas infrastructure would be required to meet these targets,

\footnotetext{
${ }^{463}$ Council Governance Conclusions (see Additional documents).

${ }^{464}$ Draft Governance Regulation (see Additional Documents).

${ }^{465}$ As this paper is being completed, Governance Regulation has not yet been published in the Official Journal of the EU.

466 Draft Governance Regulation (see Additional Documents), p. 5.

${ }^{467}$ It is understood that this target has been changed to 32 per cent in the final agreed document, see Council (2018).

${ }^{468}$ Council Note (see Additional documents).
} 

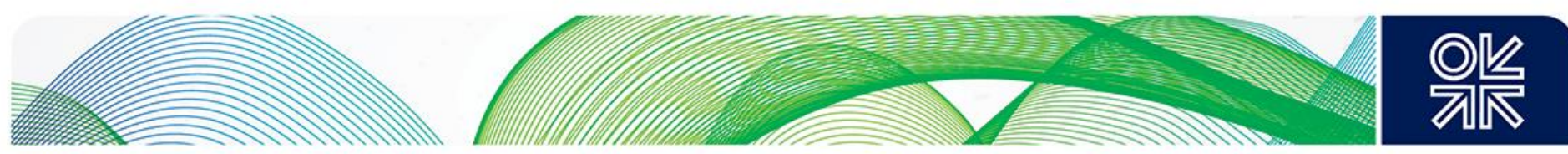

whereas in others the degree of utilization of the existing gas infrastructure might decrease. Notably the (draft) Regulation aims to establish 'a robust political process between Member States and the EC [...] in view of the achievement of the Energy Union objectives', including on infrastructure, on the basis of integrated national ECPs, thus suggesting that the ECPs will become the main instrument through which the EC could have an impact on the development and utilization of new pipeline capacity.

\subsubsection{Development of the ECPs: energy security and IEM dimensions}

The Draft Governance Regulation has obliged each member state to prepare an integrated national ECP by 1 January 2019 to cover the 2021-30 period. Each such ECP must contain a description of the national objectives, targets, and contributions in respect of each dimension of the Energy Union - namely, energy security; internal energy market; energy efficiency; de-carbonization; and research, innovation, and competitiveness - as well as a description of the policies and measures foreseen to meet them (Art. 3.2).

As far as the energy security dimension is concerned, an ECP must contain:

- national objectives with regard to:

$\circ \quad$ increasing the diversification of energy sources and supply from third countries, storage, and demand response;

- reducing energy import dependence from third countries;

- readiness to cope with constrained or interrupted supply of an energy source (including gas and electricity), in coherence with the new Security of Supply Regulation (Section 4.2), and where appropriate, a time frame for when the objectives shall be met;

- deployment of domestic energy sources (notably renewable energy);

- policies and measures to achieve these objectives, regional cooperation in this area, financing measures, including EU support and the use of EU funds, in this area at national level, if applicable.

As far as the internal energy market (IEM) dimension is concerned, an ECP must contain:

- key national objectives for:

- 'gas transmission infrastructure that are necessary for the achievement of objectives and targets' under any of the dimensions of the Energy Union and, if applicable, main infrastructure projects envisaged other than Projects of Common Interest (PCls);

- market integration, 'if applicable' and including a time frame for when the objectives shall be met.

- policies and measures to achieve the key infrastructure objectives, including, specific measures to enable the delivery of PCls and other key infrastructure projects, regional cooperation in this area, financing measures, including EU support and the use of EU funds, in this area at national level.

The ECP must also contain a description of the current situation in respect of the five dimensions ${ }^{469}$ of the Energy Union. It must also contain projections for the first ten-year period (at least until 2040 and including the year 2030) that are expected to result from the existing (implemented and adopted) policies and measures, and an assessment of the impact of planned policies and measures on meeting the national objectives for each dimension (Art. 3). Member states are obliged to include in their ECPs an assessment of interactions between existing and planned policies within one dimension of the Energy Union, and between existing and planned policies of different dimensions of the Energy Union, thus demonstrating whether the progress in respect of one dimension does not undermine the progress in respect of another (Art. 8.2). Member states are also obliged to 'take into account the interlinkages between the five dimensions of the Energy Union' while using 'consistent data and assumptions across the five dimensions'. Although each member state decides on its own national ECP and the objectives

${ }^{469}$ Energy security; internal energy market; energy efficiency; de-carbonization; and research, innovation, and competitiveness. 

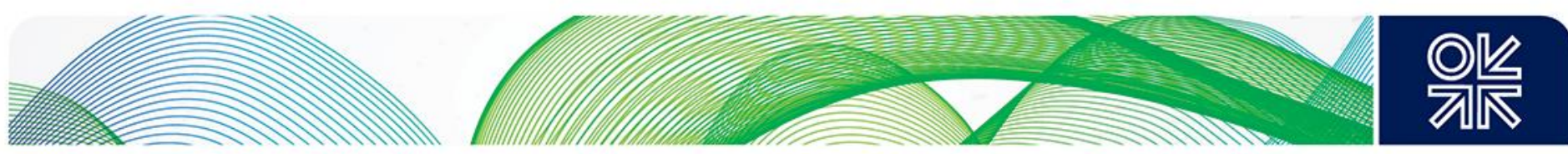

and measures to be stipulated therein, in accordance with the subsidiarity principle, the ECP must contain a description of the 'regional cooperation with other member states' which took place during its preparation. ${ }^{470}$

The Draft Governance Regulation obliges member states to have provided their draft ECPs to the EC by 1 January 2018, ${ }^{471}$ in other words one year before the deadline for their final ECPs (Art. 9). This suggests that the EC wants to have a significant insight into, and the ability to influence the content of, the draft ECPs well before they are finalized.

Notably, the EC is empowered to 'issue recommendations' on the draft ECPS to member states (Art. 9), setting out:

- the level of ambition of objectives, targets and contributions in view of collectively achieving the Energy Union objectives';

- 'policies and measures relating to member states' and Union level objectives and policies and other policies and measures of potential cross-border relevance';

- 'interactions between and consistency of' existing and planned policies and measures included in the integrated national ECPs 'within one dimension and among different dimensions of the Energy Union'.

Consequently, while preparing its recommendation on a member state's draft ECP under Art. 9, the EC could potentially conclude that:

- 'the level of ambition of objectives, targets and contributions' is insufficient in view of 'collectively achieving the Energy Union objectives'. For example, the EC might make an argument that the net import dependence is too high;

- 'policies and measures relating to member states' and Union level objectives and policies and other policies and measures of potential cross-border relevance' are inadequate. For example, the EC might make an argument that construction of new infrastructure might lead to decreased utilization of existing infrastructure, including cross-border;

- existing and planned policies and measures are inconsistent across different dimensions of the Energy Union. For example, as far as infrastructure is concerned, the EC might make an argument that while this would improve energy security (at the national level) it could undermine the IEM (at the EU level).

A member state is obliged to take 'utmost account of any recommendation' from the EC on its draft ECP although it has the right to adopt a final ECP which could diverge from the EC recommendations. However, the member state's freedom to adopt an ECP significantly diverging from the EC's recommendation would be significantly constrained both by the EC and other member states. This is because the Draft Governance Regulation places a strong emphasis on cross-border cooperation and common monitoring between member states and the EC, with member states being expected to 'contribute to the process and attainment of common objectives and targets in a comparable manner, to improve regulatory stability and investor certainty'. In particular, the Draft Regulation places an obligation on member states to 'cooperate with each other at regional level to effectively meet the targets, objectives and contributions' set in their national plans. A member state is obliged 'well before' submitting its draft plan to 'identify opportunities for regional cooperation and consult neighbouring member states and the other member states expressing an interest' (Art. 11), and to 'set out' in their draft plans 'the results of such regional consultation, including where applicable how comments have been taken into account'. A

\footnotetext{
470 Draft Governance Regulation (see Additional Documents), Explanatory Memorandum.

${ }^{471}$ This date will have to be changed once the Governance Regulation is finalized as it has passed already, thus showing that the development of the Governance Regulation has taken longer than the EC had originally envisaged.
} 

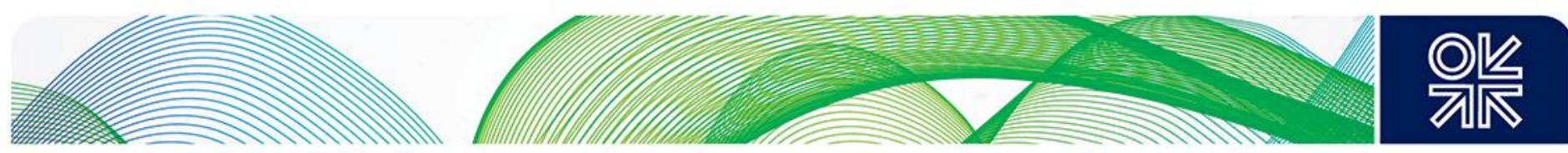

member state is also obliged to 'take into consideration the comments received from other member states' in their final plans and 'explain how such comments have been taken into account'. On its part, the EC is obliged to 'facilitate cooperation and consultation' among member states on the draft plans 'in view of their finalization'.

The Draft Governance Regulation obliges the EC to assess the final ECPs (Art. 12), in particular assessing whether:

- the targets, objectives, and contributions are sufficient for the collective achievement of the Energy Union objectives; 472

- the plans comply with the requirements set by the Regulation and with the EC recommendations.

However, it does not appear to contain any procedure to be followed in respect of a finalized ECP should the EC's assessment be negative.

While conducting its assessment of the final ECP under Art. 12, the EC could potentially conclude that:

- as far as the energy security dimension is concerned, the national targets and/or measures in respect of 'increasing the diversification of energy sources and supply from third countries' and 'reducing energy import dependence from third countries' are not 'sufficient for the collective achievement of the Energy Union objectives', and

- as far as the IEM dimension is concerned, the national objectives for gas transmission infrastructure are not 'sufficient for the collective achievement of the Energy Union objectives.

\subsubsection{Implementation of the ECPs}

Importantly, the Draft Governance Regulation has established a continuous and tight monitoring process of the implementation of the ECPs by placing an obligation on member states to provide regular and frequent updates to the EC. In addition to preparing the national ECPs by 1 January 2019 (and every ten years thereafter), member states are thus obliged to submit to the EC a draft update of the latest notified $E C P$, or to confirm that it remains valid, by 1 January 2023 (and every ten years thereafter). Also, by 1 January 2024 (and every ten years thereafter) member states are obliged to notify to the EC an update of the latest notified ECP (unless they have confirmed that it remains valid). Notably, member states are not allowed to relax their targets and only have a right to modify the targets, objectives, and contributions to reflect 'an increased ambition' (Art. 13). Furthermore, member states are obliged by 15 March 2021 (and every two years thereafter) to submit to the EC their progress reports on the implementation of ECPs, covering all five dimensions of the Energy Union (Art. 15) inter alia:473

- the energy security dimension:

$0 \quad$ national objectives as stated in the ten-year plans,

$\circ \quad$ implemented, adopted, and planned policies and measures to achieve these objectives,

- regional cooperation in implementing these objectives and policies,

- financing measures, including EU support and the use of EU funds, in this area at national level;

- the IEM dimension:

- key national objectives as stated in the ten-year plans,

- implemented, adopted, and planned policies and measures to achieve these objectives,

- regional cooperation in implementing these objectives and policies,

\footnotetext{
472 Note that the draft does not specify the Energy Union objectives other than the EU 2030 energy and climate goals. 473 In addition to bi-annual progress reports, member states are obliged by 15 March 2021 (and every year thereafter) to provide the EC with annual reports, mostly related to their greenhouse inventories (Art. 23).
} 

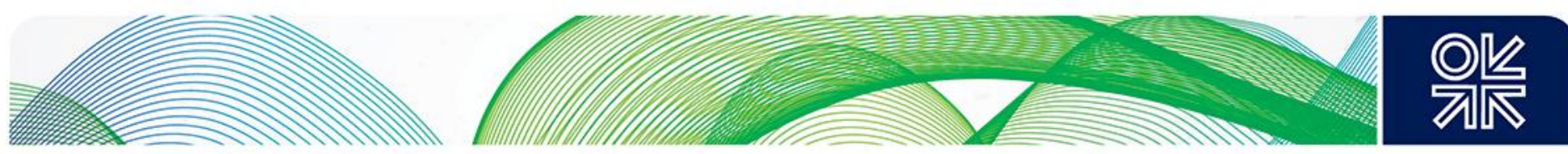

financing measures, including EU support and the use of EU funds, in this area at national level.

The EC is obliged to conduct regular biannual assessments of the progress made by each member state towards meeting its targets and in implementing its policies set out in its ECP, as well as the progress made at the EU level towards meeting the Energy Union objectives. Notably the EC would be able to conclude that the progress reached on either of those levels is insufficient. It would also be able to issue recommendations to a member state if its policy developments 'show inconsistencies with the overarching objectives of the Energy Union'.

By 31 October 2021 (and every second year thereafter) the EC is obliged to assess, in particular on the basis of the integrated national ECPs (Art. 25), the following:

- the progress made at the EU level towards meeting the Energy Union objectives,

- the progress made by each member state towards meeting its targets, objectives, and contributions, and in implementing the policies and measures set out in its integrated national ECP.

Based on such assessments, the EC is obliged to issue recommendations to a member state 'if policy developments in that member state show inconsistencies with the overarching objectives of the Energy Union' (Art. 26). Such recommendations are envisaged to ensure the achievement of the Energy Union objectives (Art. 28) and are based on inter alia the following principles:

- the member state is obliged to 'take utmost account' of the recommendation 'in a spirit of solidarity between member states and the Union and between member states',

- the member state is obliged to set out in its integrated progress report (made in the year following the year in which the recommendation was issued) 'how it has taken account' of, and 'how it has implemented or intends to implement', the EC's recommendation, whereas it is also obliged to 'provide justifications where it deviates from it'.

The Draft Regulation includes the provisions governing a 'response to insufficient ambition' of integrated ECPs and 'insufficient progress' towards the Union's energy and climate targets and objectives (Art. 27). Thus, should the EC conclude that the targets, objectives, and contributions set in the national ECPs (or their updates) are 'insufficient for the collective achievement' of those objectives and targets, it would be obliged to 'take measures at Union level' in order to ensure their collective achievement (Art. 27). Furthermore, should the EC conclude that 'insufficient progress is made by a member state towards meeting the targets, objectives and contributions', it would be obliged to issue recommendations to the member state. ${ }^{474}$ Also, by 31 October of each year, the EC is obliged to prepare a State of the Energy Union report, ${ }^{475}$ which must include inter alia its assessment of progress made at the EU level and by each member state towards meeting the Energy Union objectives, as well as the EC's recommendations issued to member states (Art. 29).

\subsubsection{Measuring progress towards the Energy Union}

Although the Draft Governance Regulation does not contain any metrics by which progress made towards the Energy Union can be measured, the EC has developed such metrics as part of the State of the Energy Union Reports, ${ }^{476}$ whereby the progress made in respect of each dimension of the Energy Union would

\footnotetext{
${ }^{474}$ Although it would appear that the main aim of this Article is to ensure that member states at least maintain their baseline share of energy from a range of energy sources - as it obliges a member state to cover the resulting gap by making a financial contributions while also obliging the EC to 'take into consideration ambitious early efforts' by member states to contribute to the EU 2030 target for renewable energy - this provision could also be used to impact the development of new gas infrastructure in a member state if it should be assessed as reflecting an 'insufficient ambition' in achieving the Energy Union objectives.

475 So far three reports have been prepared.

${ }^{476}$ Monitoring progress towards the Energy Union objectives - key indicators.
} 

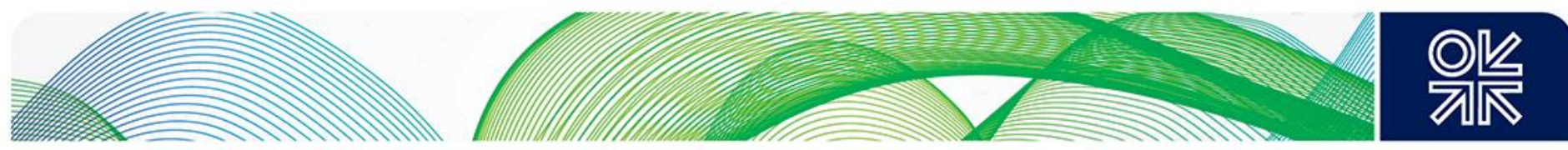

be measured by certain indicators. In particular, it is suggested that the progress reached in respect of the energy security dimension is measured by net import dependence, supply concentration index, and $\mathrm{N}-1$ rule, whereas it is suggested that progress in respect of the IEM dimension is measured by market concentration index, wholesale gas prices, and household switching rates.

However, the EC has not specified which (range of) value(s) each of those indicators should attain for progress towards the Energy Union to be considered sufficient. This suggests a significant degree of discretion over concluding whether or not a member state has made sufficient progress towards attaining the objectives. Importantly, the EC's ability to make negative assessments in respect of progress is strengthened by the fact that the Draft Governance Regulation does not define the Energy Union objectives - apart from stating that the EU 2030 climate and energy goals are part of them - thus making any assessment more subjective. This lack of clarity in respect of the Energy Union objectives would allow the EC a significant degree of discretion in making its judgement on whether the measures included by member states in their ECPs are sufficient, adequate, and consistent for reaching the Energy Union objectives. On the other hand, given that the EC metric of indicators is not legally binding on member states - as it is not part of legislation - the latter would also be able to argue that measures included in their ECPs are sufficient, adequate, and consistent for reaching the Energy Union objectives. However, their freedom to do so would be constrained - but not curtailed - by the EC and other member states. Ultimately, however, should any new pipeline be included into a member state's ECP - and its national network development plan - neither the EC nor other member states would be able to prevent it from being built, although they may be able to influence its operation - in other words through introducing safeguards ensuring that utilization of new pipeline capacity does not harm competition and is not detrimental to a well-functioning internal market.

\section{Conclusions}

Although the Draft Governance Regulation is, first and foremost, aimed at ensuring that the EU 2030 climate and energy goals:

- decreasing GHG emissions,

- increasing efficiency,

- increasing the share of renewables,

- increasing electricity interconnections between member states,

are met, it could also have an impact on the development and utilization of new gas pipeline infrastructure in the EU, despite this not being its prime objective. Such an impact, however, is likely to be limited and muted, as although the draft Regulation stipulated the EC assessment of progress made by each member state in respect of each dimension of the Energy Union, it neither defined the Energy Union objectives (apart from the EU 2030 goals) nor the threshold at which progress could be considered sufficient, thus enabling both the EC and the member state in question to argue that a new gas pipeline contributes towards the Energy Union objectives and the progress is sufficient.

Nonetheless, although the Regulation does not appear to provide the EC with the power to block a new pipeline on the grounds of not contributing towards the Energy Union objectives, it empowers the EC to exert significant pressure on a member state to justify the inclusion of any new pipeline in its ECP, and also to ensure that any potential negative impact on other member states would be minimized; for example by means of introducing safeguards ensuring that utilization of its capacity would not harm competition or be detrimental to the well-functioning internal market. Notably, in making its recommendations and assessments of the ECPs, the EC would be able to take into account whether and to what degree the comments made by other member states during the regional cooperation process have been taken into consideration by the member state while preparing its $\mathrm{ECP}$, thus making it very difficult for a member state to disregard the views of other member states. 

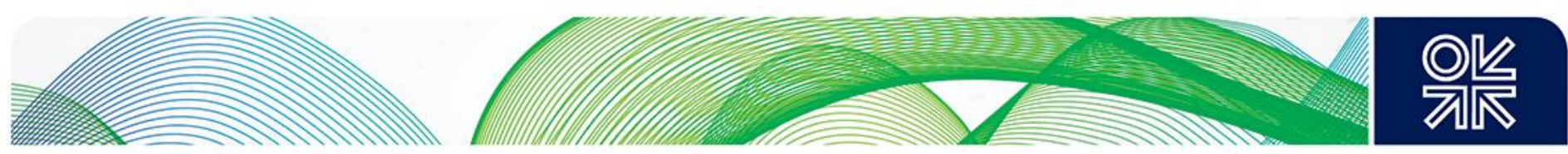

\subsection{Security of Supply Regulation}

The new Security of Supply Regulation 2017/1938, 477 which entered into force on 1 November 2017 repealing the Security of Supply Regulation $994 / 2010^{478}$ - is another EC legislative initiative which forms part of its wider Energy Union policy concept and translates it into the acquis. The adoption of the new Security of Supply Regulation was fraught with difficulties as the draft went through multiple 'trilogues' over the 2016-17 period, due to many issues of disagreement among member states. ${ }^{479}$ It was only agreed at the fourth 'trilogue' in April 2017 and adopted on 25 October 2017, following (an also lengthy) comitology process.

This paper argues that the new Security of Supply Regulation contains several provisions which could have an impact on the regulatory treatment of new pipeline capacity in the EU although - as is also the case with the Governance Regulation (Section 4.1) - this was not its main purpose. The main instruments that could be used in this respect are all analysed below.

- Common risk assessments (Section 4.2.3).

- Preventive action plans (Section 4.2.4).

- The information exchange mechanism (Section 4.2.5).

\subsubsection{The security of gas supply: shared responsibility and solidarity}

The Regulation stipulates that the security of gas supply is 'the shared responsibility' of natural gas undertakings, member states (in particular through their competent authorities), and the EC (Art. 3.1). ${ }^{480}$ It is to be safeguarded by means of:

- 'ensuring the proper and continuous functioning of the internal market in natural gas',

- 'allowing for exceptional measures to be implemented when the market can no longer deliver the gas supplies required, including solidarity measures as a last resort',

- 'providing for the clear definition and attribution of responsibilities ... regarding both preventive action and the reaction to concrete disruptions of gas supply' (Art. 1).

In addition to preserving the infrastructure standard ${ }^{481}$ and the supply standard ${ }^{482}$ obligations (already present in the previous Regulation 994/2010), the new Regulation introduced the solidarity measure under which, starting from 1 March 2019 , a member state, ${ }^{483}$ which is directly connected to a member state that has requested the application of the solidarity measure, ${ }^{484}$ is obliged to:

'take the necessary measures to ensure that the gas supply to customers other than solidarity protected customers in its territory is reduced or does not continue to the extent necessary and for as long as the gas supply to solidarity protected customers in the requesting member state is not satisfied' (Art. 13).

\footnotetext{
477 Security of Supply Regulation 2017 (see Additional documents).

478 Security of Supply Regulation 2010 (see Additional documents).

479 Issues of disagreement: composition of risk groups, regional vs national action plans, solidarity and compensation mechanism, contracts notification and access.

${ }^{480}$ The competent authorities are obliged to 'establish the roles and responsibilities' to ensure a three-level approach which would involve (1) the relevant natural gas undertakings, electricity undertakings (where appropriate) and industry; (2) member states at national or regional level; (3) the EU (Art. 3.4).

481 Inter alia an obligation to maintain physical bi-directional capacity unless exempted.

482 Security of Supply Regulation 2017, Art. 5 and 6.

483 Or its competent authority or TSO or DSO.

${ }^{484}$ It is understood that the solidarity measure could be requested in emergency.
} 

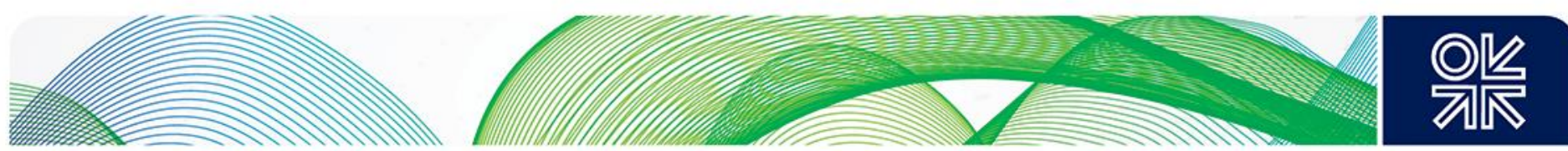

This obligation is subject to several conditions, including the requesting member state's agreement to pay 'fair and prompt compensation'. Member states are obliged to adopt the necessary measures by 1 December 2018 and describe them in their emergency plans. ${ }^{485}$

\subsubsection{Regional risk groups}

The Regulation has established 'transparent mechanisms concerning, in a spirit of solidarity, the coordination of planning for, and response to, an emergency'. In particular, it has established the list of risk groups and their composition, based on the identification of 'major transnational risks to the security of supply' in the EU (Art. 3.7) (Table 4). There are four major risk groups - Eastern, North Sea, North African, South Eastern (each of them corresponding to a major regional source of gas supply) - which are further divided into 13 groups with overlapping membership. These groups have been established by the EC on the basis of results from the EU-wide simulation of gas supply and infrastructure scenarios, prepared by ENTSOG. The EC also has the power - in consultation with the Gas Coordination Group (GCG) - to change the composition of the risk groups 'to reflect the evolution of the major transnational risks' (Art. 3.8).

The Security of Supply Regulation - just as the Draft Governance Regulation (Section 4.1) - places a significant emphasis on regional cooperation between member states in respect of security of supply. In particular, the aforementioned risk groups are envisaged to:

'serve as the basis for enhanced regional cooperation to increase the security of gas supply [and] enable agreement on appropriate and effective cross-border measures of all Member States concerned within the risk groups or outside the risk groups along the emergency supply corridors' (Art. 3.7).

In addition to regional cooperation within the established groups, regional cooperation is encouraged between all member states at all levels, as the Regulation says 'the composition of the groups shall not prevent any other form of regional cooperation benefitting security of supply'.

Table 4: Gas supply risk groups: regional cooperation

\begin{tabular}{|l|l|l|}
\hline Risk group & Country / Issue & $\begin{array}{l}\text { Countries potentially affected in the event of supply } \\
\text { interruption }\end{array}$ \\
\hline Eastern & & \\
\hline & Ukraine & $\begin{array}{l}\text { Bulgaria, Czech Republic, Germany, Greece, Croatia, Italy, } \\
\text { Luxembourg, Hungary, Austria, Poland, Romania, Slovenia, } \\
\text { Slovakia. }\end{array}$ \\
\hline & Belarus & $\begin{array}{l}\text { Belgium, Czech Republic, Germany, Estonia, Latvia, } \\
\text { Lithuania, Luxembourg, Netherlands, Poland, Slovakia }\end{array}$ \\
\hline & Baltic Sea & $\begin{array}{l}\text { Belgium, Czech Republic, Denmark, Germany, France, } \\
\text { Luxembourg, Netherlands, Austria, Slovakia, Sweden. }\end{array}$ \\
\hline & North-eastern & Estonia, Latvia, Lithuania, Finland. \\
\hline North Sea & Trans-Balkan & Bulgaria, Greece, Romania. \\
\hline
\end{tabular}

\footnotetext{
485 Including the technical, legal, and financial arrangements which 'may' cover, inter alia, gas prices, volumes, the use of interconnectors, and 'an indication of the method how the fair compensation could be calculated'. If member states do not agree, the EC may propose.
} 

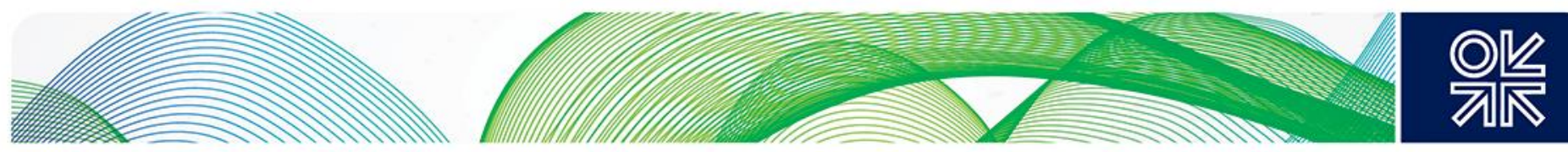

\begin{tabular}{|l|l|l|}
\hline & Norway & $\begin{array}{l}\text { Belgium, Denmark, Germany, Ireland, Spain, France, Italy, } \\
\text { Luxembourg, Netherlands, Portugal, Sweden, UK. }\end{array}$ \\
\hline & L-Gas & Belgium, Germany, France, Netherlands. \\
\hline & Denmark & Denmark, Germany, Luxembourg, Netherlands, Sweden. \\
\hline & UK & Belgium, Germany, Ireland, Luxembourg, Netherlands, UK. \\
\hline North African & Algeria & $\begin{array}{l}\text { Greece, Spain, France, Croatia, Italy, Malta, Austria, } \\
\text { Portugal, Slovenia. }\end{array}$ \\
\hline & Libya & Croatia, Italy, Malta, Austria, Slovenia. \\
\hline South-eastern & & $\begin{array}{l}\text { Bulgaria, Greece, Croatia, Italy, Hungary, Malta, Austria, } \\
\text { Romania, Slovenia, Slovakia. }\end{array}$ \\
\hline & Caspian & Greece, Italy, Cyprus, Malta. \\
\hline & Eastern Mediterranean & Ras Corridor - \\
\hline
\end{tabular}

Source: author based on the Security of Supply Regulation.

\subsubsection{Common and national risk assessments and a cooperation mechanism}

In particular, the Regulation obliges the competent authorities within each risk group to make a common risk assessment at the risk group level of 'all relevant risk factors' - including inter alia commercial and political - which could lead to 'the materialization of the major transnational risk to the security of gas supply', while also taking into account the results of the ENTSOG's EU-wide simulation of gas supply and infrastructure scenarios, ${ }^{486}$ which must include 'the identification and assessment of emergency gas supply corridors' and identify 'which member states can address identified risks, including in relation to LNG'.

The competent authorities within each risk group are obliged to agree on a cooperation mechanism to conduct such a risk assessment. The EC may - at the request of the competent authority - have 'a facilitating role' in the preparation of the assessment and in particular for the establishment of the cooperation mechanism. If the competent authorities do not agree on the cooperation mechanism, the EC is obliged to propose such a mechanism itself, after consulting with these authorities, with the latter being obliged to agree on a mechanism taking utmost account of the EC's proposal. The competent authorities of each member state are also obliged to prepare a national risk assessment of 'all relevant risks affecting the security of gas supply', which must be 'fully consistent' with the assumptions and results of the common risk assessment. Member states are obliged to notify their first common risk assessment (once agreed by all member states in the risk group) and the national risk assessments to the EC by 1 October 2018 (Art. 7.7). Both common risk assessments and national risk assessments are to be updated every four years 'unless circumstances warrant more frequent updates'.

Importantly - and of direct relevance for existing and new pipeline infrastructure in the EU - both a common risk assessment and a national risk assessment must be carried out by inter alia:

- taking into account 'risks relating to the control of infrastructure relevant to the security of gas supply to the extent that they may involve, inter alia, risks of underinvestment, undermining diversification, misuse of existing infrastructure or an infringement of Union law' (Art. 7.4.e),

- running various scenarios of exceptionally high demand for gas and disruption of gas supply, taking into account 'the history, probability, season frequency and duration' and assessing their likely consequences, such as:

\footnotetext{
${ }^{486}$ Such simulation is to be first prepared by ENTSOG by 1 November 2017 and to be repeated every four years thereafter.
} 

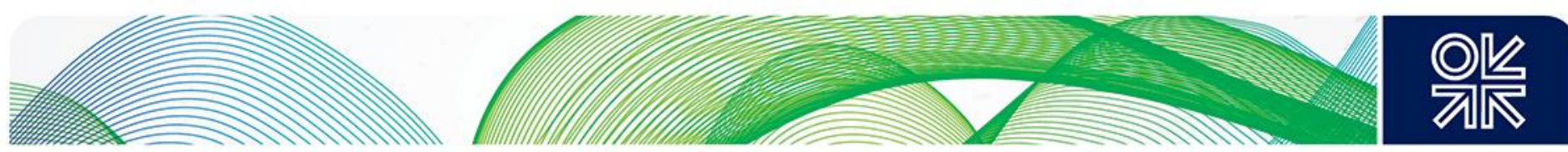

disruption of the infrastructure relevant to the security of gas supply, in particular transmission infrastructure,

- disruption of supplies from third-country suppliers, as well as, where appropriate, geopolitical risks.

\subsubsection{Preventive action and emergency plans and a cooperation mechanism}

In addition to conducting risk assessments, the Regulation has obliged the competent authorities to establish preventive action plans and emergency plans.

A preventive action plan must include 'the measures needed to remove or mitigate the risks' identified in the common and national risk assessments and in particular measures designed to address the risks 'relating to the need to enhance interconnections between neighbouring member states' and to 'the possibility to diversify gas routes and sources of gas supply and the regional utilization of existing storage and LNG capacities' (Art. 9.1.e)

An emergency plan must include 'the measures to be taken to remove or mitigate the impact' of a disruption of gas supply (Art. 8.2).

The measures contained in both plans must be 'clearly defined, transparent, proportionate, nondiscriminatory and verifiable, shall not unduly distort competition or the effective functioning of the internal market' and must not 'endanger the security of gas supply of other member states or of the Union' (Art. 8.1).

Both preventive action and emergency plans must include a regional chapter - or several regional chapters, where a member state is a member of several risk groups - which must be developed jointly by all member states in the group. The EC is obliged to act as 'a facilitator so as to enable that the regional chapters collectively enhance' the security of gas supply in the EU and 'do not give rise to any contradiction' and 'overcome any obstacles to cooperation'. In particular, the regional chapters must contain 'appropriate and effective cross-border measures, including in relation to LNG, subject to agreement between the member states implementing the measures from the same or different risk groups affected by the measure' on the basis of the aforementioned EU-wide simulation of gas flows and infrastructure and the common risk assessment (Art. 8.3). The plans must also contain the national measures necessary to implement and enforce the cross-border measures in the regional chapters (Art. 8.6).

As the cooperation mechanism for the preparation of common risk assessments, the competent authorities are obliged to agree on a cooperation mechanism for the preparation of the preventive action and the emergency plans. On its part, the EC 'may' have a facilitation role in the preparation of such plans, including in particular for the establishment of the cooperation mechanism. If the competent authorities do not agree on the cooperation mechanism, the EC is obliged to propose such a mechanism itself, whereas the competent authorities are obliged to agree on the mechanism, 'taking account' of the EC's proposal. The final versions of the preventive action plans and the emergency plans must be agreed by all member states in the risk group. The preventive action plans and the emergency plans must be made public and notified to the EC by 1 March 2019. Within four months after notification - in other words by 1 July 2019 - the EC is obliged to issue an opinion to the competent authority with the recommendation to review a plan if:

it is not effective to mitigate the risks identified in the risk assessment and/or inconsistent with the risk scenarios assessed or with the plans of another member state or risk group,

and/or it does not comply with the requirement not to unduly distort competition or the effective functioning of the internal market and/or does not comply with the EU acquis (Art. 8).

Within three months of notification of the EC's opinion - in other words by 1 October 2019 - the competent authority is obliged either to notify the amended plan to the EC or inform it of the reasons why it disagrees 

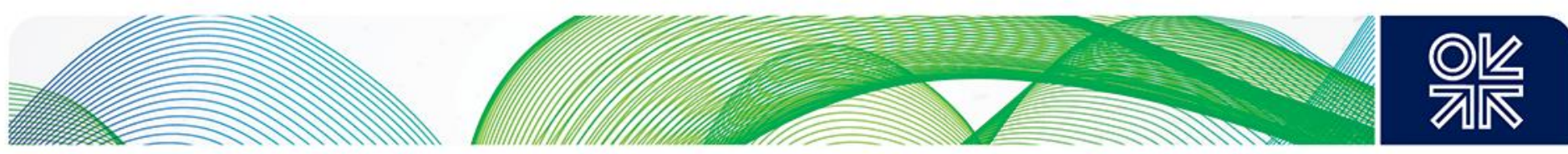

with the recommendations. In the event of disagreement, the EC may, within four months of the reply in other words 1 February 2020 - either withdraw its request or convene the competent authority (and where it considers this to be necessary, the GCG) to consider the issue, whereby the EC is obliged to 'set out its detailed reasons for requesting any amendments' and the competent authority is obliged to take 'full account' of these reasons. However, the competent authority's final position may diverge from that of the EC, in which case it is obliged to provide and make public, together with its position and the EC's detailed reasons, the justification of its position within two months (in other words by 1 April 2020). It would thus be possible - albeit extremely difficult - for a member state's final position on the preventive action and the emergency plans to diverge from that of the EC.

\subsubsection{Information exchange and supply contracts}

The Regulation has introduced an information exchange obligation in respect of gas supply contracts. In particular, irrespective of a declaration of an emergency, ${ }_{4} 487$ the competent authority of 'the most affected member state' - a member state in which most of the sales of gas, or customers, of a contract party of a given contract are located (Art. 14.11) - 'may require natural gas undertakings to provide ... information necessary to assess the overall situation of the gas supply in the member state or other member states, including contractual information' (other than price information). In turn, the EC 'may request' this information from the competent authorities (Art. 14.4).

Furthermore, irrespective of a declaration of any of the crisis levels, where the EC 'considers the gas supply in the Union or part of the Union to be at risk or is likely to be at risk that may lead to the declaration of one of the crisis levels' - namely, early warning, alert, or emergency - 'it may require the competent authorities concerned to collect and submit to the Commission information necessary to assess of the gas supply situation' (Art. 14.5). ${ }^{488}$

Furthermore, the Regulation has obliged each natural gas undertaking to notify to the competent authority of 'the most affected' member state its gas supply contracts 'immediately after their conclusion or modification' with a duration of more than one year, concluded or modified on or after 1 November 2017 (in other words the date of the Regulation's entry into force) 'that individually or cumulatively with its contracts with the same supplier or its affiliates is equivalent to 28 per cent or more of yearly gas consumption in that member state' (Art. 14.6.b). Furthermore, by 2 November 2018 natural gas undertakings are obliged to notify the competent authority of all existing contracts fulfilling the same conditions. ${ }^{489}$ This means that by 2 November 2018 the competent authorities of the most affected member states would have all such supply contracts at their disposal. Although the Regulation does not require the competent authority to transfer those contracts to the EC automatically, it says that where the competent authority 'has doubts' whether any of the aforementioned contracts puts security of gas supply of a member state or a region at risk', it is obliged to notify the contract to the EC. This means that the competent authority has a right not to notify the contract to the EC if it has no concerns about its impact on the security of supply.

Notwithstanding the above provisions:

'in circumstances duly justified by the need to guarantee transparency of key gas supply contracts relevant to the security of supply, and where the competent authority of the most affected member state or the Commission considers that a gas supply contract may jeopardize the security of gas supply of a member state, of a region or of the Union, the competent authority of the member state or the Commission may request the natural gas undertaking to provide the contract, excluding price information, for the assessment of its impact on the security of gas supply [with such request to be] reasoned' (Art. 14.7).

\footnotetext{
${ }^{487}$ This provision is understood to apply only if a member state has declared one of the crisis levels, namely early warning, alert, or emergency; however this understanding is open to interpretation and this provision might also apply if a member state has not declared any of the crisis levels.

${ }^{488}$ Here 'of' appears to be a typo.

489 The notification obligation does not apply to price information or modifications related only to the gas price.
} 

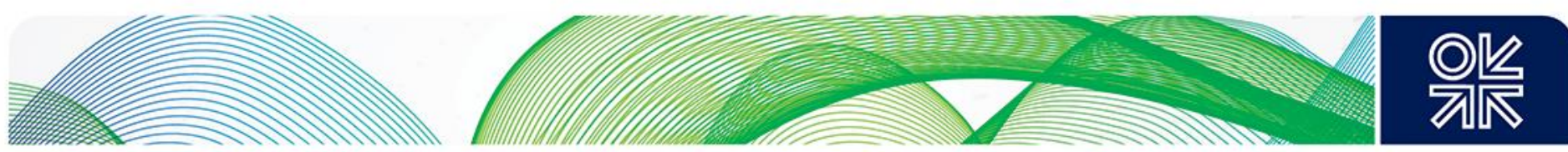

This means that in such (unspecified) circumstances both the EC and the competent authority of the most affected member state have a right to request the natural gas undertaking to provide any supply contract - irrespective of its duration or share in the annual gas consumption of that member state - if either of them considers that such contract may jeopardize security of supply.

In order to dissuade the natural gas undertaking from not providing the aforementioned information under the information exchange provisions, the Regulation has envisaged 'effective, proportionate and dissuasive' penalties to be imposed on them for failure to provide such information, the rules on which are to be developed by the member states by 2 May 2019 (Art. 14.10).

The competent authorities are obliged to assess the information provided under the information exchange provisions for security of supply purposes within three months of receipt, and to submit the results of their assessments to the EC. Importantly, the Regulation prescribes that the information received by the competent authorities under the information exchange provisions is to be taken into account by the competent authorities in the preparation of the risk assessment, ${ }^{490}$ the preventive action plan, and the emergency plan (Art. 14.9). On its part, the EC is empowered - but not obliged - to adopt an opinion proposing to the competent authorities that the risk assessments or plans be amended on the basis of such information.

\section{Conclusions}

The new Security of Supply Regulation contains a number of instruments - such as common risk assessments, preventive action plans (with regional chapters), and the information exchange mechanism - which could potentially be used both by the EC and the member states to influence the development and utilization of new pipeline capacity in the EU. However, as is the case with the Draft Governance Regulation (Section 4.1) its influence is likely to be muted and limited.

The Regulation enables the member states to identify and include, as part of their national and common risk assessments, all relevant risk factors - political and commercial - capable of endangering the security of supply, including the risks 'relating to the control of infrastructure relevant to the security of gas supply to the extent that they may involve, inter alia, risks of underinvestment, undermining diversification, misuse of existing infrastructure, or an infringement of Union law' (Art. 7.4.e). Consequently, the member state on whose territory a new pipeline is planned to be built, would be obliged to demonstrate the ways in which any such risks would be addressed.

Overall, the EC or member states concerned in respect of new gas infrastructure would not be able to stop it from being built or utilized, but it would be subject to significant scrutiny. Should the member state on whose territory it is planned to be built provide a substantiated assessment of these risks, the measures to mitigate or remove them (including in respect of cross-border issues), and confirmation that the infrastructure has been built and operated in line with the acquis applicable at the time, there appears to be nothing in the Regulation that empowers the EC or other member states to prevent its construction and operation. The aforementioned mitigating measures could include inter alia the regulatory measures that could be adopted by the national regulatory authority to ensure that the operation of new infrastructure does not distort the functioning of the internal market and is not detrimental to competition.

\footnotetext{
${ }^{490}$ Given that the contractual information is notified under the information exchange provisions to the most affected member state, it is understood that such information is to be taken into account in the preparation of the national - as opposed to common (regional) - risk assessment.
} 

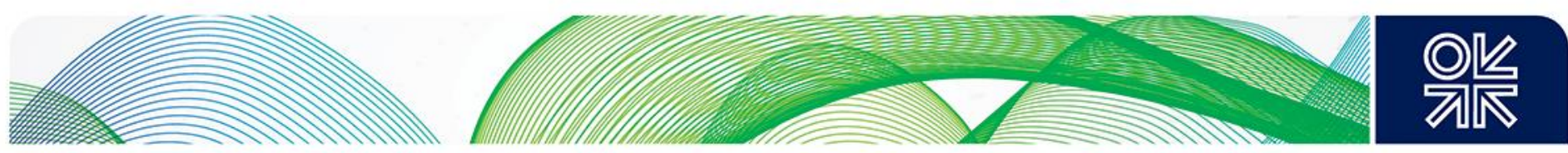

\subsection{The EC proposal to amend the Third Gas Directive (draft)}

\subsubsection{The EC amendment proposal: rationale}

On 8 November 2017 the EC published its proposal to amend the Third Gas Directive ('The EC Amendment Proposal'). ${ }^{491}$ The EC stated that should the proposal be approved by the European Council and the European Parliament, the amended Directive could be expected to enter into force by the end of 2018 at the latest. This extremely challenging timetable could only be met should the EC decide not to conduct an impact assessment of the proposal. The EC argued that no detailed impact assessment was necessary. ${ }^{492}$ However, this argument does not appear to have convinced the Council's Legal Service, which stated that due to the absence of an impact assessment, alternative measures (to those presented in the proposal) have not been examined, thus complicating the conclusion on whether the principle of proportionality has been respected. ${ }^{493}$ The EC position on impact assessment has also been severely criticized by the majority of the European gas industry. ${ }^{494}$ At the time of writing it is not clear whether there will be an impact assessment. Should the proposal proceed without the assessment it could be possible for it to be adopted by the end of 2018, whereas a decision to conduct an assessment would delay it by approximately one year.

The main rationale for amending the Directive is to make it applicable to gas pipelines to and from third (in other words non-EU) countries up to the border of EU jurisdiction, ${ }^{495}$ particularly to Nord Stream 2, which appears to be the main target of the proposal. Indeed, on 11 October 2017, the DG Energy's Director for the Internal Energy Market (IEM), Klaus-Dieter Borchardt, presenting at the European Parliament's Committee on Information, Research and Energy (ITRE) - which is responsible for scrutinizing the proposal - stated that one of the proposal's main aims was to ensure that the amended Directive would apply to (the European end of) Nord Stream 2. ${ }^{496}$ The fact that the latter is scheduled to become operational at the end of 2019 explains the urgency with which the EC has been trying to advance the proposal, in order for it to be adopted prior to Nord Stream 2's starting operation.

It is noteworthy that the EC decided to initiate the process of amending the Directive to make it applicable to pipelines to and from third countries shortly after being made aware (on 27 September 2017 by the Council's Legal Service, as part of its assessment of the EC's request for a mandate to negotiate an international agreement on Nord Stream 2 with the Russian government ${ }^{497}$ ) that the application of the Directive to such pipelines would constitute a potential conflict of laws. It is thus argued here that by initiating the amendment proposal, the EC has decided to create intentionally a conflict of laws particularly in respect of Nord Stream 2 - where none currently exists. The EC appears to be doing so in order to create a legal rationale for getting a mandate from the Council to negotiate an agreement on Nord Stream 2 with the Russian government. As the application of the amended Directive could create a conflict of laws, the EC's legal rationale for getting a mandate that could resolve the ensuing conflict of laws would be strengthened. The Council's Legal Service informed the EC that at present there is no legal rationale for such a mandate. ${ }^{498}$

\footnotetext{
${ }^{491}$ EC (2017c), Amendment Proposal. Also see EC (2017d).

${ }^{492}$ EC (2017a), p. 5. Also see 'CEEP: Opportunities and challenges of the gas directive', Biznes Alert, 22 March 2018 (see Journal articles).

${ }^{493}$ Council Legal Service's Opinion - Competences (see Additional documents), pp. 6-7

${ }^{494}$ Eurogas (2018). Also see IOGP (2017), Business Europe (2017). Also for a useful overview of the EC amendment proposal, see Barnes (2018).

${ }^{495}$ There is a legal uncertainty as to whether EU jurisdiction would extend to include the exclusive economic zones (EEZ) of its member states or only their territorial waters. The Council Legal Service's opinion concluded that the EEZs are not included, see Council Legal Service's Opinion - UNCLOS (see Additional Documents).

${ }^{496}$ Yafimava (2017b), p. 3.

${ }^{497}$ For a detailed analysis of the Council Legal Service's assessment and its impact on Nord Stream 2, see Yafimava (2017b)

${ }^{498}$ Council Legal Service's Opinion - Nord Stream 2 mandate (See Additional documents). For a detailed analysis of the Council Legal Service's Opinion - Nord Stream 2 mandate see Yafimava (2017b).
} 

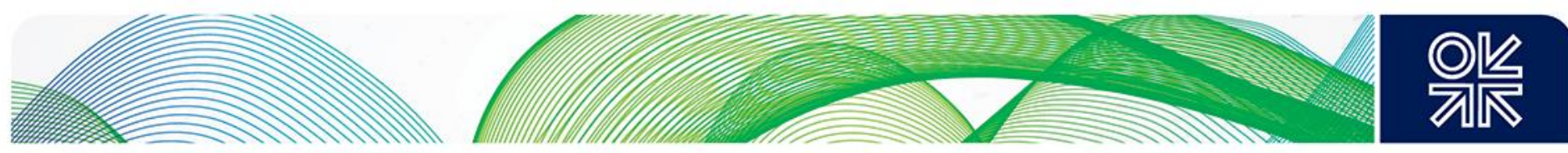

Fortification of its legal argument in support for the Nord Stream 2 mandate might not be the only rationale behind the EC proposal - especially given Borchardt's view that even if Nord Stream 2 were to be made compliant with the amended Directive it would be unlikely to conform to the Energy Union objectives ${ }^{499}$ but it is certainly the main one, and hence the proposal should be analysed first and foremost in this context.

\subsubsection{The EC amendment proposal: analysis}

Although the EC proposal preserves the general structure of the Third Gas Directive, it makes significant changes to some of its major provisions set in Art. 2 (Definitions), Art. 9 (Unbundling of transmission systems and transmission system operators), Art. 14 (Independent transmission operators), Art. 34 (Access to upstream pipeline networks), Art. 36 (New infrastructure), Art. 41 (Duties and powers of the regulatory authority), Art. 42 (Regulatory regime for cross-border issues), and Art. 49 (Emergent and isolated markets).

The main change made by the proposal is the amendment of the definition of an interconnector. While the Directive defines an 'interconnector' as:

'a transmission line ${ }^{500}$ which crosses or spans a border between Member States for the sole purpose of connecting the national transmission systems of those Member States' (Art. 2.17),

the proposal suggests re-defining it as:

'a transmission line which crosses or spans a border between Member States or between Member States and third countries up to the border of Union jurisdiction' (Art. 2.17*).

This change is significant as it has:

(a) extended the definition of an interconnector to transmission lines between member states and third countries,

(b) extended the definition of an interconnector to transmission lines between member states which may have other purposes in addition to solely connecting the national transmission systems of those member states.

The proposal's explanatory memorandum states that the rationale for this change is to make the Third Gas Directive 'in its entirety (as well as the related legal acts like the Gas Regulation, network codes and guidelines, unless otherwise provided in those acts) ... applicable to pipelines to and from third countries, including existing and future pipelines, up to the border of EU jurisdiction'. ${ }^{501}$

The proposal obliges the national regulatory authority to cooperate 'for infrastructure to and from third countries, with the relevant authorities of the third country aiming at, as regards this infrastructure, consistent application of the provisions' of the Directive 'up to the border of Union jurisdiction' (Art. $\left.41.1(\mathrm{c})^{*}\right)$. Furthermore, it obliges the national regulatory authority to 'consult and cooperate with the relevant authorities of third countries in relation to the operation of gas pipelines to and from third countries with a view to ensuring, as regards the concerned infrastructure, that the provisions of this Directive are applied consistently up to the border of Union jurisdiction' (Art. 42*).

\footnotetext{
${ }^{499}$ As noted in Section 4.1, at present, the Energy Union objectives are not defined in the acquis. The Draft Governance Regulation (see Additional Documents), which aims at operationalizing the Energy Union objectives, only states that these objectives include the EU 2030 energy and climate targets but provides no overarching definition.

500 'Transmission' means 'the transport of natural gas through a network, which mainly contains high-pressure pipelines, other than an upstream pipeline network and other than the part of high-pressure pipelines primarily used in the context of local distribution of natural gas, with a view to its delivery to customers, but not including supply' (Art. 2.3).

${ }^{501}$ Explanatory memorandum of the Amendment Proposal.
} 

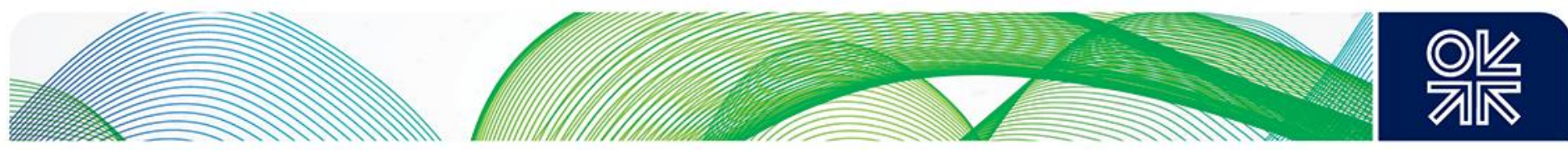

The proposal allows a member state to decide not to implement the Directive's ownership unbundling (OU) provisions in respect of 'infrastructure to and from third countries between the border of Union jurisdiction and the first interconnection point with the Union network', where:

- the transmission system belonged to a vertically integrated undertaking on the date of adoption of the proposal (expected by the end of 2018) (Art. 9.8*);502

- 'there are arrangements in place which guarantee more effective independence' of the TSO than the Directive's independent transmission operator (ITO) provisions (Art. 9.9*);

- the member state designates an independent system operator (ISO) upon a proposal from the TSO (Art. 14.1*).

The proposal stipulates two different regimes:

- an exemption for new pipeline infrastructure under Art. $36^{*}$ ('new infrastructure' is defined in the Third Gas Directive as 'not completed by 4 August 2003'503) which could be granted from:

$\circ \quad$ Art. 9 (unbundling), Art. 32 (TPA to the transmission and distribution systems and LNG facilities), Art. 33 (access to storage), Art. 34 (access to upstream pipeline networks), Art. 41(6), (8), (10) (regulated tariffs);

- a derogation for all existing pipelines and all new pipelines completed before the date of the amended Directive entry into force [expected in 2019] under Art. 49*, which could be granted from: Art. 9, Art. 10 (designation and certification of TSOs), Art. 11 (certification in relation to third countries), Art. 32, Art. 41(6), (8), (10).

The exemption regime for 'major new gas infrastructure' - in other words interconnectors, LNG, and storage facilities - is largely based on the exemption regime established by the Third Gas Directive (analysed in detail in Section 2.2) but has several additional provisions related to pipelines to and from third countries. Notably, the proposal preserves the right of a member state's national regulatory authority to decide on the exemption 'on a case-by-case basis' as stipulated by the existing Directive as well as the ACER's right to submit 'an advisory opinion to the member states concerned' in respect of the infrastructure located in the territory of more than one member state, which 'may be used as a basis for their decision'. In addition, it places an obligation on the national regulatory authority to 'consult the relevant authorities of the third countries prior to adopting a decision' 'where the infrastructure in question is under the jurisdiction of a member state and one (or more) third countries' (Art. 36.3*). Given that the proposal stipulates mandatory cooperation between the national regulatory authorities of member states and the relevant authorities of the third countries in respect of the new infrastructure under the jurisdiction of one (or more) member states and one (or more) third countries, 'with a view of ensuring' that the provisions of the amended Directive 'are applied consistently up to the border of Union jurisdiction' (Art. $42.6^{*}$ ), it appears to suggest that the conditions of the exemption that could be granted in respect of such infrastructure would have to be identical both in respect of the section of a pipeline within a member state(s) concerned and in respect of the section of a pipeline between the border of the EU jurisdiction and the first interconnection point.

In addition to the exemption regime under Art. $36^{*}$, the proposal established a new derogation regime (absent in the Third Gas Directive). Unlike the exemption regime - to which the entire Art. $36^{*}$ consisting of ten detailed sections is devoted - the derogation procedure is not clearly spelled out. The proposal does not contain a separate new article outlining the derogation regime and only briefly outlines it in one additional paragraph within the existing Art. 49, which is devoted entirely to emergent and isolated markets (thus inviting suggestions that the derogation regime might only apply to pipelines to and from third countries arriving and departing from emergent and isolated markets, which does not seem to have been the EC's intention). Specifically, the proposal states that in respect of gas pipelines to and from third

\footnotetext{
502 Here and everywhere in this chapter '*' is used to indicate an amended article.

${ }^{503}$ Art. 2(33).
} 

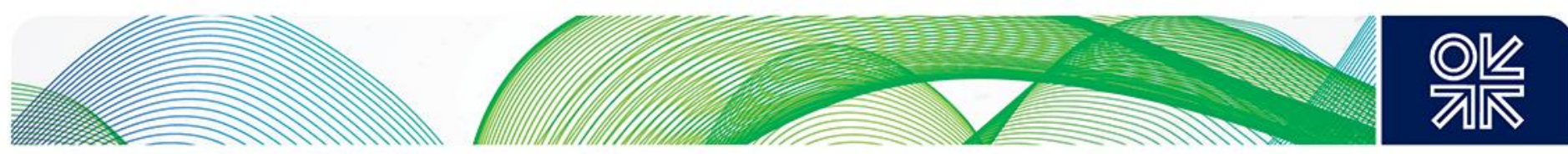

countries completed before the date of entry into force of the amended Gas Directive (expected by the $\mathrm{EC}$ at the end of 2018 or early 2019), member states 'may decide to derogate' from Art. 9, Art. 10, Art. 11, Art. 32, and Article 41(6), (8), and (10) for the sections of such pipelines between the border of Union jurisdiction and the first interconnection point. The proposal does not make it clear whether a decision to grant a derogation would be made by the member state's government - rather than by a national regulatory authority - as it does not specify whether the government has a right to delegate this responsibility to the national regulatory authority.

This appears to be different from an exemption procedure where a regulatory authority or a member state government could decide on an exemption. Notably, a member state is under no obligation to grant a derogation and therefore may refuse it. The proposal does not appear to contain any criteria for granting a derogation, apart from stating that it must not be 'detrimental to competition on or the effective functioning of the internal market in natural gas in the Union, or the security of supply in the Union' (Art. $49.9^{*}$ ), without specifying how its impact on completion, effective functioning of the internal market, and the security of supply would be measured. The proposal states that a derogation 'may be subject to conditions which contribute' to the achievement of these aims. Given that the proposal provides a member state with the right to decide on a derogation, it could be argued that it is also for a member state to decide on the conditions to which the derogation should be subject. The lack of criteria for a derogation is in contrast with the exemption procedure, which outlines a set of criteria (albeit general and unquantified, see Section 2.2) under which the new infrastructure could be exempted. A member state, where a pipeline from a third county arrives, would thus have significant discretion over whether to grant a derogation. The proposal is silent over whether the EC would have a right or an obligation to provide its opinion on the derogation and whether such an opinion is to be binding on a member state (as is the case with an exemption). The proposal has not set a specific time period within which a member state must make a decision on a derogation, but has stated that 'any decision' must be published 'within one year' after the amended Directive's entry into force, thus suggesting that the whole process of application and decision making in respect of a derogation for pipelines from third countries completed before the amended Directive's entry into force, must be completed within one year after that date.

The proposal specifies that if the pipeline is located 'in the jurisdiction of more than one member state, the member state in the jurisdiction of which the first interconnection point is located shall decide on a derogation for the pipeline' (Art. 49.9*). Notably, unlike an exemption under Art. 36*, a derogation under Art. $49^{*}$ could only be granted in respect of the section of a pipeline between the border of EU jurisdiction and the first interconnection point, but not in respect of the section of a pipeline within the member state(s) concerned. Just as for an exemption, the proposal requires a derogation to be 'limited in time' although it does not specify its limit. It obliges member states to publish 'any decision on a derogation ... within one year after the entry into force of this Directive'.

It is worth noting that the lines between the exemption and the derogation regimes are significantly blurred. There is an overlap between the provisions of the amendment proposal from which both an exemption and a derogation could be granted, namely those under Art. 9, Art. 32, and Art. 41(6), (8), (10). The reason for what at first sight could appear to be a duplication is that the derogation regime would only apply to the section of a pipeline between the border of EU jurisdiction and the first interconnection point, whereas the exemption regime would apply to both the section of a pipeline inside a member state past the first interconnection point as well as the section of a pipeline between the border of EU jurisdiction and the first interconnection point. This means that granting a derogation could make a pipeline exempt from Art. 9, 10, 11, 32, and 41 in respect of its section between the border of EU jurisdiction and the first interconnection point, but not in respect of its section within a member state(s). On the other hand, granting an exemption could make a pipeline exempt from Art. 9, 32, 33, 34, and 41 in respect of both sections at once. By establishing two different regimes under which a waiver could be granted from certain provisions of the Directive - exemption and derogation - the EC has de facto split the process of granting such waivers into two layers: 

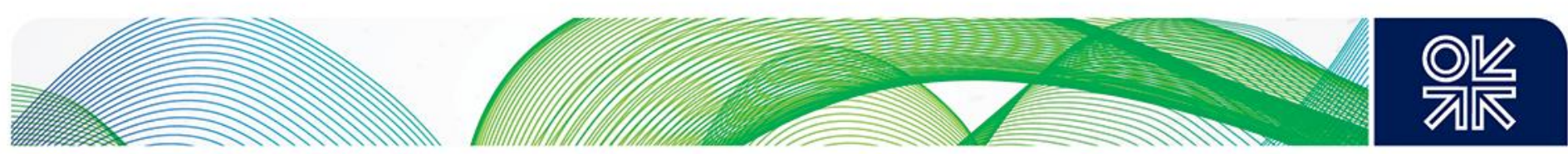

- the first in respect of the section between the border of EU jurisdiction and the first interconnection point,

- the second in respect of the section inside a member state past the first interconnection point.

Notably, there are provisions from which only a derogation - but not an exemption - could be granted, namely those under Art. 10 and Art. 11 on certification of TSOs (including in relation to TSOs controlled by 'a person or persons from a third country or third countries'). Unlike a derogation regime, an exemption regime does not envisage a possibility of being exempted from these provisions. This means that a project which has received an exemption would still have to be certified under Art. 10 or Art. 11. Conversely, there are provisions from which only an exemption - but not a derogation - could be granted, namely those under Art. 33 (on access to storage) and Art. 34 (on access to upstream networks). Unlike the exemption regime, the derogation regime does not envisage the possibility of being exempted from these provisions. This means that to get a waiver from Art. 34, an upstream network would need to apply for an exemption (and not for a derogation).

The proposal appears to have preserved the exemption regime for new infrastructure (in other words not completed by August 2003) which means that should the proposal be accepted, it would continue to be possible for new pipelines - including those from third countries - to apply for an exemption under Art. $36^{*}$. (But it would not be possible for pipelines completed before August 2003 to apply for an exemption.) Should their applications be successful - in other words both a national regulatory authority of a member state itself as well as the EC approve their exemptions - the pipelines could be exempted from Art. 9, 32, 33, 34, and 41 but would still have to comply with Art. 10 or Art. 11. (It is worth noting that pipelines built before August 2003 are not considered 'new' under the Directive and therefore would not be eligible for an exemption.) However, those pipelines that will have been completed by the time of the amended Directive's entry into force (all the existing pipelines and the pipelines completed by that date) would be able to apply for a derogation under Art. $49^{*}$. This means that all those pipelines which will not have been completed by that time would have to comply with TSO certification provisions under Art. 10 or Art. 11, irrespective of whether they have been granted an exemption under Art. $36^{*}$, as the latter does not envisage a possibility of being exempted from certification. The same is true in respect of pipelines from third countries which will have been completed by the date of the amended Directive's entry into force, but either did not apply for, or failed to be granted, a derogation - they too will have to comply with TSO certification provisions. This suggests that, at the very least, any pipeline from a third country, completed before the amended Directive's entry into force, which will have applied for, but not received, a derogation within one year after the amended Directive's entry into force, will have to be certified under Art. 11, where the decision by the national regulatory authority would be final and binding.

Given that the derogation regime is envisaged to be extremely short lived - as a derogation could only be granted to pipelines completed by the time of the amended Directive's entry into force - in other words during 2018-19 - the main rationale of the proposal appears to be to ensure that any pipeline to or from a third country completed after the Directive's entry into force would have to be certified under Art. 10 or Art. 11. (This is likely to be the case with Nord Stream 2 which would have to be certified under Art. 11 as it will be controlled by a person from a third country in other words Russia. ${ }^{504}$ ) Whereas such pipelines would still be able to apply for an exemption under Art. $36^{*}-$ and, if their application is successful, to be exempted from provisions under Art. 9, 32, 33, 34, and 41 - this would not protect them from an obligation to be certified under Art. 10 or Art. 11. As noted above, the exemption would apply to both the section of a pipeline inside a member state(s) past the first interconnection point as well as to the section of a pipeline between the border of EU jurisdiction and the first interconnection point. ${ }^{504}$ Gazprom is the sole shareholder in Nord Stream 2 whereas five European companies - Uniper, Wintershall, Engie, Shell,
OMV - are financial partners. 

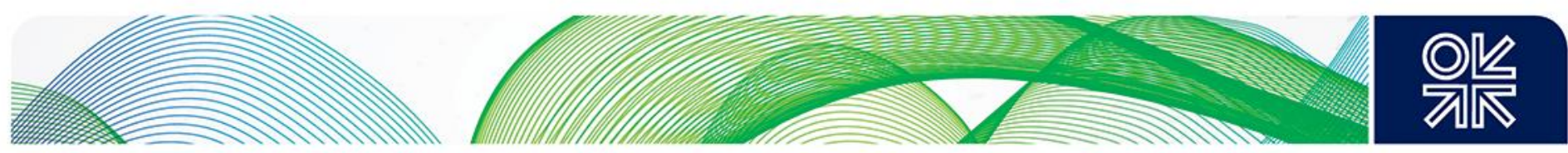

\subsubsection{The EC amendment proposal: existing and new pipelines potentially affected}

Should the proposal be adopted, the amended Third Gas Directive would become applicable to all existing and new pipelines coming to the EU from outside, up to the border of EU jurisdiction, irrespective of whether adjacent connected pipelines inside the EU are regulated. This means that the Directive would apply inter alia to the pipelines arriving to the EU from Norway ${ }^{505}$, Russia, Algeria, and Libya, as well as from the Caspian region (Table 5). As explained above, it is possible - although not certain - that the amended Directive could enter into force in 2019 in other words before any of the following new pipelines are scheduled to become operational during the 2020-2 period, for example:

- Nord Stream 2 - by the end of 2019,506

- TAP - during 2020 and by the end of 2020 at the latest,, 507

- the Baltic Pipe, including the Norwegian tie-in - by October 2022.

Any new pipelines not completed by the amended Directive's entry into force - as is likely to be the case with Nord Stream 2 and TAP - would not be able to apply for a derogation under Art. $49^{*}$ but would be eligible to apply for an exemption under Art. $36^{*}$.

Interestingly, in a document accompanying the amendment proposal, the EC argues that existing infrastructure could not request an exemption (due to being unable to meet the 'risk' criterion of Art. 36.1. $b^{\star 508}$ ). However, this argument is undermined by the fact that the 2016 OPAL exemption was granted five years after the OPAL pipeline stated operation (Section 3.2) and by the fact that the EC itself has publicly encouraged South Stream to apply for an exemption in 2014, despite the fact that the latter had already taken FID in November 2012 (Section 3.5). Most recently, this argument has been undermined by the fact that the interconnector Greece-Bulgaria (IGB), which has taken an FID in December 2015, was granted an exemption by the Greek and Bulgarian regulatory authorities in June 2018. 509 Furthermore, it is also undermined by the fact that the Directive, which became part of the acquis in March 2011, allows for exempting 'new' infrastructure, with 'new' being defined as 'not completed by 4 August 2003', thus suggesting the possibility of exempting infrastructure that already existed when the Directive became law.

Any existing pipelines or new pipelines completed before the amended Directive's entry into force including those completed before August 2003 - would be able to apply for a derogation under Art. 49* in their first member state of entry, where they may (or may not) receive a derogation at the discretion of that member state. The member states concerned would include:

- Finland (a direct cross-border pipeline from Russia),

- Poland (the Yamal-Europe and the Ukrainian transmission systems),

- Slovakia (the Ukrainian transmission system),

- Hungary (the Ukrainian transmission system),

- Romania (the Ukrainian transmission system),

- Germany (Nord Stream 1, Nord Stream 2 if completed before the amended Directive's entry into force),

- the UK ${ }^{510}$ (IUK, BBL, Moffat),

- Spain (Pedro Duran Farrel and Medgaz),

\footnotetext{
505 Norway is a non-EU EEA country.

${ }^{506}$ It is possible that Nord Stream 2 could be delayed should there be a delay in permit granting by Denmark (all other relevant countries including Russia, Germany, Sweden, and Finland have already granted the necessary permits).

${ }^{507}$ This is the time period specified in the EC TAP Exemption Decision (EC, 2013). It is possible that TAP could be delayed given that it was under review by the new Italian government as of May 2018

${ }^{508}$ In other words 'the level of risk attached to the investment must be such that the investment would not take place unless an exemption was granted'.

509 EC (2018c)

${ }^{510}$ As soon as the UK is not an EU member state.
} 

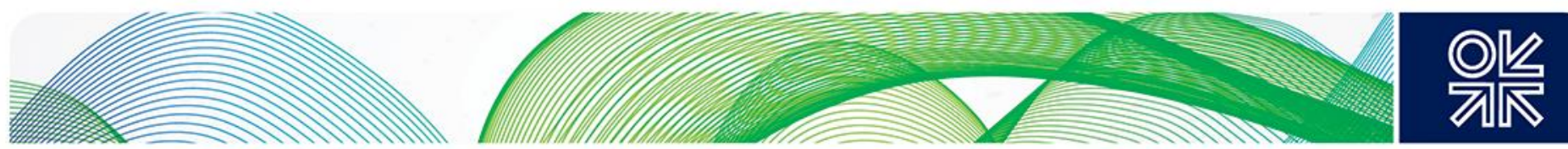

- Italy (Enrico Mattei and Green Stream),

- Greece (TANAP),

- Italy (TAP).

Table 5: Existing and new pipelines from third countries potentially affected by the amendment of the Gas Directive

\begin{tabular}{|c|c|c|}
\hline $\begin{array}{l}\text { Supplier } \\
\text { countries }\end{array}$ & Existing pipelines & New pipelines \\
\hline Norway & $\begin{array}{l}\text { The Norwegian offshore pipeline network (owned } \\
\text { by Gassled and operated by Gassco) through } \\
\text { which almost all Norwegian pipeline gas arrives } \\
\text { at receiving terminals in Germany, Belgium, } \\
\text { France, and the UK (no transit). }\end{array}$ & $\begin{array}{l}\text { The offshore pipeline connecting } \\
\text { the Europipe ll pipeline (part of the } \\
\text { Norwegian offshore pipeline } \\
\text { network) with the receiving } \\
\text { terminal in Denmark (in other } \\
\text { words the Norwegian tie-in which } \\
\text { is one part of the Baltic Pipe } \\
\text { project, which would transport } \\
\text { Norwegian gas across Denmark } \\
\text { to Poland via an offshore } \\
\text { interconnection between the two, } \\
\text { (Section 3.4); }\end{array}$ \\
\hline Russia & $\begin{array}{l}\text { The Yamal-Europe pipeline via which Russian } \\
\text { gas arrives at Poland (Belarus as a transit } \\
\text { country); } \\
\text { The Gazprom-Transgaz Belarus pipeline via } \\
\text { which Russian gas arrives at Poland and } \\
\text { Lithuania (Belarus as a transit country); } \\
\text { The Ukrainian pipeline network via which Russian } \\
\text { gas arrives at Poland, Slovakia, Hungary, and } \\
\text { Romania (Ukraine as a transit country); } \\
\text { The pipeline via which Russian gas arrives at } \\
\text { Finland (no transit). } \\
\text { Nord Stream } 1 \text { pipelines via which Russian gas } \\
\text { arrives at Germany directly (no transit). }\end{array}$ & $\begin{array}{l}\text { Nord Stream } 2 \text { pipelines via which } \\
\text { Russian gas is envisaged to arrive } \\
\text { at Germany directly by } 2020 \text {. }\end{array}$ \\
\hline Algeria & $\begin{array}{l}\text { The Enrico Mattei pipeline via which Algerian } \\
\text { pipeline gas arrives at Italy (Tunisia as transit } \\
\text { country); } \\
\text { The Pedro Duran Farrell pipeline via which } \\
\text { Algerian pipeline gas arrives at Spain (Morocco } \\
\text { as a transit country). } \\
\text { The Medgaz pipeline via which Algerian pipeline } \\
\text { gas arrives at Spain directly. }\end{array}$ & \\
\hline Libya & $\begin{array}{l}\text { The Green Stream pipeline via which Libyan gas } \\
\text { arrived at Italy (no transit). }\end{array}$ & \\
\hline $\begin{array}{l}\text { Caspian } \\
\text { region } \\
\text { (Azerbaijan) }\end{array}$ & & $\begin{array}{l}\text { TANAP via which Azeri (and } \\
\text { potentially other) gas is planned to } \\
\text { arrive at Greece (from Turkey). } \\
\text { TAP via which this gas is planned } \\
\text { to arrive at Italy (via TANAP, via } \\
\text { Greece and Albania) in } 2020 \text {. }\end{array}$ \\
\hline
\end{tabular}

Source: author's compilation; NB this list is illustrative and is not meant to be exhaustive.

Although the EC has emphasized that in practice the amendment would only have an impact on offshore pipelines and sought to downplay its potential impact on onshore pipelines to and from third countries, stating that 'core principles of the regulatory framework set out in the Gas Directive' 'have been 

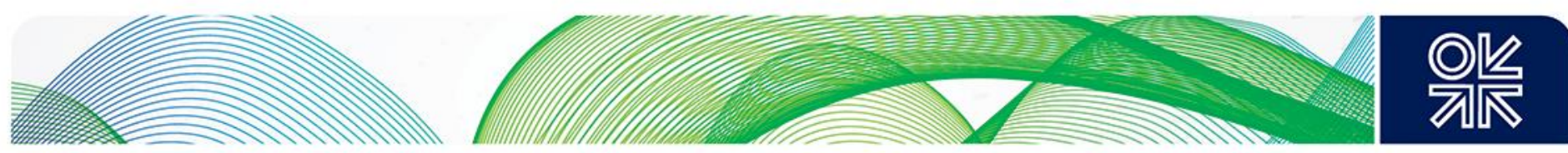

consistently applied' to the latter, ${ }^{511}$ the amendment might have an impact on onshore pipelines as well. This is because although it is clear that in the case of an onshore pipeline EU jurisdiction ends right at an EU member state's border, there is a stretch of pipeline located between the state border and the first interconnection point with the EU's domestic transmission system. Should the amended Directive apply to it, it could potentially enable the EC to approach a third country to (re-)negotiate an IGA with it - for example in respect of the Yamal pipeline or the Ukrainian gas transmission network.

It would appear that the derogation regime would not be relevant for upstream pipelines (such as the Norwegian system, connecting the offshore production sites with EU member states) as it only envisages waivers from Art. 9, 10,11,32, and 41(6, 8, 10), but not from Art. 34 which governs negotiated access to upstream pipelines. ${ }^{512}$ Notably, the amendment proposal added a new provision in Art. 34, saying that 'where the network concerned is covered by at least one member state and at least one third country', 'the member states concerned shall consult each other and shall consult the third countries concerned, with a view of ensuring, as regards the network concerned' that the provisions of the Directive 'are applied consistently up to the border of Union jurisdiction' (Art. 34.4) thus suggesting the application of Art. 34 on regulated access to upstream pipelines to the Norwegian system. However, the new Norwegian upstream pipelines - in other words those not completed before August 2003 - would be eligible for an exemption under Art. 36 which envisages waivers from Art. 34.

\subsubsection{The EC amendment proposal: the way forward}

On 21 March 2018 the European Parliament's committee on Industry, Research and Energy (ITRE committee) approved the EC proposal by a majority of 41 votes, with 13 being against and 9 abstaining. ${ }^{513}$ $A$ request made to postpone the vote until an impact assessment of the $E C$ proposal had been made, was rejected. ${ }^{514}$ Notably, the ITRE committee has made substantial changes to the EC proposal (The ITRE proposal). ${ }^{515}$

In particular, the ITRE proposal stipulates stricter rules on exemptions and derogations by 'tightening up the conditions that must be met before exceptions can be made'; it imposes a five-year maximum fixed time limit for exemptions, but not for derogations (whereas the EC proposal did not stipulate any specific time limit for either), and it increases EC involvement in deciding derogations (whereas the EC proposal did not spell out the EC's role in deciding derogations). ${ }^{516}$ Furthermore, the ITRE proposal appears to have excluded the possibility for any new infrastructure apart from infrastructure starting operation after 1 January 2019 to apply for an exemption from Art. 36*.

Interestingly, the ITRE proposal also suggested involving in the exemption and derogation decisionmaking process not only those member states where the pipelines from third countries would be located - as stipulated by the EC proposal - but also those member states whose markets could be affected by these pipelines. Furthermore, in a move clearly directed against pipelines coming from Russia (which has been subject to general EU economic sanctions since 2014), the ITRE committee has called for sanctions against third countries to be taken into account, stating that 'when deciding upon exemptions for new pipelines entering the EU, the Commission should consider any EU restrictive measures, such as economic sanctions, imposed on that third country'. ${ }^{517}$

The EC proposal and the ITRE proposal form the basis for the negotiations on amending the Third Gas Directive in the Council. The ITRE proposal could have only become the basis for such talks if a vote at a European Parliament plenary had yielded a simple majority in its favour or else if no vote had been held at all. A group of members of the European Parliament (MEPs) from several party groups - namely the

\footnotetext{
${ }^{511}$ EC (2017d), p. 5.

512 'Norway adopts EIU energy rules, averting break with bloc', Reuters, 22 March 2018. (Journal articles)

513 EP (2018a).

$514 \operatorname{EP}(2018 \mathrm{c})$

515 EP (2018b), ITRE Proposal.

516 ITRE Proposal, see EP (2018b).

517 EP (2018a)
} 

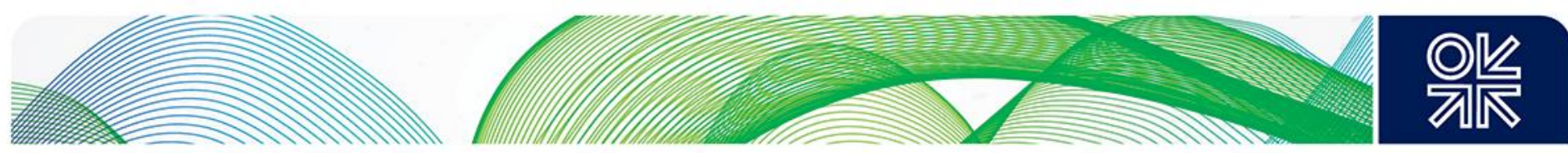

GUE/NGL and ENF - had initially filed a request, reaching the required threshold of one-tenth of the Parliament's members (77 signatures), for a plenary vote to be held on 19 April 2018. However, the motion was subsequently withdrawn overnight, which meant that there would be no vote on the ITRE proposal, thus clearing the way for negotiations with the Council on the basis of the ITRE proposal. The reasons for withdrawal are unclear, but it is possible that it may have been orchestrated to avoid the plenary vote, due to the lack of certainty as to whether sufficient support for the ITRE proposal would have been achieved. Had the vote been held and a simple majority had not been won, the ITRE proposal would have been rejected and placed on the agenda for the following Parliament's session on 2-3 May 2018, where amendments could have been made to the proposal before its adoption as the basis for a mandate for negotiations with the Council. The ITRE committee might consider the absence of a plenary vote as a positive factor enabling it to preserve its initial proposal as the basis for negotiations with the Council, while also avoiding a delay in the process of amending the Directive. However, this may well have been a Pyrrhic victory because the ITRE proposal is far less likely to be acceptable to many member states in the Council than the EC proposal.

As far the Council is concerned, the support of a qualified majority (QM) of Member States would be required for the proposal to be adopted. In line with the existing voting procedure ('the double majority rule') a QM is reached if the following two conditions are met:

(a) 55 per cent of EU member states vote in favour, and

(b) the proposal is supported by member states representing at least 65 per cent of the total EU population.

As this paper is completed, no decision has been made by the Council on the proposal, but it is understood to have been discussed in the latter's working groups. The Council's legal service has also prepared several legal opinions at the request of member states on the different aspects of the proposal, pointing out the proposal's possible inconsistencies with international law (for example UNCLOS), particularly in respect of including an EEZ within EU jurisdiction. ${ }^{518}$ Thus it is not clear whether the proposal will eventually be adopted by the Council. The initial reaction of member states to the proposal, especially those in territories in which a first interconnection point with pipelines from third countries is, or will be, located, suggests that they might be wary. For example, Italy and Spain might not be enthusiastic due to their existing import pipelines arriving from Algeria (which is not an EU member state and whose regulatory regime is significantly different from the acquis). Also, Germany, Austria, France, ${ }^{519}$ and the Netherlands, whose companies are financial partners in Nord Stream 2, regulatory treatment of which could be negatively impacted by the proposal, might not be enthusiastic either. Even the UK could be wary, although not necessarily because of the impact on Nord Stream 2 (although Shell, the Anglo-Dutch company, is a financial partner in Nord Stream 2, the UK's political position towards Nord Stream 2 has been lukewarm at best ${ }^{520}$ ) but because the amended Directive might render more powers both to the member states in which UK gas interconnectors arrive (the Netherlands, Belgium, and Ireland), and also to the $\mathrm{EC}$, in respect of derogations and exemptions. This would not be a desirable outcome at a time when the UK is leaving the EU and does not want to see its negotiating power over the latter weakened and future regulatory autonomy constrained. It is thus argued here that the EC would find it very difficult - albeit not impossible - to secure the required QM for the Directive to be amended. However, it cannot be ruled out that the Council might make a political decision to support the proposal. Should the proposal be adopted, the chances for the EC request for a Nord Stream 2 negotiating mandate to be granted would correspondingly increase. Conversely, if the amendment proposal is not adopted, the changes for getting a Nord Stream 2 mandate would weaken significantly.

\footnotetext{
${ }^{518}$ Council Legal Service's Opinion - UNCLOS (see Additional documents).

${ }^{519}$ French Senate Note (see Additional documents).

${ }^{520}$ Although the House of Commons European Scrutiny Committee report suggests that at present the UK is broadly supportive of the Gas Directive amendment, questions have been raised in respect of its potential impact on the future UK regulatory autonomy, see House of Commons Report.
} 

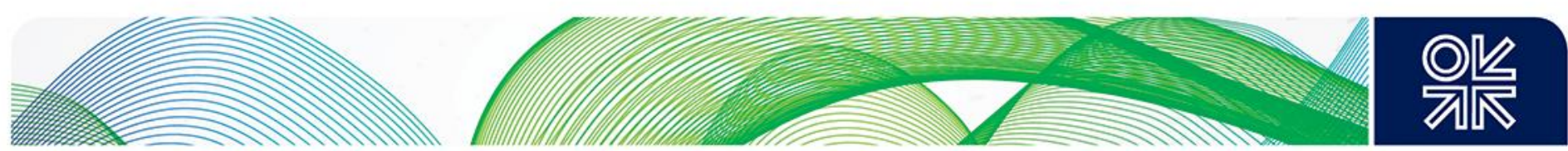

\section{Conclusions}

While the EC amendment proposal is mostly concerned with the regulatory treatment of pipelines coming to and from third countries, it could have an impact on regulatory treatment and the degree of utilization of new pipelines inside the EU which are - or are planned to be - connected to pipelines from third countries. It is beyond doubt that the EC's main rationale for advancing the amendment proposal was to:

(a) acquire a tool allowing it to have an impact on the regulatory treatment of Nord Stream 2, and

(b) strengthen its position in respect of securing a mandate from the Council to negotiate a regulatory framework for Nord Stream 2 with the Russian government.

If the EC were to secure the mandate, it would be able to approach the Russian government with a proposal to negotiate a bilateral regulatory framework governing the operation of Nord Stream 2. The EC's view is that such framework should incorporate:

'the core principles of international law and European Union law on energy, taking into account at the same time the impact of the pipeline's operation on the current gas supply from the Russian Federation to the European Union, including through Ukraine'.

If adopted, the amended Directive would only apply to the EU (Germany) - but not to the Russian - end of the Nord Stream 2 pipeline. Nonetheless, it would enable the EC to approach the Russian government with a suggestion to agree a mutually acceptable regulatory framework in respect of the entire pipeline in line with the aforementioned EC position.

The EC appears to believe that the amended Directive would provide it with leverage over the Russian government to agree on such a framework by enabling the EC (together with the German regulatory authority) to restrict the ability of Gazprom (which has a monopoly on pipeline gas exports, ${ }^{521}$ ) to use capacity in Nord Stream 2, on the basis of the argument that its German end would not be compliant with the amended Directive. However, the strength of the EC position is disputable, not least because Nord Stream 2 is planned to be connected to, and provide gas for, the fully regulated EUGAL pipelines, all of whose marketable capacity has already been allocated under legally binding contracts for 25 years. Given that neither the EC nor the German regulatory authority raised any objections in respect of the 'more capacity' procedure under which EUGAL capacity was allocated, the introduction of a capacity cap on Nord Stream 2 (which would impact the degree of EUGAL utilization) would be extremely awkward, as it would be in direct conflict with EUGAL contracts. The strength of the EC's position is further undermined by the fact that the Directive amendment (if it goes ahead) would be made after Nord Stream 2 had been initiated, thus running contrary to the principle of legal certainty, which in turn could lead to a protracted legal battle with a highly uncertain outcome.

Nonetheless, despite a questionable negotiating position and potential legal action, the EC would still likely attempt to use the amended Directive and the mandate - should either of these secure the necessary support from the Council, over which significant uncertainty remains - to minimize the impact of Nord Stream 2 on the utilization of the Ukrainian system, in order to advance its political position, aimed at preservation of significant Russian gas transit across Ukraine.

${ }^{521}$ Due to being the owner of the Russian Unified Gas Supply System (UGSS) under Russian law, see Yafimava (2015). 

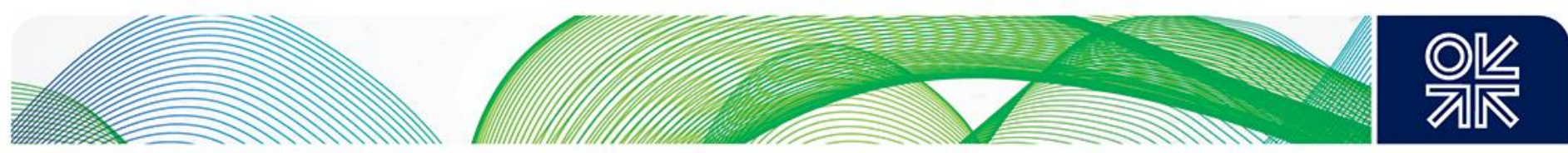

\section{Summary and Conclusions}

The Third Energy Package (TEP), adopted in March 2009 and entering into force in September 2011, established general rules for the regulatory treatment of existing and incremental pipeline capacity in the $\mathrm{EU}$, and in particular for provisions on transmission system operator (TSO) unbundling, regulated third party access (TPA), and regulated tariffs. In addition to the general rules established by the TEP, the first Capacity Allocation Mechanisms Network Code (CAM NC), adopted in 2013, provided a set of detailed regulatory procedures for existing (but not incremental) pipeline capacity. Four years later, the amended CAM NC and the Tariffs NC, both of which entered into force on 6 April 2017, provided a set of detailed regulatory procedures governing construction, allocation, and payment for incremental (as well as existing) pipeline capacity. As no specific procedures had previously existed for incremental capacity at the EU level, all new pipeline projects, initiated prior to the entry into force of CAM NC and Tariffs NC, were developed and governed by a patchwork of exemptions (TAP and OPAL pipelines), open season (OS) procedures (EUGAL pipeline), and bilateral intergovernmental agreements (IGAs) (Yamal-Europe and South Stream pipelines).

\section{Capacity Allocation Mechanisms Network Code (CAM NC)}

The CAM NC applies to all incremental capacity projects initiated prior to its entry into force unless the national regulatory authorities had granted the applicable approvals for capacity allocation before 1 August 2017 (Section 2.1). Given the long lead times associated with the development of any significant new cross-border pipeline project in the EU - at least five years - it is clear that no significant incremental capacity can be built before or by 2020 under the CAM NC. In fact, most incremental capacity that is planned to have been built by 2020 was initiated prior to the CAM NC entry into force and proceeded under alternative regimes (such as exemptions and OS procedures). However, incremental capacity projects initiated before the CAM NC entry into force, for which no applicable approvals had been given by 1 August 2017 and all incremental capacity projects initiated after the CAM NC entry into force, will have to be built under the CAM NC rules, unless an exemption is granted. This will lead to a situation when by, and after, 2020 several new pipelines will have been built in the EU in which capacity will have been allocated and contracted under different regulatory regimes (these include the CAM NC, exemptions, OS procedures, and IGAs). This raises a question about their future regulatory treatment and, in particular, the degree of consistency between the regulatory regime provided by the CAM NC and by the other frameworks.

The CAM NC establishes a detailed procedure for conducting an incremental capacity process; this consists of a market demand assessment, design, and approval and publication phases, in which the Transmission System Operator (TSO) plays a central and exclusive role. In respect of the market demand assessment, the CAM NC stipulates both the timing and the content of non-binding demand indications, as well as the same two aspects of the market demand assessment report. It stipulates, in particular, those criteria on which the demand assessment is to be developed, as well as the information that must be contained in the demand assessment report, including a conclusion on whether to initiate the project. In the event that the assessment report identifies demand for a project, the CAM NC requires a design phase. This stipulates the preparation of technical studies for the design of the project and offer levels, and is followed by a public consultation on the draft proposal. It specifically requires the consultation procedure to include an assessment of 'whether the incremental capacity is likely to result in sustained, significant decrease in the utilization of other non-depreciated gas infrastructure in the same and adjacent entry-exit systems or along the same gas transport route'. The CAM NC also sets an economic test for assessing an incremental capacity project and this includes the factors to be taken into account for setting its f-factor. The code also outlines a procedure for regulatory approval of an incremental capacity project, specifying the roles of the national regulatory authority (NRA) and the Agency for the Cooperation of Energy Regulators (ACER). 

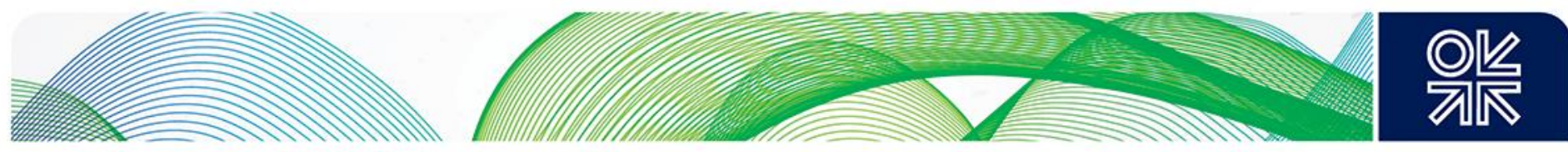

The CAM NC's Alternative Allocation Mechanism (AAM)

The regulatory treatment of incremental capacity stipulated by the CAM NC, will be used as a benchmark against which the regulatory treatment of any new pipeline project, developed under other frameworks, will be measured. While the CAM NC established auctions as the default method for allocation of existing and incremental capacity, it also allowed TSOs to use an alternative allocation mechanism (AAM). An AAM is to be designed on a case-by-case basis by a TSO and is to be approved by the NRA. The CAM NC did not specify the nature of the AAM, apart from stating that it must be 'transparent and nondiscriminatory', and that it 'may allow for the prioritization of booking duration or bids for higher amounts of capacity for a yearly standard capacity product'. In so doing, the CAM NC implied that OS procedures - as long as they are transparent and non-discriminatory - could continue to be used. The CAM NC also did not stipulate the conditions under which a TSO would have to use an AAM rather than an auction. It only stated that the AAM can be used where it is 'reasonable' to conclude - on the basis of a market demand assessment or a subsequent public consultation - that auctions are 'not suitable', thus leaving a decision to the TSO concerned. However, the CAM NC made it clear that an AAM cannot be applied unless a project involves more than two entry-exit systems (with bids requested along several IPs) and unless bids with a duration of more than one year are requested. Should the TSO decide that auctions are not suitable, the CAM NC leaves it to the TSO to design an appropriate AAM and for the national regulatory authority to decide whether to approve it. Thus, under the CAM NC, both the TSOs and NRAs have significant discretion over whether or not to apply an AAM (even if the project in question involves more than two entry-exit systems and long-term bids) and what its nature should be.

The Baltic Pipe (Section 3.4) is the first significant incremental capacity project being developed under the CAM NC. It used an AAM with an auction preceded by an OS, which can be defined as a "hybrid auction'. Given that the CAM NC only allows for the AAM to be used if a project involves more than two entry-exit systems, the usage of an AAM for the Baltic Pipe - which only involves two entry-exit systems (Poland and Denmark, as Norway cannot be considered an entry-exit system due to not being an EU member state) - would appear not to have been permissible unless the applicable approval had been granted by the regulators prior to 1 August 2017. Such approval was granted by the Polish regulator on 27 March 2017.

The choice between employing an auction or an AAM for capacity allocation is important, as it has a significant impact on the project's economics due to the different regulatory provisions envisaged under each mechanism, inter alia in respect of capacity reservation quotas and booking horizons. For example, whereas the CAM NC prescribes a reservation quota of at least 10 per cent to be applied to incremental capacity to be offered no earlier than the annual quarterly capacity auction to prevent capacity hoarding and market foreclosure, it sets no upper limit where an auction is used, but states that a quota cannot be higher than 20 per cent when employing an AAM. Also, whereas the CAM NC stipulates that the incremental capacity can be allocated for 15 years ahead, it allows for a booking horizon to be 'exceptionally' extended (provided an economic test could not be passed otherwise) by up to five additional years where the AAM is used, thus allowing for a 20 year booking horizon. However, where auctions are used, the time horizon cannot be extended beyond 15 years.

This paper concludes that although the CAM NC provides a legally binding set of detailed procedures for incremental capacity, it has left the TSOs and NRAs to decide on important specificities of these procedures, particularly in respect of capacity allocation methods. At the same time, the code has somewhat limited their room for manoeuvre by stipulating a detailed procedure for market demand assessment and design of the economic test, thus creating a firm framework within which these decisions must be taken.

\section{The Exemption Procedure}

Most European pipeline infrastructure which became operational after the TEP became part of the acquis in 2011, was built under the Exemption Regime - Art. 36 of the Third Gas Directive and Art. 22 of the Second Gas Directive previously - according to which 'major new gas infrastructure' could be exempted, upon request, from various provisions of these Directives, including those on regulated third-party access 

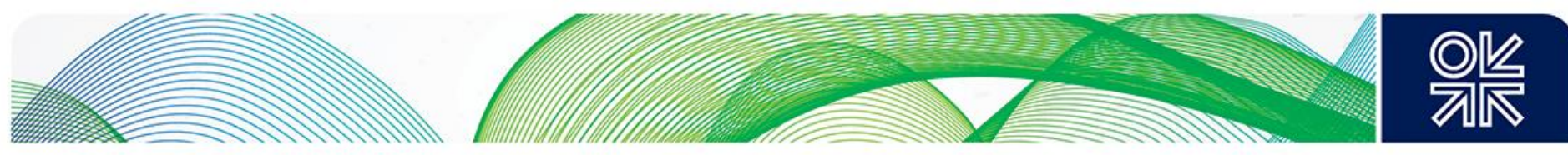

(TPA), ownership unbundling (OU), and regulated tariffs (Section 2.2). An exemption can only be granted for a limited period of time (although neither the Third nor the Second Gas Directive specified the limit). Whereas a decision to grant an exemption is made by the NRA (competent authority) - provided that the project has met the exemption criteria - European Commission (EC) approval is necessary for the exemption to become effective, as it has the power to require the regulatory authority to amend or withdraw the Exemption Decision. The exemption criteria stated inter alia that infrastructure, in respect of which an exemption is sought, must 'enhance' and 'not be detrimental' to competition. However, these criteria are defined very broadly and contain no quantitative dimension, thus suggesting a significant degree of discretion on the part of the NRAs and the EC in respect of granting an exemption. Notably, exemptions were not automatic and could be refused both by the NRA and the EC. However, in practice the majority of new gas pipeline and LNG projects which applied, received exemptions.

As, under the Exemption Regime the NRAs are obliged to 'decide upon the rules and mechanisms' for management and allocation of incremental capacity (these rules are absent from the Third, and also from the Second, Gas Directives) the EC had intended to use the Exemption Regime as a temporary regulatory 'patch' that could be used for the development of incremental capacity until legally binding EU regulatory procedures were established. Thus, when the CAM NC - which established such procedures - entered into force in April 2017, the rationale for using the Exemption Regime for incremental capacity was weakened. Therefore, logically, the usage of the Exemption Regime should be expected to decline in the future - except, perhaps, in respect of genuinely major and very expensive new infrastructure - with exemptions to be gradually phased out.

However, the 2017 EC proposal to amend the Third Gas Directive (see below and Section 4.3), in order to make it applicable to pipelines to and from third countries, if adopted, would increase the importance of the Exemption Regime - but as this paper is finalized, significant doubts remain concerning the acceptance of this proposal. These pipelines would also be able to apply for an exemption (as well as for a derogation) from certain regulatory provisions of the Directive. Regulatory principles governing these pipelines would be established as part of bilateral agreements concluded between either the EC or an EU member state government on one hand, and a third-country government on the other. However, the EC proposal runs counter to its well-established policy of phasing out exemptions, once legally binding rules and procedures for incremental capacity are in place, with the aim of establishing a level playing field for all pipelines - existing and new.

By comparing the OPAL and the TAP Exemption Decisions (Sections 3.2 and 3.3), this paper demonstrated that the application of the Exemption Regime could result in significantly different regulatory treatment being awarded to new pipelines, with some pipelines (TAP) being treated significantly more favourably than others (OPAL). As the Exemption Regime under the existing Third Gas Directive allowed the EC to grant differing regulatory treatment to intra-EU pipelines, the exemption and derogations regimes under the amended Directive could enable the EC to do the same in respect of pipelines to and from third countries. This would run contrary to the EC position that its proposed amendment is required to establish a level playing field for all such pipelines. Our conclusion is that the EC proposal to amend the Third Gas Directive threatens to undermine the comprehensive regulatory framework based on the acquis - including the TEP and the NCs - which has been constructed over several decades.

\section{Projects of Common Interest (PCI) framework}

In addition to an exemption, many pipeline and LNG infrastructure projects have been included on the EU lists of Projects of Common Interest (PCI) (Section 2.3); these include the TAP and the Baltic Pipe projects (projects considered necessary to implement specific energy infrastructure priority corridors and areas, as determined by the Infrastructure Regulation). In order to be granted PCI status, a project must meet all of the general, and contribute significantly to at least one of the specific, criteria set out in the Infrastructure Regulation. Although the PCl criteria are very similar to the exemption criteria (it would be difficult for a project to be granted an exemption but not $\mathrm{PCl}$ status and vice versa), $\mathrm{PCl}$ status does not relieve a project from its obligation to be compliant with the acquis in its entirety - unlike an exemption, under which a waiver from certain provisions of the acquis could be sought. 

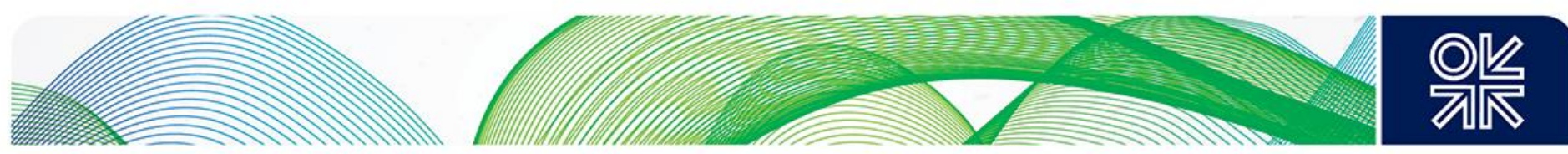

$\mathrm{PCl}$ status, although not constituting a regulatory framework per se, provides for a project to receive favourable regulatory treatment, including, in particular, accelerated permitting (limiting the time period to four years and three months), rules for cross-border cost allocation, and eligibility for EU financial assistance for studies, financial instruments, and works. In order for a project to be eligible for such assistance for works, the project must provide 'significant positive externalities' (such as inter alia security of supply) to be determined on the basis of cost-benefit analysis, be in receipt of a cross-border cost allocation decision, and be 'commercially not viable'. The EC has the final say on a project's inclusion on the EU PCI list - just as it has a final say on an exemption - thus suggesting that without its approval the project will not be granted $\mathrm{PCI}$ status and hence will not be eligible for EU financial assistance.

This paper concludes that the adoption of the CAM NC is unlikely to have an impact on the importance of $\mathrm{PCl}$ status - as the latter is complementary to the former - and it will continue to be used actively. This is not least because $\mathrm{PCl}$ status enables an infrastructure project to apply for EU financial assistance (citing, for example, security of supply concerns); it could thus potentially enable construction even if the project is not commercially viable on its own.

\section{The Open Season (OS) Procedure and Guidelines (GGPOS)}

Some European pipeline infrastructure projects have been developed under an open season (OS) procedure based on the general non-legally binding guidance provided by the Guidelines on Good Practice for Open Seasons (GGPOS), without having either an exemption or PCI status. The GGPOS were developed by European regulators in May 2007 - a few years before the TEP was adopted in July 2009 and became law in March 2011 - in response to an EC request to provide clarity on the role of OS procedures for new infrastructure. European regulators, who had long argued that the OS procedure lacked transparency and coordination, intended the GGPOS to improve the situation by providing adequate guidance, particularly in respect of capacity allocation and congestion management.

The GGPOS outlined a 'classic' OS procedure consisting of two phases:

- a non-binding phase for market demand assessment, and

- a legally binding phase for submission of binding bids.

During the first phase, a sponsor of the new infrastructure assesses how much capacity the market needs and under what terms; during the second phase the sponsor offers this capacity to the OS participants who - if satisfied with the offer - sign binding agreements. Just as with the CAM NC, the GGPOS did not prescribe any specific method for capacity allocation, stating that 'different methods' can be used; it requested any such method to be 'transparent and non-discriminatory', while placing an obligation on the NRA to verify that this was the case. Also, as with the CAM NC, which places an emphasis on continued utilization of existing capacity, the GGPOS required the usage of existing capacity to be prioritized, stating that 'full use should be made of existing infrastructure via the application of appropriate congestion management mechanisms' before initiating an OS, and considering whether new investment is needed. Unlike the CAM NC (which made the TSO the only player able to initiate an incremental capacity process), however, the GGPOS defined several categories of players which would be able to initiate an OS process, including the operator of the existing infrastructure, the NRA, the government, outside investors, and shippers.

\section{The 'More Capacity' OS Procedure and the CAM NC}

The EUGAL pipeline, which was initiated in 2015 - two years before the 2017 CAM NC's entry into force - was developed under the 'more capacity' procedure. This procedure appears to have been modelled closely on both the GGPOS and the available working drafts of the (then under development) CAM NC. In 2014, the process of amending the CAM NC 2013 (which had been in force since November 2013 but contained no regulatory procedures for incremental capacity) had been launched, with a view to developing a new chapter for incremental capacity. This process was finalized in 2017 with the adoption of the amended CAM NC, which has been in force since April 2017 (Section 2.1). 

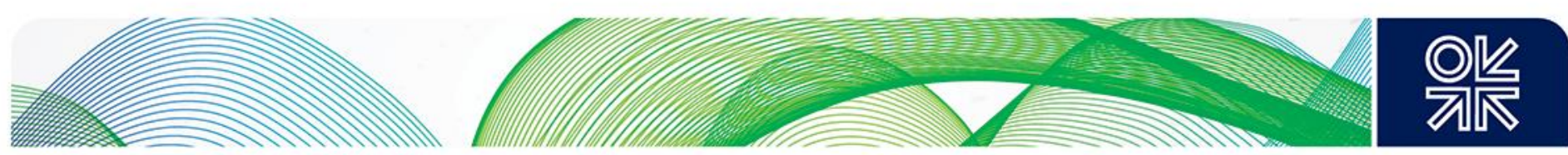

The 'more capacity' procedure consisted of two phases:

- a non-binding phase for determining market demand for new capacities, and

- a binding phase for allocating these capacities.

This is consistent with the GGPOS. During the first phase, the 'more capacity' TSOs conducted a market survey to estimate future demand for capacities at the boundaries of the GASPOOL market area. They asked interested parties to submit non-binding expressions of interest during an eight week period in August-October 2015 (consistent with the CAM NC which also stipulated an eight week period for expressing the demand for incremental capacity). In December 2015 the 'more capacity' TSOs published a demand assessment report, based on the results of the survey (also consistent with the CAM NC).The 'more capacity' report provided information on the aggregated non-binding demand indications made in respect of each of GASPOOL's boundaries, an assessment of the expected amount, direction, and duration of demand for incremental capacity at the IPs with each adjacent entry-exit system (or interconnector), and a conclusion that several technical studies will be conducted for incremental capacity projects. Thus, the content of the 'more capacity' report was broadly in line with the content of the demand assessment report mandated by the CAM NC. There were some differences, for example, in respect of the capacity booking horizon. The 'more capacity' report suggested that the capacity would be offered for a period of up to 2037 (on the GASPOOL border with Poland) and up 2041 (on the GASPOOL border with Russia, the Czech Republic, the Netherlands, and NCG) thus suggesting a booking horizon of 20 years. This was not consistent with the CAM NC 2013, in force at the time, under which the maximum booking horizon was 15 years. However, when the 'more capacity' report was prepared, there was no certainty in respect of the maximum booking horizon for incremental capacity under the amended code.

Following the conclusion of the demand assessment and completion of technical studies, the 'more capacity' TSOs conducted a four week public consultation on the draft incremental capacity projects in August-September 2016, the results of which were used to define the final offering levels of incremental capacity. The consultation centred around the preliminary agreement between the shipper and each of five 'more capacity' TSOs (confirming that the new capacities will be offered and requested in the annual auction) and the supplementary terms and conditions (STC). The 'more capacity' public consultation procedure appears to have been broadly in line with the CAM NC, certainly in respect of its duration, as the latter stipulated that the consultation must run at least for one, and at most for two, months. It is not clear whether the consultation covered the issue of 'whether the incremental capacity is likely to result in a sustained, significant decrease in the utilization of other non-depreciated gas infrastructure in the same and adjacent entry-exit systems, or along the same gas transport route', as required by the CAM NC. However, given that the 'more capacity' TSOs prepared technical studies in respect of those incremental capacity projects which met at least one of the following criteria:

(a) requested capacity is higher than technically available capacity, and

(b) requested capacity is higher than potentially available existing capacity,

this suggested that the existing technical capacity would not be underutilized should the aforementioned incremental capacity projects be developed. This, in turn, suggests that the 'more capacity' procedure is consistent with the GGPOS and the CAM NC, both of which place a significant emphasis on the utilization of existing capacity prior to the development of incremental capacity.

Once the consultation was completed, the 'more capacity' TSOs defined the final offer levels and discussed the conditions for holding auctions as well as economic tests with the German regulatory authority. In February 2017, the 'more capacity' TSOs informed the market players that the auctions would be held in March 2017, while also providing information on the procedure, the offering levels, and the expected minimum demand for positive economic tests; the final offering levels were published on the PRISMA website. Capacity has been auctioned as of the end of 2019 until the end of 2039, thus tallying with the 20 year booking period. This is consistent with the CAM NC, which required that there must be an announcement one month in advance of an auction date. Notably, 10 per cent of incremental capacity 

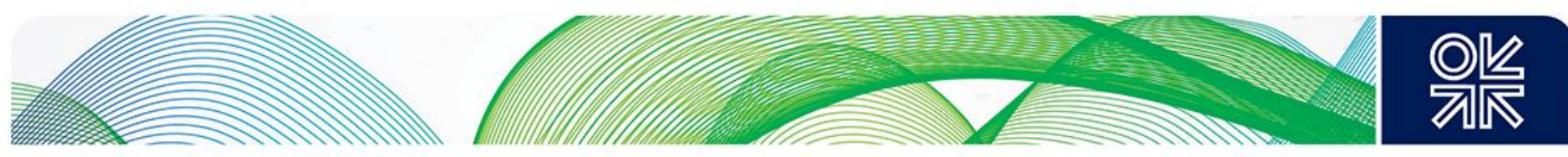

was set aside for short-term booking in future quarterly and shorter-term auctions, and another 10 per cent was set aside for mid-term bookings in the first five gas years immediately following the auction. This is consistent with the CAM NC, which stipulates that at least 10 per cent of incremental capacity is to be set aside and not offered earlier than the annual quarterly auction. The auctions for incremental capacities were held in parallel with the auctions for existing capacities, with incremental capacities allocated for a period extending up to 2039 - a booking horizon of 20 years. This is consistent with the amended CAM NC, which stipulated a 15 year booking horizon, but allowed this to be (exceptionally) extended by a further five years (where the AAM is used and the economic test cannot be met otherwise).

Thus, by the time the CAM NC entered into force in April 2017, the 'more capacity' procedure had been completed, with legally binding auctions for existing and incremental capacity being held in March 2017. The usage of the 'more capacity' procedure - which is essentially a 'hybrid' auction procedure whereby an auction is preceded by an OS - prior to the CAM NC's entry into force was fully legitimate when no legally binding framework existed at the EU level. It is worth noting that although it is understood that no regulatory approvals for 'more capacity' allocation procedures were required under German and EU law at the time, the 'more capacity' TSOs were closely coordinating with the German regulatory authority during all stages of the process.

The 'more capacity' procedure, under which the capacity in EUGAL was allocated, is consistent with the various drafts of the CAM NC available at the time, as well as with GGPOS. Furthermore, it is broadly in line with the final CAM NC, mirroring many of its provisions including on demand assessment and design phase.

This paper concludes that as long as the capacity allocation provisions - stipulated by the OS procedures, under which projects initiated prior to the CAM NC's entry into force had been developed - were in line with the GGPOS and were not vastly different from, and broadly consistent with, the procedures being developed as part of the amended CAM NC (in its various preliminary drafts), neither the EC nor (to a lesser extent) the NRA would be in a strong position to request a significant change in the regulatory treatment of a project, compared to the treatment awarded to it under the OS procedures under which it had been developed.

Once in force, the CAM NC superseded the GGPOS by providing a set of legally binding regulatory procedures in respect of incremental capacity. However, as noted above, the CAM NC left the TSOs and the NRAs to decide on important specificities of these procedures - particularly in respect of capacity allocation - just as the GGPOS had done previously. This suggests that the usage of an OS procedure will also continue to be legitimate in the future, even with the CAM NC in force.

\section{Intergovernmental Agreements (IGAs)}

Some new European pipeline infrastructure was developed under an IGA regime, whereby specific regulatory provisions were devised by IGA parties themselves (governments of the countries across whose territories the pipeline in question would be built), rather than by their regulatory authorities. Some of this new infrastructure became operational before the TEP came into force (for example YamalEurope), while some which was already under development when the TEP entered into force has subsequently been cancelled (for example South Stream).

As long as no legally binding framework for incremental capacity existed at the EU level, the IGA framework initially allowed its parties a significant degree of freedom in designing regulatory procedures governing incremental capacity, including allocation, congestion management, and tariffs. However, such flexibility began to decrease when the EC secured a right to check the compatibility of IGAs with the acquis - initially ex post in 2012 and subsequently ex ante in 2017. Given that prior to 6 April 2017, the acquis only contained general rules, but no detailed regulatory procedures, in respect of incremental capacity, the EC was able to exercise a significant degree of discretion in its assessments of compatibility of IGAs with the acquis. Even before the EC had acquired the power to check compatibility with the acquis, it was able to facilitate (at Poland's request) the renegotiation of several clauses of the RussianPolish IGA (underpinning the Yamal-Europe pipeline) that were deemed to be incompatible with the 

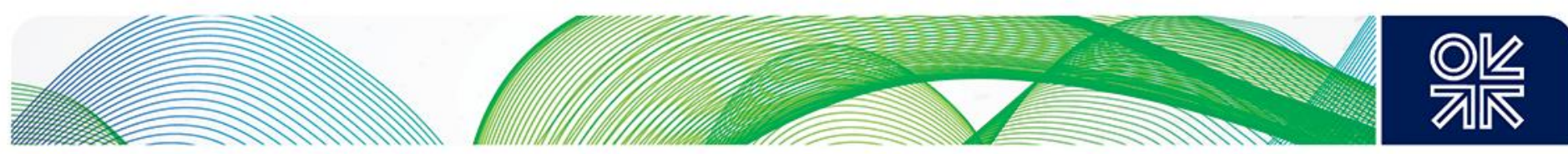

acquis, resulting in its amendment in 2010. Once the EC had acquired this power, it requested the relevant member states to re-negotiate their South Stream IGAs with Russia, while alleging that these IGAs were incompatible with the acquis. This, however, was not strictly true as the acquis did not contain detailed procedures for incremental capacity at the time. In the event, the EC failed to achieve the renegotiation of South Stream IGAs as Russia decided to cancel the project altogether.

The importance of an IGA as a regulatory framework for incremental capacity projects is likely to decline in the future, as it would no longer be possible for IGA parties to include any procedures that could be considered by the EC as being incompatible with the acquis, including the CAM NC. The latter has left the decision on important specificities of regulatory procedures - such as the justification for, and the choice of, an AAM - to the TSOs and the NRAs. Therefore, it might be preferable for an investor to develop its project on the basis of the CAM NC rather than on the basis of an IGA, the former being a purely regulatory framework, thus avoiding the political and regulatory risk potentially associated with the latter (as the EC would still maintain a significant degree of discretion in respect of compliance assessment). Moreover, should the 2017 EC proposal to amend the Third Gas Directive succeed, the importance of IGAs between member states and third countries' governments would decrease further as, according to the Council legal service's assessment of the proposal, it could lead to member states losing their right to conclude IGAs with third countries altogether. Conversely, the importance of international agreements between the EC and third parties' governments would likely increase.

New legislative initiatives: the Governance and Security of Supply Regulations, and the Amendment to the Third Gas Directive

In 2014, in response to the worsening political relationship between the EU and Russia, the EU developed several new policy initiatives such as the European Energy Security Strategy and the Energy Union policy concept, the main goals of which were to reduce its dependence on Russian gas imports and increase resilience in the event of potential interruptions. The EU has since begun to translate these policy initiatives into legislation by adopting the new Security of Supply Regulation in 2017, developing the Governance Regulation (2016-18), and proposing to amend the Third Gas Directive (2017-18).

The Draft Governance Regulation requires the EC to assess the progress made by each member state in respect of each dimension of the Energy Union - including energy security and the internal energy market (IEM) - to be measured against complex metrics (including net import dependence, supply concentration and the $\mathrm{N}-1$ rule, market concentration, wholesale gas prices, and household switching rates) thus effectively operationalizing the Energy Union objectives (Section 4.1). This requirement could have an impact on the development of new pipelines by measuring their compatibility with the Energy Union objectives. However, the impact is likely to be limited, as the draft Regulation neither defined the Energy Union objectives themselves (apart from stating that they include the EU 2030 goals) nor the threshold at which the progress in reaching them could be considered sufficient, enabling both the EC and the member state in question to argue that a new pipeline contributes towards the Energy Union objectives and that the progress is sufficient. Whereas the EC could issue a negative recommendation on an Energy and Climate Plan (ECP) which includes a new pipeline (while also taking into account whether and to what degree the comments made by other member states as part of regional cooperation had been taken into consideration), the member state could still decide to adopt it. The draft Regulation does not appear to provide the EC with the power to block a new pipeline on the grounds of it not contributing towards the Energy Union objectives. But it empowers the EC to exert significant pressure on the member state in question to justify the inclusion of any new pipeline in the ECP, and to ensure that any potential negative impacts on other member states would be minimized.

The Security of Supply Regulation, adopted in 2017, could also potentially be used both by the EC and the member states to influence the development and utilization of new pipeline capacity in the EU, but likewise its impact is likely to be limited (Section 4.2). The Regulation enables member states to identify all security of supply risk factors - political and commercial - including risks relating to control of infrastructure, 'to the extent that they may involve, inter alia, risks of underinvestment, undermining diversification, misuse of existing infrastructure or an infringement of Union law', as part of their risk 

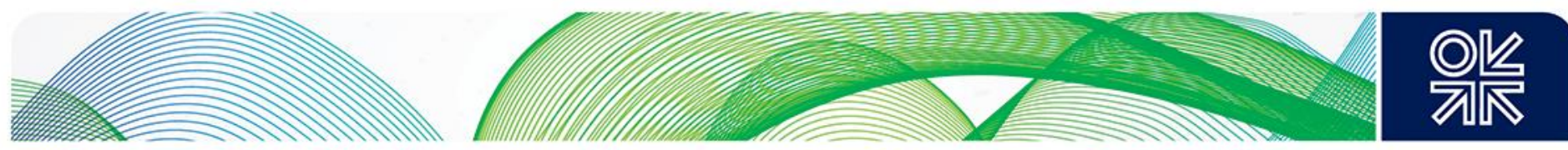

assessments. Thus, a member state which believes that a new pipeline might pose such risks - even if it is not (planned to be) located on its territory - could include these in its common risk assessment, as long as it belongs to the same regional group as the member state(s) where the pipeline is (planned to be) located. Should such risks be included in the common risk assessment, a member state on the territory where the new pipeline is (planned to be) built would be obliged to demonstrate - as part of its national preventive action plan (which must include a regional chapter) - how such risks would be addressed. This would include measures addressing the risks 'relating to the need to enhance interconnections between neighbouring member states', and 'the possibility to diversify gas routes and sources of gas supply and the regional utilization of existing storage and LNG capacities'. A member state, which has raised concerns in respect of new infrastructure, would be able to contribute towards the development of these measures and express views on whether these measures are considered 'appropriate and effective', as part of the joint development of the plan's regional chapter.

The Regulation would thus make any new pipeline, in respect of which either the EC or a member state raised security of supply concerns, subject to significant regulatory scrutiny. This is especially true for new pipelines which are (planned to be) used mostly for transporting gas from a supplier, which has a portfolio of contracts amounting to at least 28 per cent of the most affected member state's annual consumption, as such infrastructure would likely be included in the common risk assessment, and in the risk prevention plan under the Regulation's information exchange provisions. However, should the member state, on the territory where the new pipeline is (planned) to be built, be able to provide a substantiated assessment of the security of supply risks, including measures to mitigate or resolve them (including in respect of cross-border issues) and a confirmation that the infrastructure is being (or has been) built and operated in line with the legislation applicable at the time, nothing in the Regulation would empower either the EC or other member states to prevent its construction or limit its operation.

Among all three new legal initiatives, the EC's proposal to amend the Third Gas Directive has the strongest potential to impact the development and the operation of new pipeline capacity (Section 4.3). If adopted, the amended Directive would become applicable to existing and new pipelines to and from third countries, irrespective of whether adjacent connected pipelines inside the EU are regulated. Thus, both the EC and a member state, where the first interconnection point between a pipeline from a third country and a domestic intra-EU pipeline is located, would have a significant degree of discretion in respect of regulatory treatment of the (EU end of) the pipeline by means of exemption and derogation processes. In particular, this could have an impact on the degree of utilization of the pipeline from a third country, and consequently on the degree of utilization of intra-EU existing or new pipelines to which the pipeline from a third country is (planned to be) connected.

In particular, the amended Directive would enable the EC to influence the regulatory treatment of Nord Stream 2, including inter alia in respect of strengthening its chances of getting a mandate from the Council for negotiating an international agreement on Nord Stream 2 with the Russian government. In the EC's view, the latter should incorporate 'the core principles of international law and European Union law on energy, taking into account at the same time the impact of the pipeline's operation on the current gas supply from the Russian Federation to the European Union, including through Ukraine'. Although the amended Directive would only apply to the EU (German) end of Nord Stream 2 (at Lubmin II), it would enable the EC to approach the Russian government with a suggestion to agree a framework for the entire pipeline in line with the aforementioned EC position. The latter could be based on the view that as long as the EU end of Nord Stream 2 does not comply with the amended Directive, it would have to secure an exemption from the German regulatory authority which would ultimately have to be approved by the EC. In turn, the EC could request a fixed or floating cap to be applied in respect of Gazprom's utilization of Nord Stream 2 capacity at Lubmin II, which would be made conditional on the degree of utilization of the Ukrainian transit corridor post-2019. A negotiating mandate for Nord Stream 2 would make this task easier. Furthermore, the EC could issue a negative opinion in respect of certification of Nord Stream 2 (under Art. 11), of which the German regulatory authority would have to take 'utmost account', although it would have a right to adopt a certification decision which differs from the EC's opinion. 

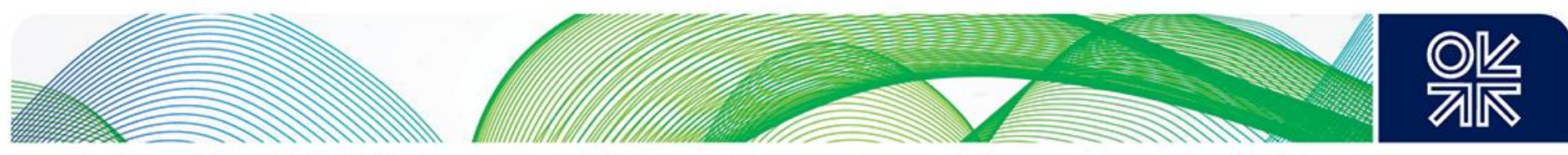

There is an important distinction to be made between the EC's Nord Stream 2 mandate (of which the utilization of the Ukrainian corridor post-2019 would be a part), and an EC mediation role between Russia and Ukraine that it has previously played (in respect of supplies and transit during the winters of 201415 and 2015-16) and which it is again seeking to play in order to negotiate the post-2019 Ukraine transit agreement. In our view, if the parties (Russia/Gazprom and Ukraine/Naftogaz) were willing - currently doubtful but possible - the EC could mediate the conclusion of the post-2019 Ukraine transit agreement without having to have the Nord Stream 2 mandate, thus dealing with the issues of Ukrainian transit and Nord Stream 2 separately. This paper argues that the negotiation of the Ukraine transit agreement via mediation, rather than via the Nord Stream 2 mandate, would be preferable and stands a higher chance of being successful.

However, even if the Directive is amended and the mandate to negotiate a new pipeline agreement with Russia is received, the strength of the EC legal/regulatory position is debatable and would bring the EC into conflict not only with the Russian government (which has strongly criticized the proposal as aimed at derailing Nord Stream 2 altogether) but also with the German government and NRA. Any cap on the amount of Nord Stream 2 capacity that Gazprom would be able to utilize would necessarily impact the utilization rate of EUGAL, to which Nord Stream 2 is planned to be connected (as no other supplier apart from Gazprom would have any gas available at Lubmin II). However, all of the marketable capacity in EUGAL was allocated for 20 years ahead under legally binding contracts in March 2017 (in other words, before the EC proposal to amend the Gas Directive was launched) in line with the 'more capacity' procedure.

A Nord Stream 2 capacity cap would thus be in direct conflict with the EUGAL capacity contracts and would be an extremely awkward development both for the EC and the German regulatory authority, neither of which publicly raised any objections in respect of the 'more capacity' procedure, and could have legal repercussions. The EC's position is also undermined by the fact that Nord Stream 2 was initiated well before the EC's proposal to amend the Gas Directive, with the feasibility study conducted in October 2012 and private financing agreements signed in April 2017, and it would be undermined further once its construction had started. The Russian government, Gazprom and private European investors would be able to argue that application of the amended Directive to Nord Stream 2 would run contrary to the principle of legal certainty. This, in turn, could lead to a protracted legal battle with a highly uncertain outcome thus further undermining confidence in the EU regulation.

However, despite its questionable position and any potential legal action which may result, should the amended Directive and the mandate secure the necessary support from the Council, the EC appears likely to attempt to make the degree of Nord Stream 2 utilization conditional on maintaining a specified volume of Russian gas transit through the Ukrainian system. We believe that the amendment of the Directive might not be the optimal way of achieving the EU's goal of preserving the transit of Russian gas across Ukraine. This could be achieved at a lower reputational, political, and economic cost, by dealing with the issue of transit of Russian gas across Ukraine on its own - in other words, conditional on the reform of the Ukrainian gas sector resulting in the establishment of a new TSO with a transportation tariff set in line with the acquis. This would contribute towards transportation of gas across Ukraine remaining commercially viable for the Ukrainian TSO, for Gazprom, and for any other shippers - rather than being artificially set as conditional on the degree of Nord Stream 2 utilization. Should there be confidence in the Ukrainian regulation and tariff levels, European shippers might be willing to transit substantial volumes of gas across Ukraine (in which case delivery points would have to be changed to the Ukraine-Russia border). On its part, Gazprom might also be interested in continuing to transit some gas across Ukraine beyond the mid-2020s; however, its willingness to transit substantial volumes would likely depend on the improvement of the political relationship between Russia and Ukraine.

\section{General conclusions}

The process of developing a legally binding regulatory framework for the creation of incremental capacity and hence for the construction of new EU gas pipelines has been uneven and slow. Eight years after the TEP was adopted in March 2009, and more than five years after it entered into force in September 2011, 

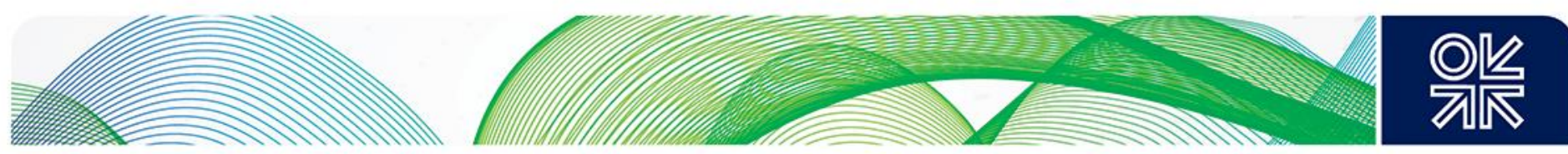

the CAM NC was finally established in March 2017. However, it did not fully resolve all the problematic issues in respect of the regulatory treatment of incremental capacity. The passage of time meant that many new pipelines, which were initiated around the time of the TEP's adoption and entry into force, developed under a patchwork of TEP exemptions, OS procedures, and IGAs. This meant that incremental capacity was allocated and contracted under different regulatory regimes which - while not dissimilar were not identical to the regulatory framework established by the CAM NC.

In addition, although the CAM NC established a legally binding regulatory framework for conducting an incremental capacity process, it left important regulatory specificities, particularly in respect of capacity allocation methods, for the TSOs and NRAs to decide. This meant that the latter have been able to develop capacity allocation methods which differ across the EU. As a result, there are differences in the regulatory treatment of incremental capacity both between the CAM NC and the previous frameworks (exemptions, OS procedures, and IGAs) as well as within the CAM NC itself. Thus, the problem of the regulatory treatment of incremental capacity - created under diverse frameworks with varying degrees of consistency - has not been fully resolved at the EU level and uncertainty remains in respect of its future treatment.

These problems have been made more difficult by the ongoing politicization of EU gas regulation, particularly in respect of Russian gas, and this adds further uncertainty in respect of the regulatory treatment of new EU pipelines, connected with Russian export pipelines. Signs of such politicization started to appear even before the sharp deterioration in the EU-Russia political relationship in the aftermath of the 2014 Ukraine crisis. For example, the cap imposed in 2009 by the EC on the utilization by Gazprom of OPAL (and hence Nord Stream 1) capacity was not justifiable on regulatory grounds. Such signs became even more evident post-2014, when the EU started to develop its new policy initiatives, which aimed de facto at reducing EU dependence on Russian gas and placing artificial constraints on Russia's Europe-bound export pipeline capacity, in order to inter alia preserve significant transit of Russian gas across Ukraine.

As the EC exhausted its ability to control capacity in Nord Stream 2 on the basis of the existing acquis, it launched several legislative initiatives - most importantly, the proposal to amend the Third Gas Directive. If adopted, the amended Directive would enable the EC to control the degree of utilization of capacity in pipelines coming to the EU from third countries, and hence the degree of utilization of capacity in the EU's internal pipelines, thus increasing the (already significant) uncertainty in respect of regulatory treatment of incremental capacity in the EU (including the projects that have been initiated prior to its adoption). At the time of writing, lack of political agreement among member states means that it is uncertain whether such regulatory action will succeed. To the extent that it does succeed, it will politicize - and ultimately undermine - an EU regulatory framework that has been painstakingly constructed over several decades.

This paper concludes that, given the uncertainty and complexity associated with the regulatory treatment of incremental capacity, the projects that have been initiated prior to the CAM NC's entry into force should proceed under the rules which were in place at the time of their initiation. Although the EC and the regulatory authorities might be tempted to request some changes in respect of their regulatory treatment - particularly where this differs from what would have been required under the CAM NC - this temptation should be resisted, as further changes would unnecessarily increase uncertainty and complexity. Overall, the complexity and the lack of clarity associated with the regulatory framework for incremental capacity in the EU (resulting from the way in which regulation has developed, as well from its subsequent politicization) suggests that very few major new pipelines will be built in the EU in the future, apart from those under construction or foreseen in this paper (including TAP, EUGAL, and the Baltic Pipe) and possibly also those pipelines needed for connecting the second string of Turkish Stream with European markets. This is because it will be much easier for those wishing to bring additional gas to Europe to do so via $\mathrm{LNG}$ import terminals. 

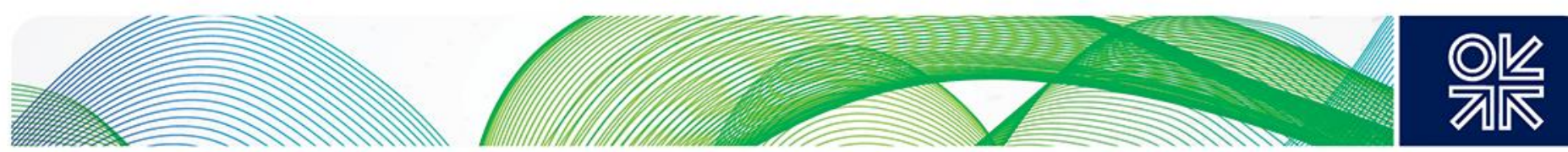

\section{Abbreviations}

AAM - Alternative Allocation Mechanism

ACER - Agency for the Cooperation of Energy Regulators

AEEG - Italian regulatory authority

$\mathrm{BBL}$ - Balgzand-Bacton pipeline

BEMIP - Baltic Energy Market Interconnection Plan

BNetzA - Bundesnetzagentur (German Regulatory Authority)

BZK - Coupled capacity

CAM - Capacity Allocation Mechanism

CBA - Cost-Benefit Analysis

CEER - Council of European Energy Regulators

CEF - Connecting Europe Facility

CJEU - Court of Justice of the EU

CMP - Congestion Management Procedures

DEPA - Greek national gas company

DESFA - Greek national transmission company

DG COMP - EU Directorate General for Competition

DG ENERGY - EU Directorate General for Energy

DZK - Dynamically allocable capacity

EC - European Commission

ECP - Energy and Climate Plan

ECPRs - Energy and Climate Progress Reports

ECS - Energy Charter Secretariat

ECT - Energy Charter Treaty

EE - Entry-Exit

EEC - European Economic Community

EEZ - Exclusive Economic Zones

$\mathrm{El}$ - Expression of Interest

EIA - Environmental Impact Assessment

EnCT - Energy Community Treaty

ENTSOG - European Network of Transmission Systems Operators for Gas

ERE - the Albanian regulatory authority

ERGEG - European Regulators' Group for Electricity and Gas

ERU - Energetický regulační úrad (Czech Regulatory Authority)

ESI - Energy Sector Inquiry

EU - European Union

FG - Framework Guidelines

FID - Final Investment Decision

FNB - Die Fernleitungsnetzbetreiber (German association of TSOs)

FZK - Firm freely allocable capacity

GCS - gas compressor station 

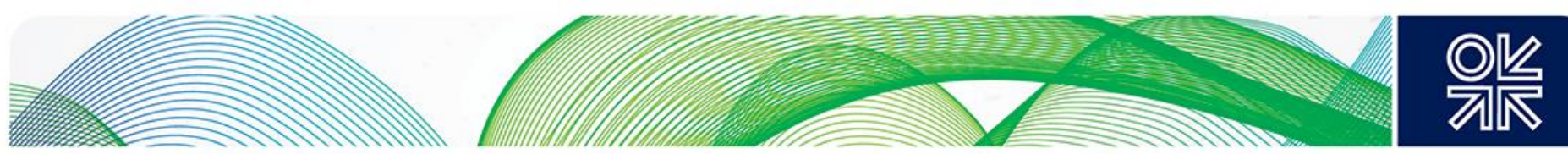

GGPOS - Guidelines for Good Practice on Open Season procedures

GRIPs - Gas Regional Development Plans

GTM - Gas Target Model

GTM - Gas Target Model

HDB - Hungarian Development Bank

HGA - Host Government Agreement

HHI - Herfindahl-Hirschman Index

IEM - Internal Energy Market

IGA - Intergovernmental Agreement

IGB - Interconnector Greece-Bulgaria

IP - Interconnection Point

ISO - Independent System Operator

ITG - Interconnector Turkey-Greece

ITO - Independent Transmission Operator

ITRE - European Parliament's Committee on Information, Research and Energy

JV - Joint Venture

LBTG - Lubmin-Brandov Gastransport

LNG - Liquified Natural Gas

LTSC - Long-Term Supply Contract

LTTC - Long-Term Transportation Contract

$\mathrm{mcm}$ - thousand cubic metres

$\mathrm{MoU}$ - memorandum of understanding

MSE - the Italian Ministry of Economic Development

NC - Network Code

NDP - Network Development Plan

NEL - Nordeuropäische Erdgasleitung

NRA - National Regulatory Authority

NSI - North South Interconnections

OIES - Oxford Institute for Energy Studies

OPAL - Ostsee-Pipeline-Anbindungsleitung

OS - Open Season

OU - Ownership Unbundling

$\mathrm{PCl}$ - Project of Common Interest

PGNiG - Polskie Górnictwo Naftowe i Gazownictwo

PP - Point-to-Point

PRISMA - European gas capacity trading platform

QMV - Qualified Majority Voting

RAE - Greek regulatory authority

$\mathrm{RCP}$ - regulatory compliance programme

RfG - Danish Rules for Gas Transport

SGC - Southern Gas Corridor

SCP - South Caucasus Pipeline 

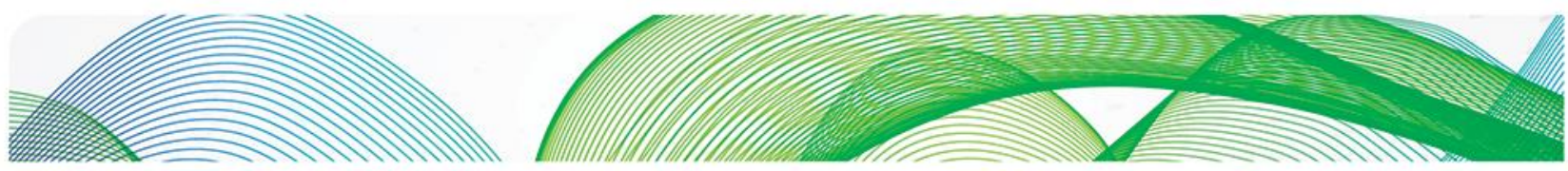

\section{임}

SCPX - South Caucasus Pipeline Expansion

SD - Shah Deniz

SEA - Single European Act

SEM - Single European Market

SEP - Second Energy Package

SGC - Southern Gas Corridor

TANAP - Trans Anatolian Pipeline

TAP - Trans Adriatic Pipeline

TEN - Trans-European Network

TEP - Third Energy Package

TFEU - Treaty on Functioning of the EU

TFEU - Treaty on the Functioning of the European Union

TPA - third party access

TSO - transmission system operator

TYNDP - Ten-Year Network Development Plan

UGS (system) - Unified gas supply (system)

UGSS - Russian Unified Gas Supply System

UIOLI - use-it-or-lose-it

UOKiK - Urząd Ochrony Konkurencji i Konsumentów (Polish Competition Authority)

VIU - Vertically integrated undertaking 

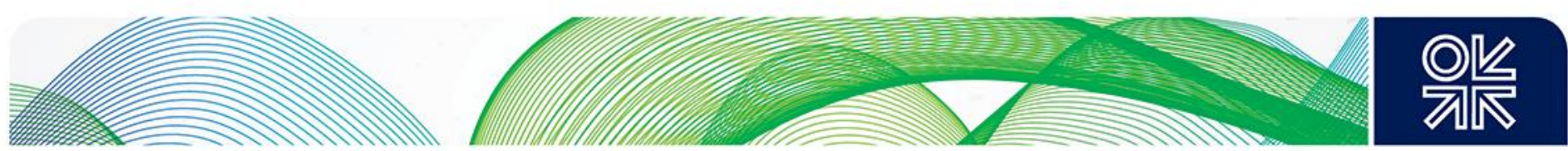

\section{Bibliography}

ACER (2012): 'Reasoned Opinion on the Network Code on Capacity Allocation Mechanisms for the European gas transmission network', ACER Opinion No 04-2012, 4 June 2012.

ACER (2013): 'ACER Guidance to ENTSOG on the development of amendment proposals to the Network Code on Capacity Allocation Mechanisms on the matter of incremental and new capacity', 3 December 2013, https://www.acer.europa.eu/Media/News/Documents/ACER\%20Guidance\%20on\%20NC\%20CAM\%20 Amendments\%20(final).pdf.

ACER (2015a): 'ACER's changes to ENTSOG's amendment proposal on Incremental Capacity', Public consultation on the Incremental Capacity Proposal, PC_2015_G_02, https://acer.europa.eu/Official documents/Public consultations/Pages/PC 2015 G 02.aspx. (ACER's First draft)

ACER (2015b): 'Public consultation on the Incremental Capacity Proposal and further NC CAM amendments', PC_2015_G_05, Draft ACER proposal on NC CAM amendments for public consultation (17 July-31 August 2015), https://acer.europa.eu/Official documents/Public consultations/Pages/PC 2015 G 05.aspx. (ACER's Second draft)

Baltic Pipe Project: Shipper information meeting, Stavanger 20 June 2017, https://en.energinet.dk/Gas/Shippers/Open-Season-2017.

Barnes (2018): Barnes, A., 'The Gas Directive Amendment - a solution in search of a problem?', 19 February 2018, https://www.linkedin.com/pulse/gas-directive-amendment-solution-search-problem-alexbarnes/

BP (2013a): 'Shah Deniz major sales agreements with European gas purchasers concluded', press release, 19 September 2013, https://www.bp.com/en az/caspian/press/pressreleases/Shah-Denizsales-agreements-European-purchasers.html.

BP (2013b): 'Shah Deniz final investment decision paves way for Southern Gas corridor gas link with Europe', press release, 17 December 2013, https://www.bp.com/en_az/caspian/press/pressreleases/Shah-Deniz-Final-Investment-Decision-pavesway-.html

BNetzA (2015): Decision concerning adjustment of capacity provisions in the gas sector (KARLA Gas 1.1), BK7-15-001, 14 August 2015, available at https://www.bundesnetzagentur.de/DE/ServiceFunktionen/Beschlusskammern/1BK-Geschaeftszeichen-Datenbank/BK7GZ/2015/2015 0001bis0999/2015 001bis099/BK7-150001/Beschluss_englisch.pdf;jsessionid=E19273FC1CA49371721FD24CC33EACA0?_blob=publicati onFile\&v=3

Business Europe (2017): Letter to Mr Maroš Šefčovič, Vice-President in charge of the Energy Union, European Commission, from Markus Beyrer, 13 December 2017.

CEER (2012): 'Market-Based Investment Procedures for Gas Infrastructure: Issues and Approaches', a CEER Public Consultation Paper, Ref: C12-GWG-87-03, 18 June 2012.

Council (2018): Governance of the Energy Union: Council confirms deal reached with the European Parliament, 29 June 2018, http://www.consilium.europa.eu/en/press/pressreleases/2018/06/29/governance-of-the-energy-union-council-confirms-deal-reached-with-theeuropean-parliament/ 

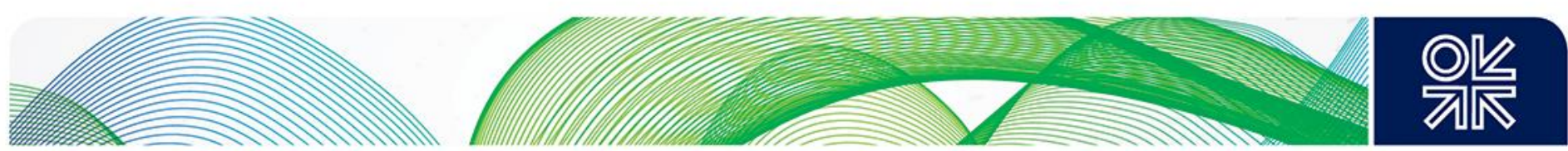

DERA (2017a): 'Opinion on principles for market zone and the methodology for determining tariffs in connection with the Baltic Pipe project', (Danish Energy Regulatory Authority), 16/10895 HNJ/MHB, Danish Competition and Consumer Authority, 31 January 2017 (DERA Opinion).

DERA (2017b): 'Summary of DERA's approval of parameters and setting of the f-factor for the economic test for the Baltic Pipe project', 17/10973 MHB, Danish Energy Regulatory Authority, 28 November 2017.

EC (2004): 'Guidelines on the assessment of horizontal mergers under the Council Regulation on the control of concentrations between undertakings', Communication (EC), Official Journal of the European Union (OJ), 2004/C 31/03, 5 February 2004.

EC (2008): 'Guidelines on the assessment of non-horizontal mergers under the Council Regulation on the control of concentrations between undertakings', OJ, 2008/C 265/07, Brussels: EC, 18 October 2008, https://eur-lex.europa.eu/legal-content/EN/TXT/PDF/?uri=CELEX:52008XC1018(03)\&from=EN.

EC (2009): 'Commission staff working document on Article 22 of Directive 2003/55/EC concerning common rules for the internal market in natural gas and Article 7 of Regulation (EC) No 1228/2003 on conditions for access to the network for cross-border exchanges in electricity - New Infrastructure Exemptions', SEC(2009) 642 final, Brussels: EC, 6 May 2009, https://ec.europa.eu/energy/sites/ener/files/documents/sec_2009-642.pdf.

EC (2013): 'Decision on the exemption of the Trans Adriatic Pipeline from the requirements on third party access, tariff regulation and ownership unbundling laid down in Articles 9, 32, 41(6), 41(8) and 41(10) of Directive 2009/73/EC', C(2013) 2949 final, Brussels: EC, 16 May 2013, p. 4, https://ec.europa.eu/energy/sites/ener/files/documents/2013 tap decision en.pdf (EC TAP Exemption Decision).

EC (2014a): 'European Energy Security Strategy', Communication from the Commission to the European Parliament and the Council, COM(2014) 330 final, Brussels: EC, 28 May 2014 (Energy Security Strategy).

EC (2014b): 'In-depth study of European Energy Security' (accompanying the document [COM(2014) 330 final\}), Commission Staff Working Document, SWD(2014) 330 final/3, Brussels: EC, 2 July 2014.

EC (2015a): 'A Framework Strategy for a Resilient Energy Union with a Forward-Looking Climate Change Policy', Communication from the Commission to the European Parliament, the Council, the European Economic and Social Committee, the Committee of the Regions and the European Investment Bank, COM(2015) 80 final, Brussels: EC, 25 February 2015 (Energy Union Strategy).

EC (2015b): 'State of the Energy Union 2015', Communication from the Commission to the European Parliament, the Council, the European Economic and Social Committee, the Committee of the Regions and the European Investment Bank, COM(2015) 572 final, Brussels: EC, 18 November 2015 (First Energy Union Report).

EC (2016a): 'Decision on review of the exemption of the Ostseepipeline-Anbindungsleitung (OPAL) from the requirements on third party access and tariff regulation granted under Directive 2003/55/EC', $\operatorname{COM}(2016) 6950$ final, Brussels: EC, 28 October 2016,

https://ec.europa.eu/energy/sites/ener/files/documents/2016 opal revision decision en.pdf (EC OPAL Exemption Decision).

EC (2016b): 'Certification of TAP AG', Commission Opinion, C(2016) 538 final, Brussels: EC, 28 January 2016 (EC TAP Certification Opinion). 

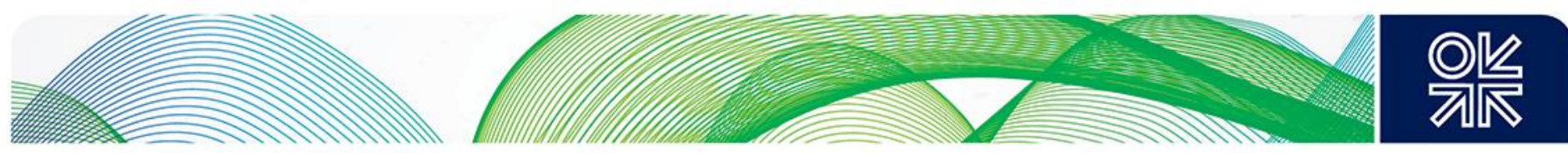

EC (2017a): 'Assessing the amendments to Directive 2009/73/EC setting out rules for gas pipelines connecting the European Union with third countries', Commission staff working document, SWD(2017) 368 final, Brussels: EC, 8 November 2017.

EC (2017b): 'Monitoring progress towards the Energy Union objectives - key indicators', Second Report on the State of the Energy Union, Commission Staff Working Document, SWD(2017) 32 final, Brussels: EC, 1 February 2017.

EC (2017c): 'Proposal for a Directive of the European Parliament and of the Council amending Directive 2009/73/EC concerning common rules for the internal market in natural gas', COM(2017) 660 final, 2017/0294(COD), Brussels: EC, 8 November 2017 (Amendment Proposal).

EC (2017d): 'Assessing the amendments to Directive 2009/73/EC setting out rules for gas pipelines connecting the European Union with third countries', Commission staff working document, SWD(2017) 368 final, Brussels: EC, 8 November 2017.

EC (2018a): Exemption Decisions, European Commission Directorate-General for Energy, 7 June 2018, https://ec.europa.eu/energy/sites/ener/files/documents/exemption_decisions2018.pdf.

EC (2018b): 'Antitrust: Commission imposes binding obligations on Gazprom to enable free flow of gas at competitive prices in Central and Eastern European gas markets', Brussels: EC Press Release, 24 May 2018, http://europa.eu/rapid/press-release_IP-18-3921_en.htm.

EC (2018c): 'Receipt of a notification of the Bulgarian and the Greek national regulatory authority to exempt the interconnector Greece Bulgaria from third party access, tariff and ownership unbundling provisions according to Article 56 of Directive 2009/73/EC, 7 June 2018,

https://ec.europa.eu/energy/sites/ener/files/documents/2018_igb_receipt.pdf.

Energinet (2016a): 'Gaz-System S.A. and Energinet.dk are investigating a possible connection between the two transmission systems', 15 March 2016, https://en.energinet.dk/Infrastructure-

Projects/Projektliste/BalticPipe/News-about-Baltic-Pipe/GAZ-SYSTEM-S-A-and-Energinet-dk-areinvestigating-a-possible-conn.

Energinet (2016b): 'For Public Consultation: Tariff principles and market design in a Baltic Pipe Open Season', dok 15/11929-11, 2 November 2016 (Tariff Principles).

Energinet (2017a): 'Information Package 1: Scenario-Based Costs of Transportation and Uniform Tariff Simulations', dok 16/09169-38, 6 June 2017.

Energinet (2017b): 'Information package 2', dok 16/09169-50, 5 September 2017.

Energinet (2018): 'Energinet submits Baltic Pipe application to Minister', press release, 19 March 2018, https://en.energinet.dk/About-our-news/News/2018/03/16/Energinet-submits-Baltic-Pipe-application-toMinister.

Energinet, 'Baltic Pipe: Gas pipeline, connecting Denmark and Poland with Norway's gas fields', https://en.energinet.dk/Infrastructure-Projects/Projektliste/BalticPipe.

Energinet, 'Tariffs and fees on the Danish gas market', https://en.energinet.dk/gas/tariffs-and-fees.

ENTSOG (2012a): 'Network Code on Capacity Allocation Mechanisms, an ENTSOG Network Code for ACER review and Comitology Procedure', CAP0210-12, 6 March 2012. 

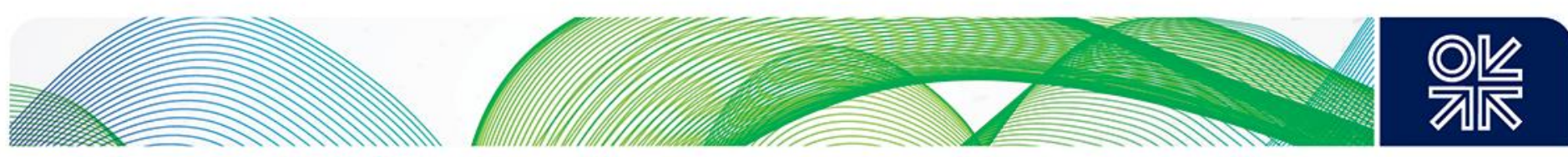

ENTSOG (2012b): 'Network Code on Capacity Allocation Mechanisms, an ENTSOG Network Code for further ACER review and Comitology Procedure', CAP291-12, 17 September 2012.

ENTSOG (2014): 'Final Incremental Proposal, An ENTSOG Amendment Proposal for an existing Regulation and a chapter of a Network Code', INC0223-14, 26 December 2014 Final; ENTSOG. (Proposal on amending Commission Regulation (EU) No 984/2013 of 14 October 2013 on principles linked to the offer of incremental and new capacity in gas transmission systems, Incremental Proposal, INC0224-14, 26 December 2014, Final). (ENTSOG's draft CAM NC)

ENTSOG (2017a): 'Ten-Year Development Plan 2017', Annex 1 - Project List. April 2017, https://www.entsog.eu/public/uploads/files/publications/TYNDP/2017/entsog tyndp 2017 main 17042 8 web xs.pdf. (TYNDP 2017)

ENTSOG (2017b): 'Gas Regional Investment Plan', (North West, Central Eastern Europe, BEMIP, Southern Corridor, South North Corridor, South), https://www.entsog.eu/publications/gas-regionalinvestment-plan-grips.

ENTSOG (2017c): 'North West Gas Regional Investment Plan 2017 Main Report (NW GRIP 2017).

ENTSOG (2018): 'Ten Year Development Plan 2018', (Draft), Annex 1 - Project List, (Draft TYNDP 2018).

EP (2018a): 'Gas: MEPs strengthen EU rules on pipelines to and from third countries', press release, European Parliament, 21 March 2018, http://www.europarl.europa.eu/news/en/press-

room/20180320IPR00143/gas-meps-strengthen-eu-rules-on-pipelines-to-and-from-third-countries.

EP (2018b): ${ }^{* * * * \mid}$ Report on the proposal for a directive of the European Parliament and of the Council amending Directive 2009/73/EC concerning common rules for the internal market in natural gas (COM(2017)0660 - C8-0394/2017 - 2017/0294(COD)), Committee on Industry, Research and Energy, Rapporteur Jerzy Buzek, A8-0143/2018, 11 April 2018 (ITRE Proposal).

EP (2018c): 'Gas directive: plenary needs to confirm negotiating mandate', press release, European Parliament, 18 April 2018, http://www.europarl.europa.eu/news/en/press-room/20180418IPR02019/gasdirective-plenary-needs-to-confirm-negotiating-mandate.

ERE (2013): Decision (Albanian Exemption Decision).

ERGEG (2007): 'Guidelines for Good Practice on Open Season Procedures', Ref: C06-GWG-29-05c, European Regulators' Group for Electricity and Gas, 21 May 2007,

https://www.entsog.eu/public/uploads/files/publications/incrementalcapacity/ERGEG\%20Guidelines\%20 of\%20Good\%20Practice\%20-\%200pen\%20Season\%20Procedures\%20(GGPOS).pdf (GGPOS).

ERO (2017): Decision of the President of the Energy Regulatory Office DRG.DRG-2.7129.1.2017.IRS, Warsaw, 25 August 2017.

Eurogas (2018): 'Eurogas views on the modification of the Gas Directive', Position Paper, January 2018.

FNB Gas (2016a): 'Konsultationsdokument Netzentwicklungsplan Gas 2016', 15 February 2016, https://www.fnb-gas.de/files/2016 02 12-konsultationsdokument nep-gas-2016.pdf (First

Consultation NDP 2016).

FNB Gas (2016b): 'Entwurf Netzentwicklungsplan Gas 2016', 1 April 2016, https://www.fnbgas.de/files/2016 04 01-entwurf nep-gas-2016.pdf (First Draft NDP 2016). 

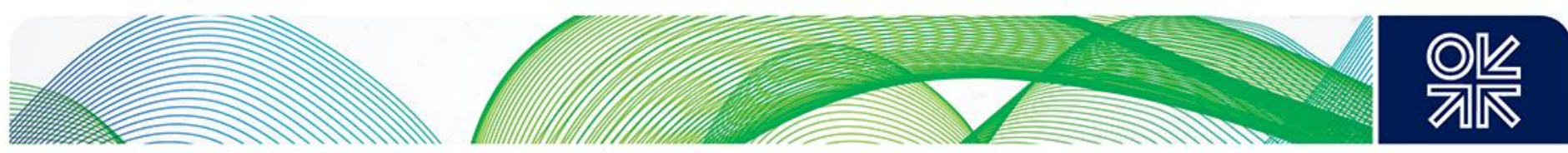

FNB Gas (2017a): 'German gas transmission system operators publish second consultation document NDP 2016-2026', press release, 27 February 2017, https://www.fnb-

gas.de/files/2017_02_28_pi_fnb_gas_2._consultation_document_ndp_gas_2016-2026_en.pdf.

FNB Gas (2017b): '2. Konsultationsdokument Netzentwicklungsplan Gas 2016-2026', ('Consultation on Network Development Plan Gas 2016-2026'), 27 February 2017, https://www.fnbgas.de/files/2017 0227 konsultationsdokument2 nep-gas-2016-final.pdf (Second Consultation NDP 2016).

FNB Gas (2017c): 'TSOs publish 2017 implementation report and statement of long-term capacity requirements', press release, 31 March 2017.

FNB Gas (2017d): ‘German TSOs submit second draft 2016-2026 Gas NDP to Federal Network Agency', press release, 5 April 2017.

FNB Gas (2017e): '2 Entwurf Netzentwicklungsplan Gas 2016-2026', 5 April 2017, https://www.fnbgas.de/files/2017 0405 entwurf2 nep-gas-2016.pdf (Second Draft NDP 2016).

FNB Gas (2017f): 'Demand assessment for new transport capacities finished according to European guidelines: transmission system operators publish market demand assessment reports', press release, 27 July 2017.

FNB Gas (2017g): 'German gas TSOs publish final NDP for the period from 2016 to 2026', press release, 16 October 2017.

FNB Gas (2017h): 'Netzentwicklungsplan Gas 2016-2026', 16 October 2017, https://www.fnbgas.de/files/2017 1016 nep-gas-2016-2026.pdf (NDP 2016).

FNB Gas (2017i): 'Incremental capacity: German gas TSOs launch first consultation under EU rules', press release, 19 October 2017.

FNB Gas (2018a): '2018 NDP confirms continuity of earlier network development projects whilst taking account of additional European import needs and addressing the important role gas infrastructure has in delivering energy transition', press release, 12 February 2018.

FNB Gas (2018b): 'Konsultationsdokument, Netzentwicklungsplan Gas 2018-2028', ('Consultation on Network Development Plan Gas 2018-2028'), German Federal Network Agency, 12 February 2018 (Draft NDP 2018).

FNB Gas (2018c): 'Executive Summary - Draft Gas Network Development Plan (NDP) 2018-2028', 29 March 2018, https://www.fnb-gas.de/files/2018_03_29_executive_summary_draft_ndp_20182028_en.pdf.

GASCADE (2017a): 'Successful booking of new transport capacities', press release, 7 March 2017, https://www.gascade.de/en/press/press-releases/press-release/news/successful-booking-of-newtransport-capacities/.

GASCADE (2017b): 'GASCADE signs EUGAL participation agreement with three German transmission system operators', press release, 18 October 2017, https://www.gascade.de/en/press/pressreleases/press-release/news/gascade-signs-eugal-participation-agreement-with-three-germantransmission-network-operators/. 

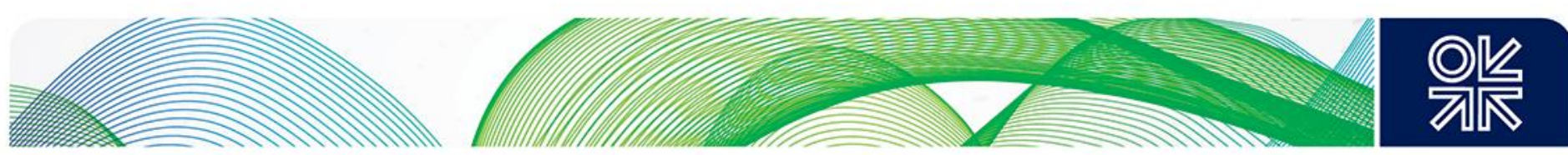

GASCADE (2017c): 'EUGAL: planning approval procedure to start in Mecklenburg-Western Pomerania', press release, 24 October 2017, https://www.gascade.de/en/press/press-releases/pressrelease/news/eugal-planning-approval-procedure-to-start-in-mecklenburg-western-pomerania/.

GASCADE (2017d): 'EUGAL: planning approval procedure to start in Brandenburg', press release, 30 October 2017, https://www.gascade.de/en/press/press-releases/press-release/news/eugal-planningapproval-procedure-to-start-in-brandenburg/.

GASCADE (2017e): ‘EUGAL: planning approval procedure underway in Saxony', press release, 1 December 2017, https://www.gascade.de/en/press/press-releases/press-release/news/eugal-planningapproval-procedure-underway-in-saxony/.

Gazprom Export (2016): 'Gazprom Export's third gas auction successfully completed', press release, 5 September 2016.

Gazprom, Nord Stream 2, News and Events, http://www.gazprom.com/about/production/projects/pipelines/built/nord-stream2/.

Gazprom (2012): 'Final investment decision adopted for South Stream offshore section', press release, 15 November 2012, http://www.gazprom.com/press/news/2012/november/article148506/ http://www.gazprom.com/press/news/2012/november/article148506/.

Gaz-System (2018), 'Co-financing agreement for Baltic Pipe engineering works officially signed', 25 May 2018, press release, http://en.gaz-system.pl/press-centre/news/information-for-the-media/artykul/202759/.

Gaz-System (2017a): 'Baltic Pipe: Launching of the Binding Open Season Procedure', press release, 6 June 2017, http://en.gaz-system.pl/pdf/press-centre/news/information-for-the-media/artykul/202507/.

Gaz-System (2017b): 'Baltic Pipe: the final phase of the open season 2017 ends up with a positive test', press-release, 31 October 2017.

Gaz-System (2017c): 'Baltic Pipe: positive result of economic tests carried out by Gaz-System and Energinet', press-release, 30 November 2017.

Gaz-System (2018a): 'Ten-year national development plan agreed upon with the president of the energy regulatory office and approved by the general meeting of shareholders', press release, 10 January 2018.

Gaz-System (2018b): 'Signing of capacity agreements completes the 2017 Open Season Procedure [for the Baltic Pipe project]', press release, 1 February 2018.

Heather (2012): Heather, P., 'Continental European gas hubs: are they fit for purpose?', OIES Paper NG 63, June 2012, p. 17, https://www.oxfordenergy.org/wpcms/wp-content/uploads/2012/06/NG-63.pdf.

Honoré (2017): Honoré, A., 'The Dutch gas market: trials, tribulations, and trends', OIES Paper NG 118, May 2017, https://www.oxfordenergy.org/publications/dutch-gas-market-trials-tribulations-trends/.

UK House of Commons European Scrutiny Committee, Seventh Report of Session 2017-19, HC 301vii, 22 December 2017, https://publications.parliament.uk/pa/cm201719/cmselect/cmeuleg/301-vii/301vii.pdf (House of Commons Report).

IOGP (2017): 'IOGP response on the European Commission's Gas Directive proposals feedback request', 20 December 2017. 

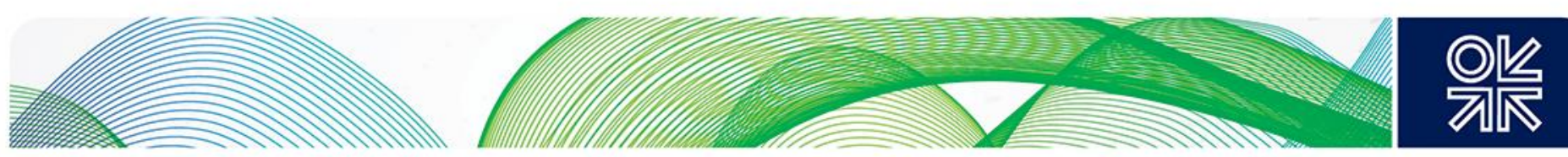

More Capacity (2015a): 'Europe-wide market survey “more capacity” very successful: Transmission network operators release demand analysis', press release, 7 December 2015, https://www.morecapacity.eu/en/news/press-release/news/europe-wide-market-survey-more-capacity-very-successfultransmission-network-operators-release-de/.

More Capacity (2015b): ‘Demand analysis for the “more capacity” market survey', December 2015, https://www.morecapacity.eu/fileadmin/downloads morecapacity/presse/more capacity Report Demand Analysis.pdf (More Capacity Demand Analysis).

More Capacity (2016): “"more capacity”: Consultation on the marketing procedure to begin', press release, 4 August 2016, https://www.more-capacity.eu/en/news/press-release/news/more-capacityconsultation-on-the-marketing-procedure-to-begin-2/.

More Capacity (2017a): '“more capacity”: Conclude preliminary agreements until 27 January 2017', press release, 17 January 2017, https://www.more-capacity.eu/en/news/press-release/news/morecapacity-conclude-preliminary-agreements-until-27-january-2017/.

More Capacity (2017b): 'Successful auctions for new transport capacities', press release, 7 March 2017, https://www.more-capacity.eu/en/news/press-release/news/successful-auctions-for-newtransport-capacities/.

More Capacity, 'Glossary', https://www.more-capacity.eu/en/our-project/glossary/\#c6858.

More Capacity, 'Marketable capacities', https://www.more-capacity.eu/en/marketing/marketablecapacities/.

More Capacity, 'Market-based allocation of new cross-market-area capacities', https://www.morecapacity.eu/en/our-project/.

More Capacity: 'Preliminary agreement on the holding capacity auctions and on the submission of bids in such capacity auctions (hereinafter referred to as the "preliminary agreement")', https://www.morecapacity.eu/fileadmin/downloads morecapacity/konsultation/more capacity Preliminary agreement ca pacity auctions.pdf (Preliminary Agreement).

More Capacity, 'Supplementary Terms and Conditions', https://www.more-

capacity.eu/fileadmin/downloads morecapacity/konsultation/more capacity Supplementary Terms an d Conditions of Business.pdf (Supplementary Terms and Conditions).

More Capacity, 'The Consultation', https://www.more-capacity.eu/en/consultation/.

More Capacity, Preliminary Agreement on the holding [of] capacity auctions and on the

MSE (2013): Decree concerning exemption of TAP AG, 13 March 2013 (Italian Exemption Decision).

Nord Stream (2018): 'Nord Stream reaches average utilization of 93 per cent in $2017-51 \mathrm{bcm}$ delivered to the European Union', press release, 16 June 2018, https://www.nord-stream.com/pressinfo/press-releases/nord-stream-reaches-average-utilisation-of-93-in-2017-51-bcm-delivered-to-theeuropean-union-500/

Ørsted Annual Report 2017, https://orsted.com//media/Aarsrapport2017/Orsted_Annual_Report_2017_Final.ashx?la=en\&hash=33829CD1D14D0E2C 6A373D15EE28B21B27265369. 

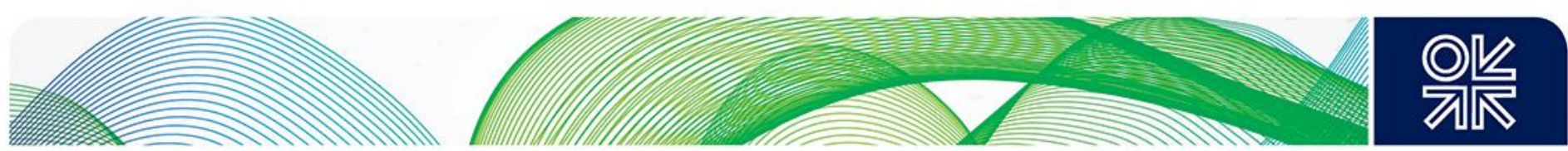

Pirani (2016): Pirani, S., 'Azerbaijan's gas supply squeeze and the consequences for the Southern Corridor', OIES Paper NG 110, July 2016, https://www.oxfordenergy.org/wpcms/wpcontent/uploads/2016/07/Azerbaijans-gas-supply-squeeze-and-the-consequences-for-the-SouthernCorridor-NG-110.pdf.

Pirani and Yafimava (2016): Pirani, S. and Yafimava, K., 'Russian Gas Transit Across Ukraine Post2019: pipeline scenarios, gas flow consequences, and regulatory constraints', OIES Paper NG 105, OIES, February 2016, pp. 27-9.

RAE (2013): Decision on the exemption of TAP AG, N 111/2013, 28 February 2013 (Greek Exemption Decision).

Rzayeva (2015): Rzayeva, G., 'The Outlook for Azerbaijani Gas Supplies to Europe: Challenges and Perspectives', OIES Paper NG 97, June 2015, https://www.oxfordenergy.org/wpcms/wpcontent/uploads/2015/06/NG-97.pdf.

Stern (2014): Stern, J. (ed), 'Reducing European dependence on Russian gas: distinguishing natural gas security from geopolitics', OIES Paper NG 92, October 2014, https://www.oxfordenergy.org/wpcms/wp-content/uploads/2014/10/NG-92.pdf.

Stern and Yafimava (2007): Stern, J., and Yafimava, K., 'The 2007 Russia-Belarus Gas Agreement', Oxford Energy Comment, OIES, January 2007.

Stern and Yafimava (2017a): Stern, J., and Yafimava, K., 'The EU Competition Investigation into Gazprom's Sales to Central and Eastern Europe: a comment on commitments', Oxford Energy Comment, April 2017, OIES.

Stern and Yafimava (2017b): Stern, J., and Yafimava, K., 'The EU Competition investigation of Gazprom's sales in central and eastern Europe: a detailed analysis of the commitments and the way forward', OIES Paper NG 121, July 2017, OIES.

Stern, Pirani, and Yafimava (2015): Stern, J., Pirani, S., and Yafimava, K., 'Does the cancellation of South Stream signal a fundamental reorientation of Russian gas export policy?', Oxford Energy Comment, OIES, January 2015.

TAP (2012): 'TAP launches market test', press release, 15 June 2012, https://www.tap-ag.com/newsand-events/2012/06/15/tap-launches-market-test.

TAP (2013a): 'Greece, Italy and Albania sign a tri-lateral intergovernmental agreement, demonstrating their full support for TAP', press release, 13 February 2013, https://www.tap-ag.com/news-andevents/2013/02/13/greece-italy-and-albania-sign-a-tri-lateral-intergovernmental-agreementdemonstrating-their-full-support-for-tap.

TAP (2013b): 'Albanian Parliament ratifies Host Government Agreement between Albania and TAP', press release, 17 April 2013, https://www.tap-ag.com/news-and-events/2013/04/17/albanianparliament-ratifies-host-government-agreement-between-albania-and-tap.

TAP (2013c): 'The Greek Parliament ratifies the Host Government Agreement with TAP', press release, 3 December 2013, https://www.tap-ag.com/news-and-events/2013/12/03/the-greek-parliament-ratifiesthe-host-government-agreement-with-tap. (Text of the agreement is available in Government Gazette, A/89/18.04.2013 (dated voted 2 December 2013), http://www.hellenicparliament.gr/en/NomothetikoErgo/Psifisthenta-Nomoschedia?pageNo=26.) 

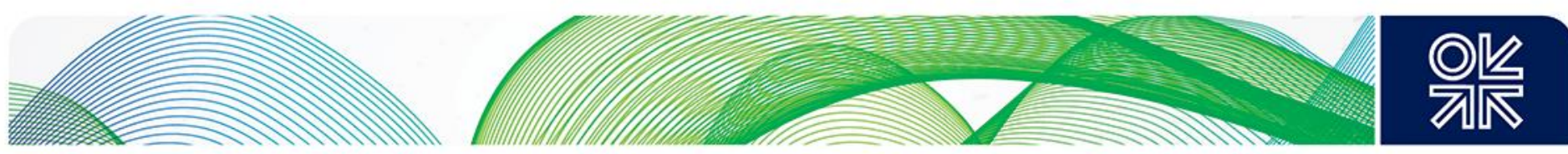

TAP (2014a): 'TAP announces the second phase of the market test', press release, 19 February 2014, https://www.tap-ag.com/news-and-events/2014/02/19/tap-announces-the-second-phase-of-the-markettest.

TAP (2014b): 'TAP closes market test', press release, 1 December 2014, https://www.tapag.com/news-and-events/2014/12/01/tap-closes-market-test.

TAP (2015): 'TAP and TANAP sign Agreement for Cooperation during Construction', press release, 11 December 2015, https://www.tap-ag.com/news-and-events/2015/12/11/tap-and-tanap-sign-agreementfor-cooperation-during-construction.

TAP (2016a): 'TAP Certified as Independent Transmission Operator (ITO)', press release, 29 April 2016, https://www.tap-ag.com/news-and-events/2016/04/29/tap-certified-as-independent-transmissionoperator-ito.

TAP (2016b): 'Trans Adriatic Pipeline Holds Ceremony to Mark Start of Construction', press release, 17 May 2016, https://www.tap-ag.com/news-and-events/2016/05/17/trans-adriatic-pipeline-holdsceremony-to-mark-start-of-construction.

Yafimava (2009): Yafimava, K., 'Belarus: the domestic gas market and relations with Russia', in Pirani (ed) (2009), Russian and CIS markets and their impact on Europe, OUP/OIES, 2009.

Yafimava (2010): Yafimava, K., 'The June 2010 Russian-Belarusian Gas Transit Dispute: a surprise that was to be expected', OIES Paper NG 43, July 2010.

Yafimava (2011): Yafimava, K., The Transit Dimension of EU Energy Security: Russian Gas Transit Across Ukraine, Belarus, and Moldova, OUP/OIES, 2011.

Yafimava (2013): Yafimava, K., 'The EU Third Package for Gas and the Gas Target Model: major contentious issues inside and outside the EU', OIES Paper NG 75, April 2013, https://www.oxfordenergy.org/wpcms/wp-content/uploads/2013/04/NG-75.pdf.

Yafimava (2015): Yafimava, K., 'Evolution of gas pipeline regulation in Russia: third party access, capacity allocation and transportation tariffs', OIES Paper NG 95, March 2015.

Yafimava (2016): Yafimava, K., 'The revived Turkish Stream: what, where, and when?', Oxford Energy Forum, November 2016, Issue 107, OIES.

Yafimava (2017a): Yafimava, K., 'The OPAL Exemption Decision: past, present, and future', OIES Paper NG 117, January 2017, https://www.oxfordenergy.org/wpcms/wp-content/uploads/2017/01/TheOPAL-Exemption-Decision-past-present-and-future-NG-117.pdf.

Yafimava (2017b): Yafimava, K., 'The Council Legal Service's assessment of the European Commission's negotiating mandate and what it means for Nord Stream 2', OIES Energy Insight 19, October 2017, https://www.oxfordenergy.org/wpcms/wp-content/uploads/2017/10/The-Council-LegalServices-assessment-of-the-European-Commissions-negotiating-mandate-and-what-it-means-for-NordStream-2.pdf.

Yafimava (2017c): Yafimava, K., 'The OPAL Exemption Decision: a comment on the CJEU's ruling to reject suspension', Oxford Energy Insight 18, September 2017, p. 9, https://www.oxfordenergy.org/wpcms/wp-content/uploads/2017/09/The-OPAL-Exemption-Decision-acomment-on-CJEU's-ruling-to-reject-suspension.pdf. 

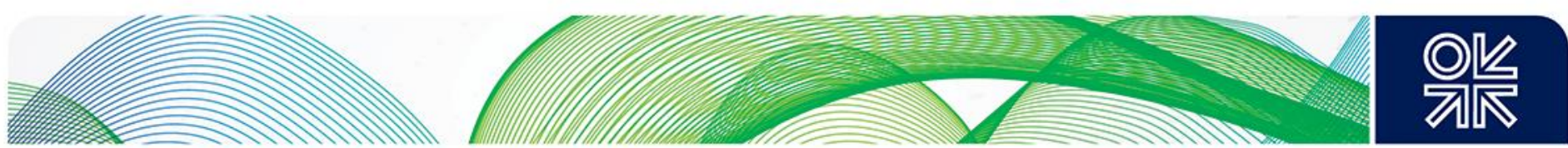

AEEG, ERE, RAE (2016): 'Regulators certify TAP AG as an independent transmission operator', press release, 18 April 2016, https://www.arera.it/allegati/com_stampa/16/160418en.pdf. 

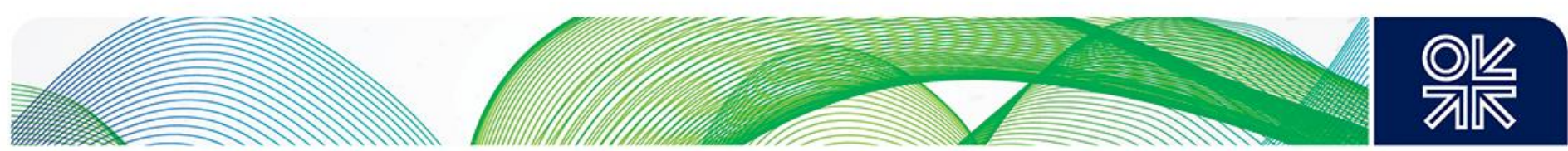

Additional documents (Directives, Protocols, Regulations, Intergovernmental Agreements, etc.)

Abstract of feasibility study: Baltic Pipe project, Gaz-System S.A. and Energinet.dk, 24 April 2017, https://www.ceep.be/www/wp-content/uploads/2017/07/Abstract-of-Feasibility-Study_Final.pdf.

ACER Regulation 713: 'Regulation (EC) No 713/2009 of the European Parliament and of the Council of 13 July 2009 establishing an Agency for the Cooperation of Energy Regulators', OJ L 211/1.

Amendment Proposal: 'Proposal for a Directive of the European Parliament and of the Council amending Directive 2009/73/EC concerning common rules for the internal market in natural gas', COM(2017) 660 final, 2017/0294 (COD), Brussels: EC, 8 November 2017.

Appendix 3 to OS 2017 Rules: Baltic Pipe Project: Appendix 3 to the OS 2017 Rules - Rules applicable to participation in the Danish part of the OS 2017, 6 December 2016

Appendix 4 to OS 2017 Rules: Baltic Pipe Project: Appendix 4 to the Open Season 2017 Rules Additional Gaz-System's S.A. Rules for the Open Season 2017.

Balancing NC: 'Commission Regulation (EU) No 312/2014 of 26 March 2014 establishing a Network Code on Gas Balancing of Transmission Networks', OJ L 91/15.

Booking Phase Guidelines: 'Guidelines for management and allocation of capacity of the Trans Adriatic Pipeline (TAP) project according to paragraph 6 of article 36 of the Directive 2009/73/EC, phase II: invitation to interested parties to submit binding booking requests for capacity products'.

CAM NC 2013: 'Commission Regulation (EU) No 984/2013 of 14 October 2013 establishing a Network Code on Capacity Allocation Mechanisms in Gas Transmission Systems and supplementing Regulation (EC) No 715/2009 of the European Parliament and of the Council', OJ L 273/5.

CAM NC: 'Commission Regulation (EU) 2017/459 of 16 March 2017 establishing a network code on capacity allocation mechanisms in gas transmission systems and repealing Regulation (EU) No 984/2013', OJ L 72/1.

Council Governance Conclusions: Council, 'Governance system of the Energy Union - Council conclusions', 14459/15, (ENER 403, CLIMA 139), Brussels: Council of the EU, 26 November 2015, http://data.consilium.europa.eu/doc/document/ST-14459-2015-INIT/en/pdf.

Council Legal Service's Opinion - Competences: Council, 'Proposal for a Directive of the European Parliament and of the Council amending Directive 2009/73/EC concerning common rules for the internal market in natural gas - legal basis, allocation of competences, derogations', Opinion of the Legal Service, 7502/18, (JUR 152, ENER 109, CODEC 442), Brussels: Council of the EU, 26 March 2018.

Council Legal Service's Opinion - Nord Stream 2: Council, 'Recommendation for a Council decision authorising the opening if negotiations on an agreement between the European Union and the Russian Federation on the operation of the Nord Stream 2 pipeline - allocation of competences and related legal issues', Opinion of the Legal Service, 12590/17, (JUR 445, ENER 370, COEST 250), Brussels: Council of the EU, 27 September 2017. 

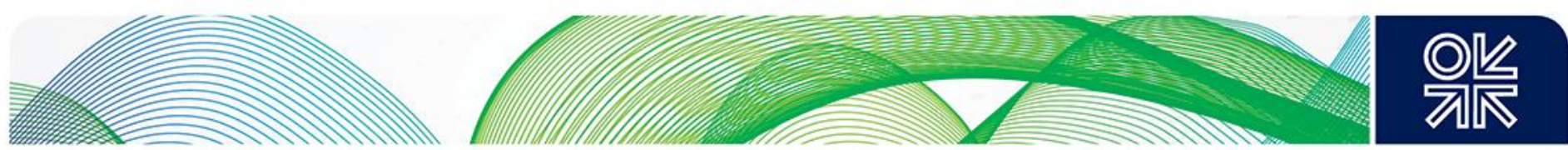

Council Legal Service's Opinion - UNCLOS: Council, 'Directive 2009/73/EC of the European Parliament and of the Council of 13 July 2009 concerning common rules for the internal market in natural gas and repealing Directive 2003/55/EC - compatibility with UNCLOS', Opinion of the Legal Service, 6738/18, (JUR 96, ENER 88, CODEC 301), Brussels: Council of the EU, 1 March 2018, https://www.politico.eu/wp-content/uploads/2018/03/NS2-Gas-Legal-Opinion-March-2018.pdf.

Council Note: Council, 'Proposal for a Regulation of the European Parliament and of the Council on the Governance of the Energy Union, amending Directive 94/22/EC, Directive 98/70/EC, Directive 2009/31/EC, Regulation (EC) No 663/2009, Regulation (EC) No 715/2009, Directive 2009/73/EC, Council Directive 2009/119/EC, Directive 2010/31/EU, Directive 2012/27/EU, Directive 2013/30/EU and Council Directive (EU) 2015/652 and repealing Regulation (EU) No 525/2013', Note from the General Secretariat of the Council to Permanent Representatives Committee, 8536/18, (ENER 131, CLIMA 71, CODEC 676), Brussels: Council of the EU, 8 May 2018, Annex, available http://data.consilium.europa.eu/doc/document/ST-8536-2018-INIT/en/pdf.

Decision 2017/684: 'Decision (EU) 2017/684 of the European Parliament and of the Council of 5 April 2017 on establishing an information exchange mechanism with regard to intergovernmental agreements and non-binding instruments between Member States and third countries in the field of energy, and repealing Decision No 994/2012/EU', OJ L 99/1.

Decision 994/2012: 'Decision No 994/2012/EU of the European Parliament and of the Council of 25 October 2012 establishing an information exchange mechanism with regard to intergovernmental agreements between Member States and third countries in the field of energy', OJ L 299/13.

Decision 1364/2006: 'Decision No 1364/2006/EC of the European Parliament and of the Council of 6 September 2006 laying down guidelines for trans-European energy networks and repealing Decision 96/391/EC and Decision No 1229/2003/EC, OJ L 262.

Draft ACER Regulation: Proposal for a regulation of the European Parliament and of the Council establishing a European Union Agency for the Cooperation of Energy Regulators (recast) - general approach, 9478/18, Brussels, 5 June 2018, http://data.consilium.europa.eu/doc/document/ST-94782018-INIT/en/pdf.

Draft Governance Regulation: 'Proposal for a Regulation of the European Parliament and of the Council on the Governance of the Energy Union', COM(2016) 759 final, 2016 / 0375 (COD), Brussels, 30 November 2016

Draft OS 2017 Rules: Baltic Pipe Project: Open Season 2017 rules (draft for market consultation), 6 December 2016.

EU Merger Regulation: 'Council Regulation (EC) No 139/2004 of 20 January 2004 on the control of concentrations between undertakings (the EC Merger Regulation)', OJ L 24/1.

First Gas Directive: 'Directive 98/30/EC of the European Parliament and of the Council of 22 June 1998 concerning common rules for the internal market in natural gas', OJ L 204/1.

First Market Test Guidelines: 'Guidelines for management and allocation of capacity to the Trans Adriatic Pipeline (TAP) project according to paragraph 6 of Article 36 of the Directive 2009/73/EC, phase 1: invitation of interested parties to express their interest in reserving capacity', Decision No 39 , 23 April 2012. 

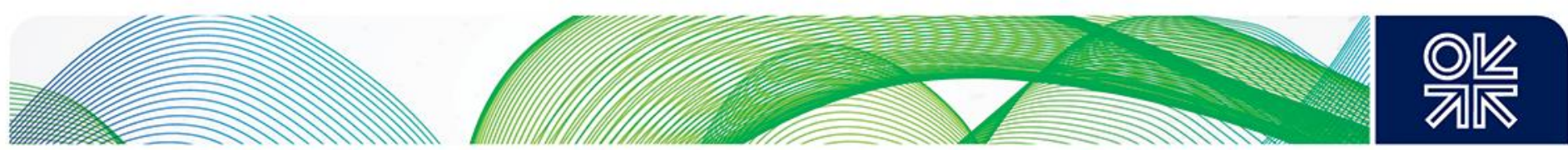

First PCI List: 'Commission Delegated Regulation (EU) No 1391/2013 of 14 October 2013 amending Regulation (EU) No 347/2013 of the European Parliament and of the Council on guidelines for transEuropean energy infrastructure as regards the Union list of projects of common interest', OJ L 349/28, available at https://eur-lex.europa.eu/legal-content/EN/TXT/PDF/?uri=CELEX:32013R1391\&from=EN.

French Senate Note: Council, 'Proposal for a Directive of the European Parliament and of the Council amending Directive 2009/73/EC concerning common rules for the internal market in natural gas [doc. $14204 / 17-\operatorname{COM}(2017) 660$ final]', Reasoned opinion of the French Senate on the application of the principles of subsidiarity and proportionality, 5276/18, (ENER 14, COEST 4, CODEC 36, INST 21, PARLNAT 16), Brussels: Council of the EU, 12 January 2018.

Gas Regulation 1775: 'Regulation (EC) No 1775/2005 of the European Parliament and of the Council of 28 September 2005 on conditions for access to the natural gas transmission networks', OJ L 289/1.

Gas Regulation 715: 'Regulation (EC) No 715/2009 of the European Parliament and of the Council of 13 July 2009 on conditions for access to the natural gas transmission networks and repealing Regulation (EC) No 1775/2005', OJ L 211/36.

Gas Transit Directive: 'Council Directive [EEC] of 31 May 1991 on the transit of natural gas through grids', (91/296/EEC), OJ L 147/37.

Greece-TAP HGA: Host Government Agreement between Greece and TAP, 26 June 2013, https://www.hellenicparliament.gr/en/Nomothetiko-Ergo/Psifisthenta-Nomoschedia?pageNo=26

Infrastructure Regulation: 'Regulation (EU) No 347/2013 of the European Parliament and of the Council of 17 April 2013 on guidelines for trans-European energy infrastructure and repealing Decision No 1364/2006/EC and amending Regulations (EC) No 713/2009, (EC) No 714/2009 and (EC) No 715/2009', OJ L 115/39.

Interoperability NC: 'Commission Regulation (EU) 2015/703 of 30 April 2015 establishing a network code on interoperability and data exchange rules', OJ L 113/13.

ITRE Proposal: See EP (2018b)

TAP-TANAP MoU: Memorandum of Understanding (MoU), signed by TAP and TANAP in November 2012.

OS 2017 Rules: Baltic Pipe project: Open Season 2017 Rules Version 1.02, 6 June 2017 (amended 10 July 2017 and 5 September 2017).

Order of the Court: Order of the General Court, 9 March 2018, CJEU, http://curia.europa.eu/juris/document/document.jsf?text=\&docid=200278\&pagelndex=0\&doclang=EN\& mode $=$ Ist $\&$ dir $=\&$ occ $=$ first $\&$ part $=1 \& c i d=553650$

Second Energy Union Report: 'Second Report on the State of the Energy Union, Communication from the Commission to the European Parliament, the Council, the European Economic and Social Committee, the Committee of the Regions and the European Investment Bank, COM(2017) 53 final, Brussels: EC, 1 February 2017 

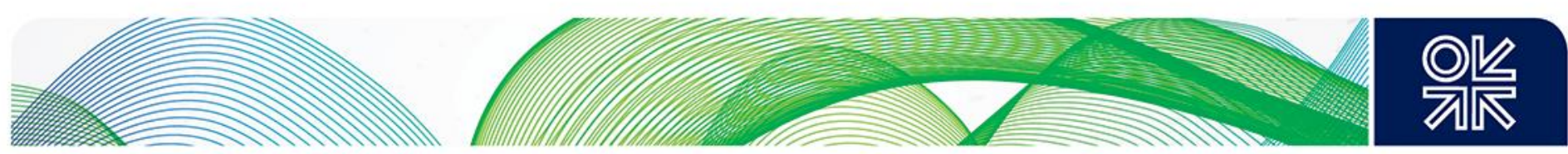

Second Gas Directive: 'Directive 2003/55/EC of the European Parliament and of the Council of 26 June 2003 concerning common rules for the internal market in natural gas and repealing Directive 98/30/EC', OJ L 176/57.

Second PCI List: 'Commission Delegated Regulation (EU) 2016/89 of 18 November 2015 amending Regulation (EU) No 347/2013 of the European Parliament and of the Council as regards the Union list of projects of common interest', OJ L 19/1, available at https://eur-lex.europa.eu/legalcontent/EN/TXT/PDF/?uri=CELEX:32016R0089\&from=EN

Security of Supply Regulation 2010: 'Regulation (EU) No 994/2010 of the European Parliament and of the Council of 20 October 2010 concerning measures to safeguard security of gas supply and repealing Council Directive 2004/67/EC', OJ L 295/1.

Security of Supply Regulation 2017: 'Regulation (EU) 2017/1938 of the European Parliament and of the Council of 25 October 2017 concerning measures to safeguard the security of gas supply and repealing Regulation (EU) No 994/2010', OJ L 280/1.

TAP Joint Opinion: 'Joint Opinion of the Energy Regulators on TAP AG's Exemption Application', available at https://www.autorita.energia.it/allegati/docs/13/249-13all.pdf.

TAP Joint Certification Decision: 'Energy regulators final decision on the certification of TAP AG' available at https://www.arera.it/allegati/docs/16/172-16all.pdf

Tariffs NC: 'Commission Regulation (EU) 2017/460 of 16 March 2017 establishing a network code on harmonised transmission tariff structures for gas', OJ L 72/29.

The 2003 Additional Protocol: Additional Protocol to 'The 1993 IGA' signed 12 February 2003 (in Russian), www.mid.ru/foreign_policy/international_contracts/2_contract/-/storage-viewer/bilateral/page2/46234?_storageviewer_WAR_storageviewerportlet_advancedSearch=false\&_storageviewer_WAR_st orageviewerportlet_keywords=\%D1\%8F\%D0\%BC\%D0\%B0\%D0\%BB\&_storageviewer_WAR_storagevi ewerportlet_fromPage=search\&_storageviewer_WAR_storageviewerportlet_andOperator $=1$.

The 2010 Protocol amending the 2003 Additional Protocol: Protocol amending 'The 2003 Additional protocol', signed 29 October 2010 (in Russian),

www.mid.ru/foreign_policy/international_contracts/2_contract/-/storage-viewer/bilateral/page-

2/45061?_storageviewer_WAR_storageviewerportlet_advancedSearch=false\&_storageviewer_WAR_st orageviewerportlet_keywords=\%D1\%8F\%D0\%BC\%D0\%B0\%D0\%BB\&_storageviewer_WAR_storagevi ewerportlet_fromPage $=$ search\&_storageviewer_WAR_storageviewerportlet_andOperator $=1$.

The 2010 Protocol amending the Russian-Polish IGA: Protocol amending the 'The 1993 Agreement' signed 29 October 2019 (in Russian), www.mid.ru/foreign_policy/international_contracts/2_contract//storage-viewer/bilateral/page-

2/45064?_storageviewer_WAR_storageviewerportlet_advancedSearch=false\&_storageviewer_WAR_st orageviewerportlet_keywords=\%D1\%8F\%D0\%BC\%D0\%B0\%D0\%BB\&_storageviewer_WAR_storagevi ewerportlet_fromPage $=$ search\&_storageviewer_WAR_storageviewerportlet_andOperator $=1$. 

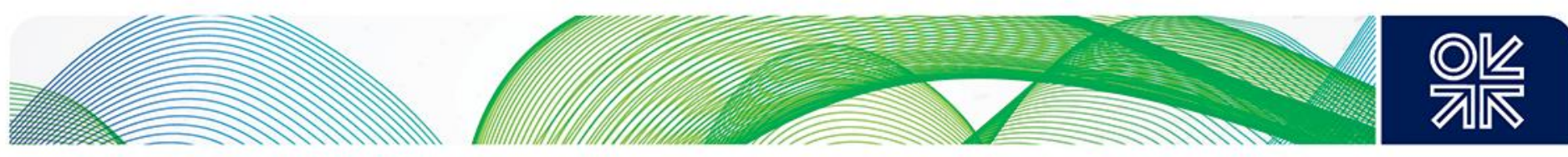

The President's Order: 'The President of the General Court rejects the applications for a stay of execution of the Commission's decision that $50 \%$ of the transport capacities of the OPAL gas pipeline are to be subject to a bidding procedure', press release No 83/17 General Court of the European Union, Order of the President of the General Court in Cases T-849/16 R, T-883/16 R and T-130/17 R, Luxembourg, 21 July 2017.

The Russian-Austrian IGA: Agreement between the government of the Russian Federation and the government of the Republic of Austria on cooperation for the development and operation of a gas pipeline on the territory of the Republic of Austria (in Russian),

http://www.mid.ru/ru/foreign_policy/international_contracts/2_contract/-/storage-viewer/bilateral/page2/45037?_storageviewer_WAR_storageviewerportlet_advancedSearch=false\&_storageviewer_WAR_st orageviewerportlet_keywords=\%D0\%B0\%D0\%B2\%D1\%81\%D1\%82\%D1\%80\%D0\%B8\%D0\%B9\%D1 $\% 81 \% \mathrm{D} 0 \% \mathrm{BA} \% \mathrm{D0} \% \mathrm{BE} \% \mathrm{D} 0 \% \mathrm{~B} 9$ \&_storageviewer_WAR_storageviewerportlet_fromPage $=$ search\&_st orageviewer_WAR_storageviewerportlet_andOperator $=1$.

The Russian-Bulgarian IGA: Agreement between the government of the Russian Federation and the government of the Republic of Bulgaria on cooperation for the development of a gas pipeline for transiting natural gas across the territory of the Republic of Bulgaria (in Russian), http://www.mid.ru/ru/foreign_policy/international_contracts/2_contract/-/storage-viewer/bilateral/page2/45662?_storageviewer_WAR_storageviewerportlet_advancedSearch=false\&_storageviewer_WAR_st orageviewerportlet_keywords=\%D0\%B1\%D0\%BE\%D0\%BB\%D0\%B3\%D0\%B0\%D1\%80\%D0\%B8\%D0 $\% B 8 \&$ storageviewer_WAR_storageviewerportlet_fromPage=search\&_storageviewer_WAR_storagevi ewerportlet_andOperator $=1$.

The Russian-Croatian IGA: Agreement between the government of the Russian Federation and the government of the Republic of Croatia on cooperation for the development and operation of a gas pipeline on the territory of the Republic of Croatia (in Russian), http://www.mid.ru/ru/foreign_policy/international_contracts/2_contract/-/storage-viewer/bilateral/page1/45142?_storageviewer_WAR_storageviewerportlet_advancedSearch=false\&_storageviewer_WAR_st orageviewerportlet_keywords=\%D1\%85\%D0\%BE\%D1\%80\%D0\%B2\%D0\%B0\%D1\%82\%D0\%B8\%D0 \%B8+\%D0\%B3\%D0\%B0\%D0\%B7\%D0\%BE\%D0\%BF\%D1\%80\%D0\%BE\%D0\%B2\%D0\%BE\%D0\%B4 $\% \mathrm{D} \%$ B0\&_storageviewer_WAR_storageviewerportlet_fromPage=search\&_storageviewer_WAR_stora geviewerportlet_andOperator=1.

The Russian-Greek IGA: Agreement between the government of the Russian Federation and the government of the Republic of Greece on cooperation for the development and operation of a gas pipeline on the territory of the Republic of Greece (in Russian), http://www.mid.ru/ru/foreign_policy/international_contracts/2_contract/-/storage-viewer/bilateral/page3/45576?_storageviewer_WAR_storageviewerportlet_advancedSearch=false\&_storageviewer_WAR_st orageviewerportlet_keywords=\%D0\%B3\%D1\%80\%D0\%B5\%D1\%87\%D0\%B5\%D1\%81\%D0\%BA\%D0 $\% B E \% D 0 \% B 9 \&$ storageviewer_WAR_storageviewerportlet_fromPage=search\&_storageviewer_WAR_ storageviewerportlet_andOperator=1. 

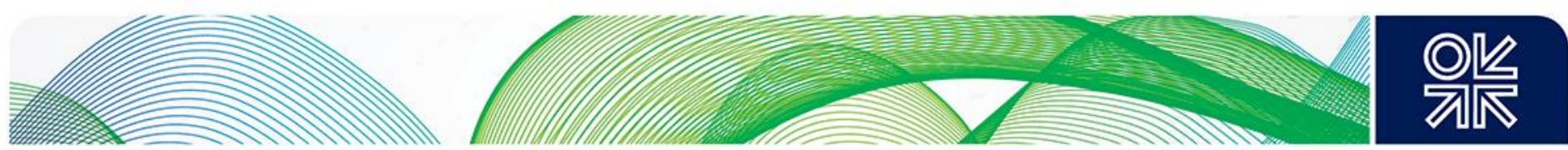

The Russian-Hungarian IGA: Agreement between the government of the Russian Federation and the government of the Republic of Hungary on cooperation for the development of a gas pipeline for transiting natural gas across the territory of the Republic of Hungary (in Russian), http://www.mid.ru/ru/foreign_policy/international_contracts/2_contract/-/storage-viewer/bilateral/page2/45559?_storageviewer_WAR_storageviewerportlet_advancedSearch=false\&_storageviewer_WAR_st orageviewerportlet_keywords=\%D0\%B2\%D0\%B5\%D0\%BD\%D0\%B3\%D0\%B5\%D1\%80\%D1\%81\%D0 $\% \mathrm{BA} \% \mathrm{D} 0 \% \mathrm{BE} \% \mathrm{D0} \% \mathrm{~B} 9 \&$ storageviewer_WAR_storageviewerportlet_fromPage=search\&_storageview er_WAR_storageviewerportlet_andOperator $=1$.

The Russian-Polish IGA: Agreement between the government of the Russian Federation and the government of the Republic of Poland on the development of gas transmission pipelines system for transit of Russian gas across the territory of the Republic of Poland and on supplies of Russian gas to the Republic of Poland of 25 August 1993 (in Russian), http://docs.cntd.ru/document/1900987.

The Russian-Serbian IGA: Agreement between the government of the Russian Federation and the government of the Republic of Serbia on cooperation in the oil and gas sector (in Russian), http://www.mid.ru/ru/foreign_policy/international_contracts/2_contract//storage-viewer/bilateral/page4/45601?_storageviewer_WAR_storageviewerportlet_advancedSearch=false\&_storageviewer_WAR_st orageviewerportlet_keywords=\%D1\%81\%D0\%B5\%D1\%80\%D0\%B1\%D0\%B8\%D0\%B8\&_storageview er_WAR_storageviewerportlet_fromPage=search\&_storageviewer_WAR_storageviewerportlet_andOpe rator $=1$.

The Russian-Slovenian IGA: Agreement between the government of the Russian Federation and the government of the Republic of Slovenia on cooperation for the development and operation of a gas pipeline on the territory of the Republic of Slovenia (in Russian),

http://www.mid.ru/ru/foreign_policy/international_contracts/2_contract/-/storage-viewer/bilateral/page7/45424?_storageviewer_WAR_storageviewerportlet_advancedSearch=false\&_storageviewer_WAR_st orageviewerportlet_keywords=\%D1\%81\%D0\%BB\%D0\%BE\%D0\%B2\%D0\%B5\%D0\%BD\%D0\%B8\%D 0\%B8\&_storageviewer_WAR_storageviewerportlet_fromPage=search\&_storageviewer_WAR_storagev iewerportlet_andOperator $=1$.

The Turkish-Azeri IGA: 'Intergovernmental Agreement between the government of the republic of Turkey and the government of the Republic of Azerbaijan concerning the Trans Anatolian natural gas pipeline system', signed 26 June 2012 (in English), http://www.tanap.com/content/file/TANAPIGA.pdf.

The Russian-Turkish IGA: Agreement between the government of the Russian Federation and the government of the Republic of Turkey on the Turkish Stream project, signed 10 October 2016 (in Russian), http://www.mid.ru/ru/foreign_policy/international_contracts/2_contract/-/storageviewer/bilateral/page-

1/51663?_storageviewer_WAR_storageviewerportlet_advancedSearch=false\&_storageviewer_WAR_st orageviewerportlet_keywords=\%D1\%82\%D1\%83\%D1\%80\%D0\%B5\%D1\%86\%D0\%BA\%D0\%BE\%D0 $\% B 9 \&$ storageviewer_WAR_storageviewerportlet_fromPage $=$ search\&_storageviewer_WAR_storagevi ewerportlet_andOperator $=1$.

Third Gas Directive: 'Directive 2009/73/EC of the European Parliament and of the Council of 13 July 2009 concerning common rules for the internal market in natural gas and repealing Directive 2003/55/EC', OJ L 211/94. 

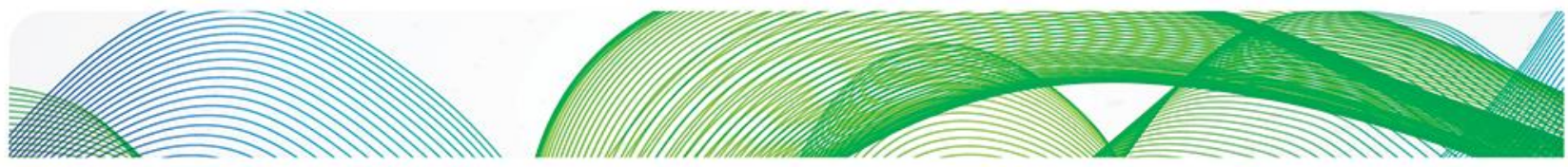

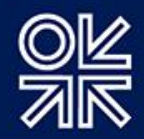

Third PCI List: 'Commission Delegated Regulation (EU) 2018/540 of 23 November 2017 amending Regulation (EU) No 347/2013 of the European Parliament and of the Council as regards the Union list of projects of common interest', OJ L 90/38, available at https://eur-lex.europa.eu/legalcontent/EN/TXT/PDF/?uri=CELEX:32018R0540\&from=EN. 

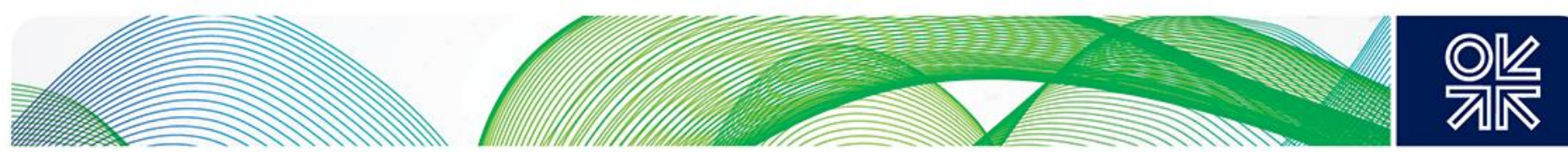

\section{Company websites}

DEPA: https://www.hradf.com/en/portfolio/view/25/public-gas-corporation.

Gazprom, Gazprom Transgaz Belarus: http://www.gazprom.com/about/subsidiaries/list-items/gazpromtransgaz-belarus/.

TANAP: http://www.tanap.com/tanap-project/why-tanap/.

TAP: https://www.tap-ag.com/about-us/our-shareholders.

Plinovodi: http://www.plinovodi.si/en/company/history-of-the-company/.

Plinacro: http://www.plinacro.hr/default.aspx?id=467.

OMV: http://www.omv.com/portal/01/com/omv/OMV_Group/about, https://www.gasconnect.at/en/aboutus/about-us/.

Srbijagaz: http://www.srbijagas.com/o-preduzecu/osnovni-podaci.69.html.

Gassco: https://www.gassco.no/en/.

\section{Journal articles}

'A look at the six suitors for Greece's gas grid DESFA', 8 August 2017, The National Herald, 8 August 2017, https://www.thenationalherald.com/171457/greece-receives-six-expressions-interest-gas-gridoperator-desfa/.

'CEEP: Opportunities and challenges of the gas directive', Biznes Alert, 22 March 2018, http://biznesalert.com/ceep-gas-directive/.

‘EC: Russia should apply for South Stream exemption', Natural Gas Europe, 7 December 2013.

'Exclusive: Italy's new government to review TAP gas pipeline', Reuters, 6 June 2018, https://www.reuters.com/article/us-tap-italy-exclusive/exclusive-italys-new-government-to-review-tapgas-pipeline-idUSKCN1J21SI.

'Germany fully approves Russia-built Nord Stream 2 gas pipeline', Reuters, 27 March 2018, https://www.reuters.com/article/us-russia-germany-nordstream/germany-fully-approves-russia-builtnord-stream-2-gas-pipeline-idUSKBN1H31IF.

'Germany grants permit for Nord Stream 2 Russian gas pipeline', Reuters, 31 January 2018, https://www.reuters.com/article/us-nordstream-germany-permit/germany-grants-permit-for-nord-stream2-russian-gas-pipeline-idUSKBN1FK15J.

'Greece gets two binding bids in gas grid sale', Reuters, 16 february 2018, https://uk.reuters.com/article/eurozone-greece-privatisation-desfa/refile-update-1-greece-gets-twobinding-bids-in-gas-grid-sale-idUKL8N1Q6513 

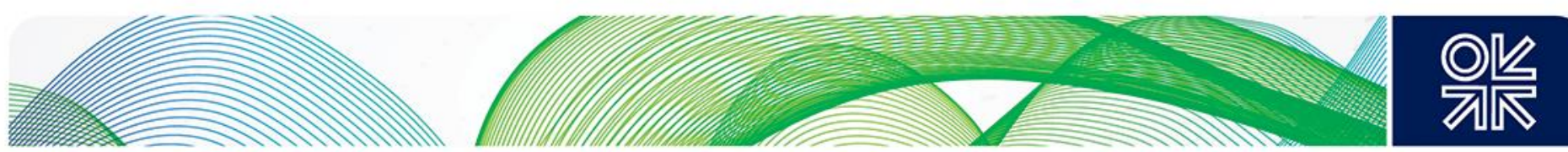

'Greece to push back DESFA gas grid privatization deadline: source', Reuters, 18 December 2017, https://uk.reuters.com/article/us-eurozone-greece-privatisation-desfa/greece-to-push-back-desfa-gasgrid-privatization-deadline-source-idUKKBN1EC1BA.

'Italy intends to endorse new chapter in NATO-Russia ties: Under-Sec of State, Sputnik, 25 June 2018 https://sputniknews.com/europe/201806251065748373-italy-nato-russia-salvini/.

'Medvedev: in Europe attempts are made to force the Russian Federation to cancel Nord Stream 2' (in Russian), TASS, 14 November 2017, http://tass.ru/ekonomika/4727057.

“'Mr Energy" Claude Turmes quits as MEP', EurActive, 29 May 2018, https://www.euractiv.com/section/energy/news/mr-energy-claude-turmes-quits-as-mep/.

'Netherlands to halt gas production at Groningen by 2030', Reuters, 29 March 2018, https://uk.reuters.com/article/uk-netherlands-groningen-gas/netherlands-to-halt-gas-production-atgroningen-by-2030-idUKKBN1H520E.

'Norway adopts EU energy rules, averting break with bloc', Reuters, 22 March 2018, https://www.reuters.com/article/us-norway-eu-energy/norway-adopts-eu-energy-rules-averting-breakwith-bloc-idUSKBN1GY2OY.

'Poland's PGNiG confirms interest in gas transit via Baltic Pipe', Reuters, 31 October 2017.

'SNAM-led consortium wins DESFA tender', Ekathimerini, 19 April 2018, http://www.ekathimerini.com/227874/article/ekathimerini/business/snam-led-consortium-wins-desfa-tender

'South Stream bilateral deals breach EU law, Commission says', EurActive, 4 December 2013, https://www.euractiv.com/section/competition/news/south-stream-bilateral-deals-breach-eu-lawcommission-says/.

'Switzerland: EGL Becomes Axpo', LNG World News, 1 October 2012, https://www.Ingworldnews.com/switzerland-egl-becomes-axpo/.

'TANAP to supply gas to TAP in mid-2019', Interfax Natural Gas Daily, 29 June 2018, http://interfaxenergy.com/gasdaily/article/31537/tanap-to-supply-gas-to-tap-in-mid-2019.

'TAP first phase sold out, Russia, Eastmed could piggybank on expansion', New Europe, 6 February 2017, https://www.neweurope.eu/article/tap-first-phase-sold-russia-eastmed-piggyback-expansion/

'Trans Adriatic Pipeline to cost 4.5 billion euros: project chief', Anadolu Agency, 31 January 2017, http://www.hurriyetdailynews.com/trans-adriatic-pipeline-to-cost-45-billion-euros-project-chief-109179. 

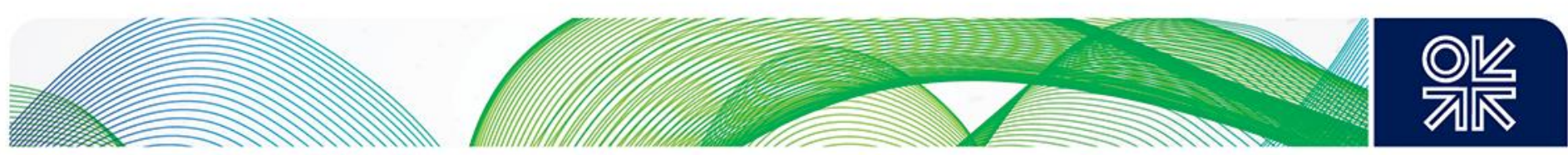

\section{Annex. More Capacity Draft Preliminary Agreement and Supplementary Terms and Conditions}

\section{Draft Preliminary Agreement: analysis}

The draft Preliminary Agreement has stipulated that the 'more capacity' TSOs - GASCADE, Gasunie, ONTRAS, NEL, and Fluxys - had not made a final decision on network expansion measures to create new technical capacities, and new technical capacities will not exist by the time the capacity auctions are held in March 2017. It further stated that creation of new technical capacities depends 'in particular on all necessary permissions for network expansion and operation ... being obtained, as well as on the regulatory framework and the permissions required in this regard'.

By concluding the Preliminary Agreement, a shipper undertakes to submit bids for a specific amount of capacity, whereas a TSO undertakes to market it in capacity auctions, thus increasing 'planning security', improving the TSOs' coordination of existing capacities at the shared market area boundaries, and enabling the parties to 'prepare, hold and take part' in auctions. The Preliminary Agreement reaffirms that the existing capacities must be allocated first, in order to ensure efficient use of the existing infrastructure, before new technical capacities are created by means of network expansion.

The Preliminary Agreement defines new technical capacities as 'capacity to be allocated by means of open allocation procedures, apart from capacity which remains unsold after it has been initially offered by means of such procedure' (CAM NC 2013, Art. 2) whereas it defines existing capacities as 'available capacity' in other words 'the part of the technical capacity that is not allocated and is still available to the system at the moment' (Gas Regulation 715, Art. 2.1.20).

The Preliminary Agreement placed the following obligations on the shipper and the 'more capacity' TSO:

The shipper is obliged to submit bids in the first round of the auction ('initial bids') in the amount stipulated in the Preliminary Agreement (Annex 1) as part of the capacities offered by the 'more capacity' TSO in annual or quarterly auctions on PRISMA (Art. 2);

The 'more capacity' TSO is obliged to notify the shipper in writing, at least four weeks before the start of an auction, as to the specific auction for which this notification is intended and of the amount of the initial bid(s) to be submitted; this is to ensure, in particular, that relevant reservation quotas are taken into account (Art. 2);522

The 'more capacity' TSO is obliged to upload capacities on PRISMA for the annual auction in March 2017 and for each subsequent year specified in Annex 1 at least in the amount corresponding to the total of the agreed bids to be placed under this Preliminary Agreement (Art. 4);

the TSO 'reserves the right not to offer new technical capacities in full or for all gas years specified in Annex 1 in March 2017 if there are delays in expansion of neighbouring markets' or if such expansion work is 'cancelled in full' (Art. 5), in which case the TSO is obliged to give the shipper a written notice of its decision in good time (before the auction in March 2017). If and insofar as the TSO decides to offer the new technical capacities in full or in part, the shipper remains obliged to fulfil its obligations under the Preliminary Agreement.

The Preliminary Agreement states that the shipper's failure to submit initial bids at all, or to not submit in full, would constitute a violation of a contractual obligation. Should such failure 'impair the costeffectiveness of network expansion' leading the 'more capacity' TSO to fail to accomplish network expansion at all, or to only accomplish it in part, the shipper would be obliged to reimburse the loss or damage incurred by the TSO (limited to four times the value of the agreement, defined on the basis of 522 The notification would not be sent in the initial annual auction for existing capacities and new technical capacities in March
2017. 

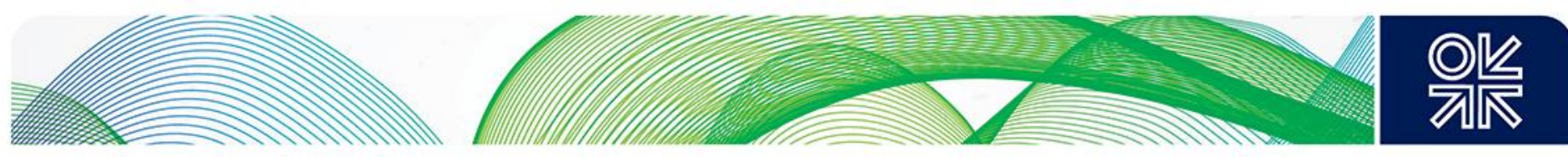

the respective specific capacity tariff that is applied at the time the agreement was concluded in accordance with the published price sheet for the capacity product at the respective network point) in trusting that the contractual obligations would be fulfilled (Art. 3).

The Preliminary Agreement contains a force majeure clause, allowing either party - a 'more capacity' TSO and a shipper - to be released from their obligations under the agreement if it is unable to perform its obligations because of force majeure. (Art. 4). Accordingly, the other party shall be released from its corresponding obligations 'to the extent and as long as' the first party is 'prevented from performing its obligations because of force majeure'. The Preliminary Agreement defines 'force majeure' as 'any unforeseeable external circumstance which the Party affected could not have been expected to prevent or could not have prevented in good time by applying reasonable care and measures which it would have been technically feasible and commercially viable to take'. The agreement states that '[w] thout limitation, force majeure shall include natural disasters, terrorist attacks, power failure, failure of telecommunications connections, strikes and lock-outs, provided that the lock-outs are lawful, and legal provisions or measures by governments, courts or authorities, irrespective of whether such measures are lawful'.

The Preliminary Agreement states that the parties 'shall endeavour to the best of their ability to settle any dispute between them' in connection with the agreement 'amicably by means of negotiation'. If one of the parties considers that the disputes cannot be settled by mutual agreement, all disputes and other matters from and in connection with this agreement shall be ruled on, finally and bindingly, by a court of arbitration, with any recourse to the courts of law being excluded, with Frankfurt being the place of the arbitration proceedings. German law shall apply, to the exclusion of any conflict of law provisions between states, unless these are binding law. The UN Convention on Contracts for the International Sale of Goods shall not apply.

Notably, the Preliminary Agreement also states that if any of the provisions of the agreement or its annexes 'are or become invalid or unenforceable', the other provisions shall remain in full force and effect.

The Preliminary Agreement contains the usual provisions on confidentiality, whereby the parties are obliged to treat confidentially all information which they obtain in connection with the Preliminary Agreement ('confidential information') and not to disclose it or make it accessible to third parties without the prior written consent of the party affected. It allows either party to disclose, without the written consent of the other party, any confidential information obtained from the other party to:

(a) an affiliated party,

(b) to its representatives, consultants, banks, and insurers 'if and to the extent' it needed to for proper performance of their contractual obligations,

(c) to anyone to the extent that the confidential information was 'legitimately known to the party receiving the information at the time it was obtained from the other party', 'was already in the public domain or becomes publicly available other than through an act or omission of the receiving party', or 'has to be disclosed by a party due to a statutory provision or a court or official order or a request of the regulatory authorities'.

Furthermore, the Preliminary Agreement allows the 'more capacity' TSO to disclose any confidential information obtained from the shipper without the latter's written consent if:

(a) this is required to ensure any necessary coordination between the five 'more capacity' TSOs (GASCADE, Gasunie, ONTRAS, Fluxys, and NEL), or

(b) if this is done in aggregated form and the published information does not reveal any indicators as to the identity of the shipper.

The confidentiality obligations shall remain in force for a period of five years after the Preliminary Agreement has been signed. 

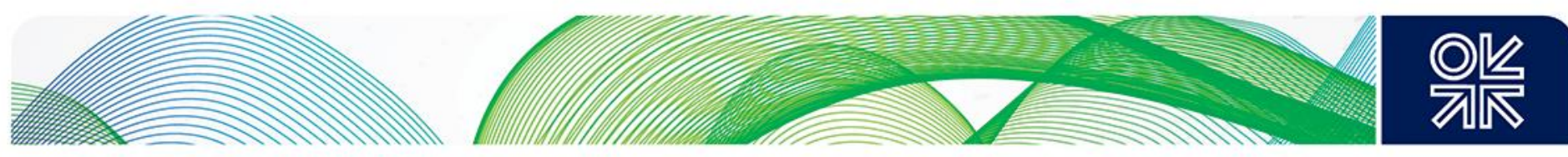

The Preliminary Agreement came into effect once it was signed. It will continue to apply until the parties have fulfilled the obligations specified in Article 1, in particular the obligation of the shipper to submit initial bids and the obligation of the 'more capacity' TSO to offer capacities.

The Preliminary Agreement has included the provisions on tariffs, stating that the tariffs for existing capacities shall be defined as in Art. 25 of the General Terms and Conditions (GTC) and that the tariffs for new technical capacities shall also be defined as in Art. 25 of the GTC provided that the parties:

agree variable tariffs for the performance period of the entry or exit contract in each case from 1 October to 31 December which are defined as 'the tariffs that are formed in future in accordance with regulatory requirements or are approved in future by the regulatory authorities, as well as the other tariffs or tariff components stated in Article 25 Section 1 of the General Terms and Conditions of Service and any future cost allocations that will apply on 1 October of a year in the respective performance period of the entry or exit contract according to the price sheet published on the website of the more capacity TSO'; and

agree variable tariffs for the performance period of the entry or exit contract in each case from 1 January to 30 September which are defined as 'the tariffs that are formed in future in accordance with regulatory requirements or are approved in future by the regulatory authorities, as well as the other tariffs or tariff components stated in Article 25 Section 1 of the General Terms and Conditions of Service and any future cost allocations that will apply in each case on 1 January of a year in the respective performance period of the entry or exit contract according to the price sheet published on the website of the more capacity TSO'.

The Preliminary Agreement stipulates that the specific capacity tariff, applied at the time of the auction and formed in accordance with regulatory requirements, shall be used, but notes that the use of such a tariff 'shall not constitute an agreement on the tariffs and shall say nothing about the level of the actually agreed tariffs to be charged'.

\section{The draft Supplementary Terms and Conditions (STC): analysis}

The General Terms and Conditions (GTC) of service, including the Supplementary Terms and Conditions (STC) of business which govern the conclusion of contracts for new capacity, were applied to the initial bids issued in the auctions in accordance with the Preliminary Agreement.

The STC stipulate that new technical capacities shall be offered for a period of 25 years 'as of the anticipated commissioning of the underlying network expansion measures' (Art. 2.1). However, it notes that if 'a bundled capacity product is formed with the new technical capacities and it is not disclosed on the part of the neighbouring TSO as new technical capacity' in line with Art. 3 of CAM NC (2013) (in other words as capacity 'to be allocated by means of open allocation procedures ... such as open season procedures'), new technical capacities shall be offered in accordance with Art. 11 of the CAM NC (2013) (in other words through auctions for no longer than 15 years). (Notably the new CAM NC (2017) has since been adopted, according to which incremental technical capacities are to be offered at the auctions for a maximum of 15 years unless an alternative capacity allocation mechanism is applied, in which case the booking horizon could be extended by a maximum of five years. It is not clear whether the STC have been revised to take into account the CAM NC (2017)).

The STC stipulate that capacity contracts between the TSO and the shipper are to be concluded in line with the TSO's General Terms and Conditions (GTC) (Art. 1) with the exception that the contract 'shall be effective subject to the condition precedent' that all of the following conditions are met:

upon completion of the respective auctions for new technical capacities on the primary capacity platform, all offered standard capacity products of the existing capacities with an equivalent or higher quality at the border crossing points have been marketed across the TSOs in the respective flow direction (in other words existing capacities are booked out with priority); 

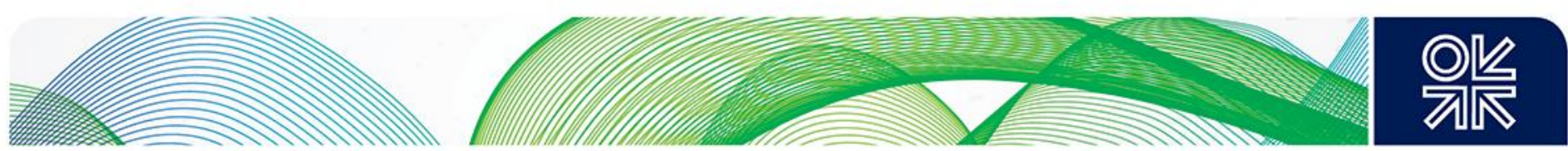

as part of an economic assessment based on the entry and exit contracts concluded subject to the above condition precedent, the TSO has determined that the measures to create new technical capacities for an offering level are cost effective;

the costs of the expansion measures required for creating the new technical capacities have been acknowledged by the regulatory authorities;

the TSO's management has agreed to expansion of the network.

The STC state that if one or more of the four conditions listed above are not met by 30 June 2019, these conditions shall be regarded as if they have not been fulfilled, and therefore the entry or exit contract shall become 'definitively ineffective' (Art. 3.2). However, irrespective of the occurrence of one or more of these conditions, the TSO 'shall be authorized' to decide by 1 June 2019 that the contract 'shall definitively be effective' (Art. 3.3). In both cases (i.e. immediately after the occurrence of all four conditions by 30 June 2019, or when the TSO decides by 1 June 2019 that the contract will be effective even if some or all of these conditions have not occurred), the TSO is obliged to give the shipper a written notice that the contract is effective (Art. 3.4). The STC state that if one or more of the aforementioned conditions is not fulfilled and the contract does not become effective, claims for liability against the TSO shall be excluded (Art. 4.4). As this paper is being completed, it is understood that all capacity contracts concluded as part of 'more capacity' process have become effective.

Marketing of new technical capacities is to be done in line with the terms and conditions of the primary capacity platform, PRISMA. Only the contract which corresponds to the highest offering level for which the TSO has determined that the measure to create new technical capacities for an offering level is costeffective shall become effective (irrespective of the four conditions listed above), whereas all other allocations shall be cancelled by the TSO by giving the shipper a written notice (Art. 4). The STC have stated that the results of the auctions shall be published after the end of the auctions, whereas shippers who have taken part in the auctions are to receive separate confirmations of the auctions' results.

The STC stipulate further that once the contract becomes effective, the TSO 'shall endeavour to take all economically reasonable measures to ensure that the capacities allocated to the shipper are 'made available on time for the performance period' of the contract. They further note that 'the necessary permissions under public law and the regulatory framework shall be taken into adequate account in assessing whether the measures are economically reasonable and justifiable' (Art. 6). The STC note that if it 'transpires in the course of network expansion that the new technical capacities cannot be adhered to at the border crossing points' at the start of the term of the contract, 'in particular, due to the fact that definitive permissions under public law have not been received', the TSO is obliged to notify the shipper 'immediately' and inform it 'whether and when' the start of the contract's term 'can be expected', stating that 'the delay may also cover' the entire term of the contract, with the parties' obligations towards each other to be 'suspended during the delay'. It also noted that 'any further claims' by the parties against each other are to be excluded.

Also importantly, the STC state that if upstream or downstream transport capacities are not available at the start of the term of the contract, the shipper shall still be 'obliged to fulfil the contract, in particular to pay the tariffs' agreed in the contract and shall not be allowed to 'rescind or otherwise terminate' the contract (Art. 6.3). 